


\title{
BILIDER-ATLAS
}

\author{
ZUR WISSENGCHATTHCH-POPUIÄREN
}

\section{NATURGESCHICH'TE DER AMPHIBIEN}

IN IHBES

\section{SÄMMTLICHEN HAUP'TEORMEN.}

LEOP. JOS. FITZINGER,

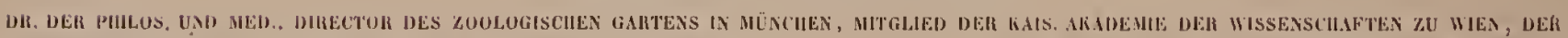

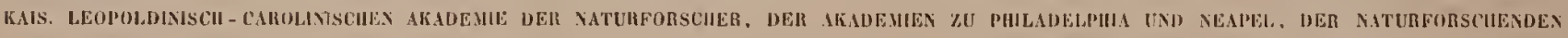

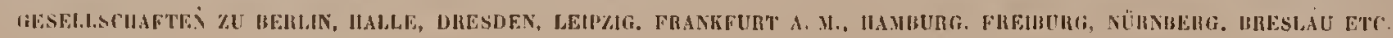

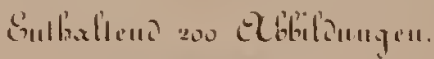

$1^{2}, \mathrm{LL}$

\section{WIEN.}

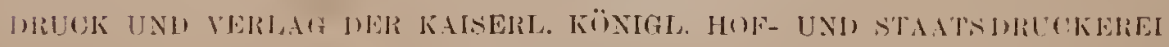

1864. 



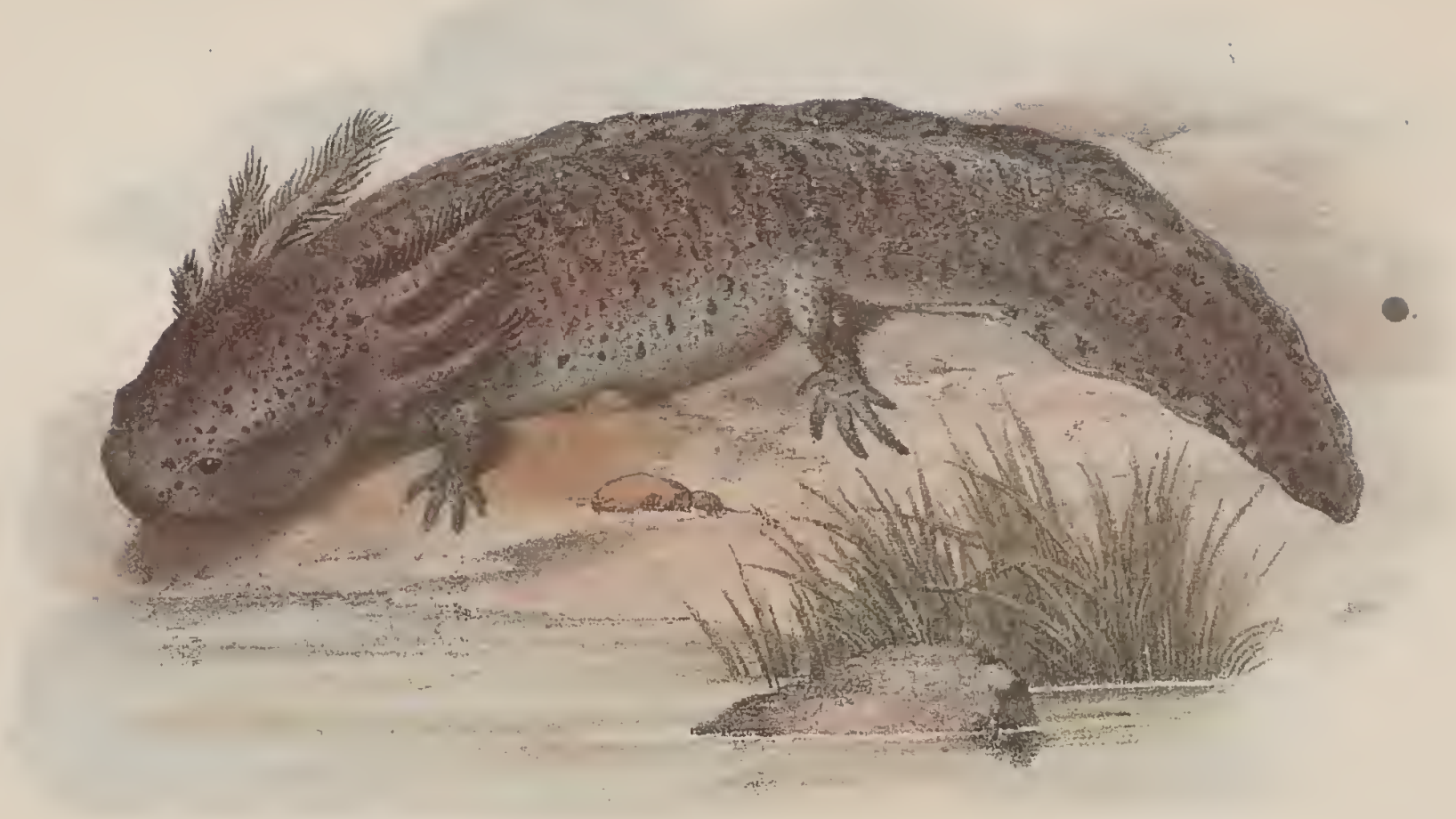

Hity 1.9?

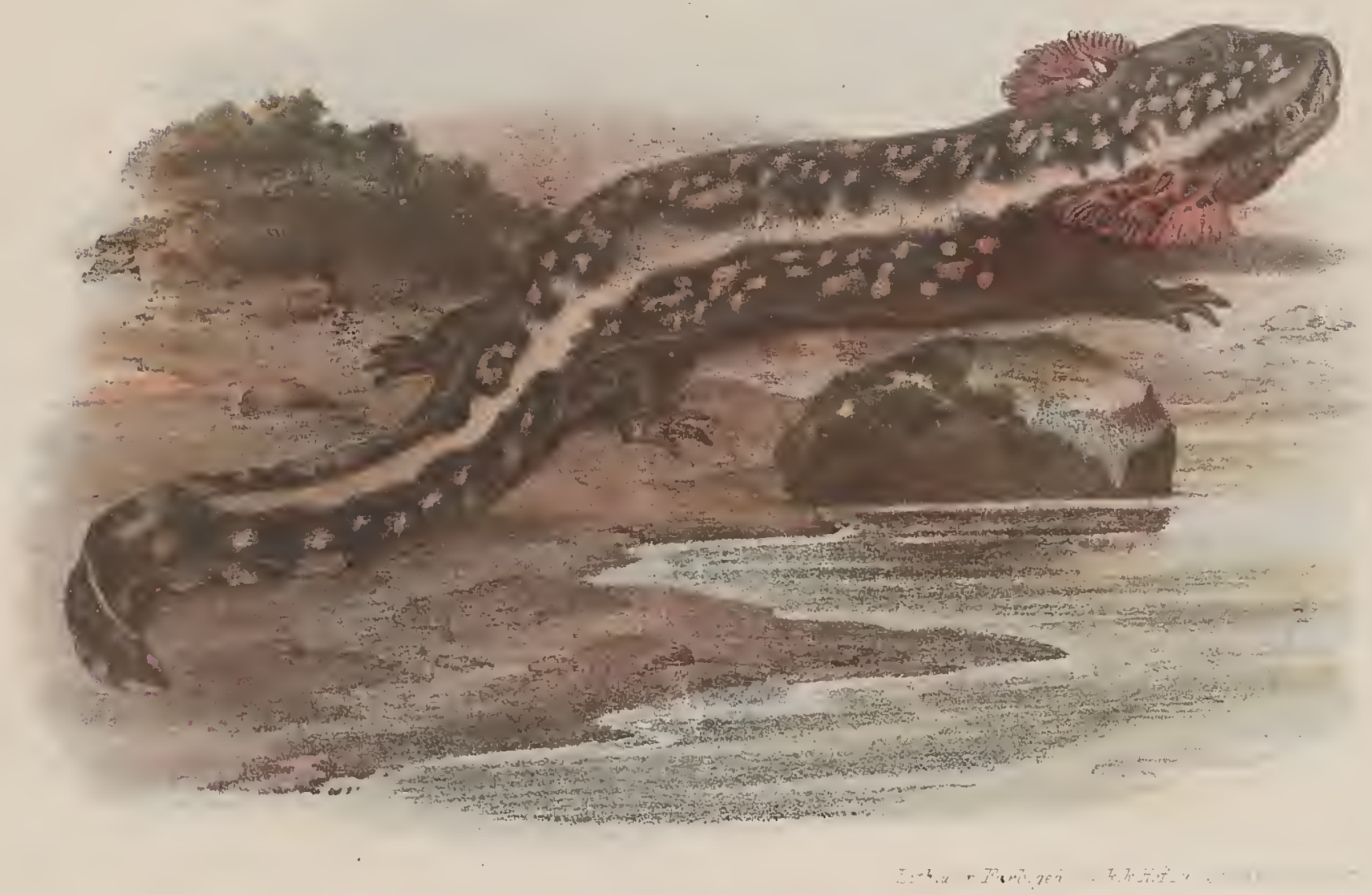

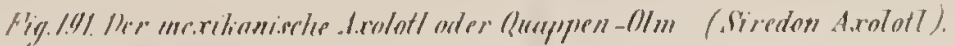

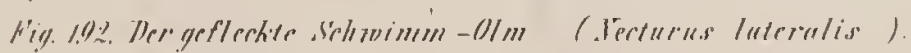




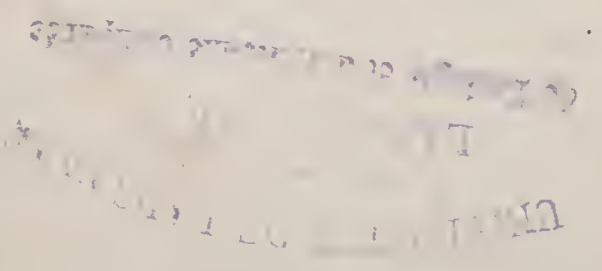


Nig. 193

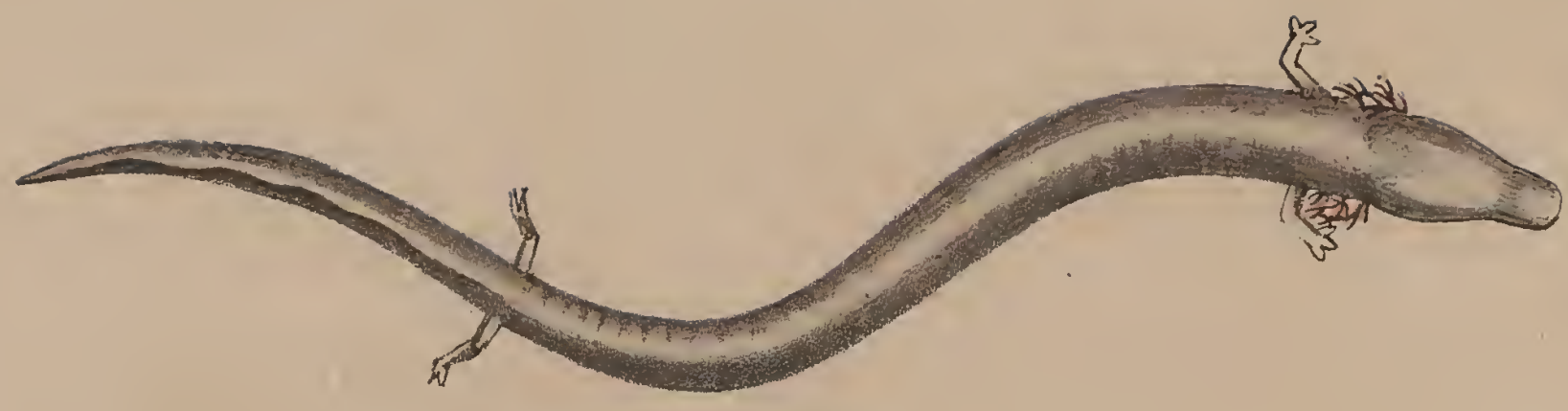

kivg. 194.

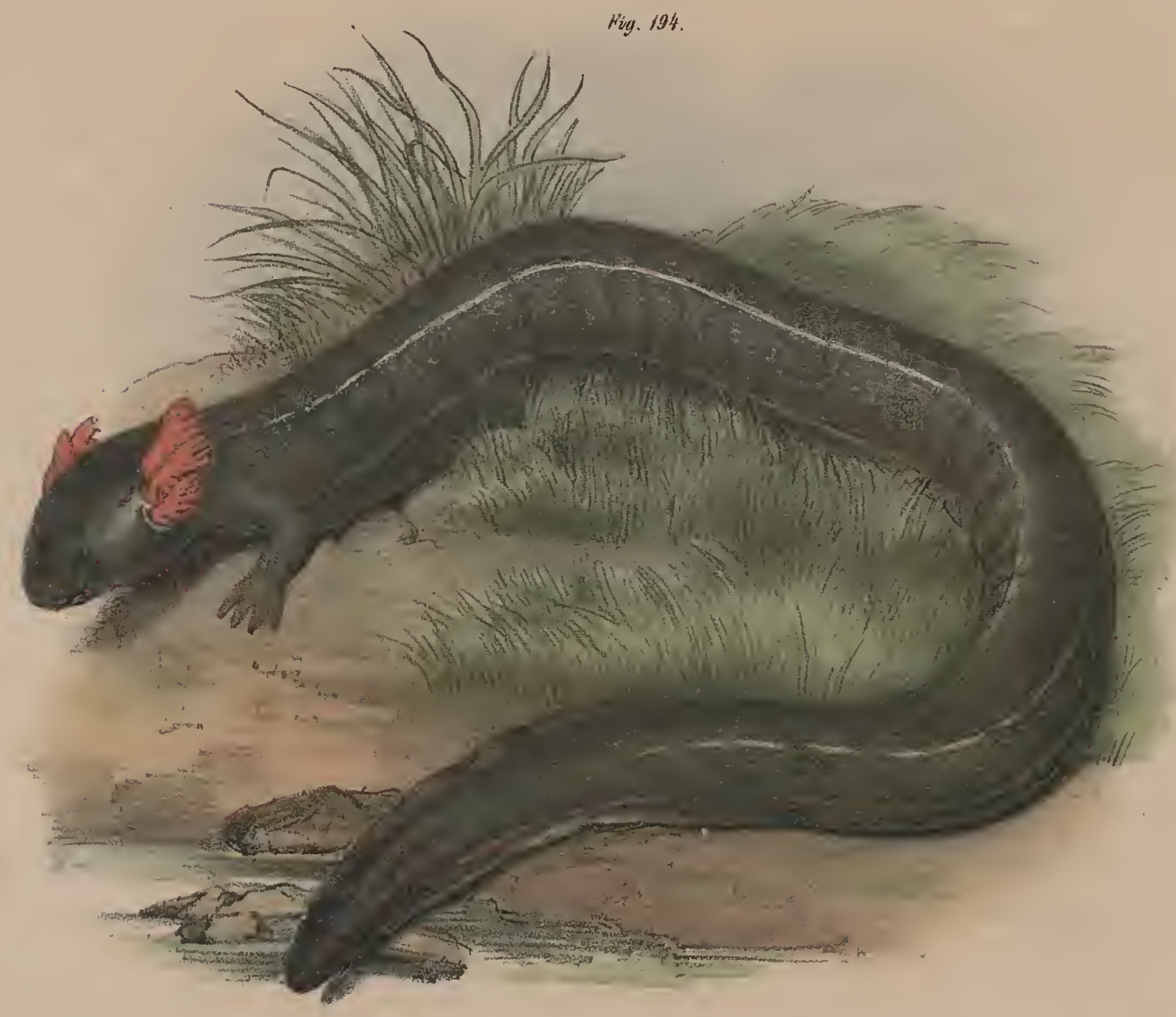

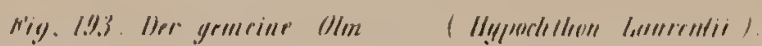

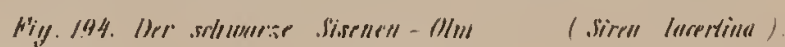



Fiy, 4.;.
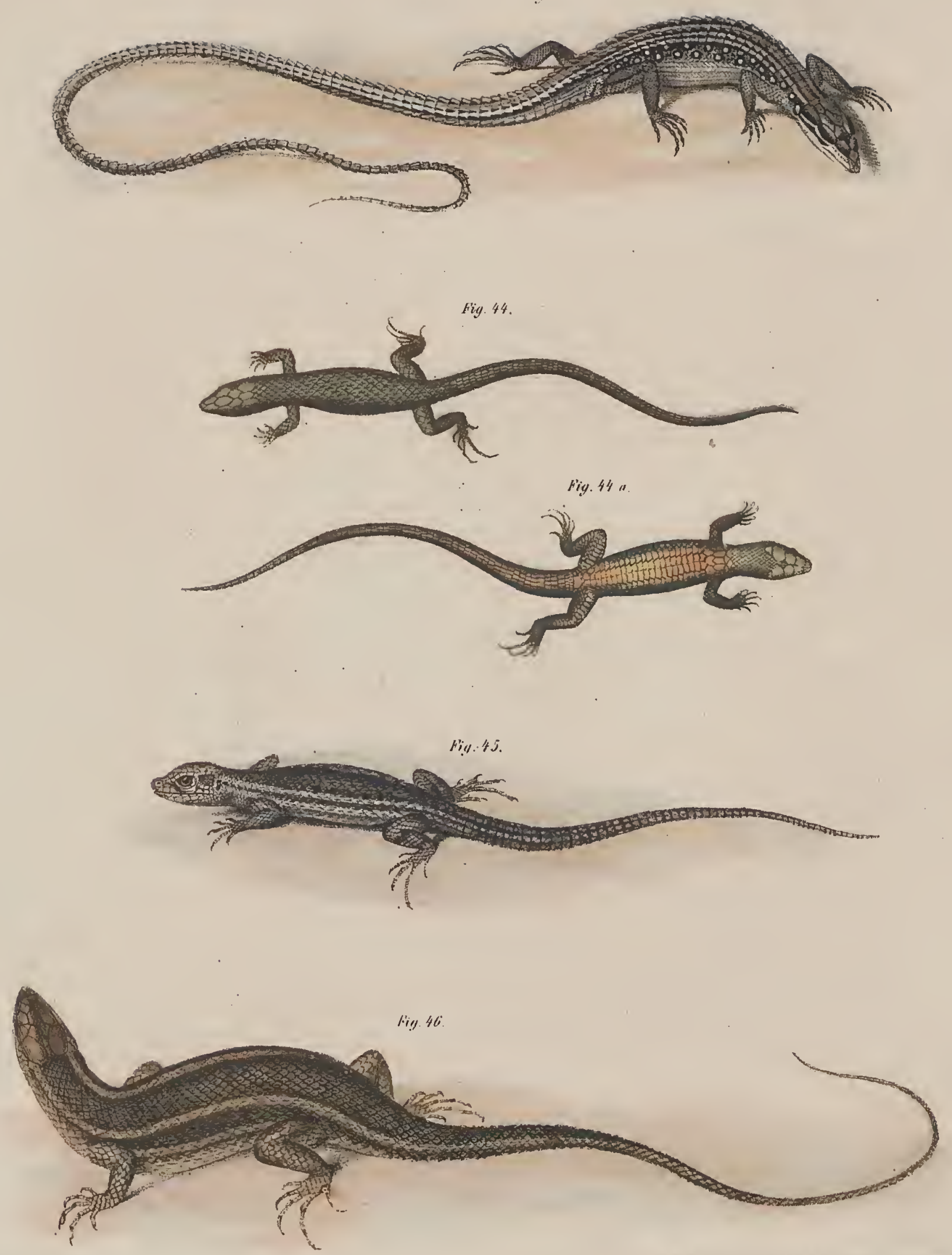

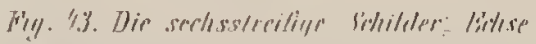

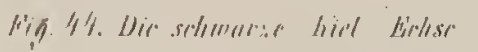

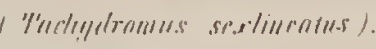

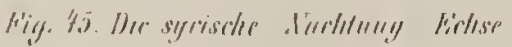

(Timpichloplenlis megr").

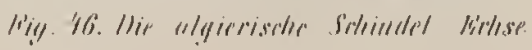

(.Im!sses kiturenheryii ).

( Isrummurms Alyirus). 



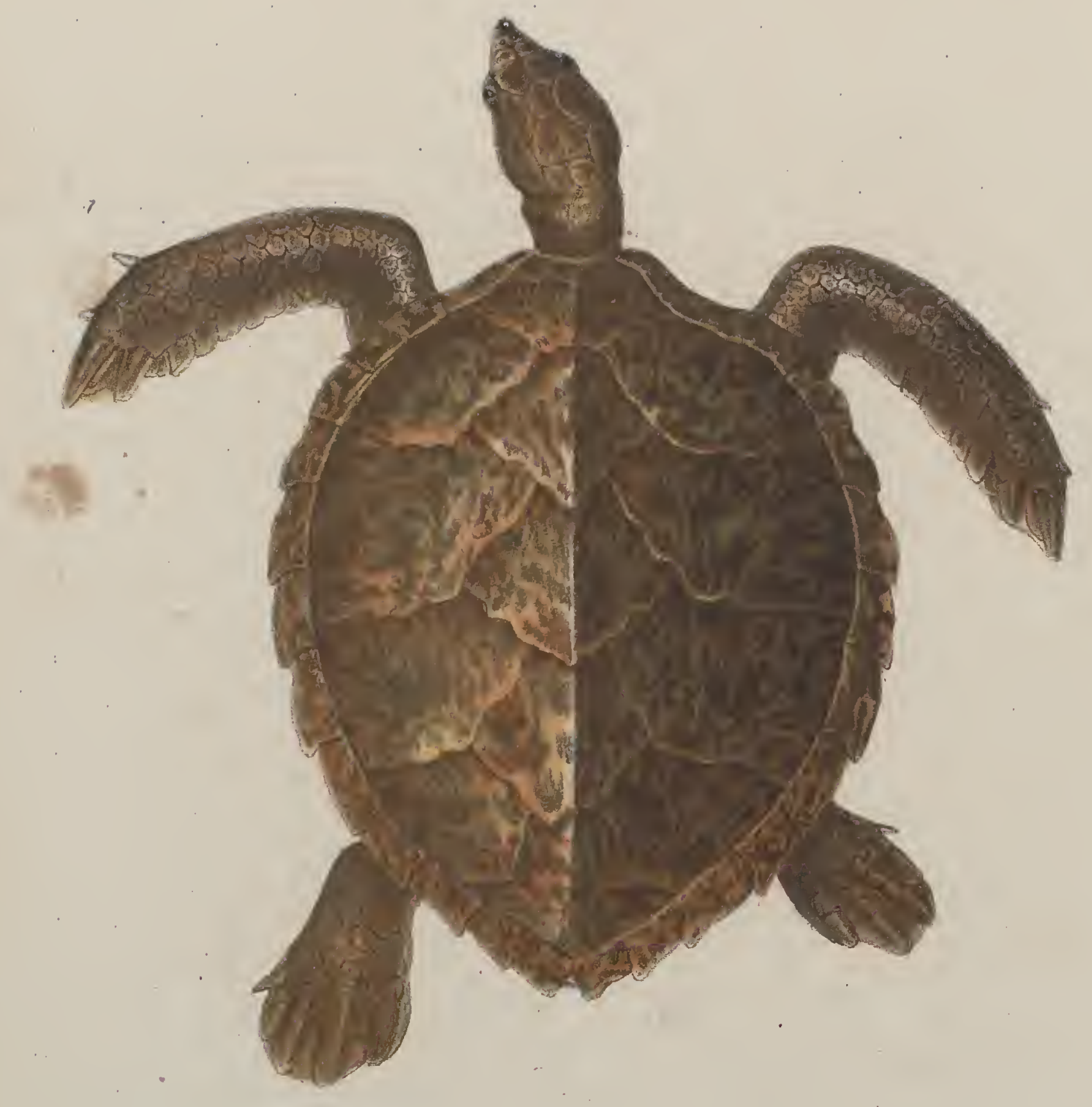

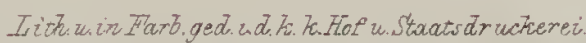

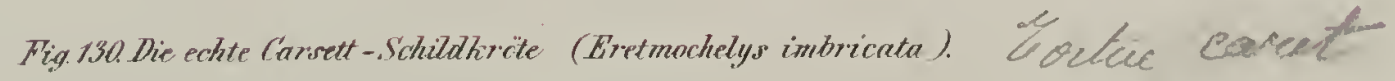




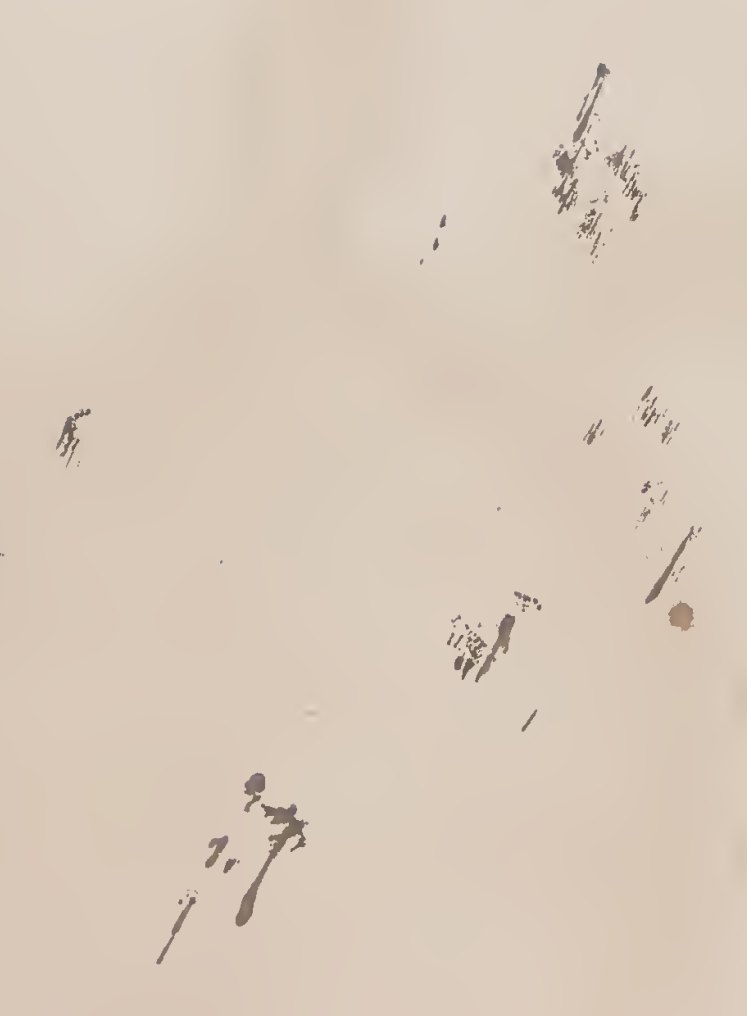



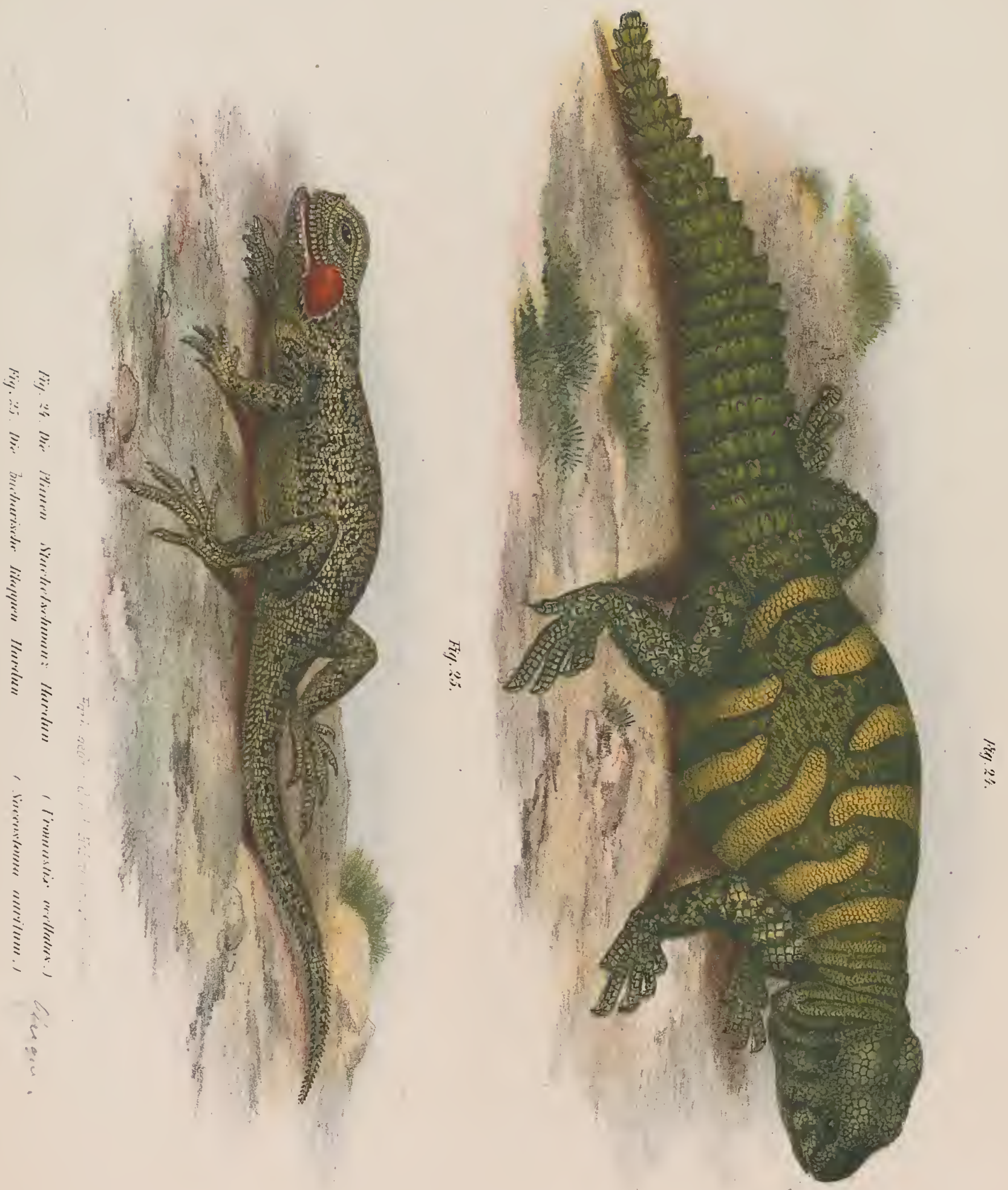


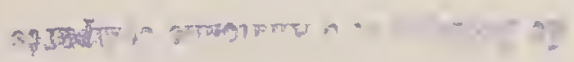

$\ldots$ 


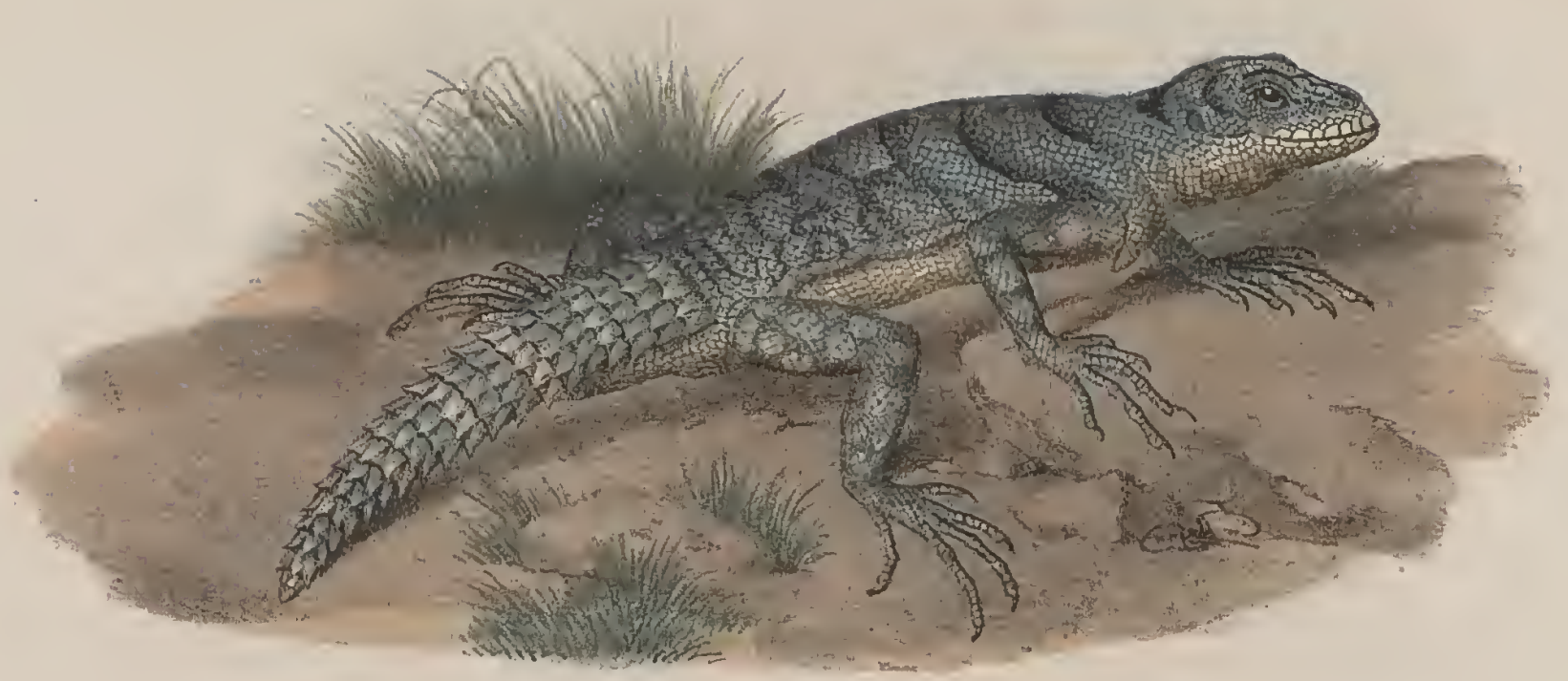

F'iif $\%$. "
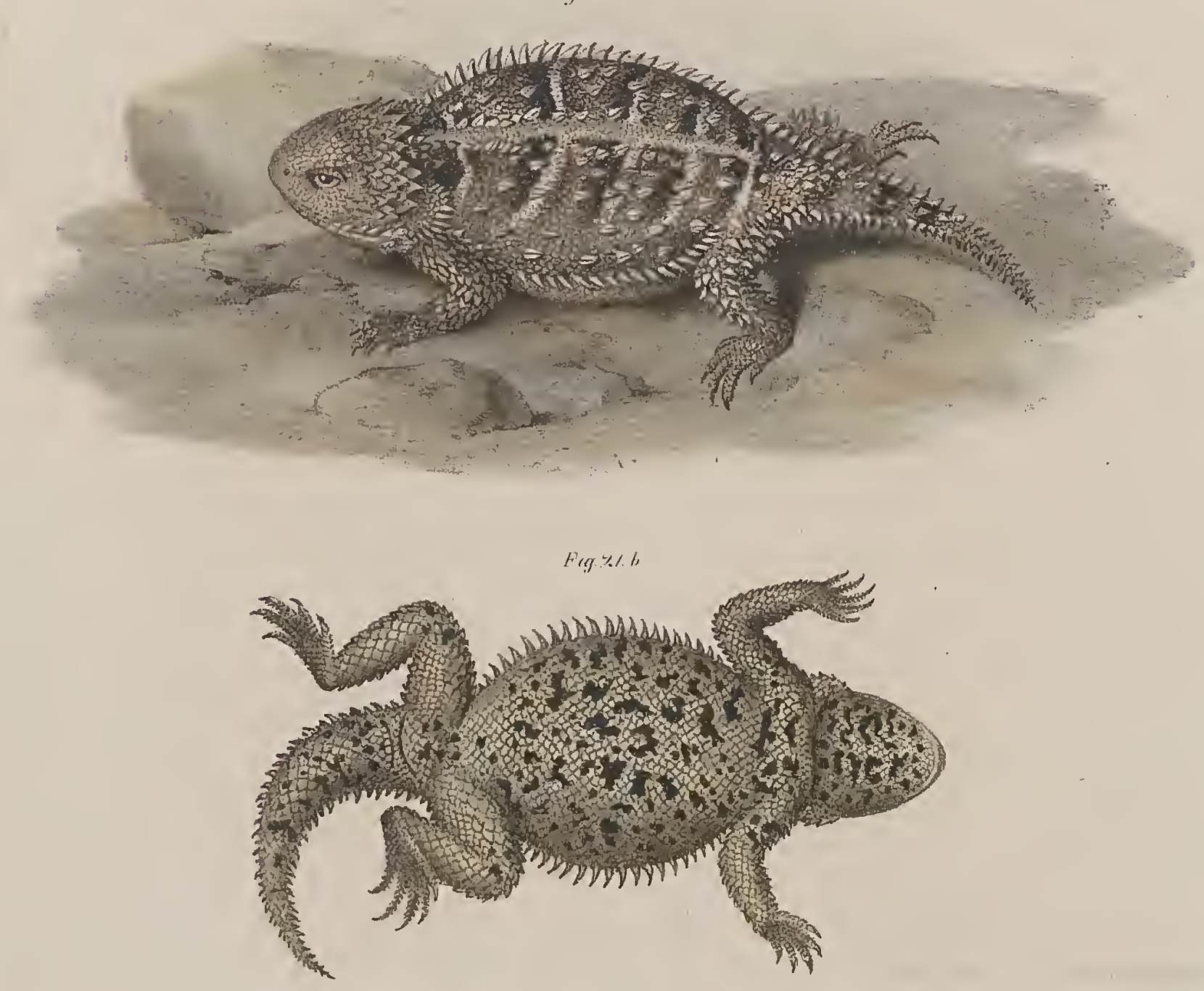

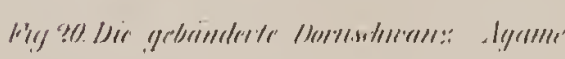

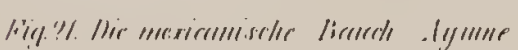

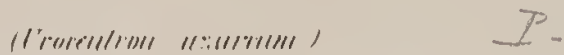

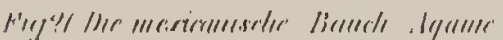

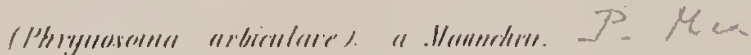

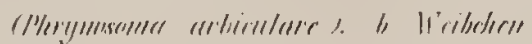


3द⿱

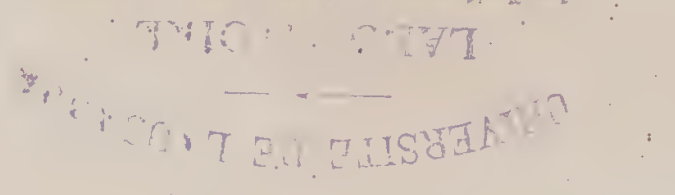

$+\frac{1}{4}$ 

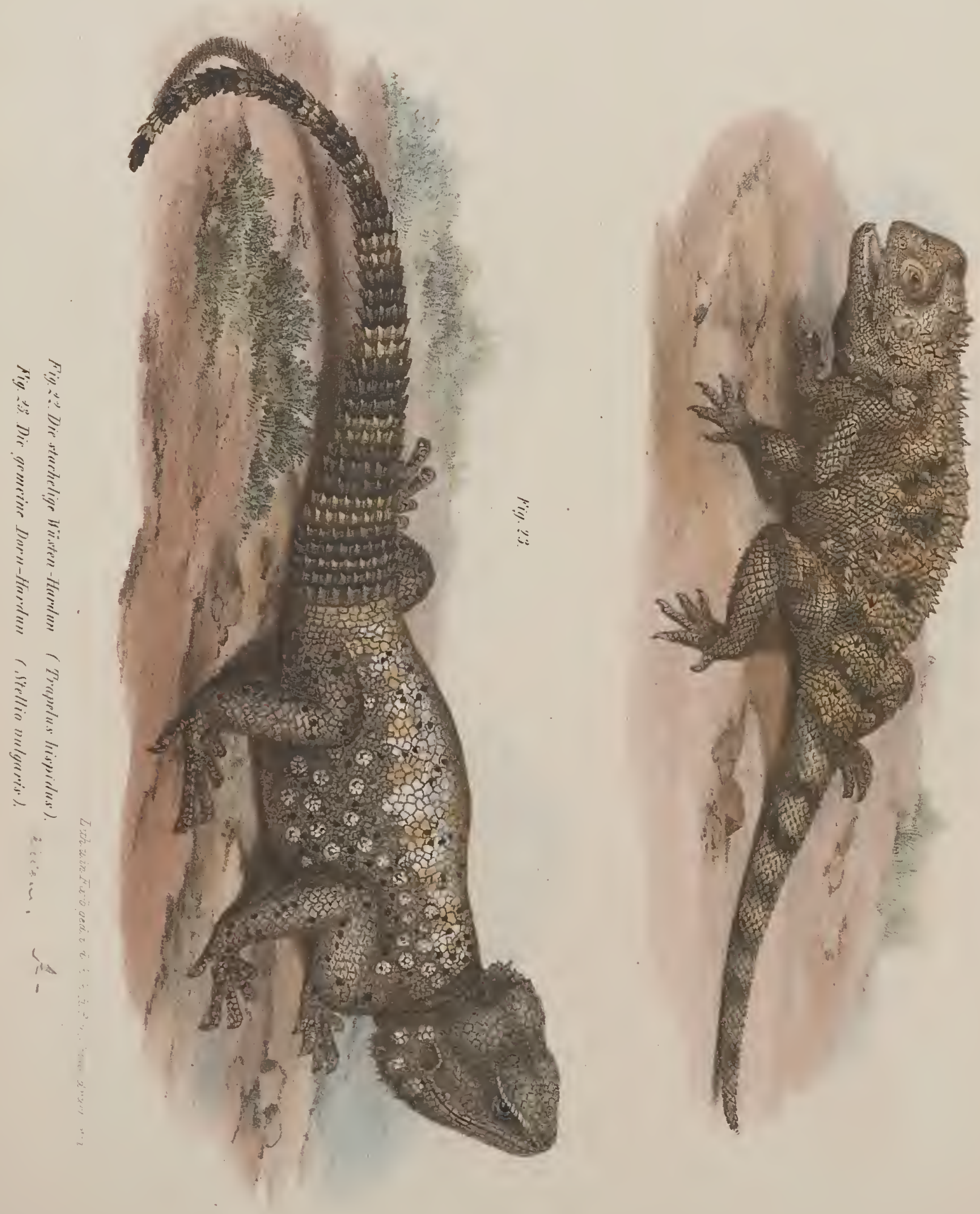


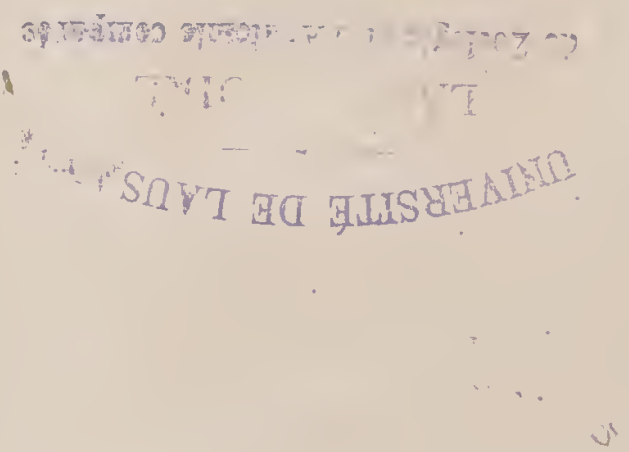




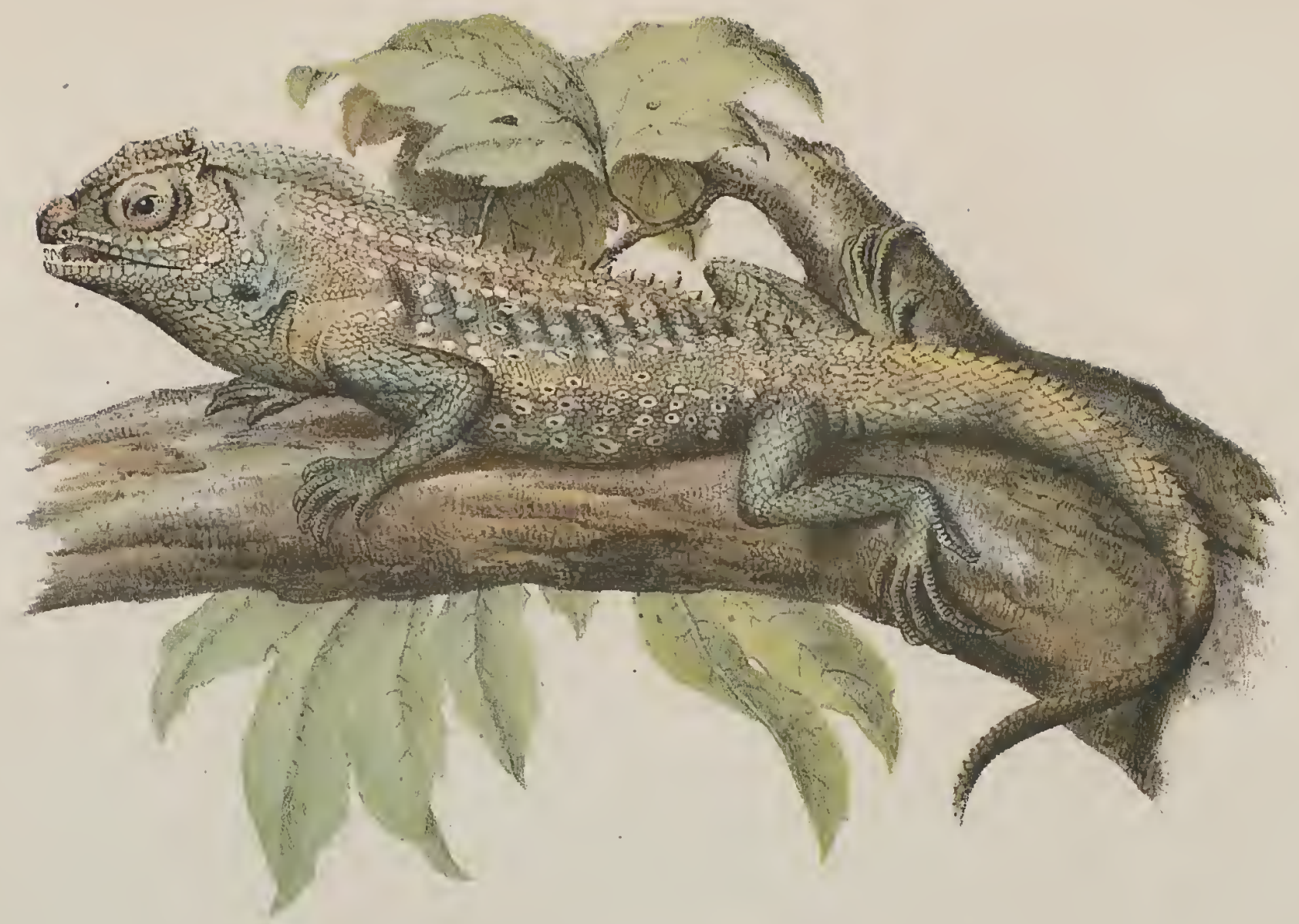

ligy.

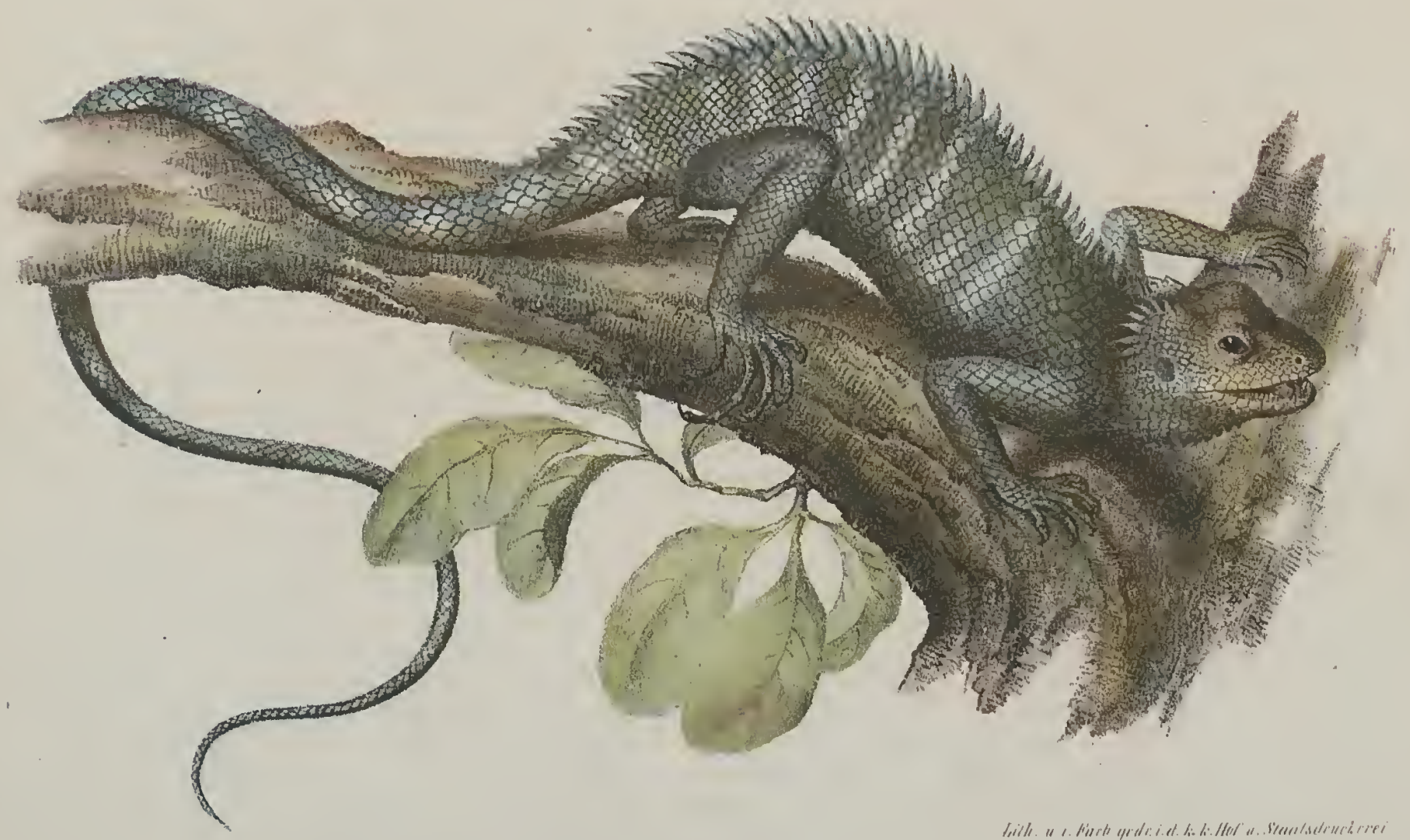

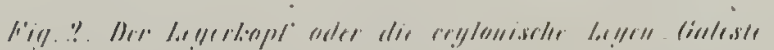

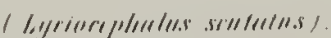

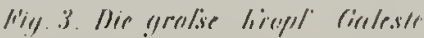

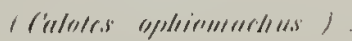




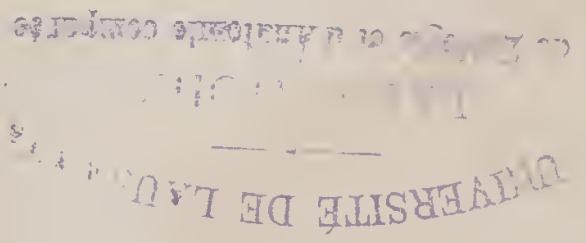




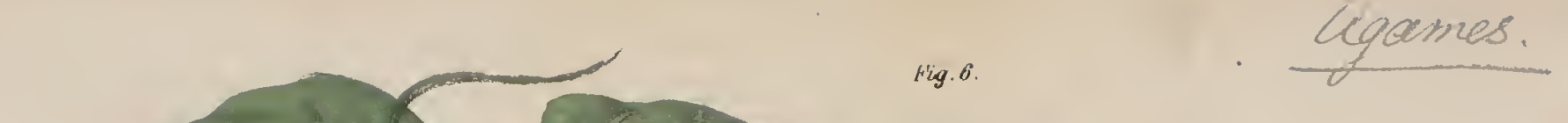

Fing. 6.
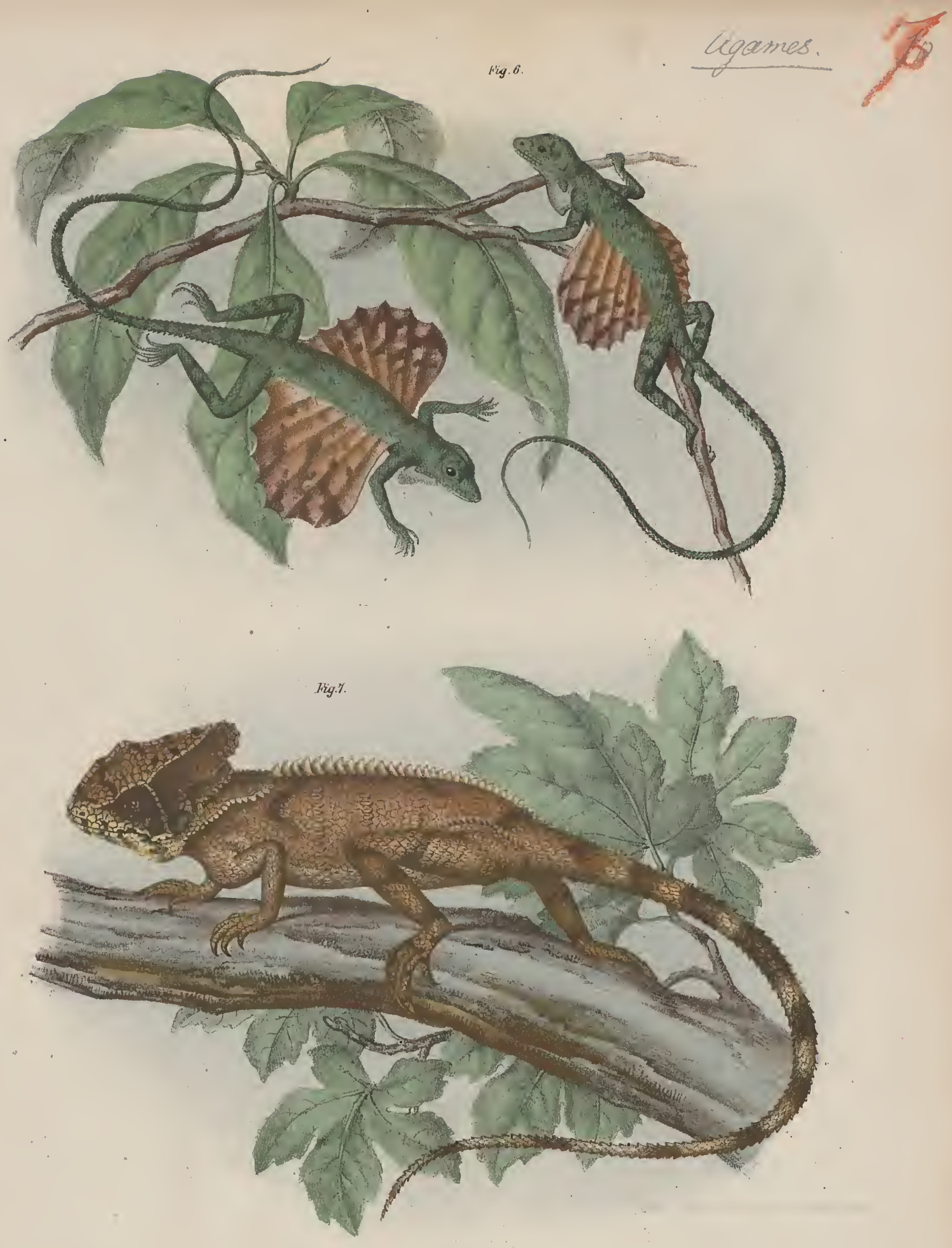

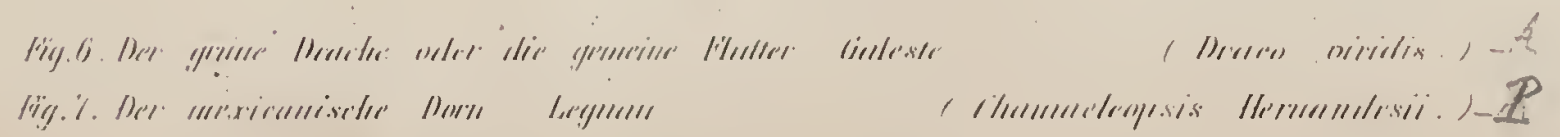




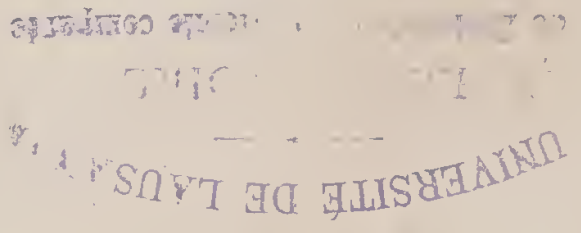




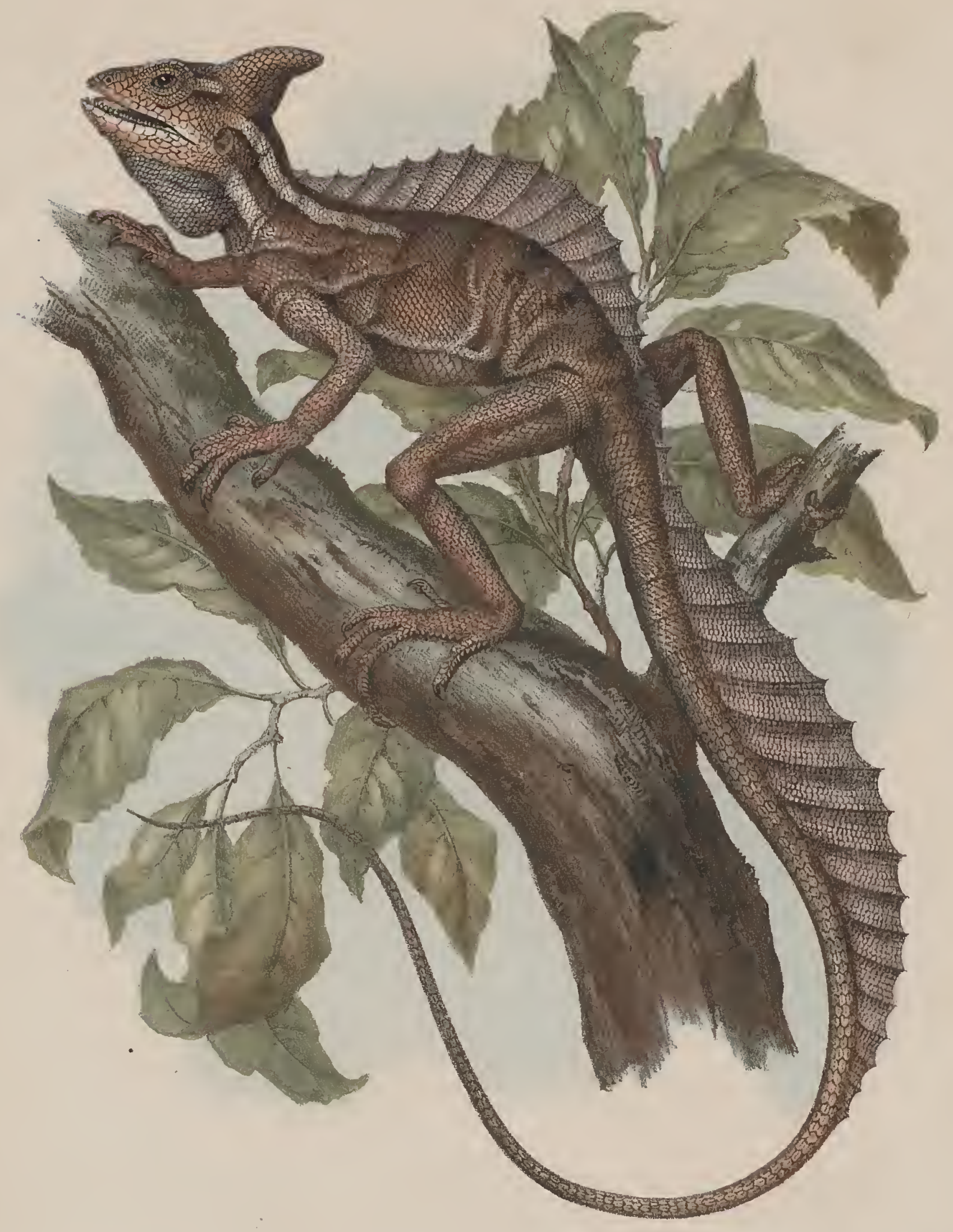

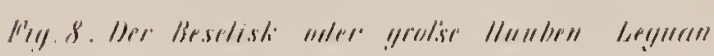

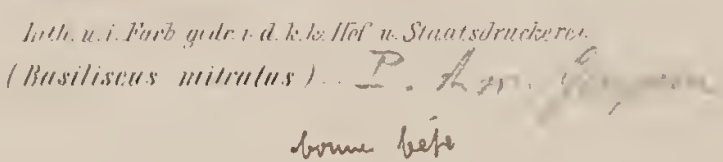




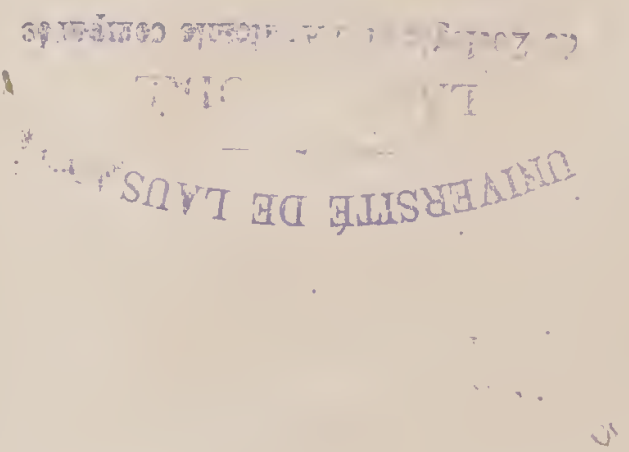


Fig. 28.

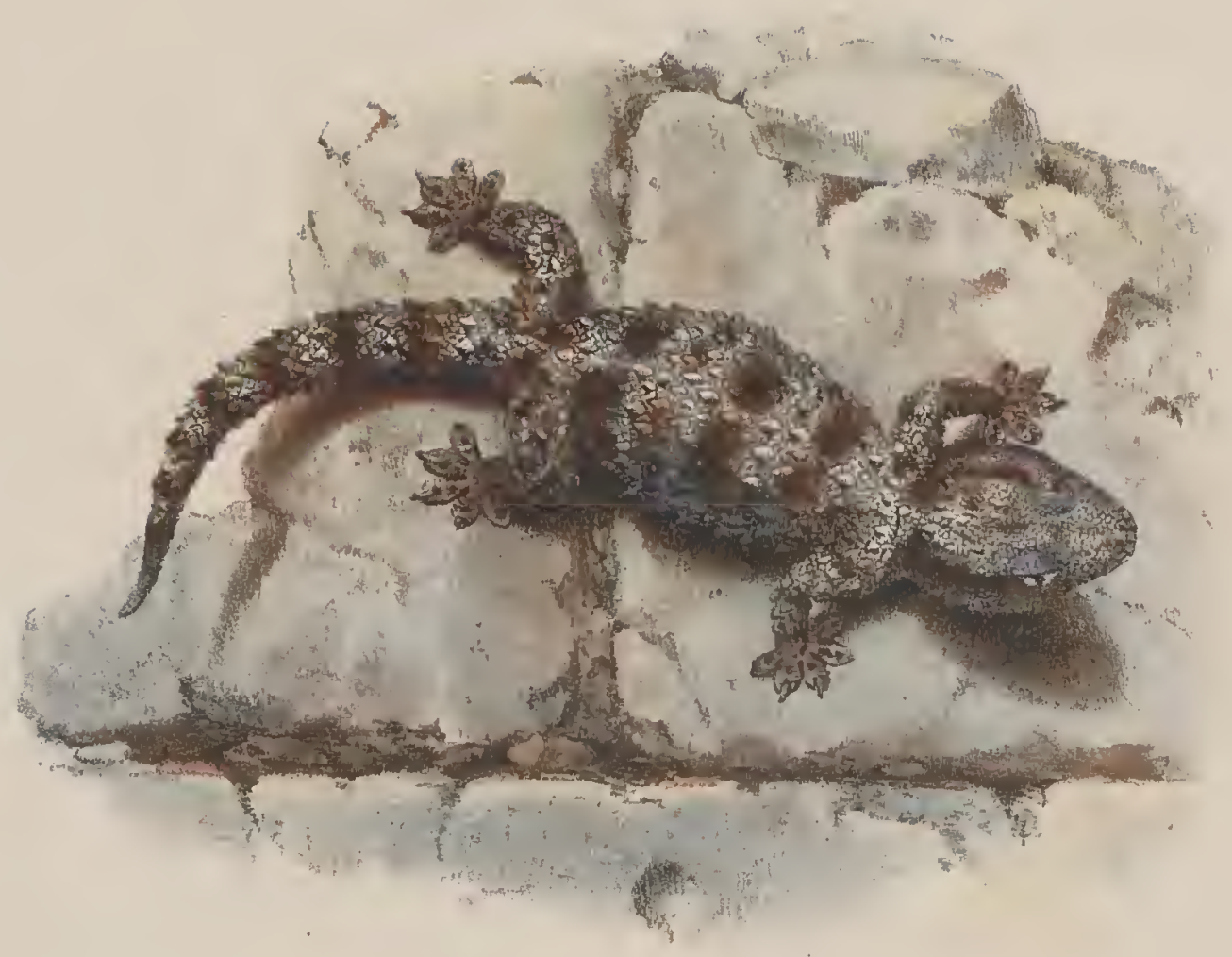

Fiy. 29.

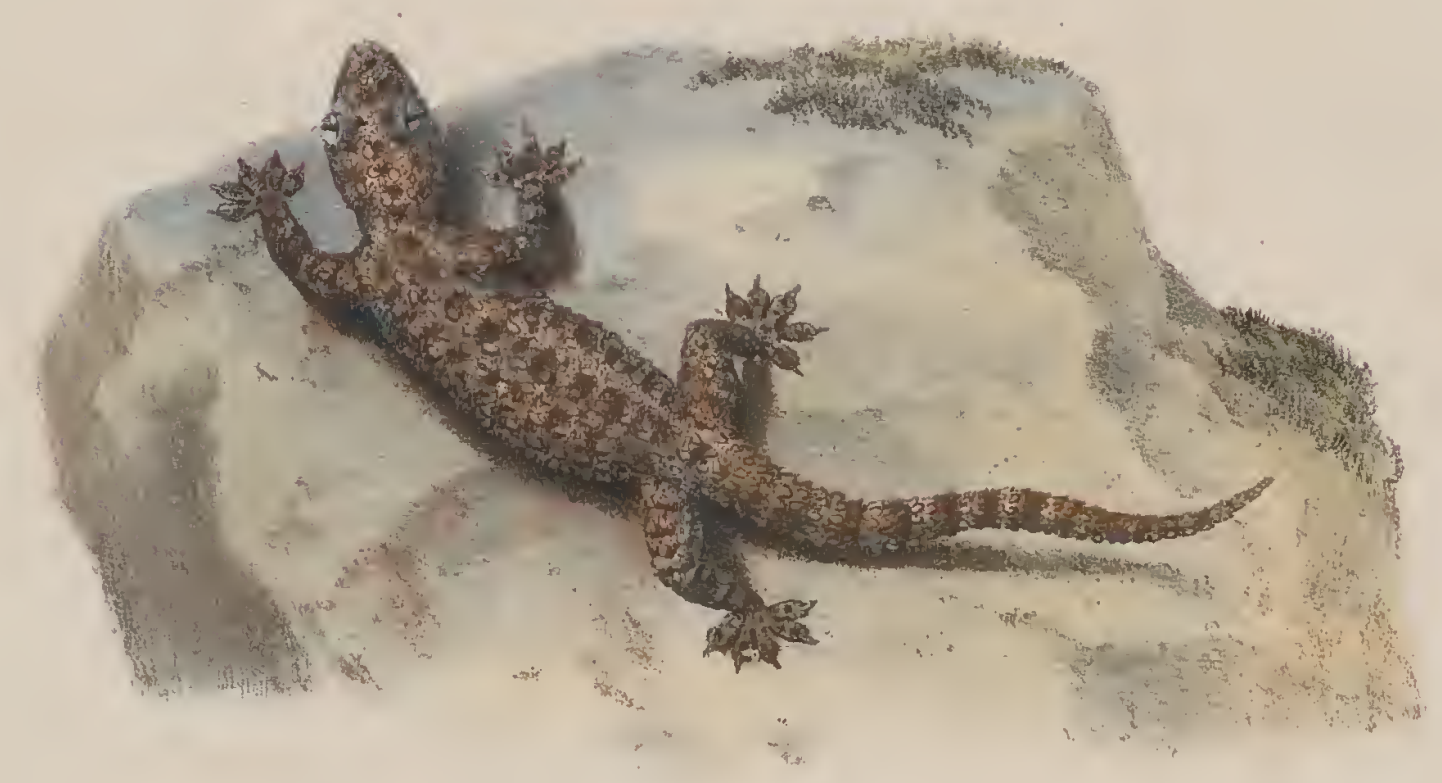

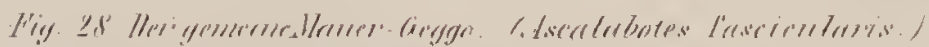

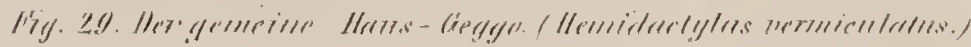




$$
\therefore
$$

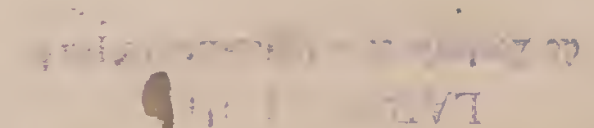

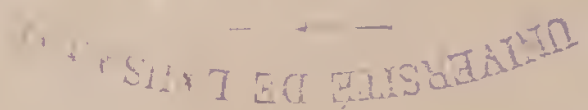




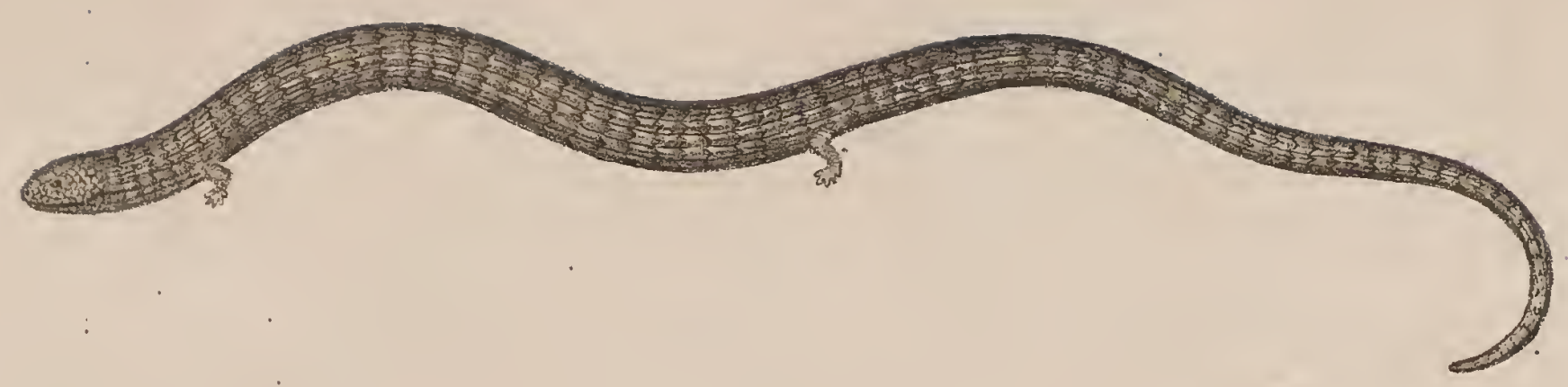

Fig. 56

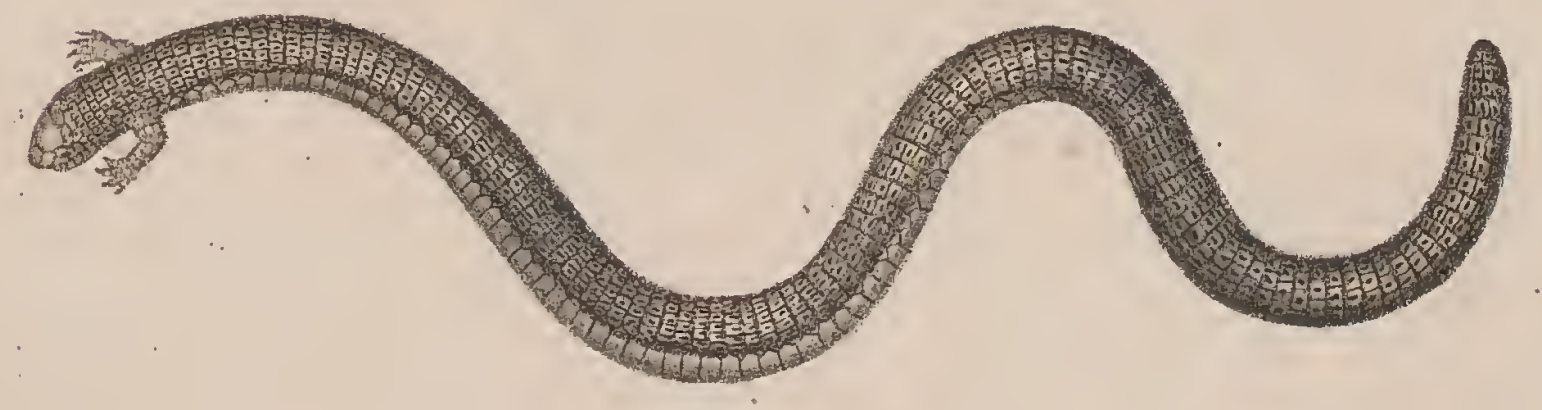

Fing. $5 \%$

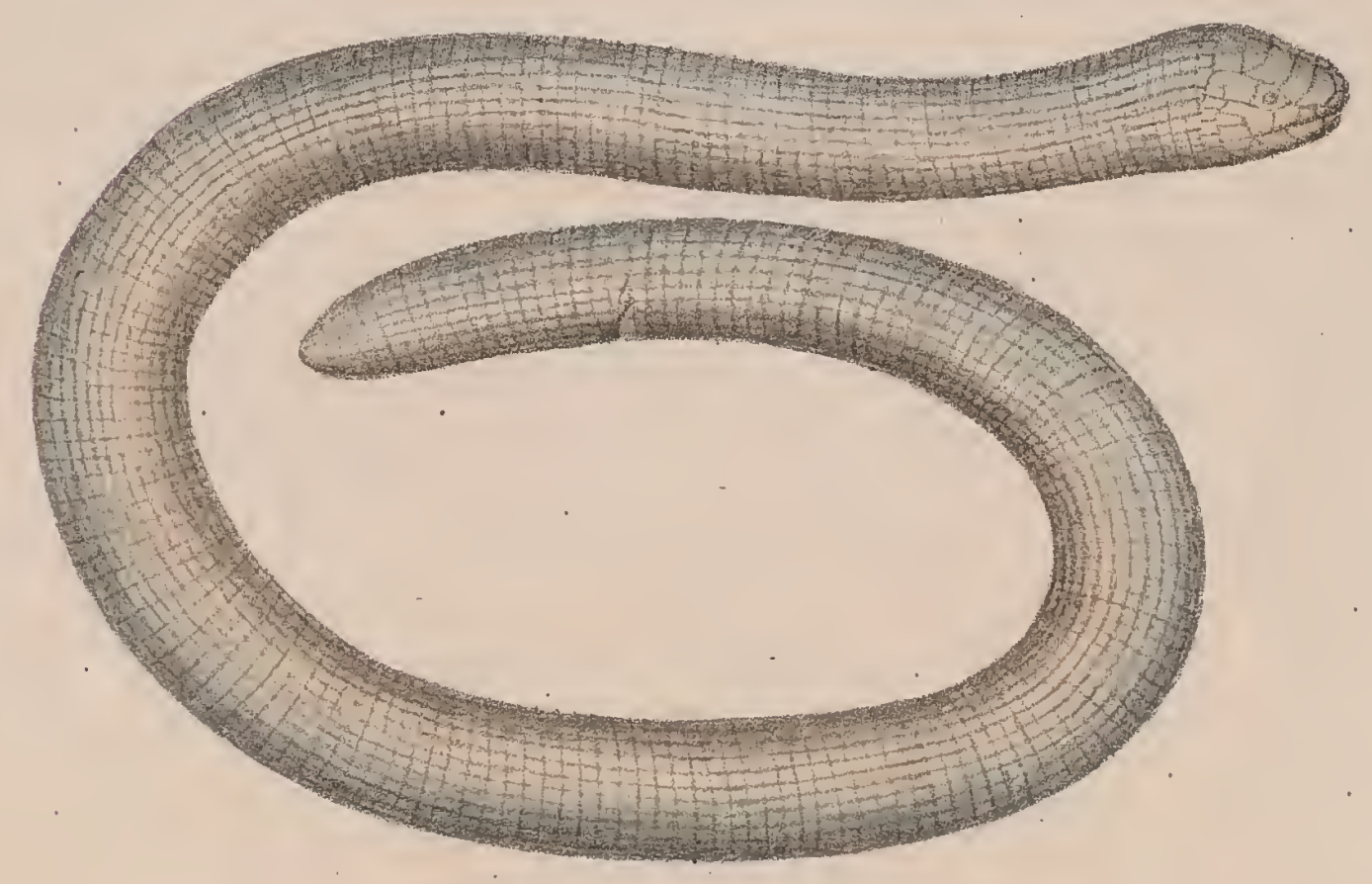

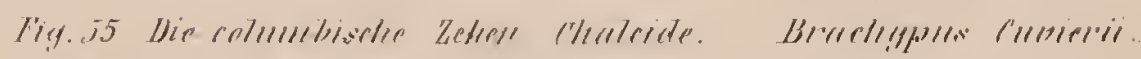

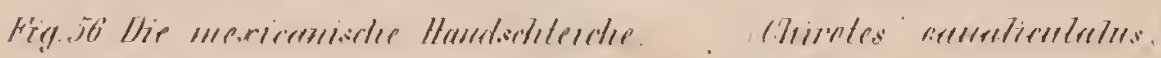

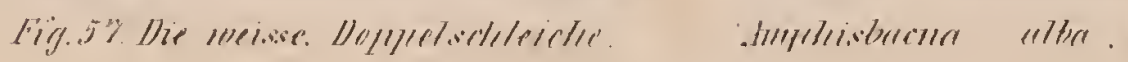




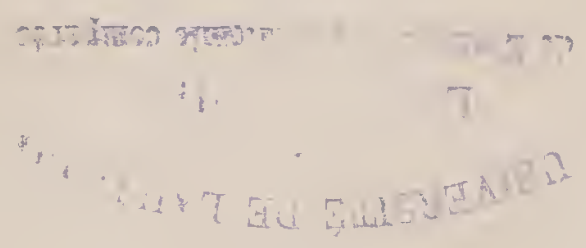

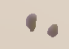




\section{4}

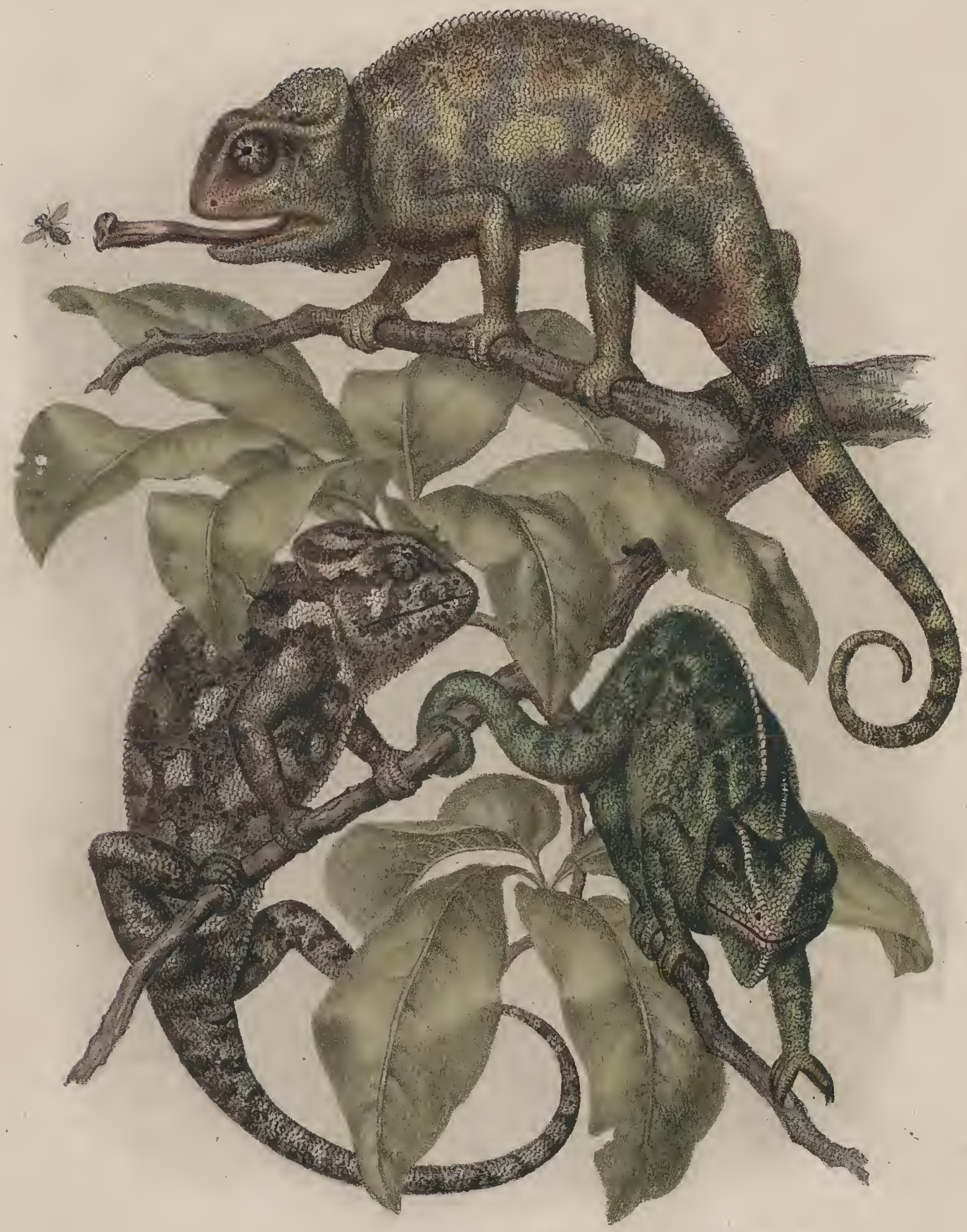

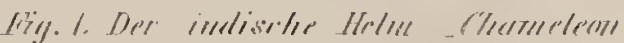

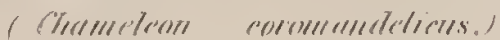




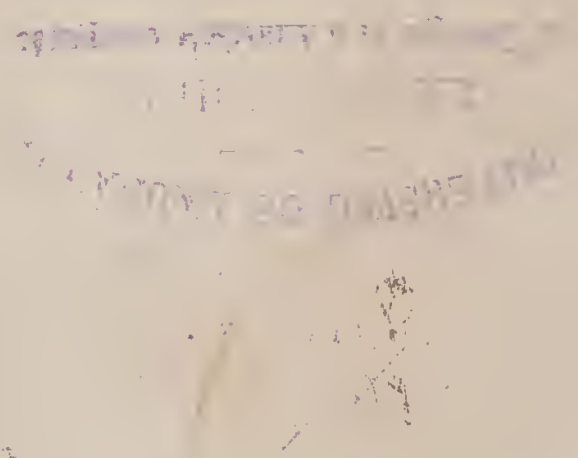

a

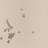

1. .

- 


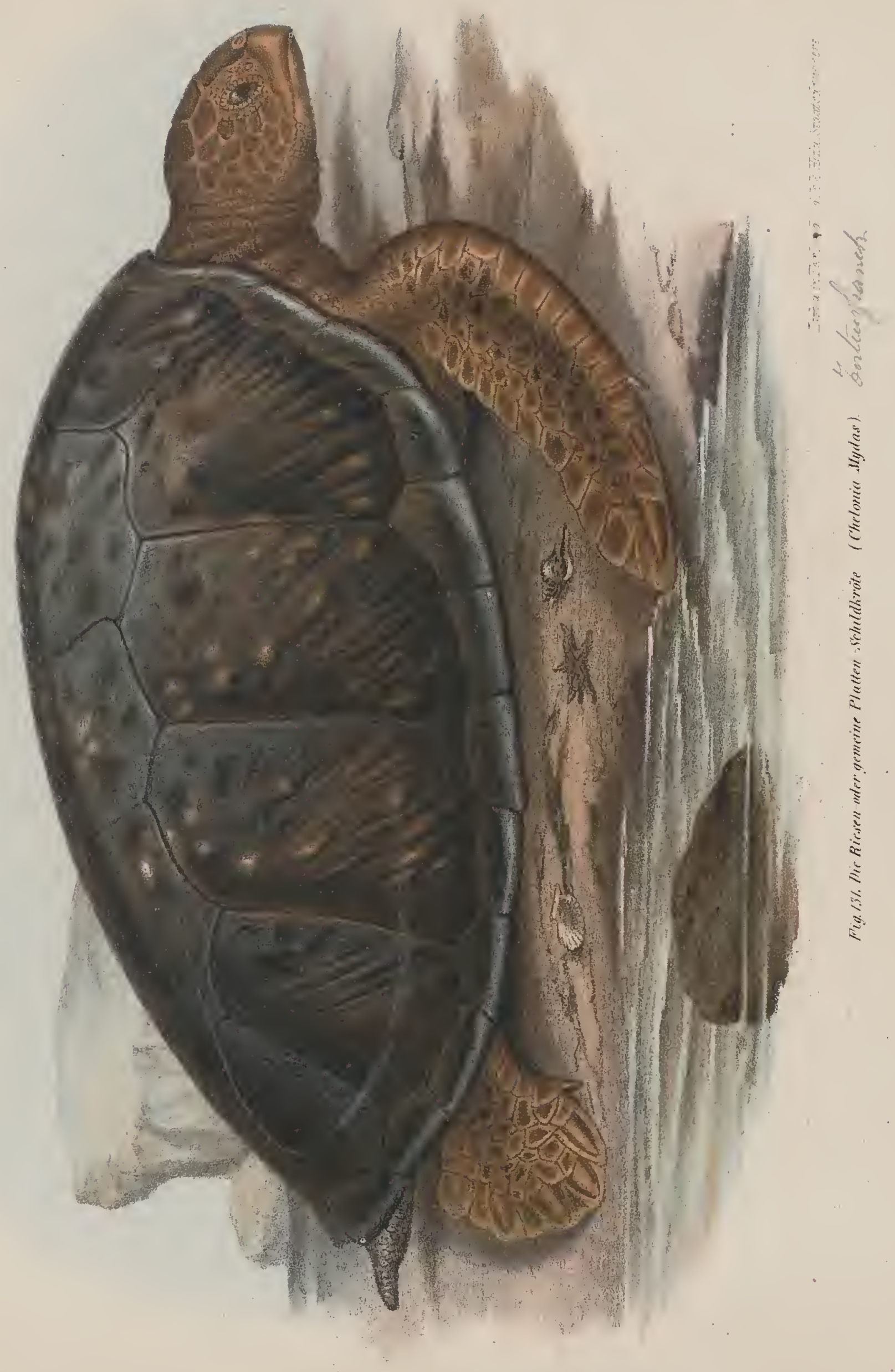




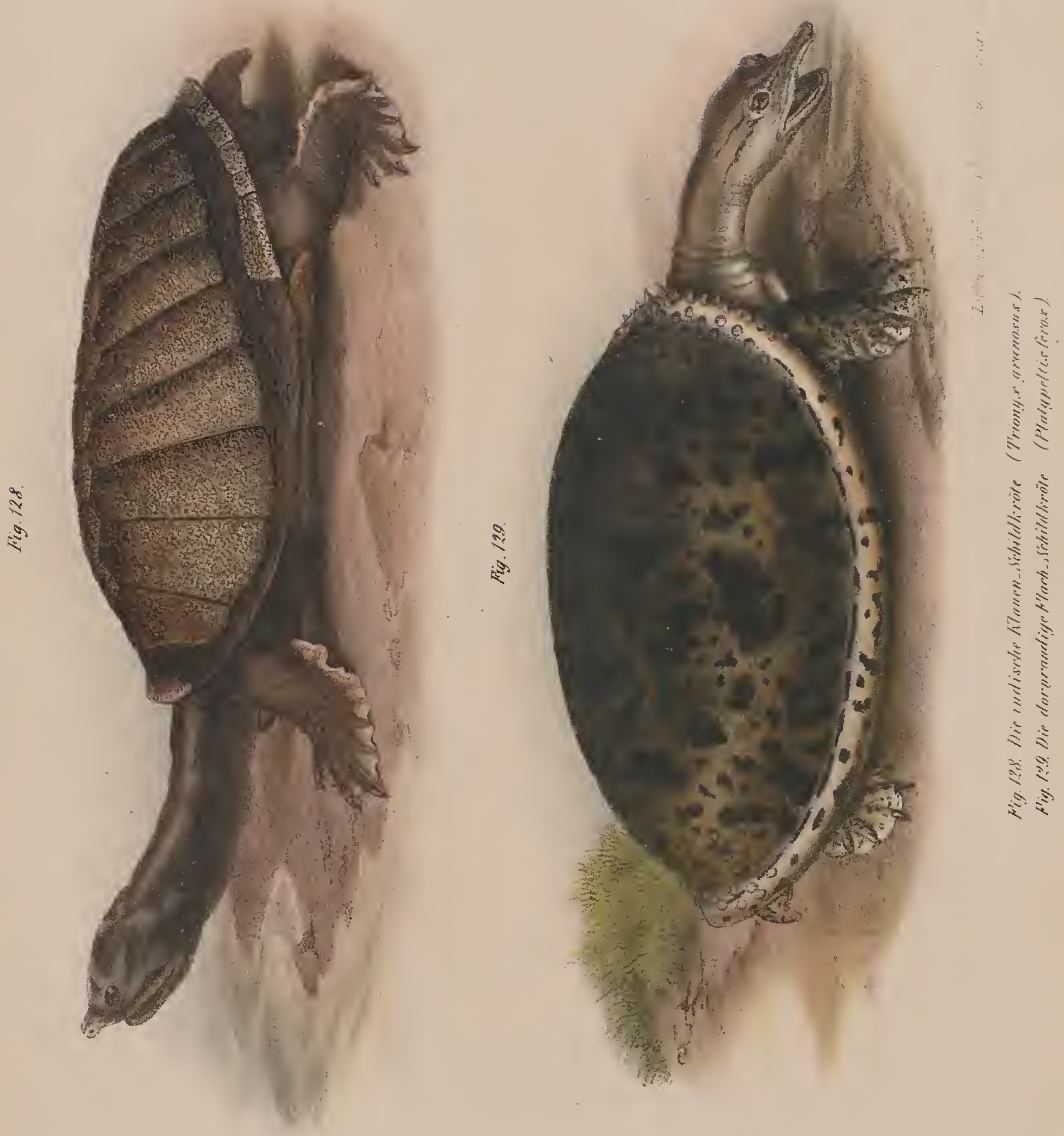
?

?

.

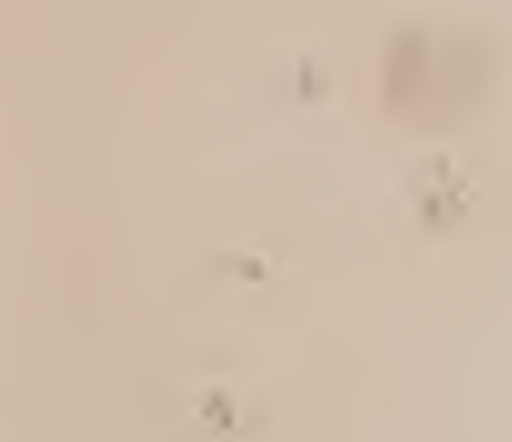

,

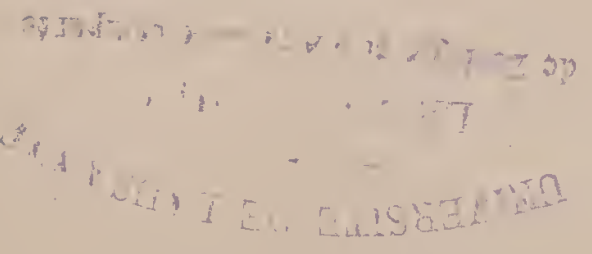



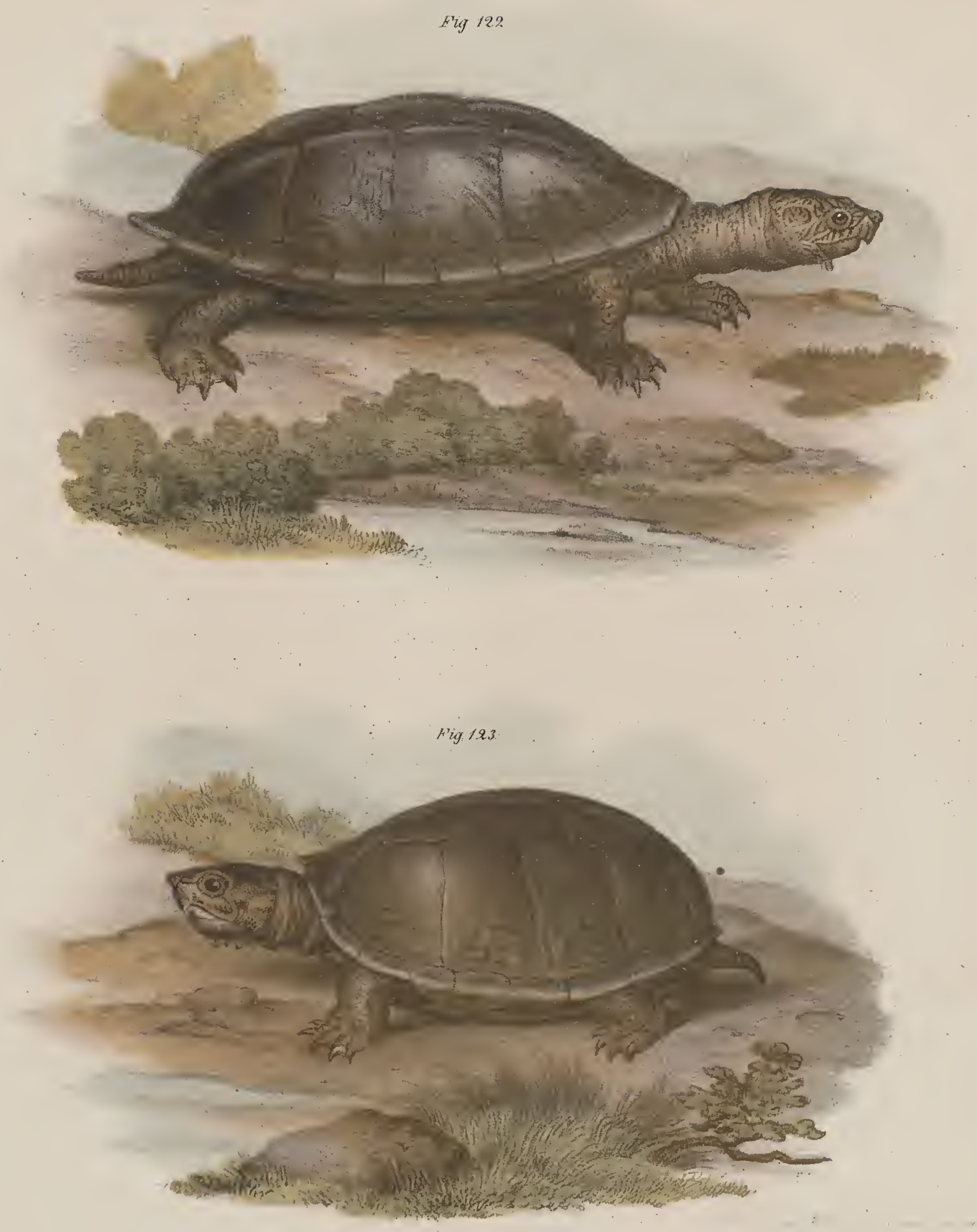

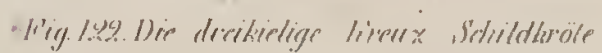

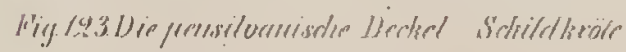





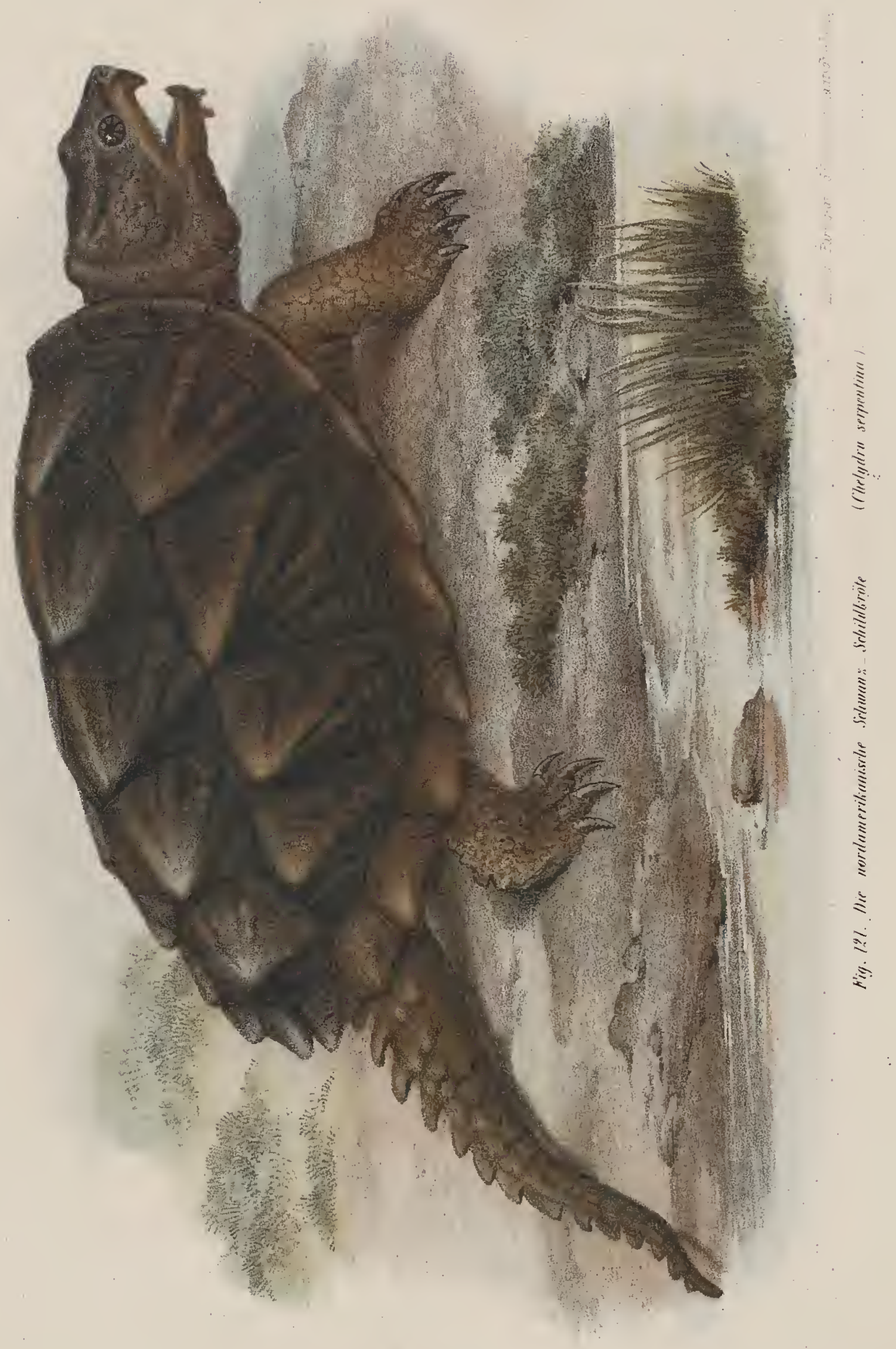


ใด้

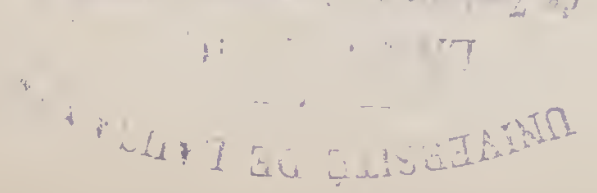




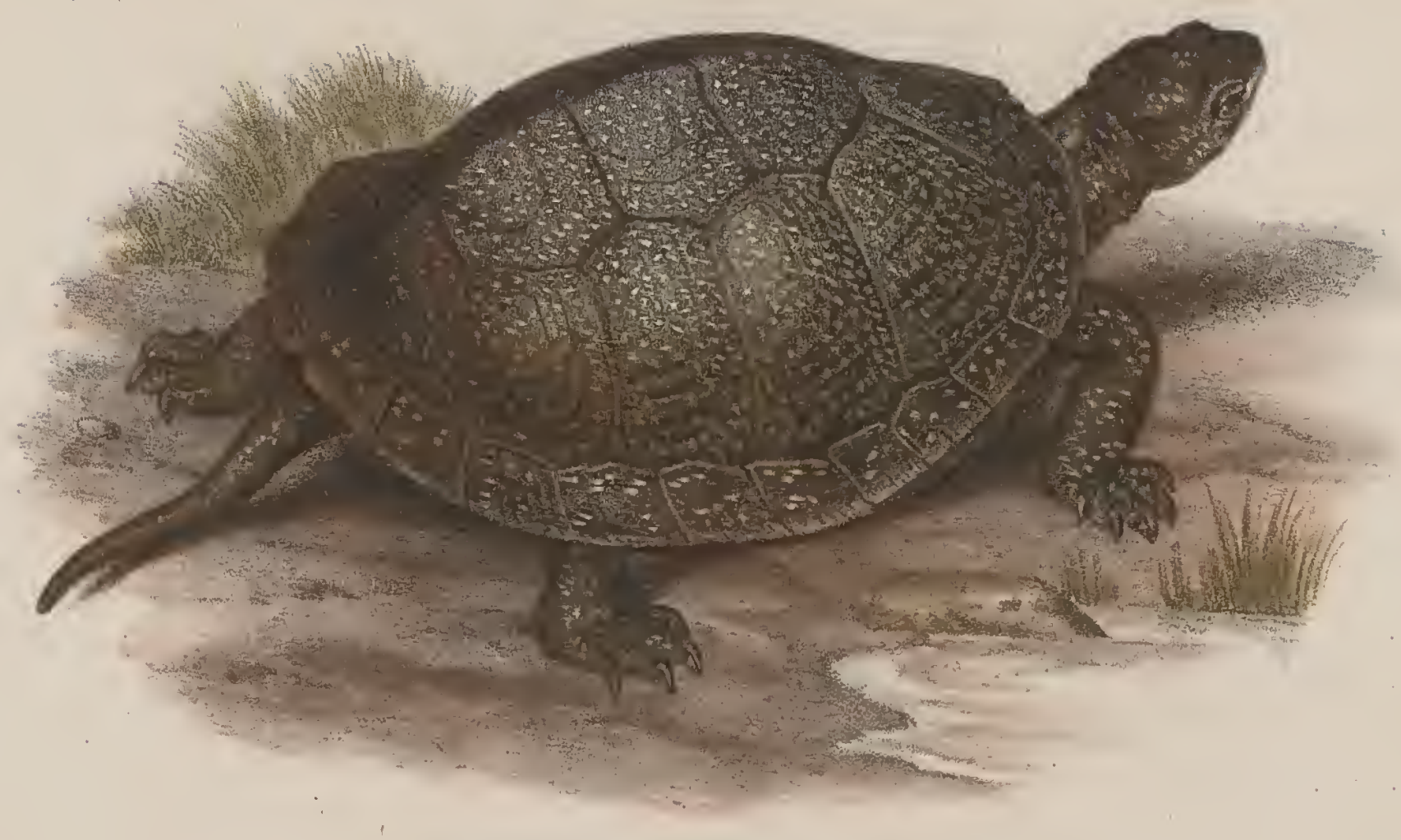

Fig. 120

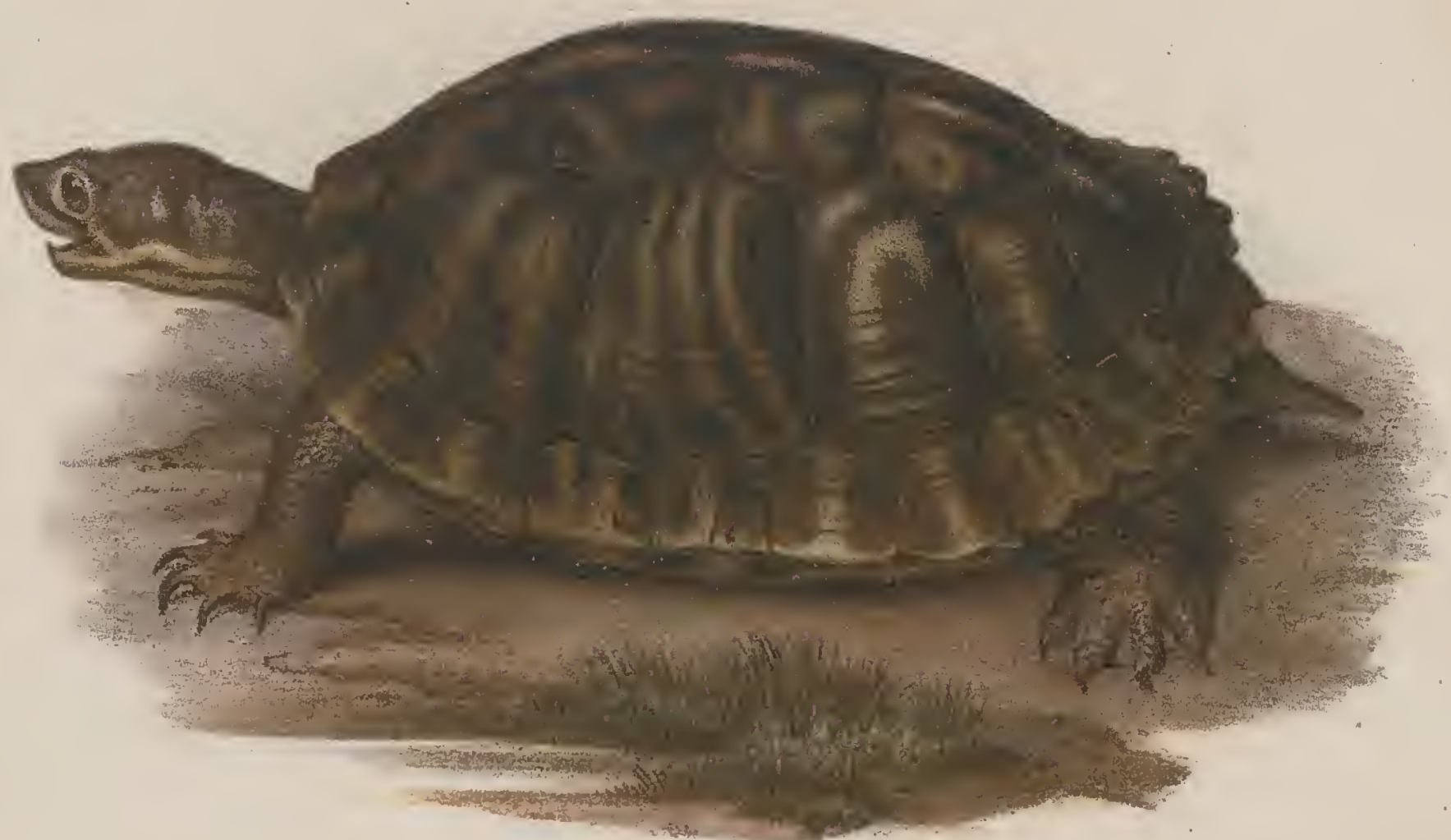

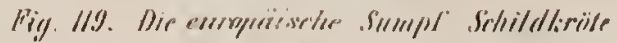

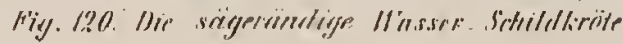

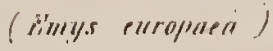

(linemmys serrotn) 


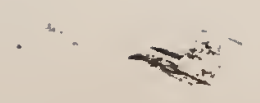

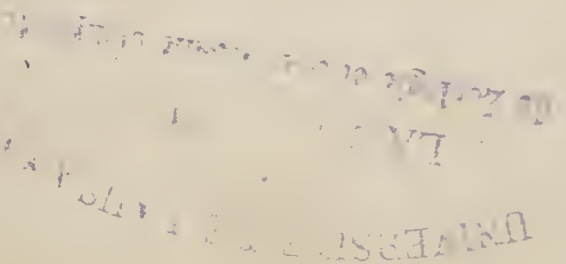



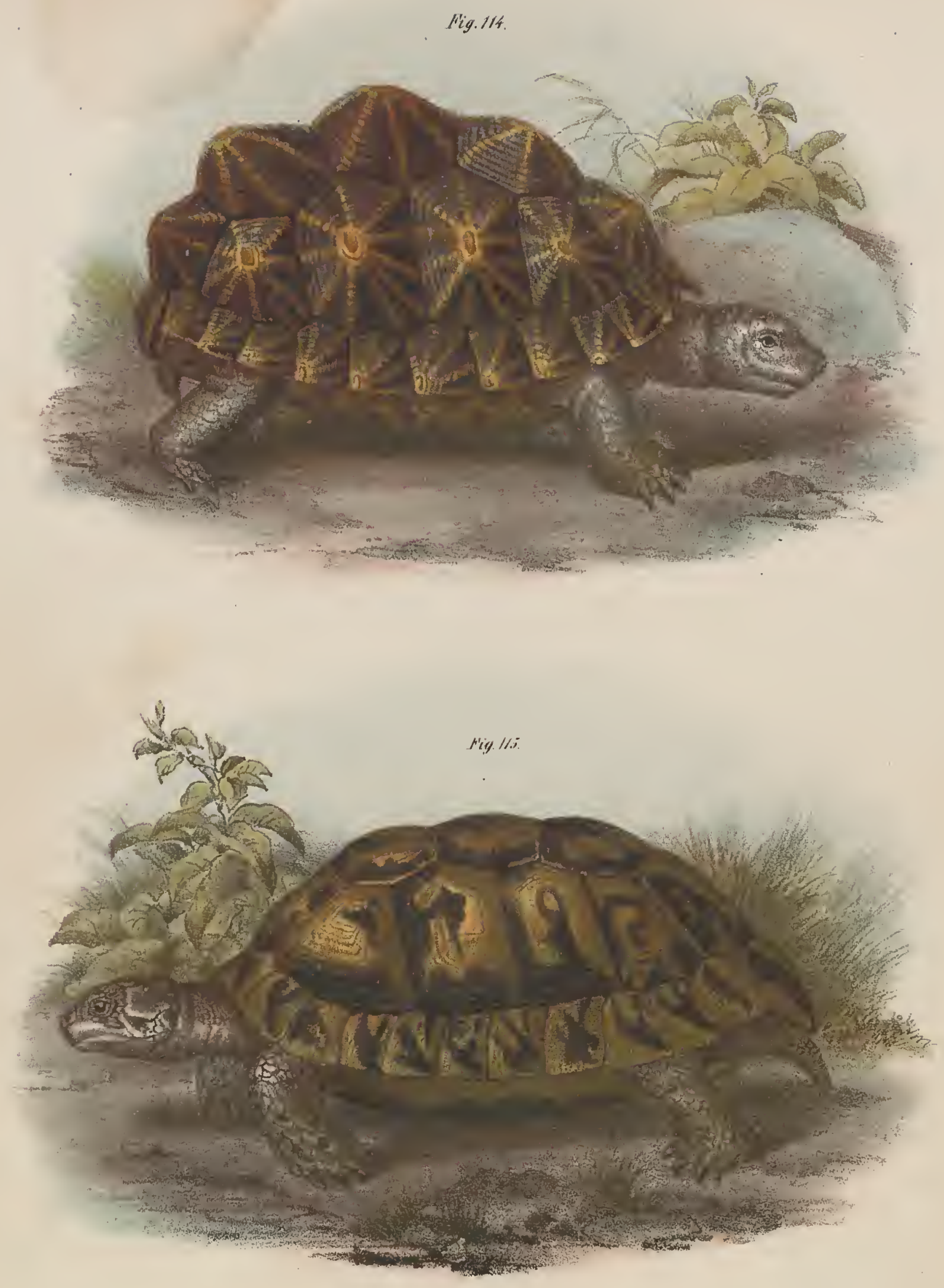

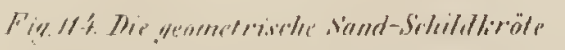

(. Psammobates grometricus)

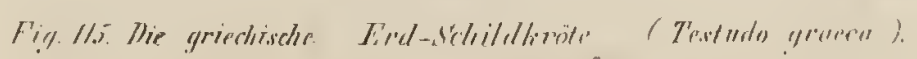


,

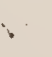

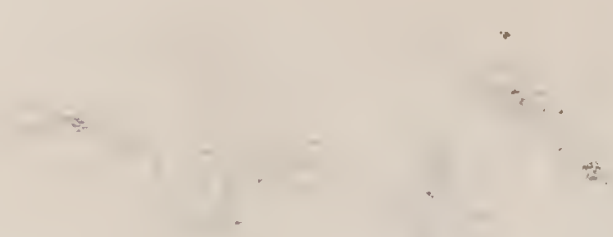

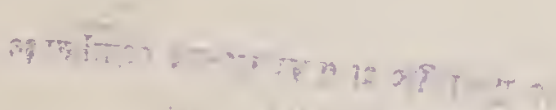

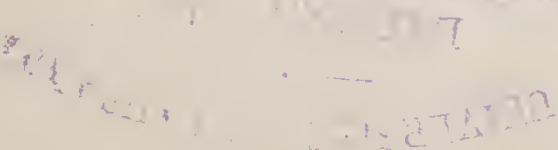




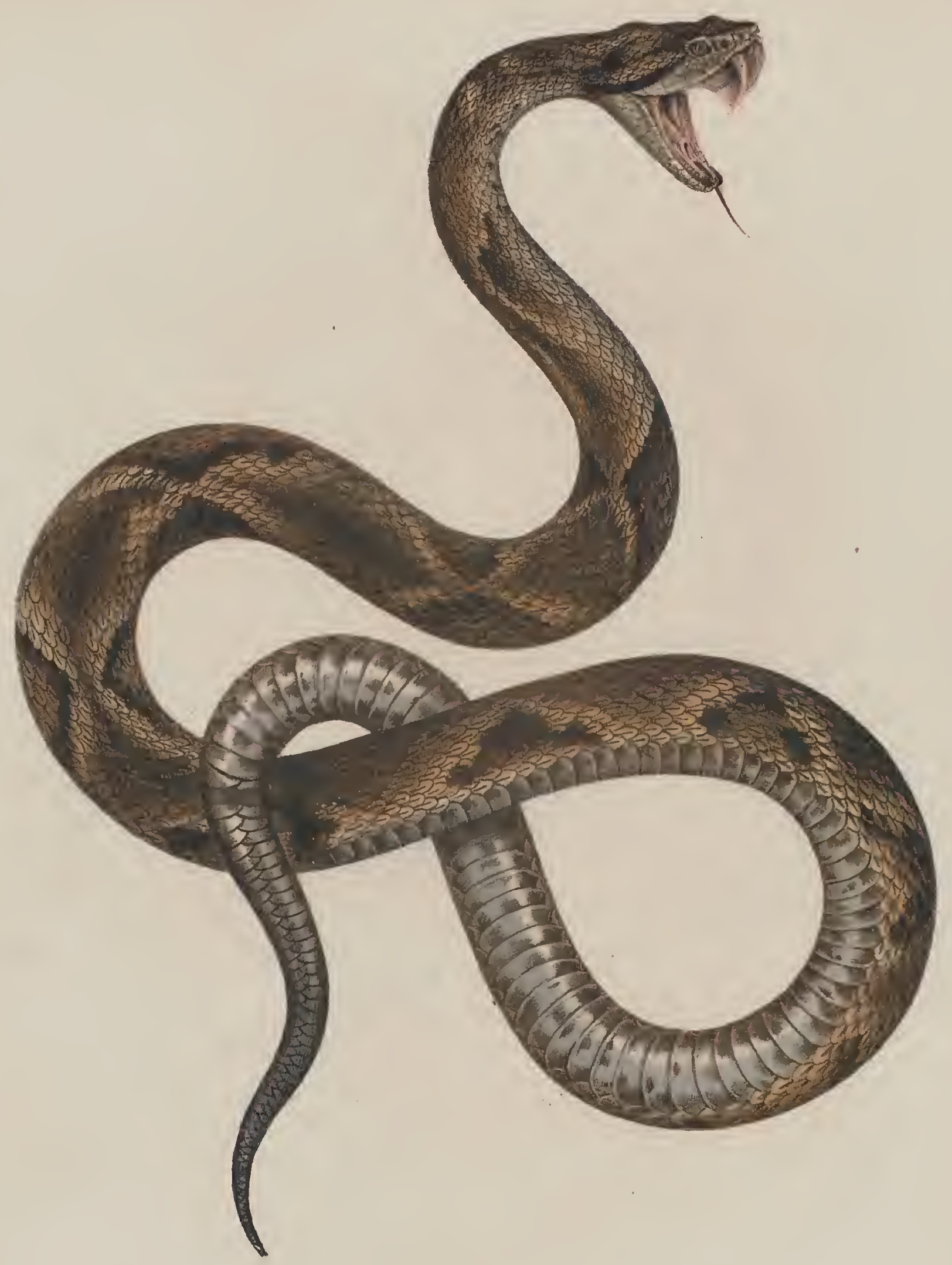

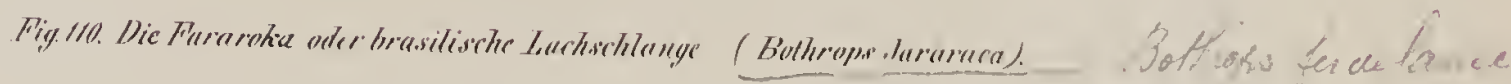





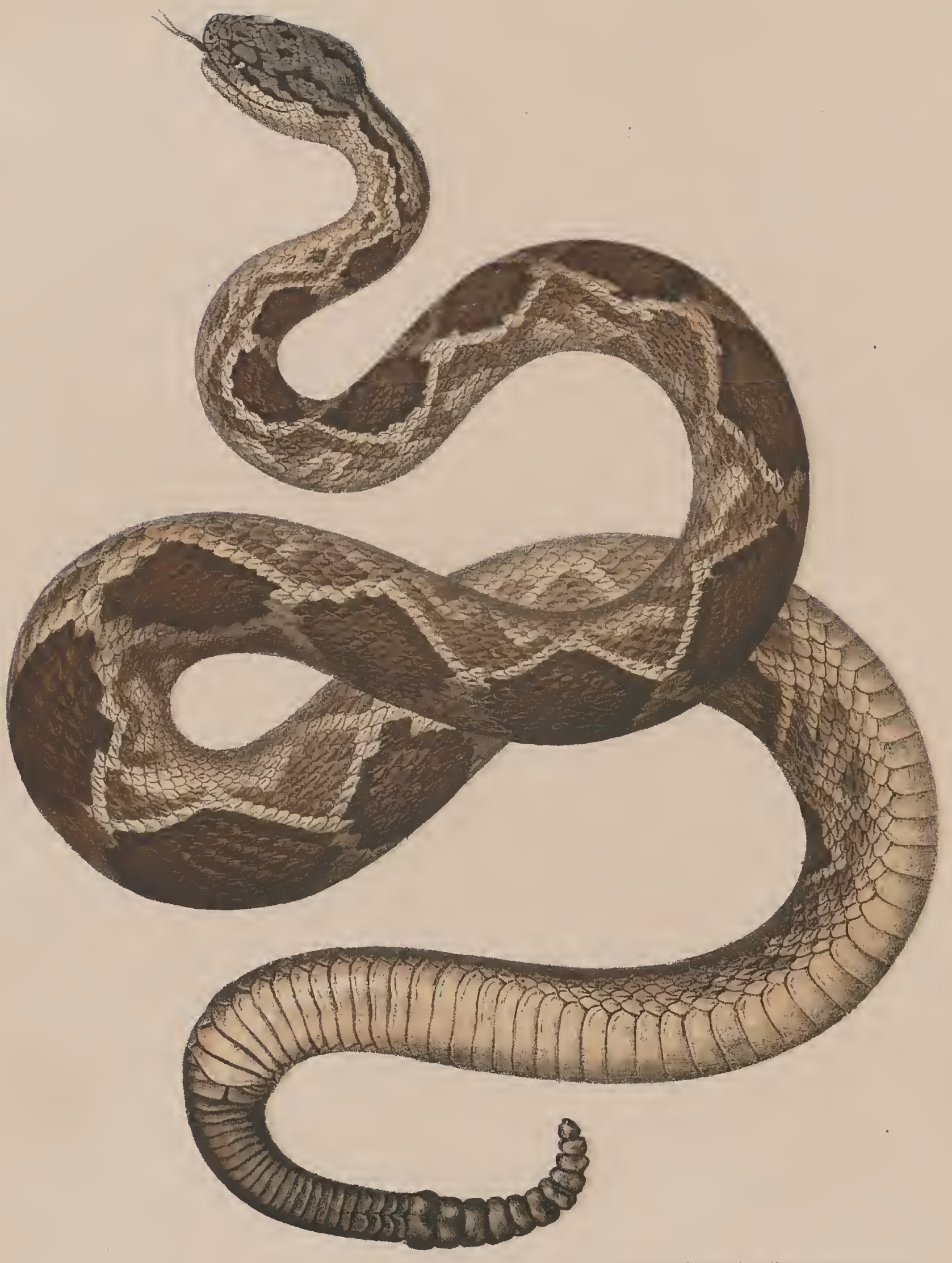

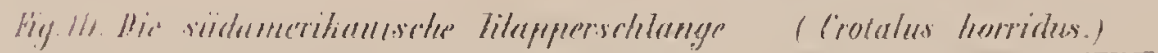




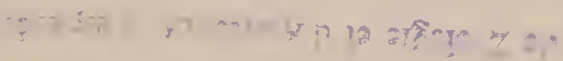

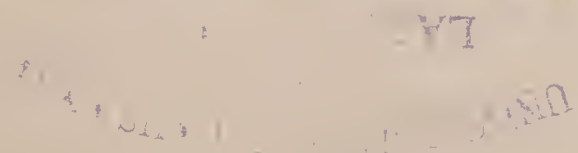




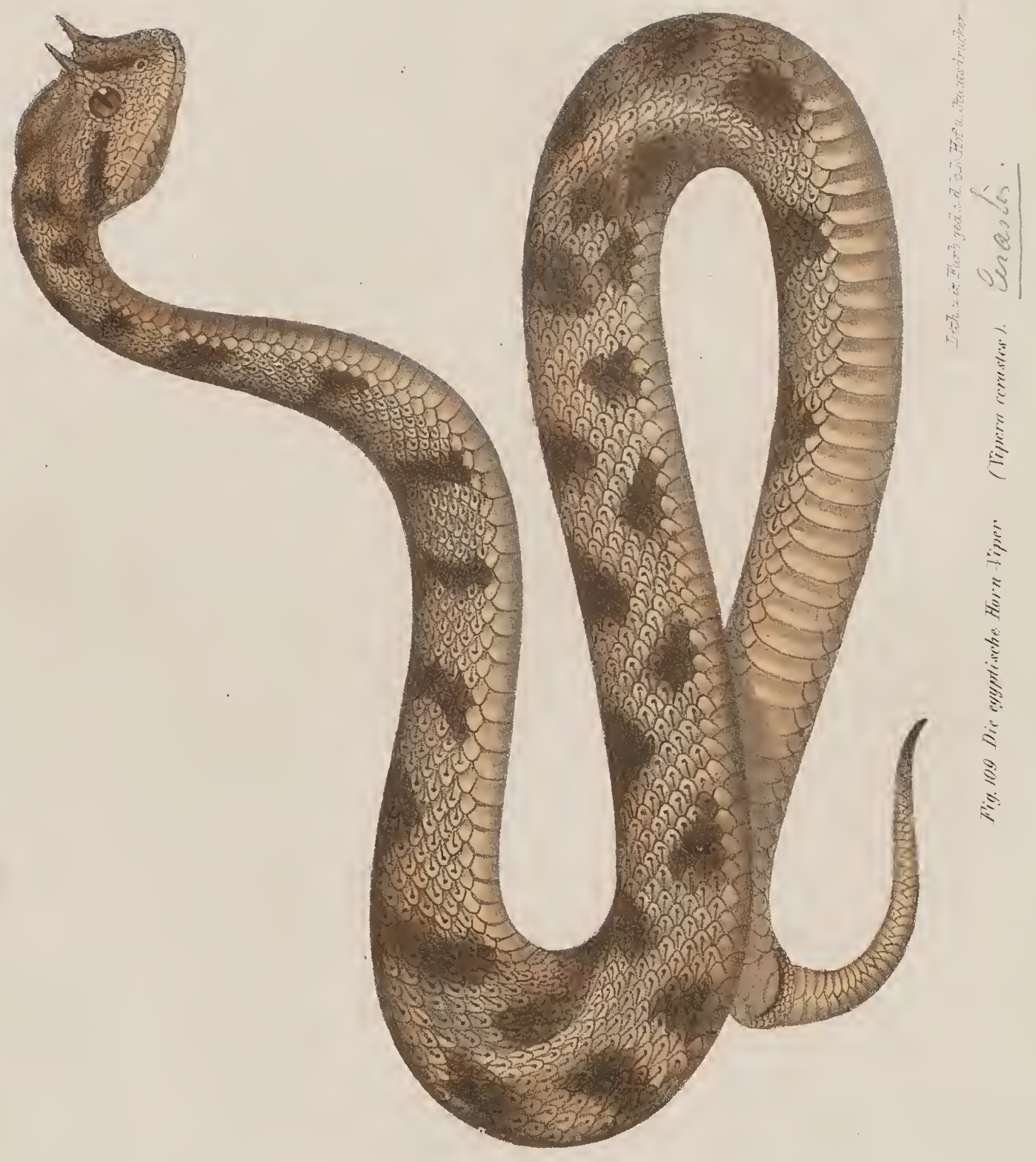


73ำ

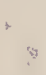

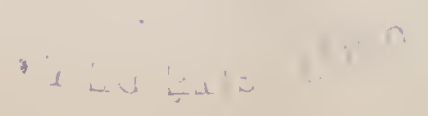




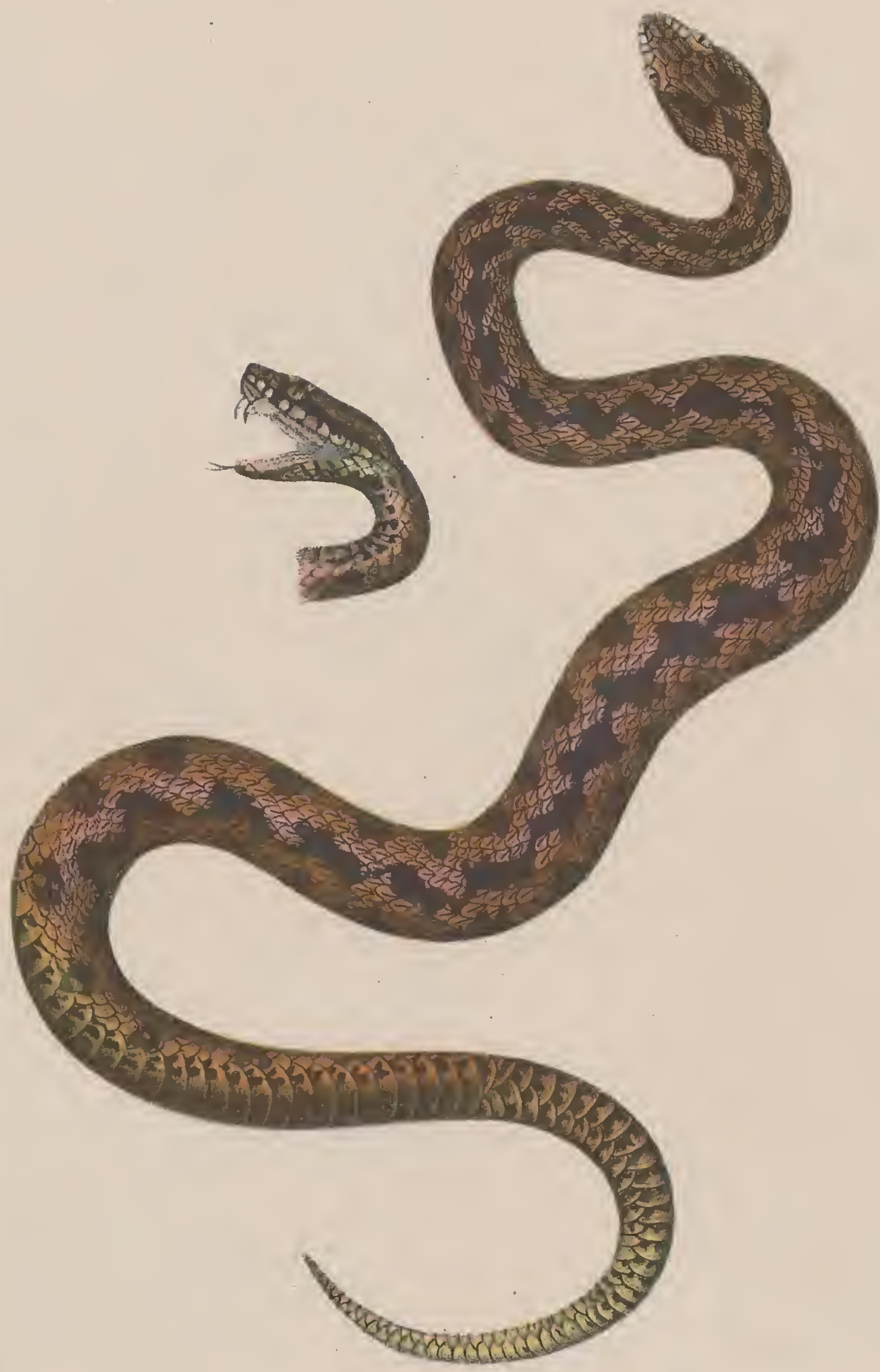

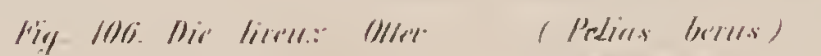




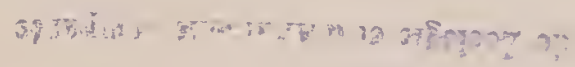

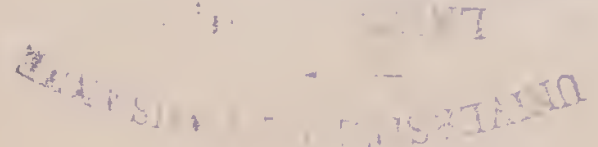




$$
5
$$




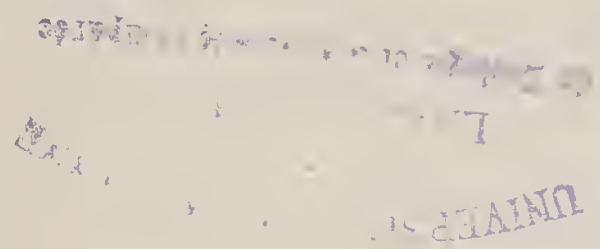

年

fes

2 


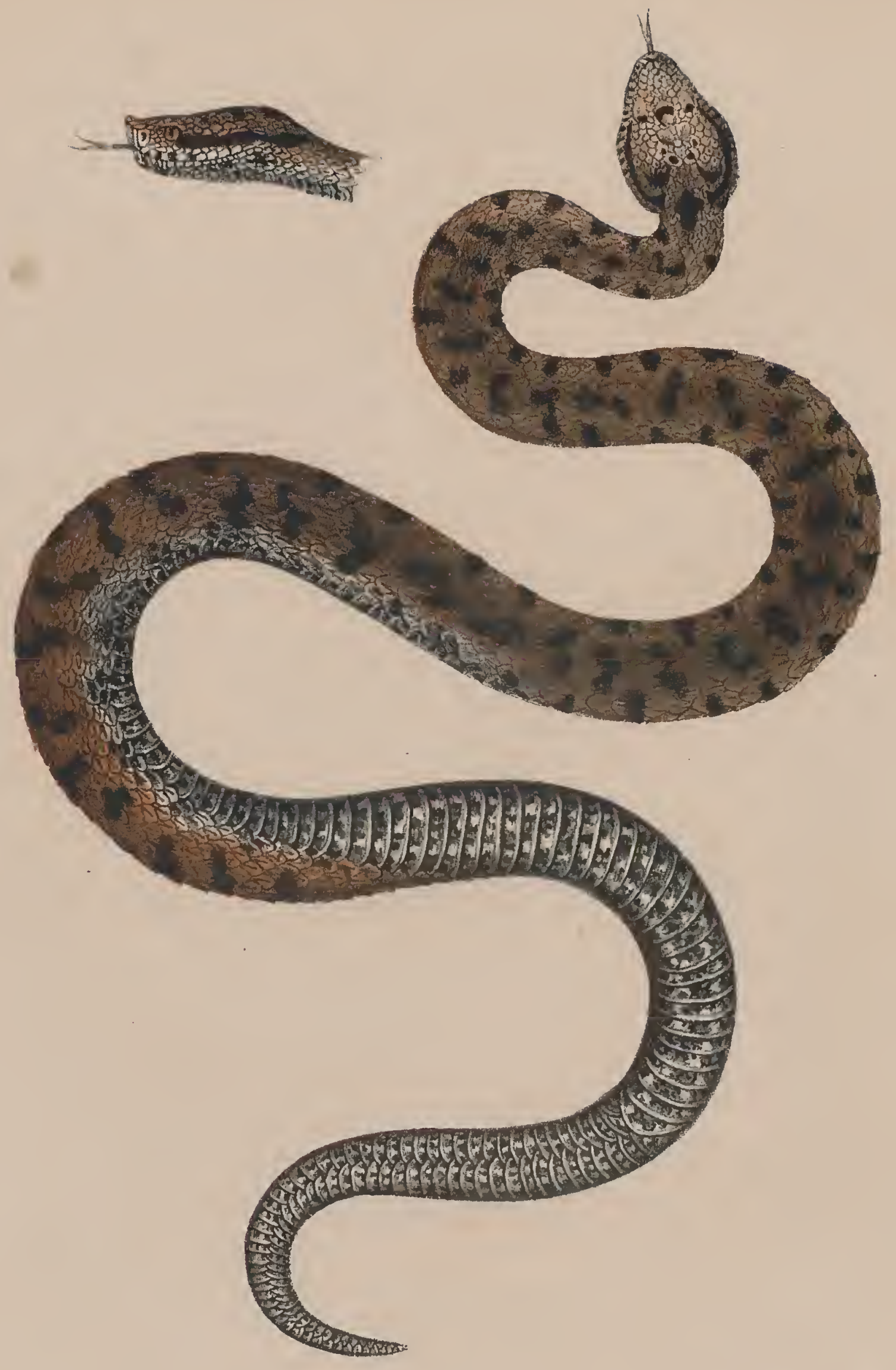

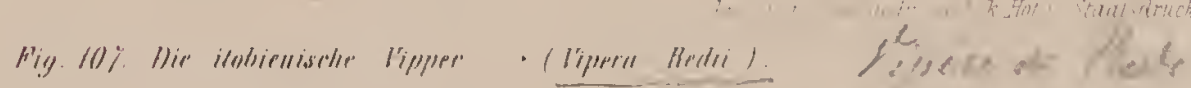




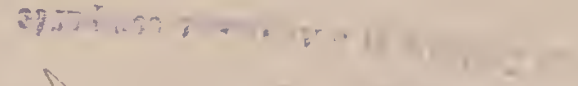

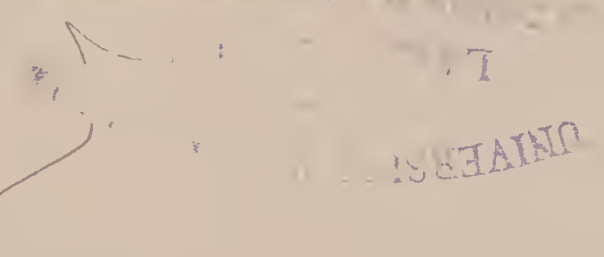




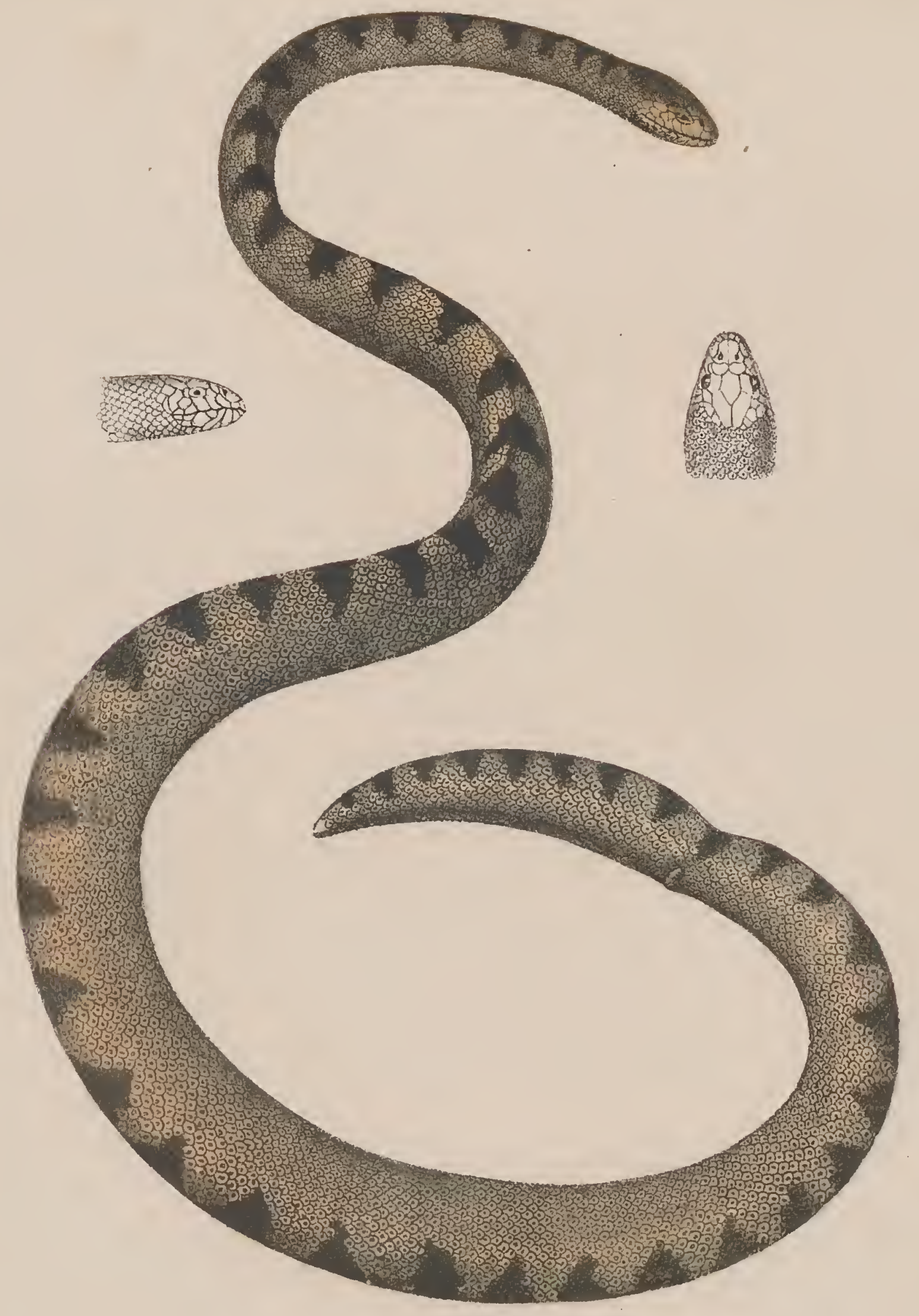

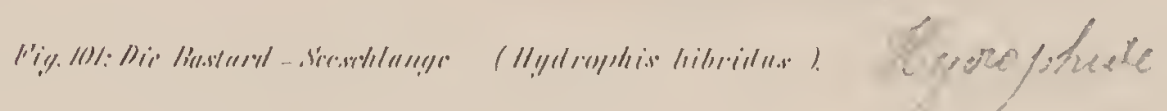


4

!

i

$-2$

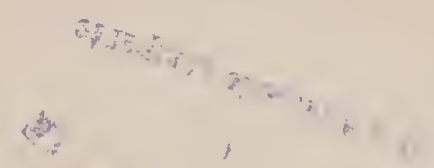

$$
\begin{aligned}
& 8 \times 7^{-21} \\
& \text { sctis rall }
\end{aligned}
$$




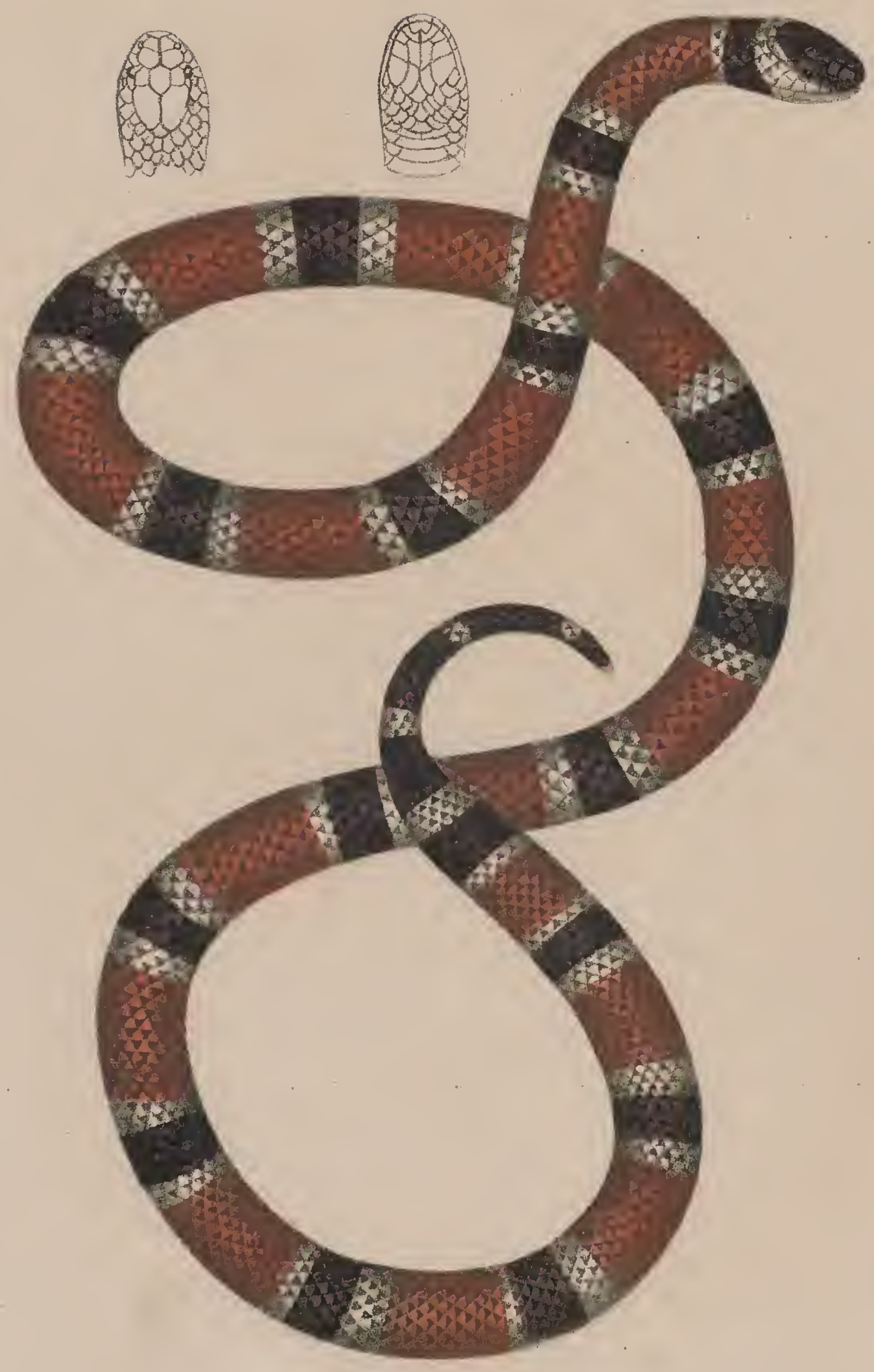

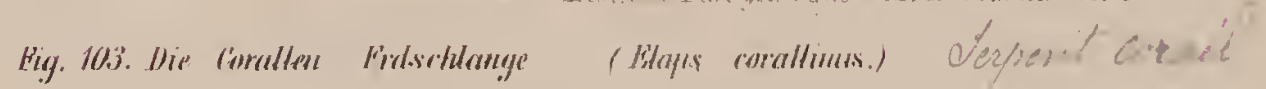



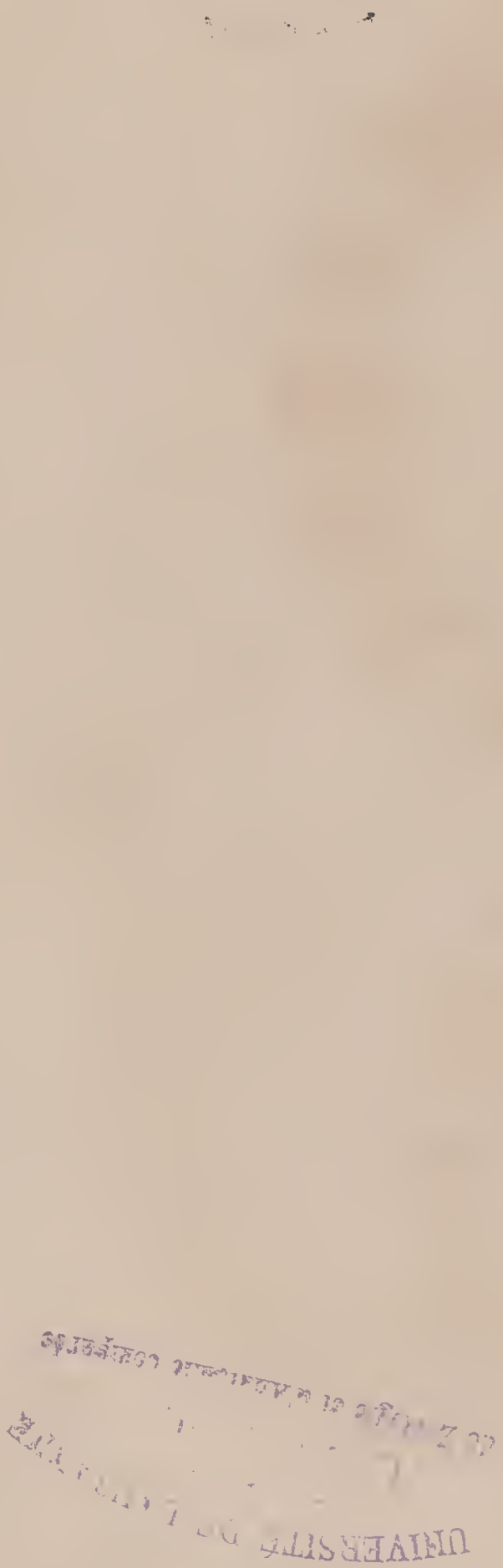

6 


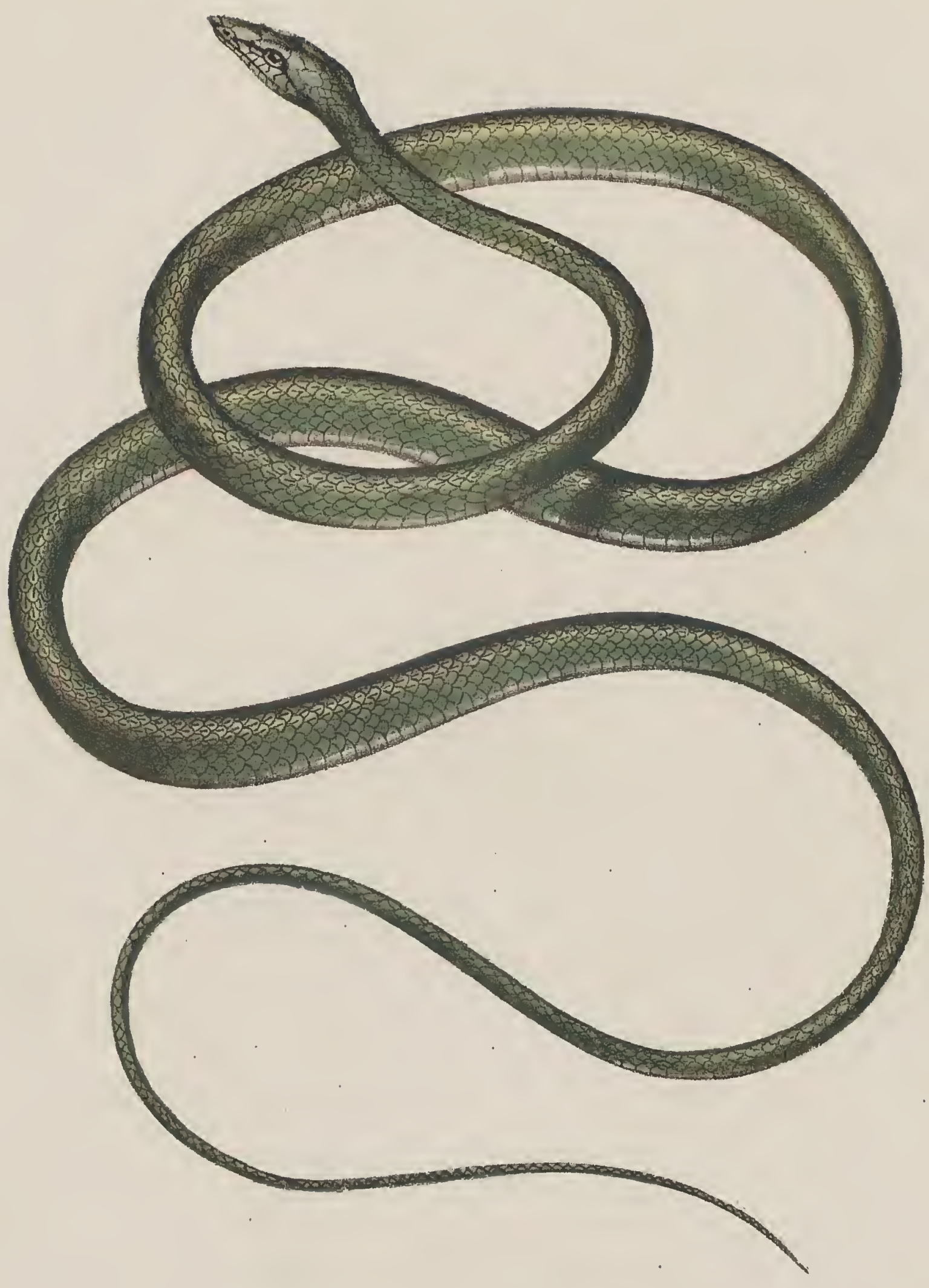

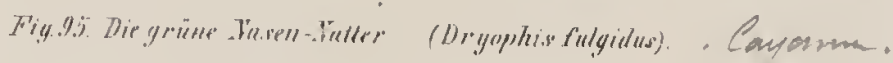




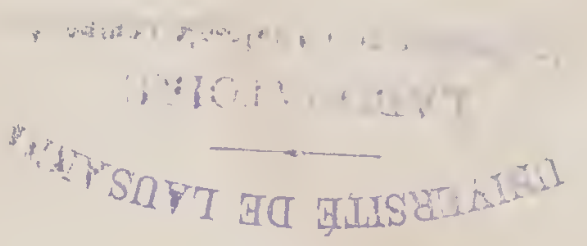

$\therefore$

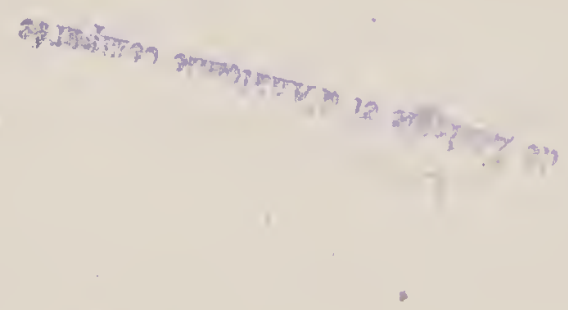




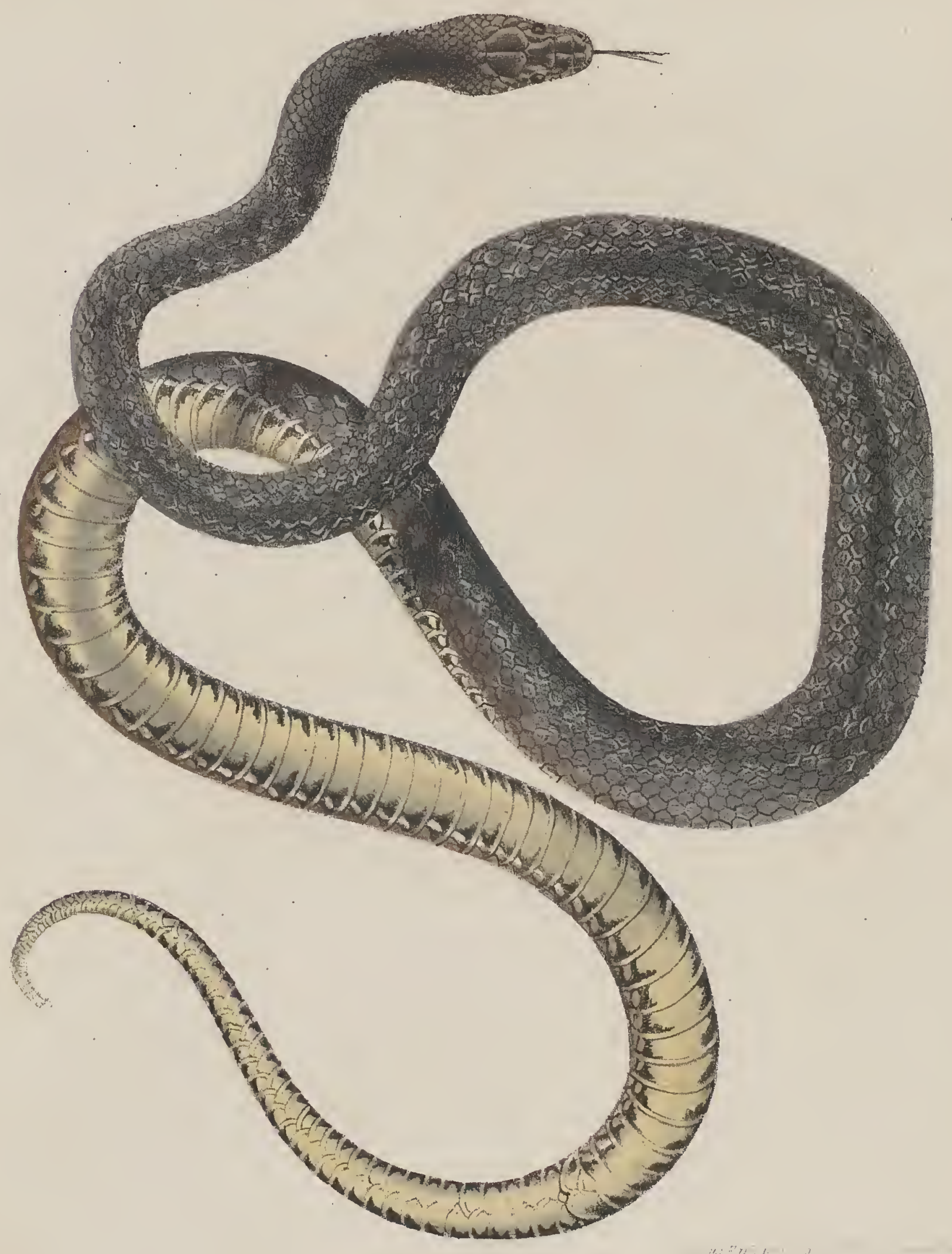

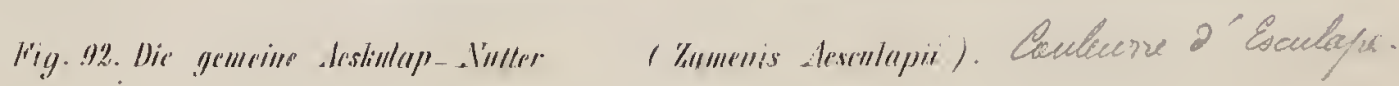




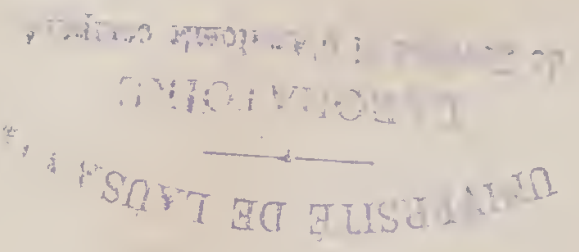




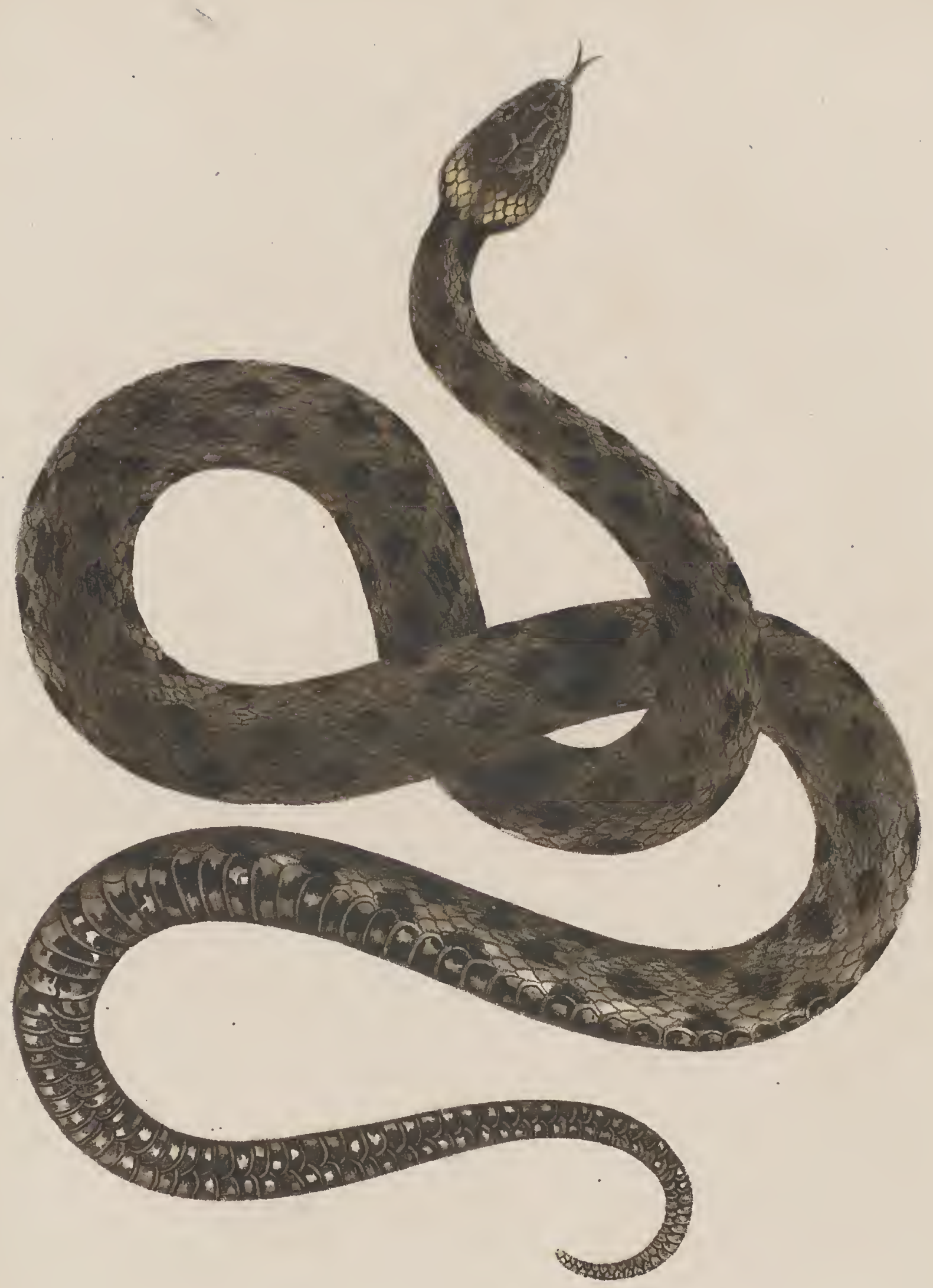

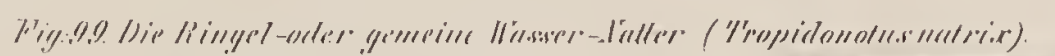




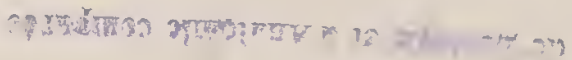

i. 


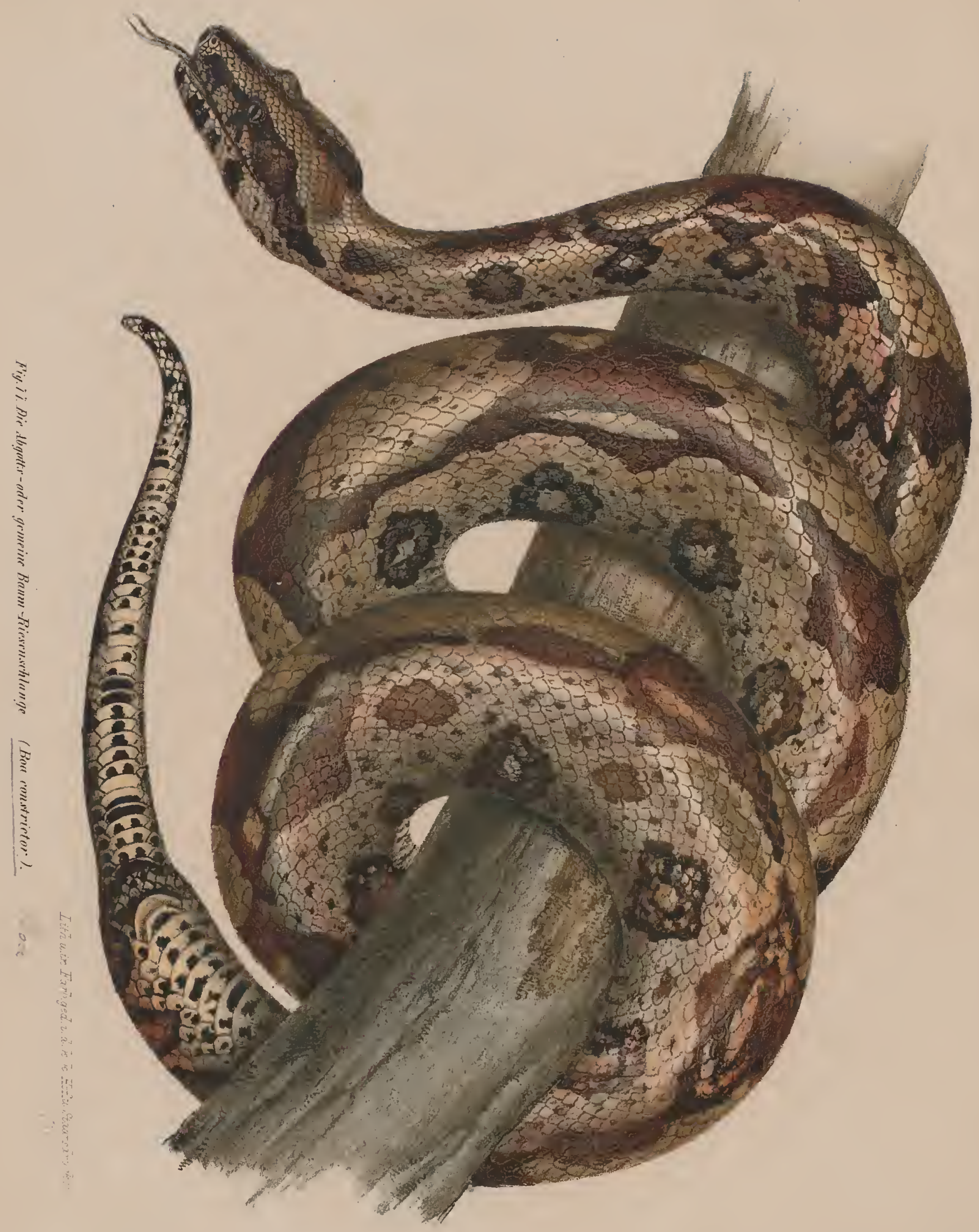




$$
\therefore
$$

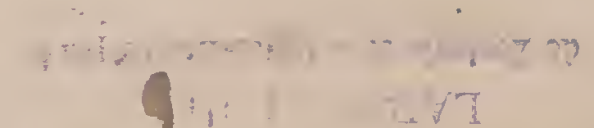

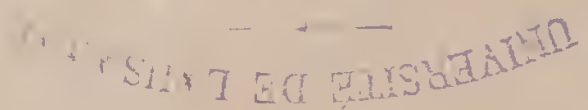




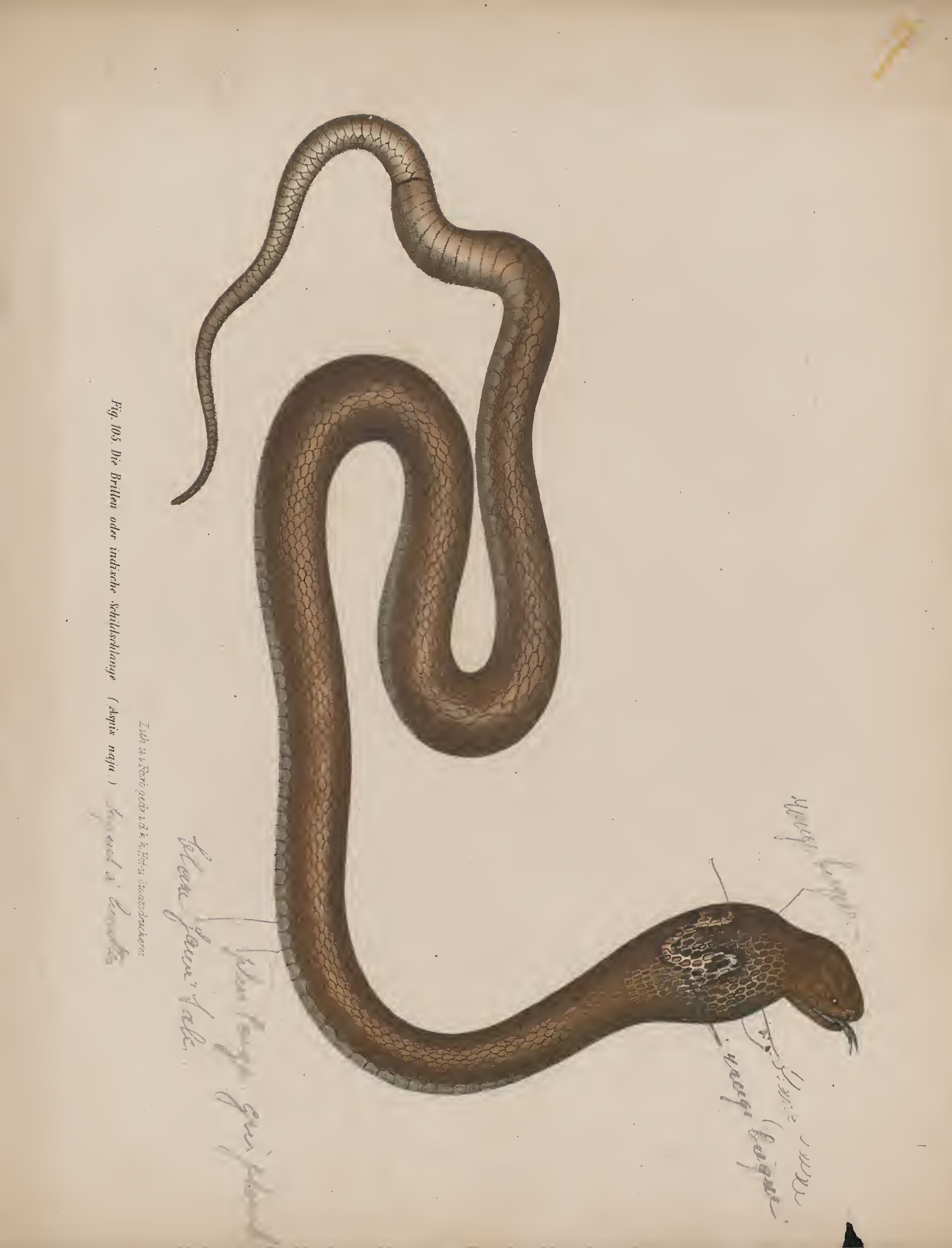


Fig. 34

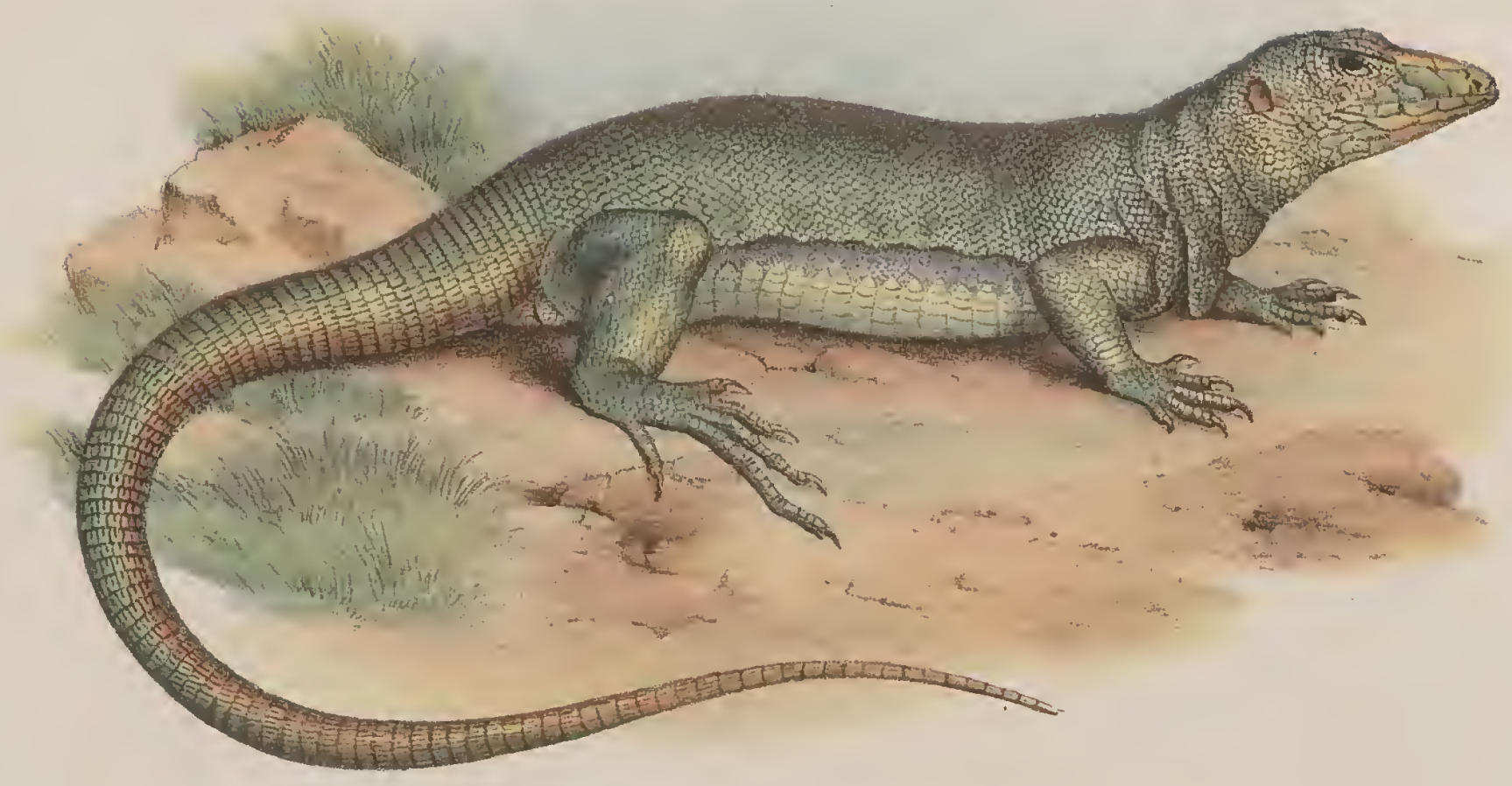

Fig. 35

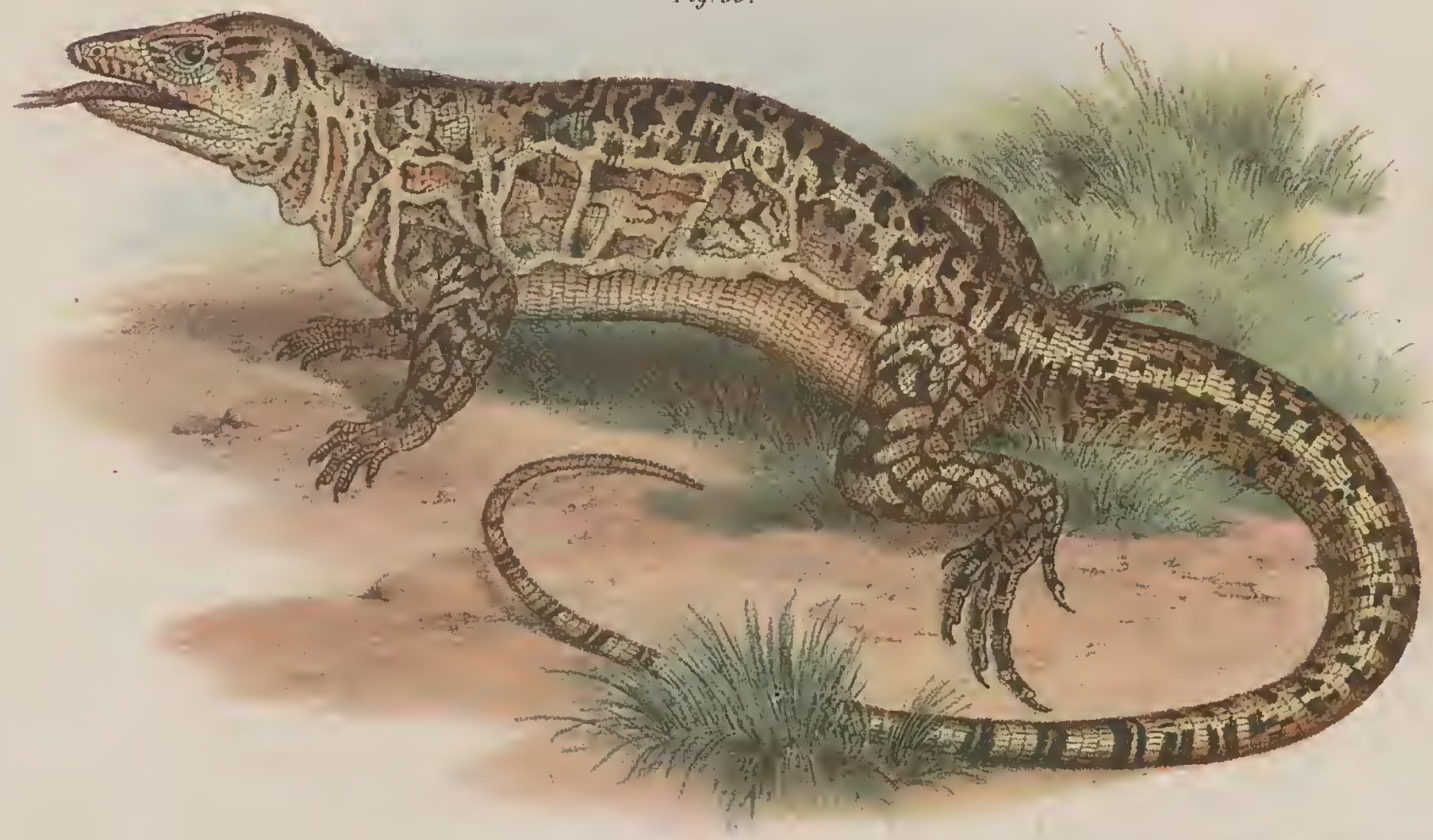

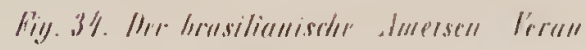

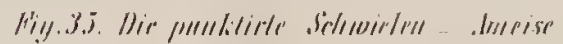

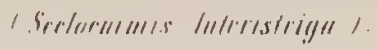

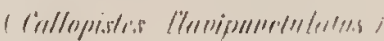




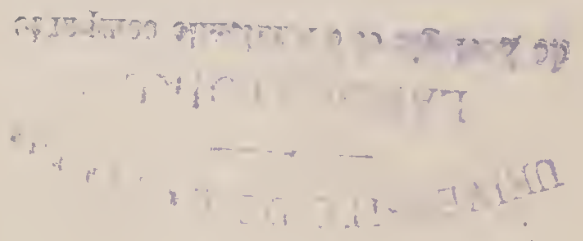

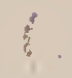




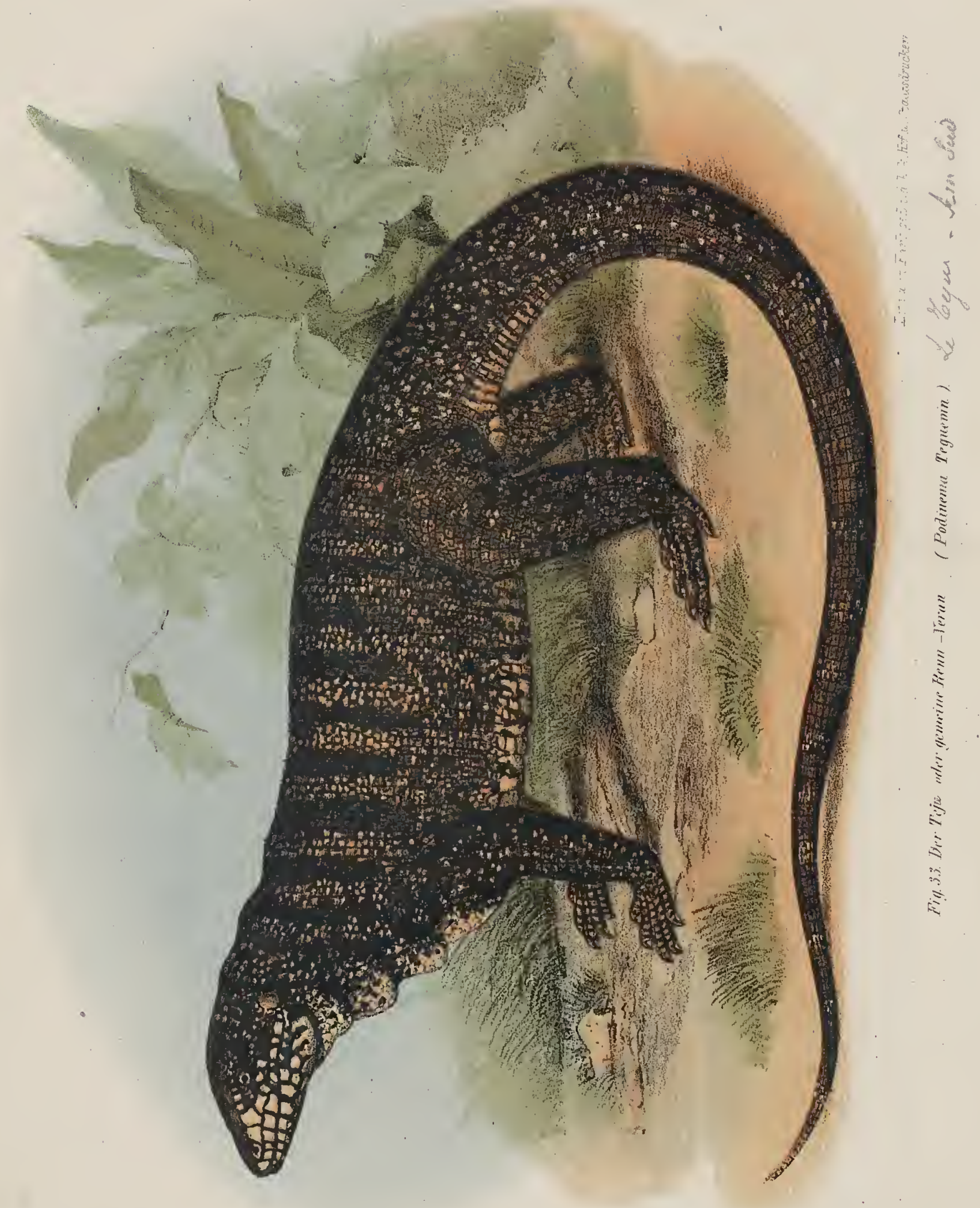




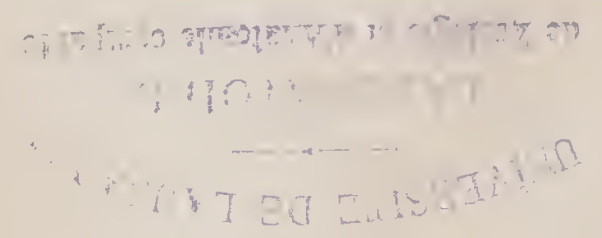




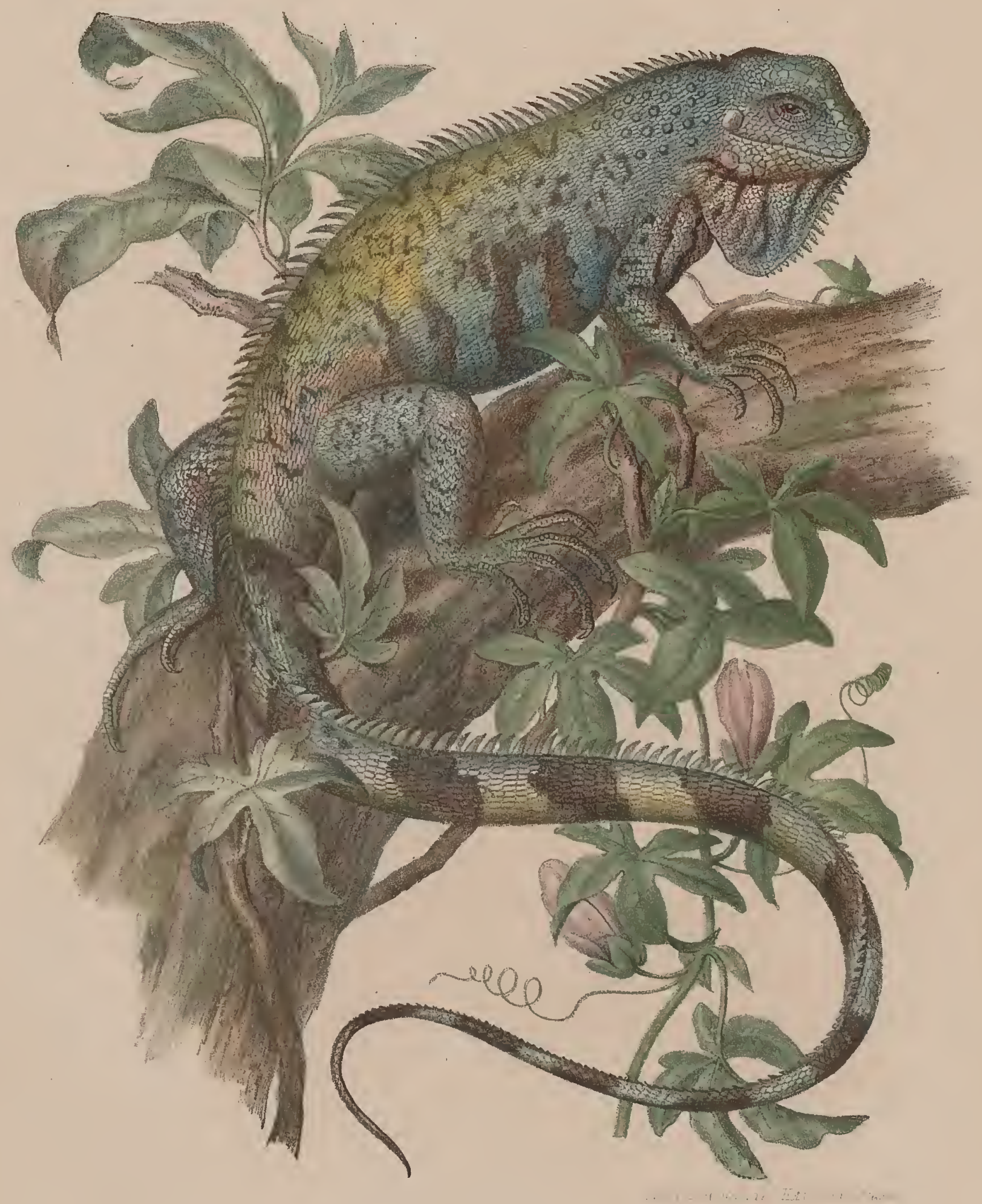

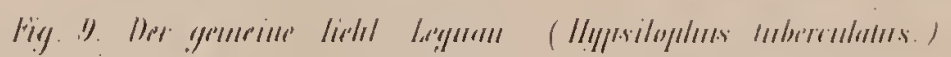

$$
\therefore, \ldots+\frac{1}{10} \text { secta }
$$




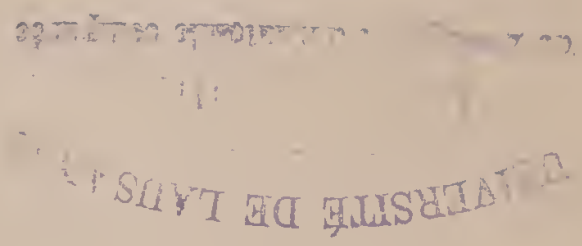

ง. 

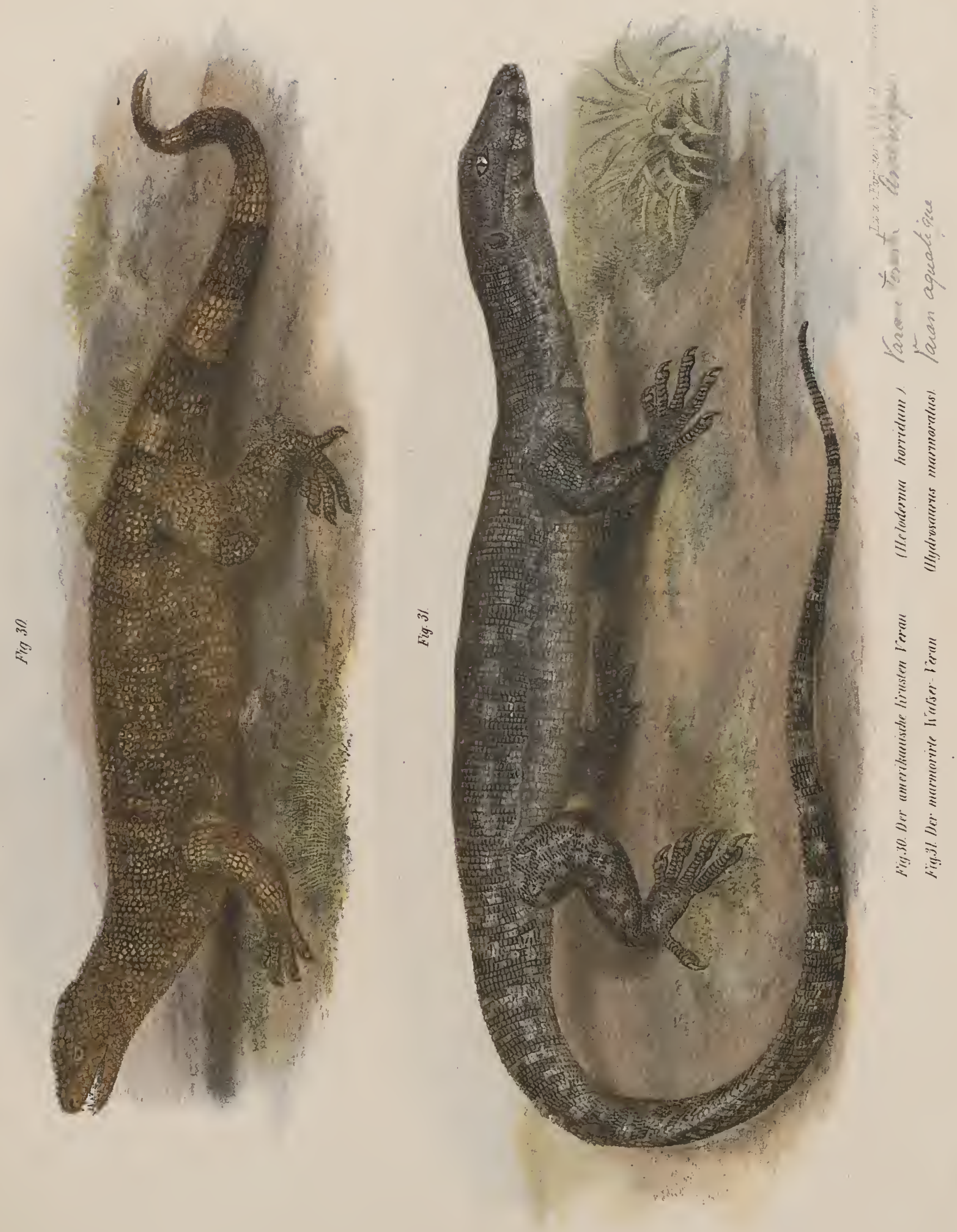


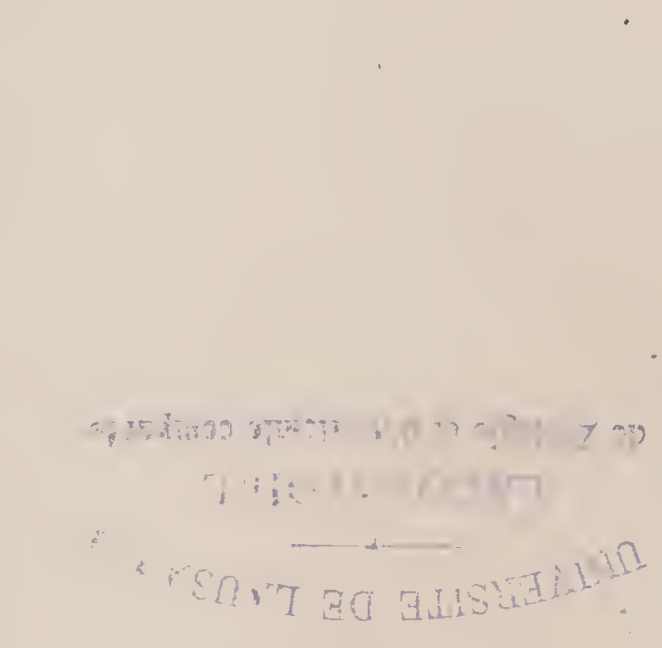


$\operatorname{Iing} 40$
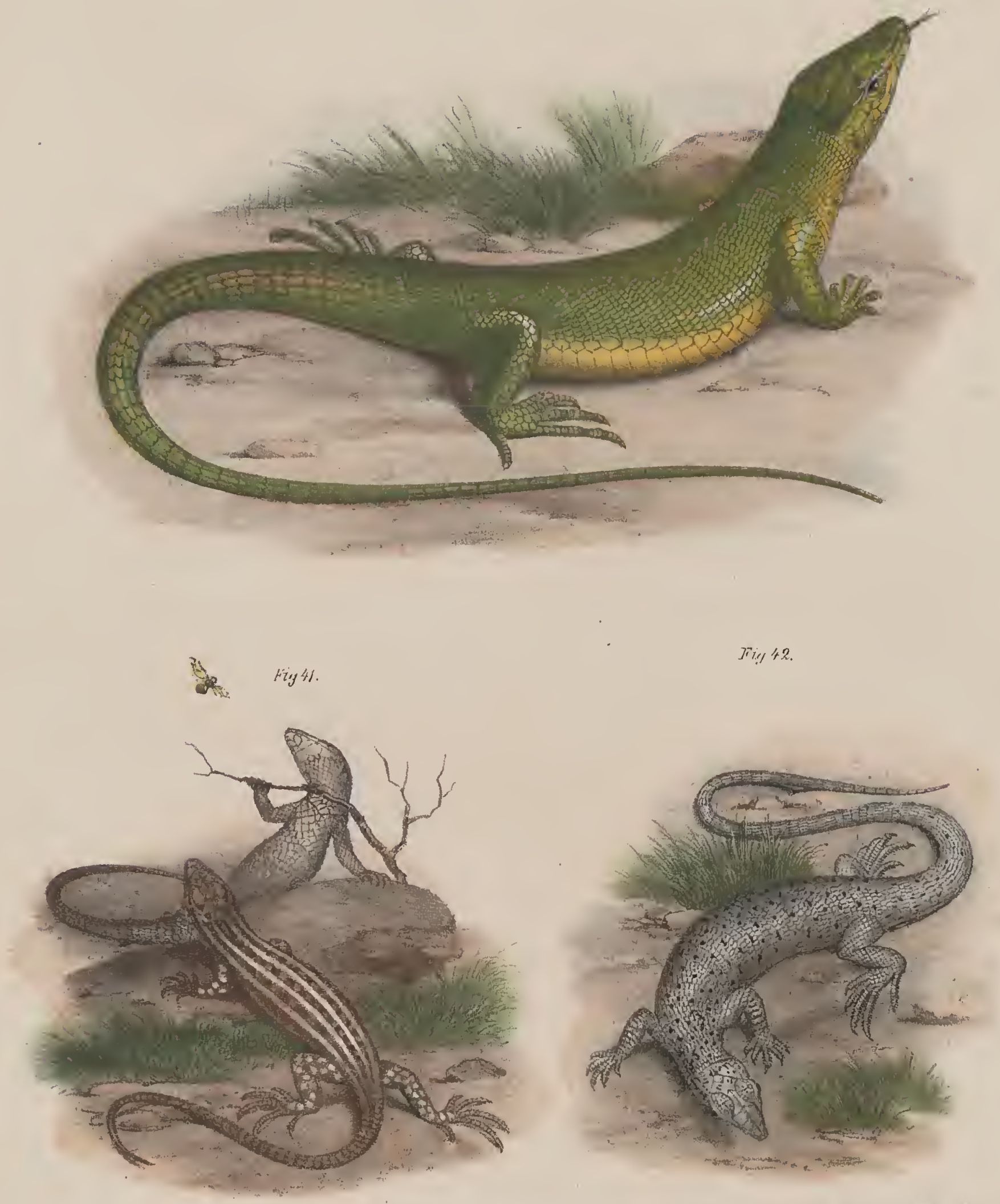

7 Tin 42 .

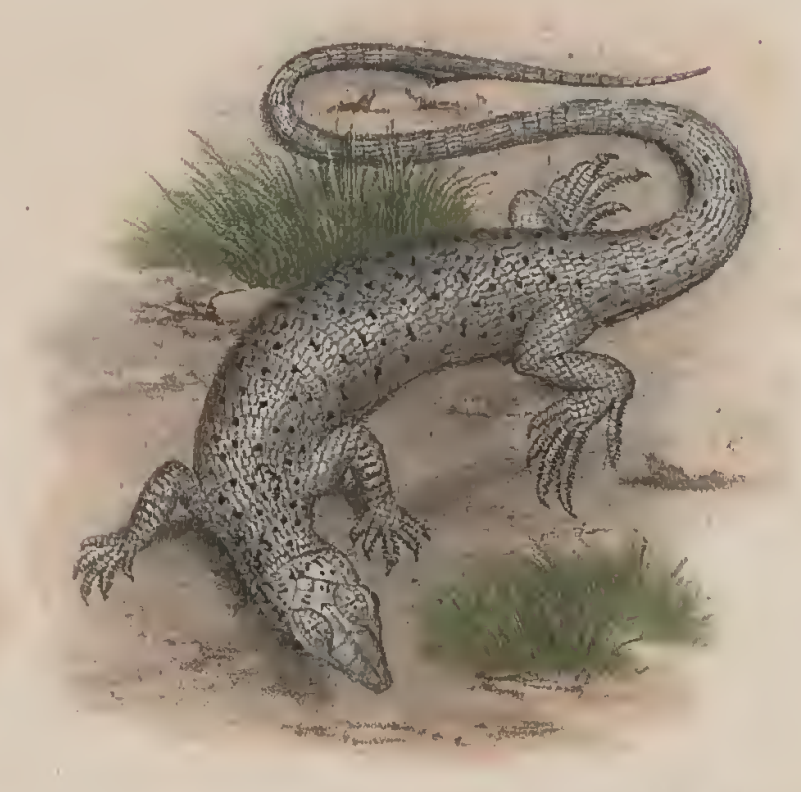

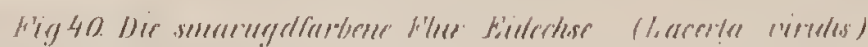

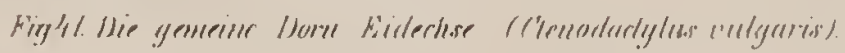

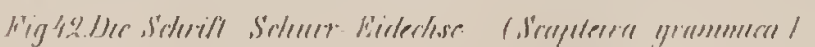




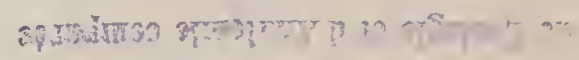

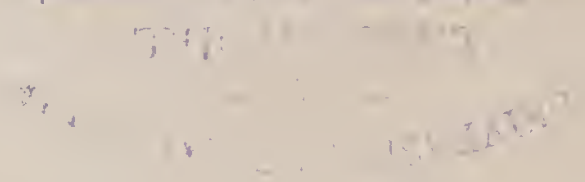



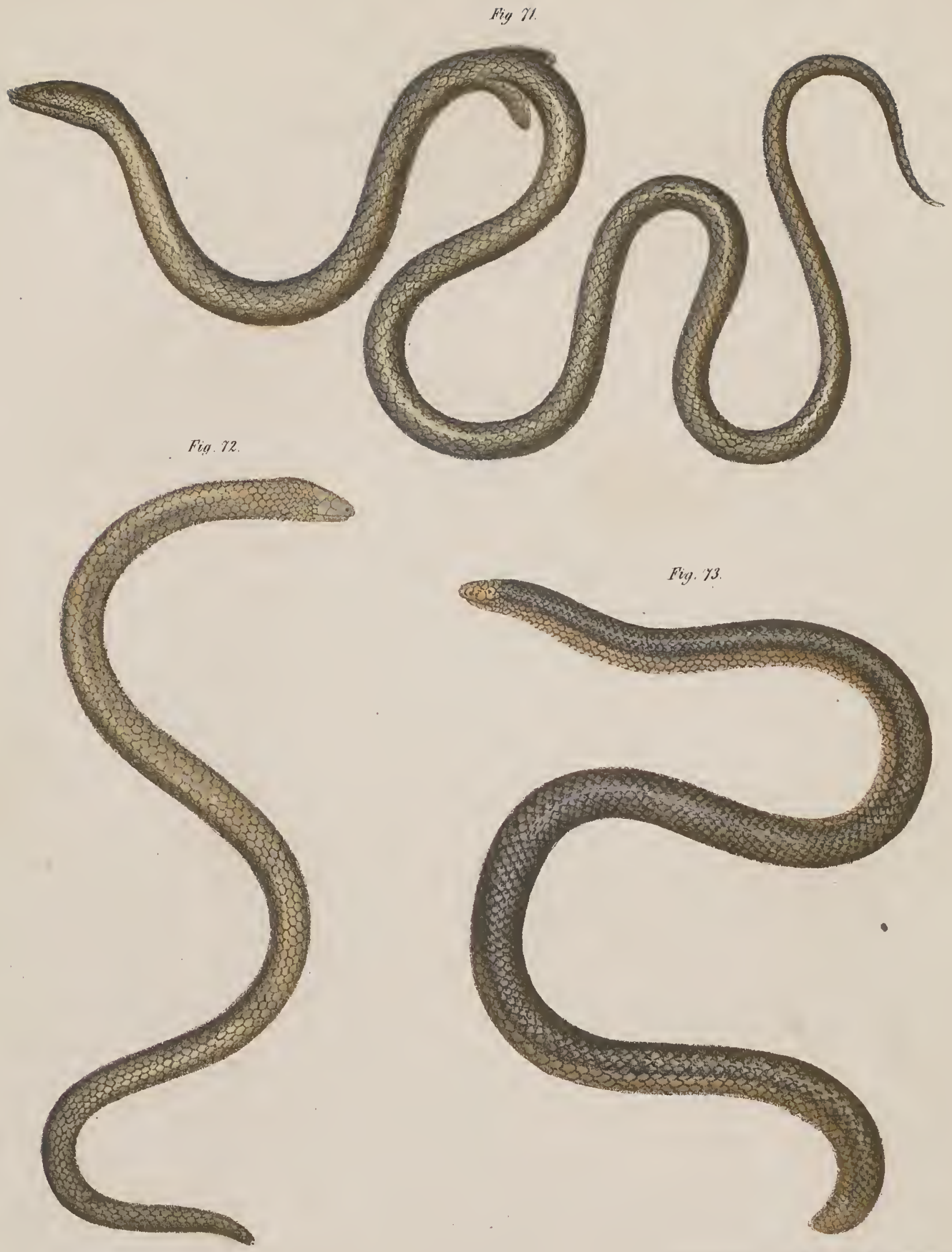

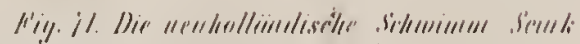

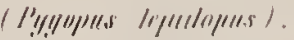

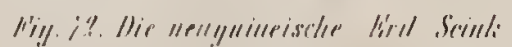

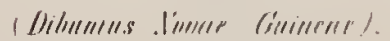

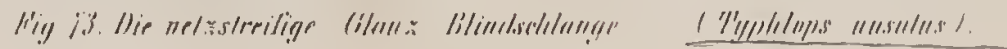




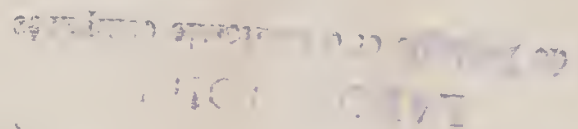

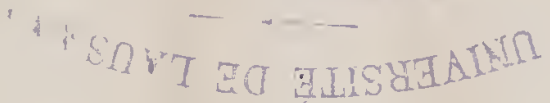

○

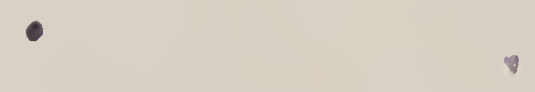




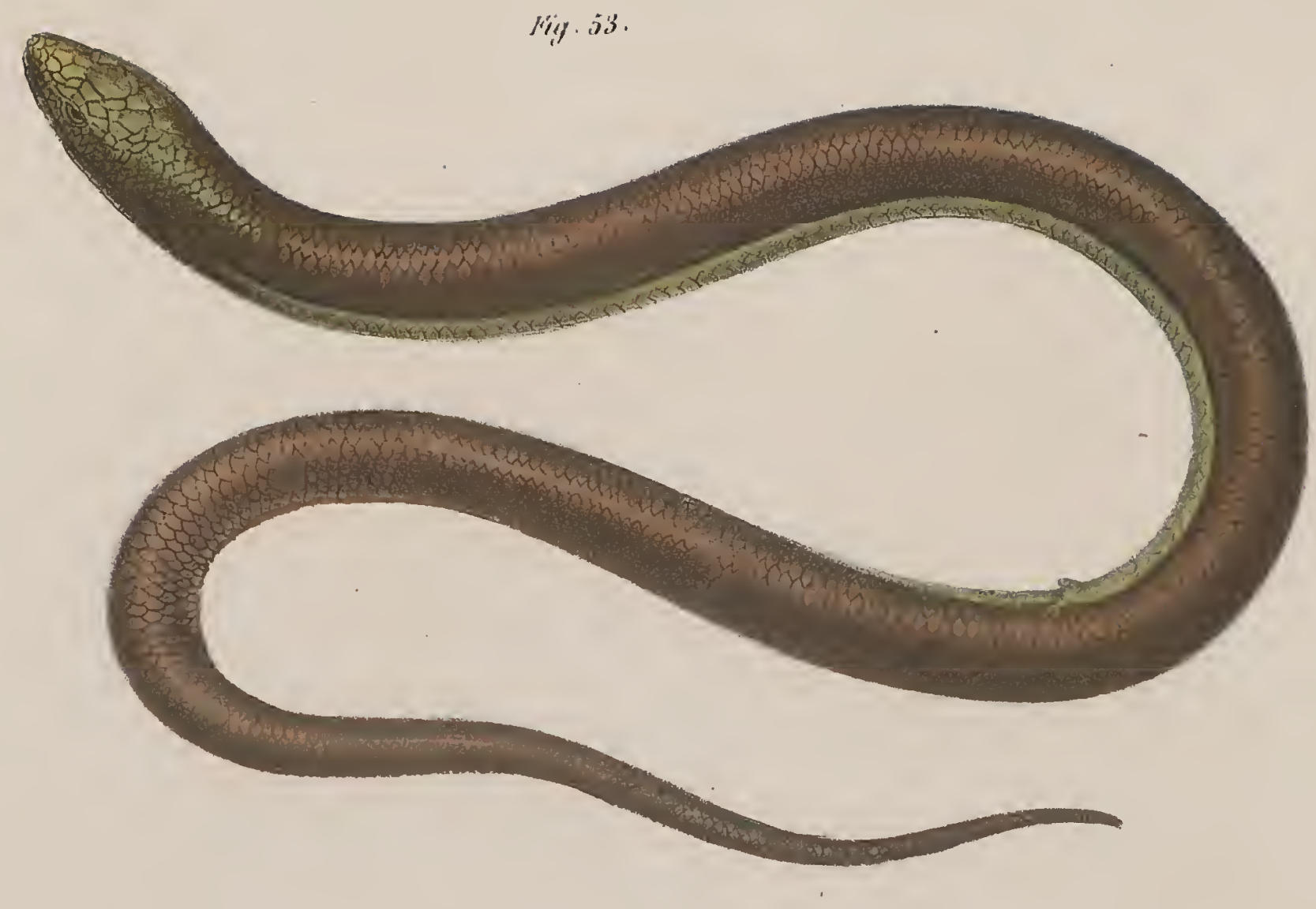

ligy. i4.

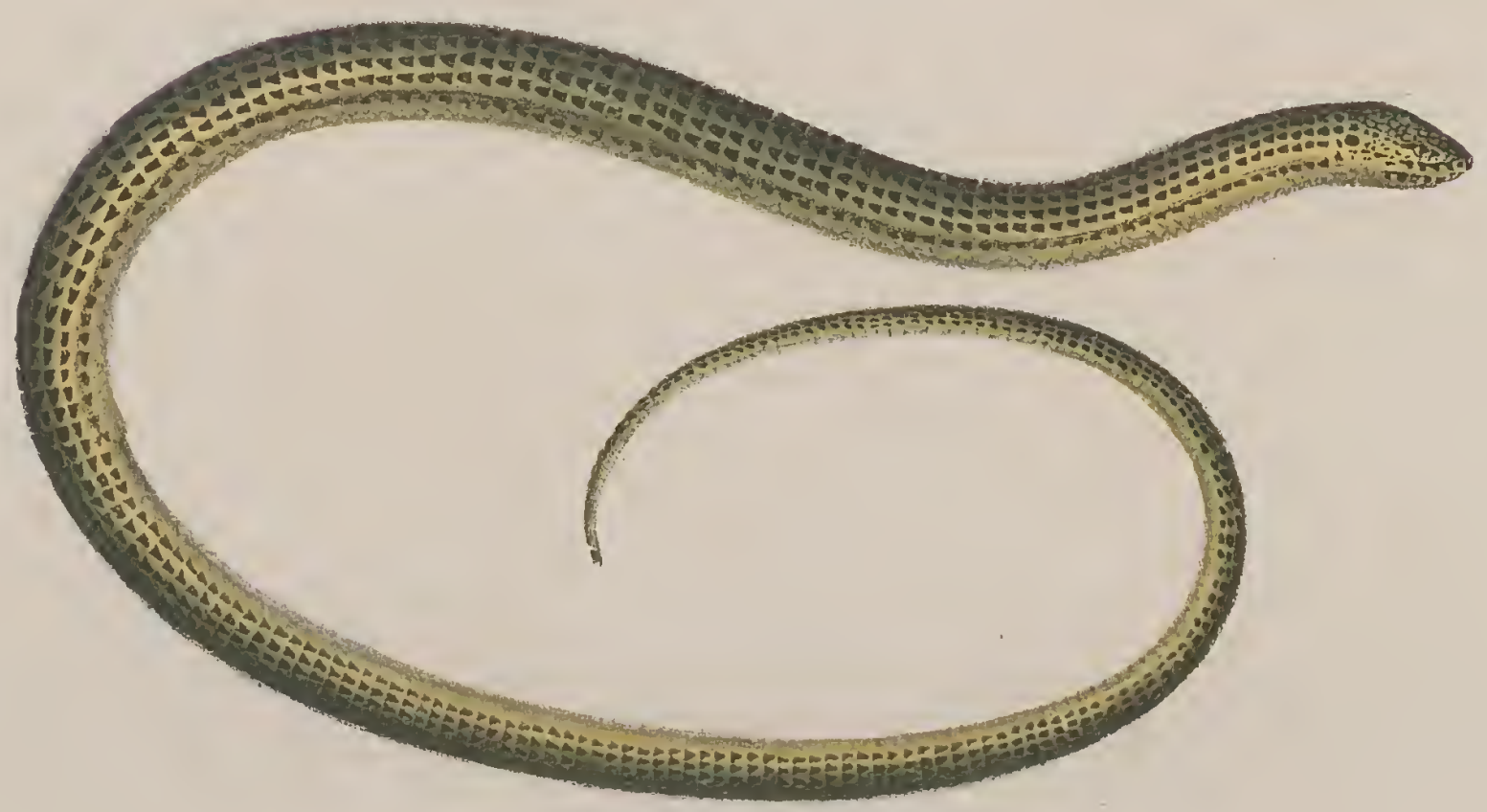

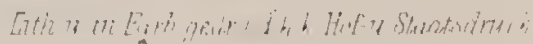

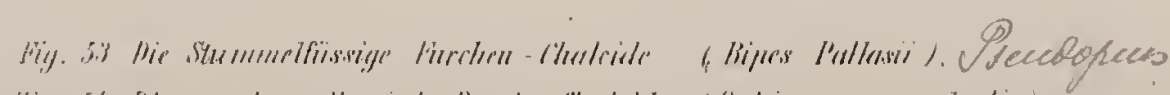

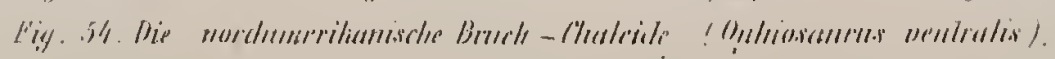




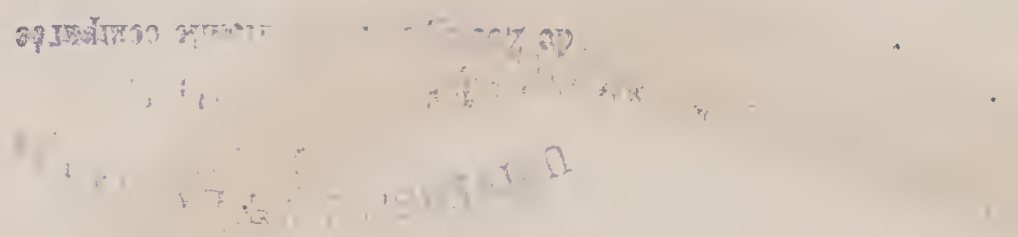




$$
3 \xi
$$





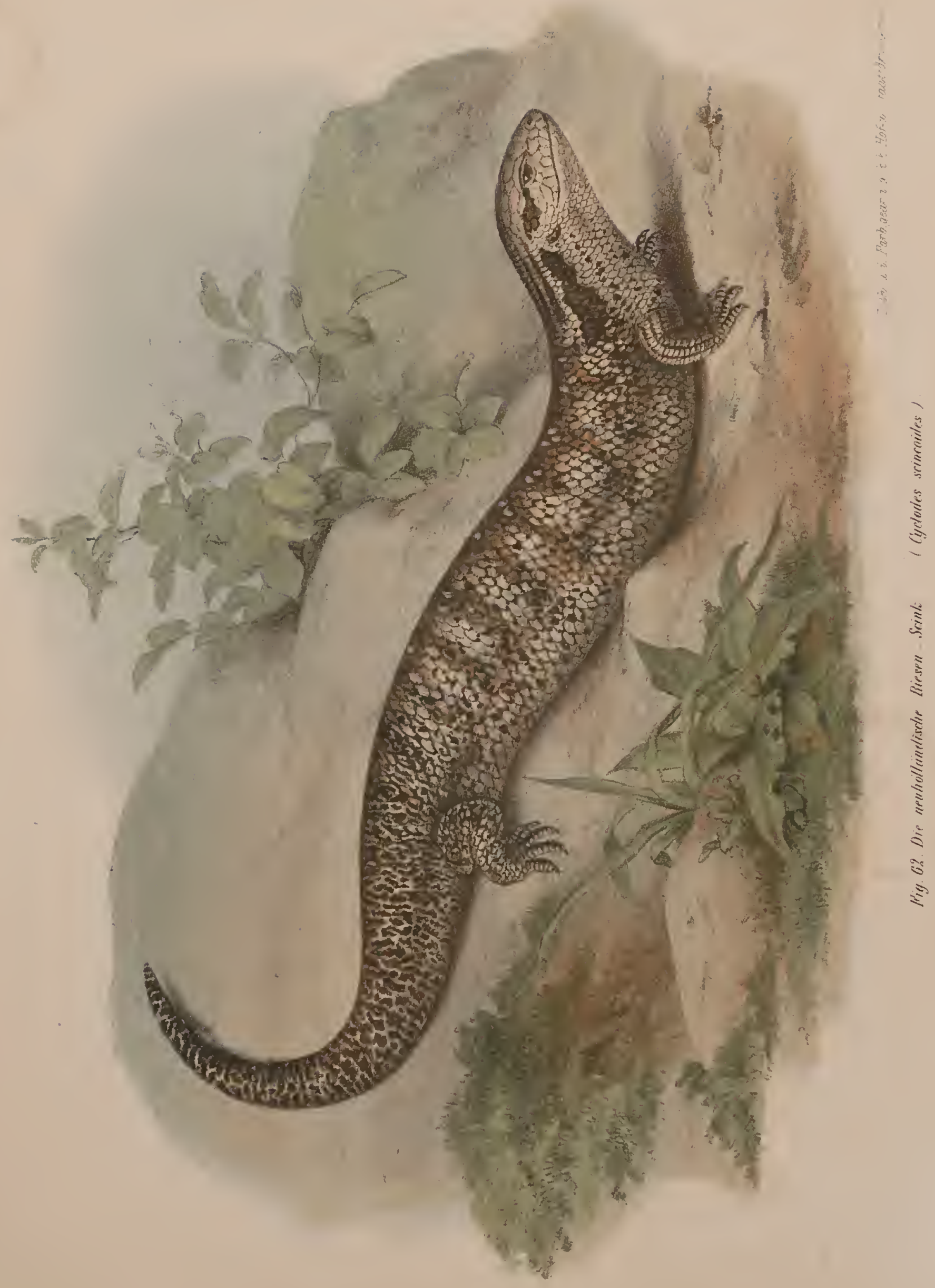




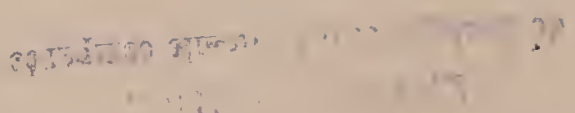

$y-11=x$ ust $y x^{x}$

$-$

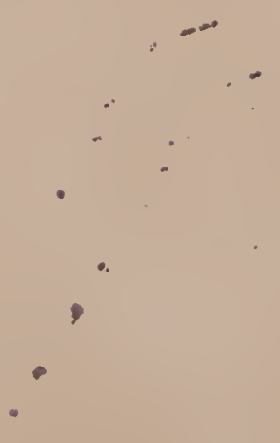

$\checkmark$

$>$ 
Mig. 65.

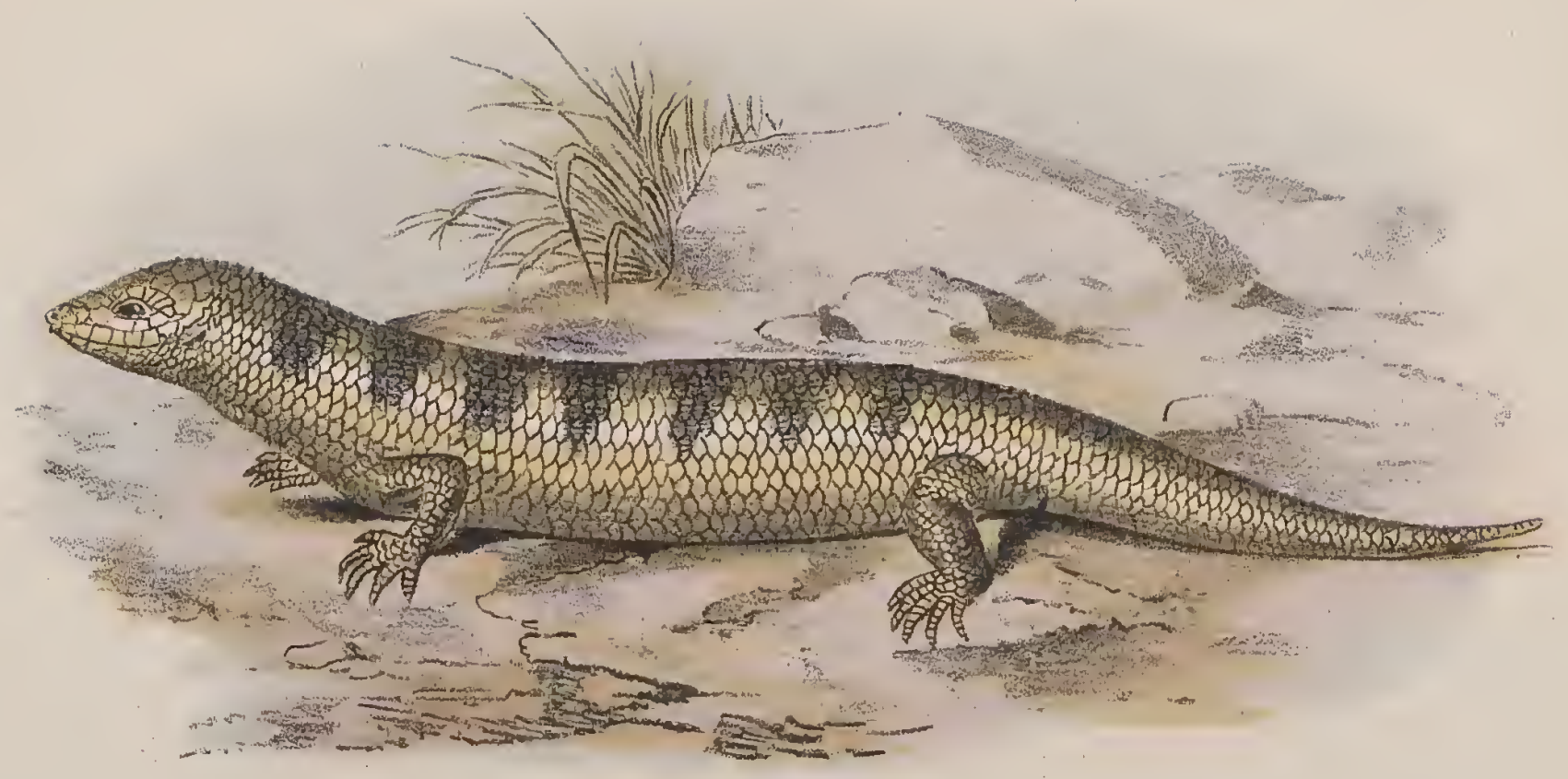

fing liti

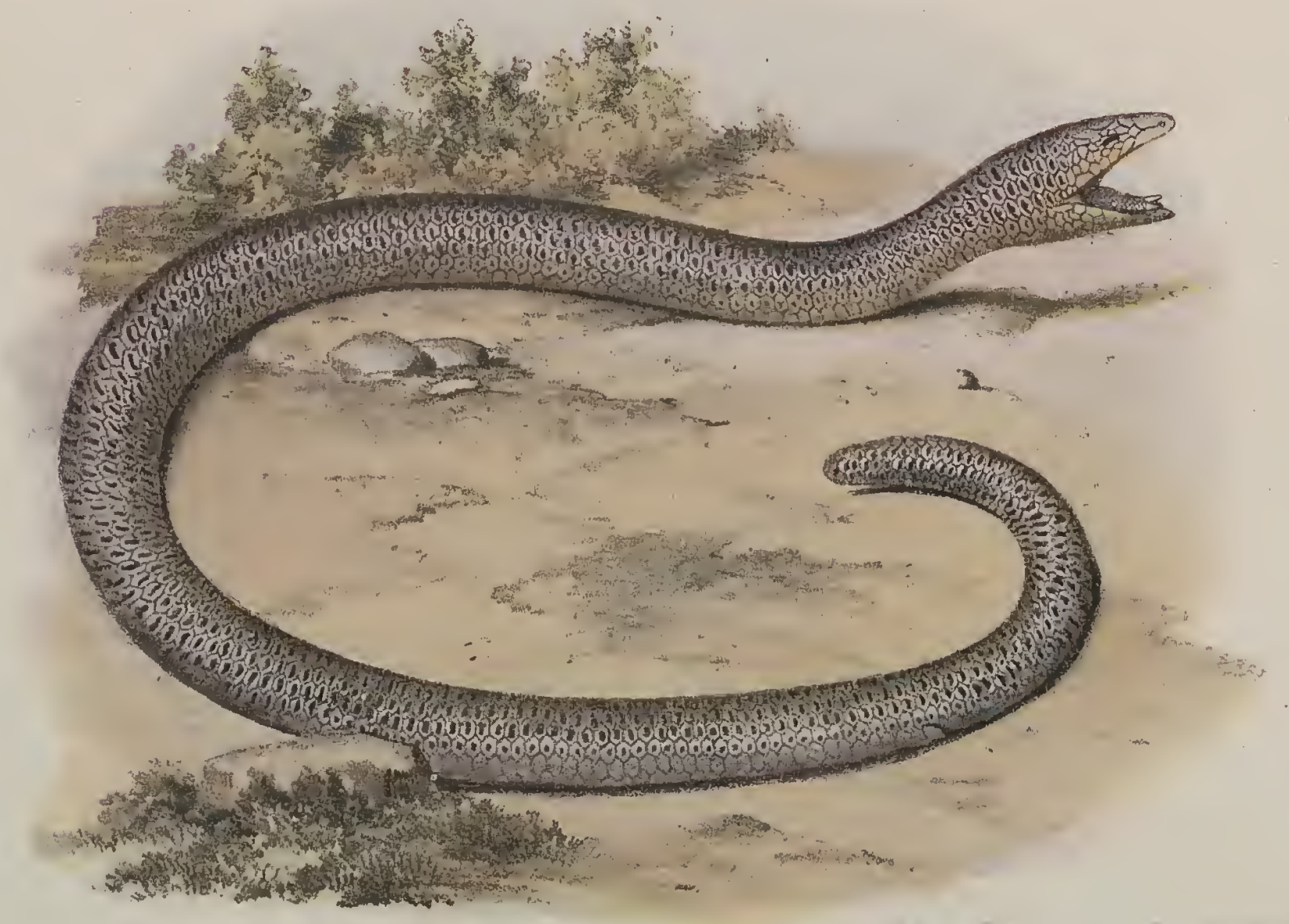

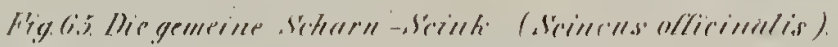

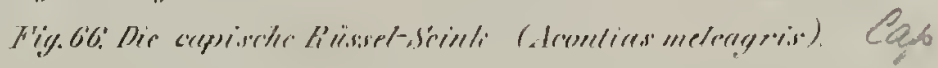




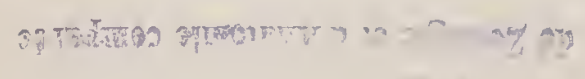

$+2+\frac{1}{2}+\frac{1}{2}$ 


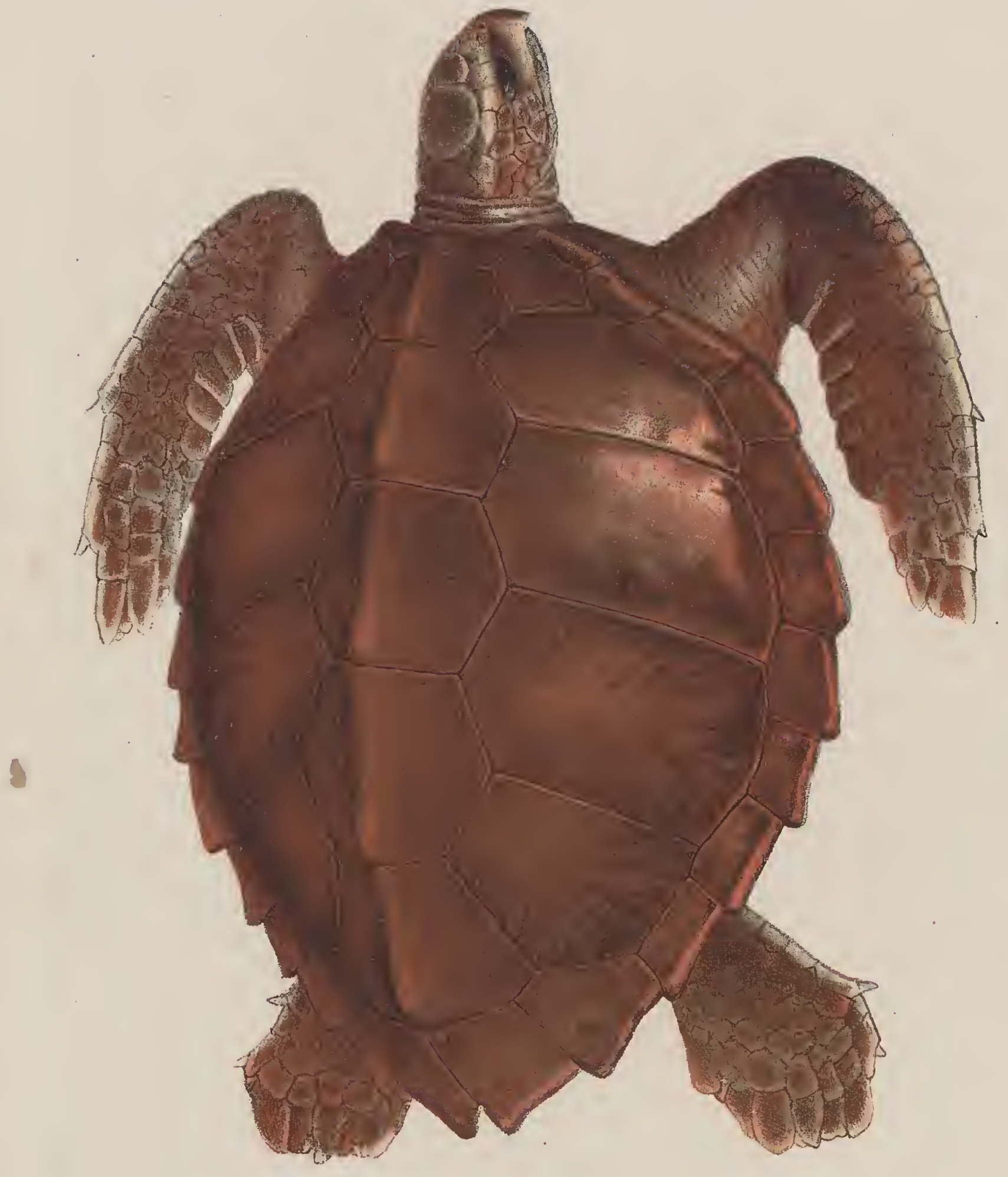

s 


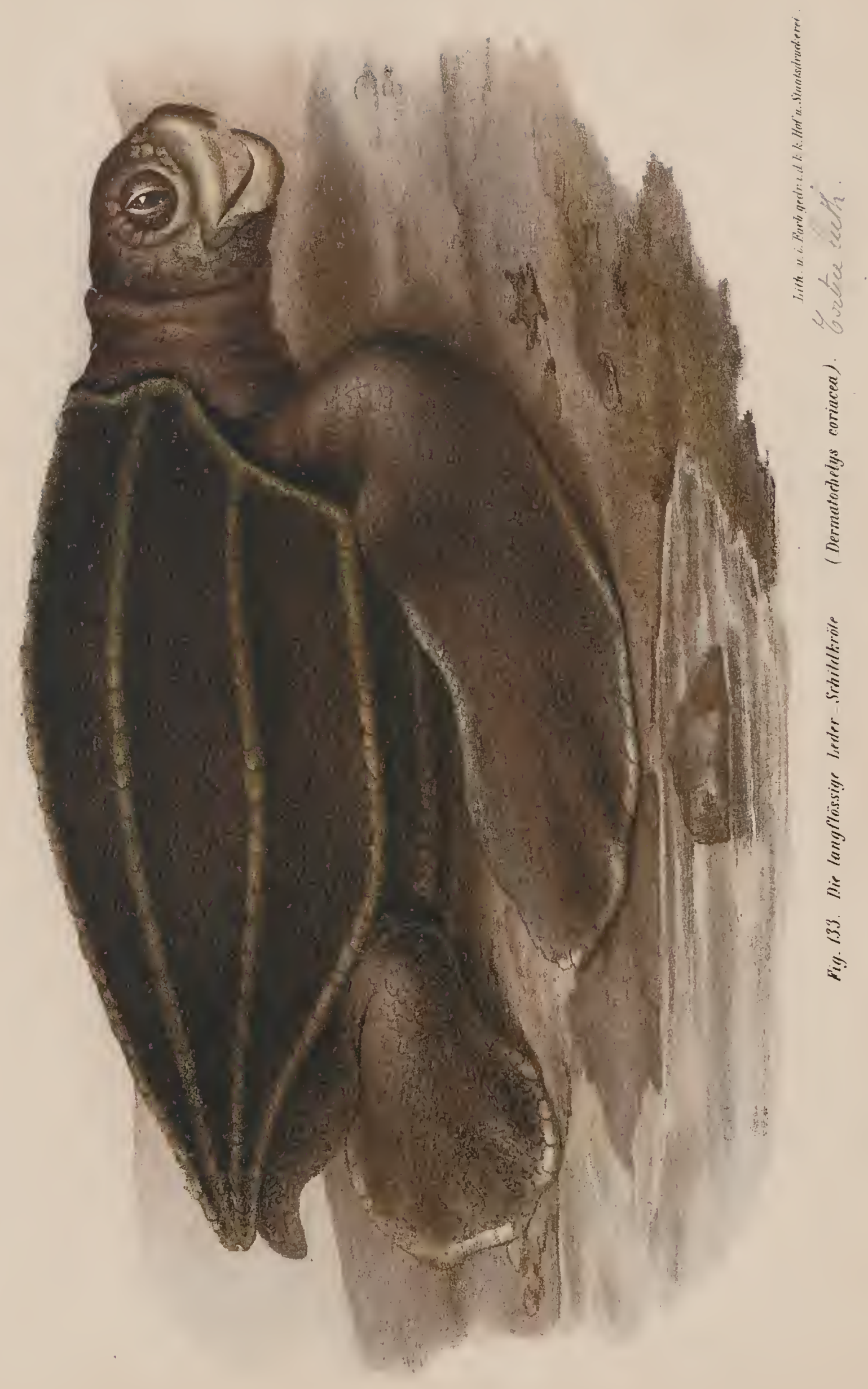




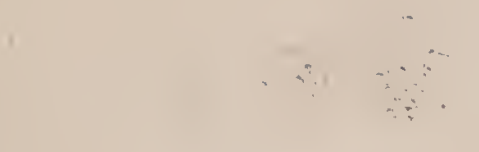

$\cdots$

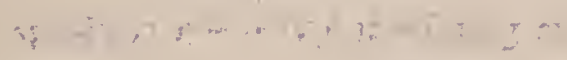

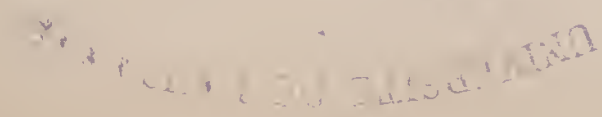




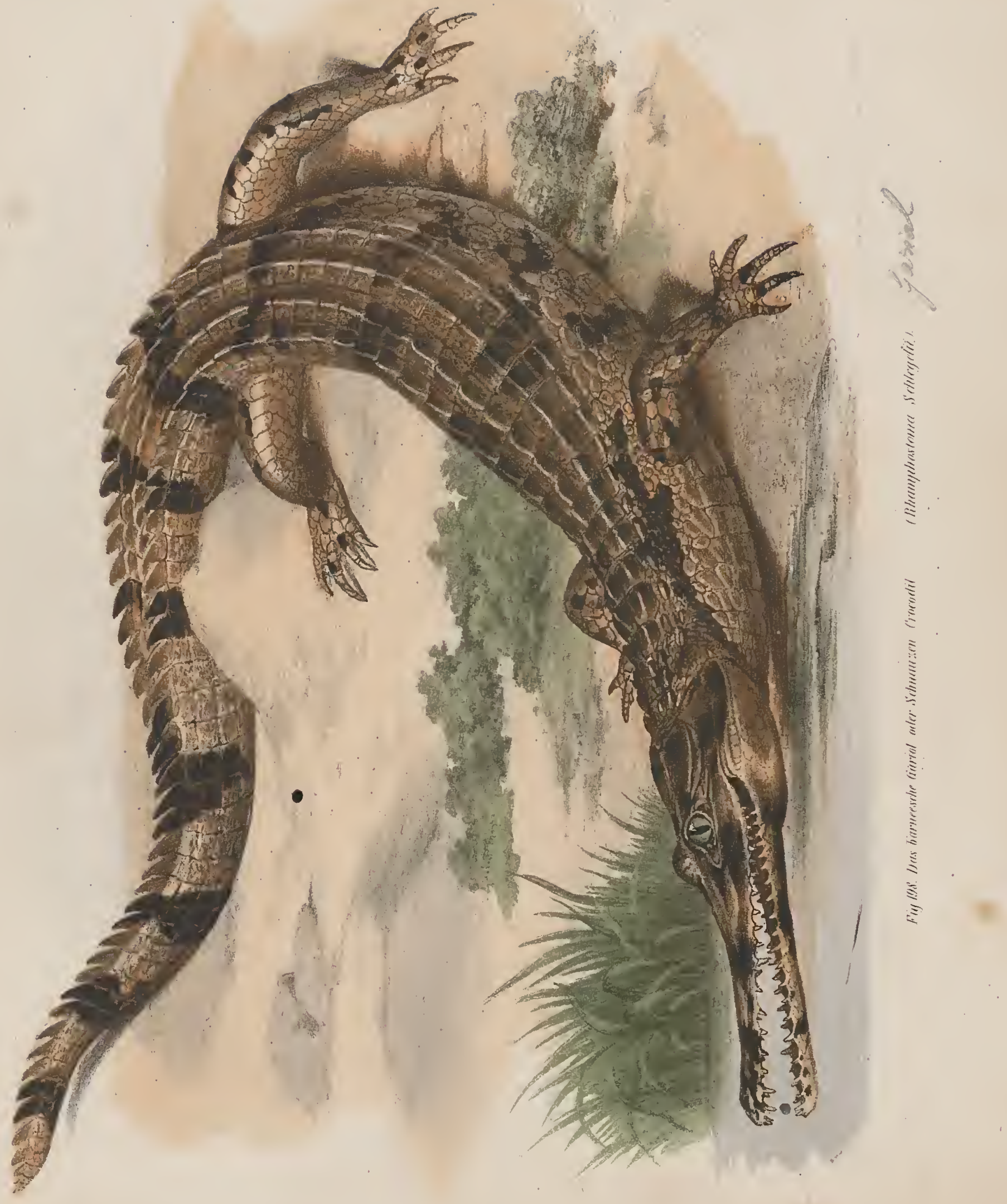




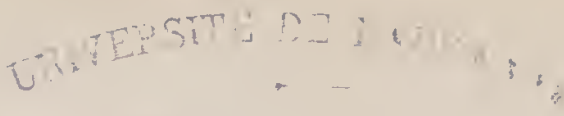

$$
\begin{aligned}
& \text { L. : : : : }
\end{aligned}
$$

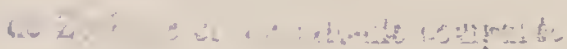

, 


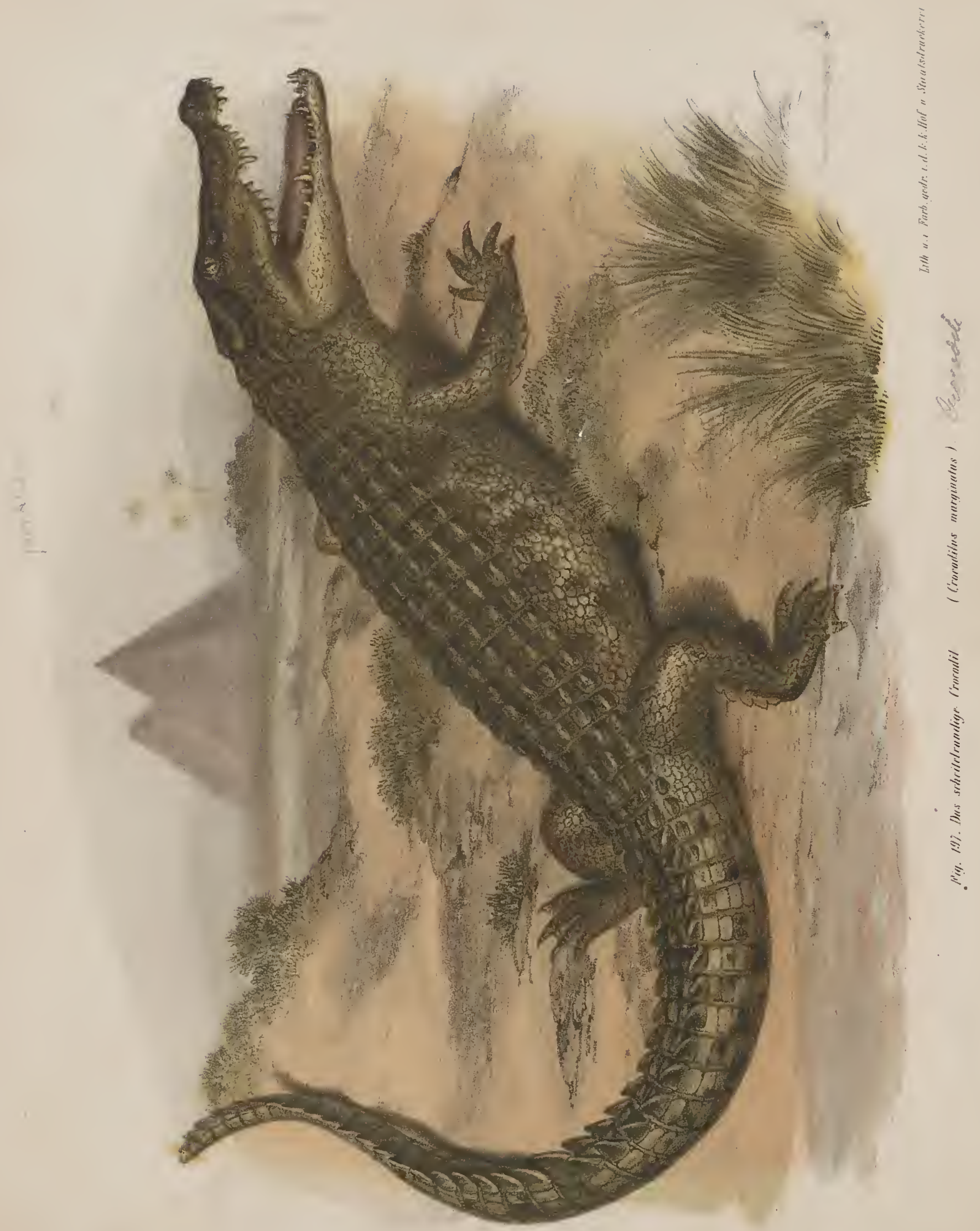


6

3

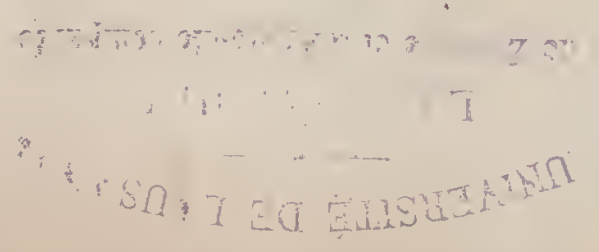




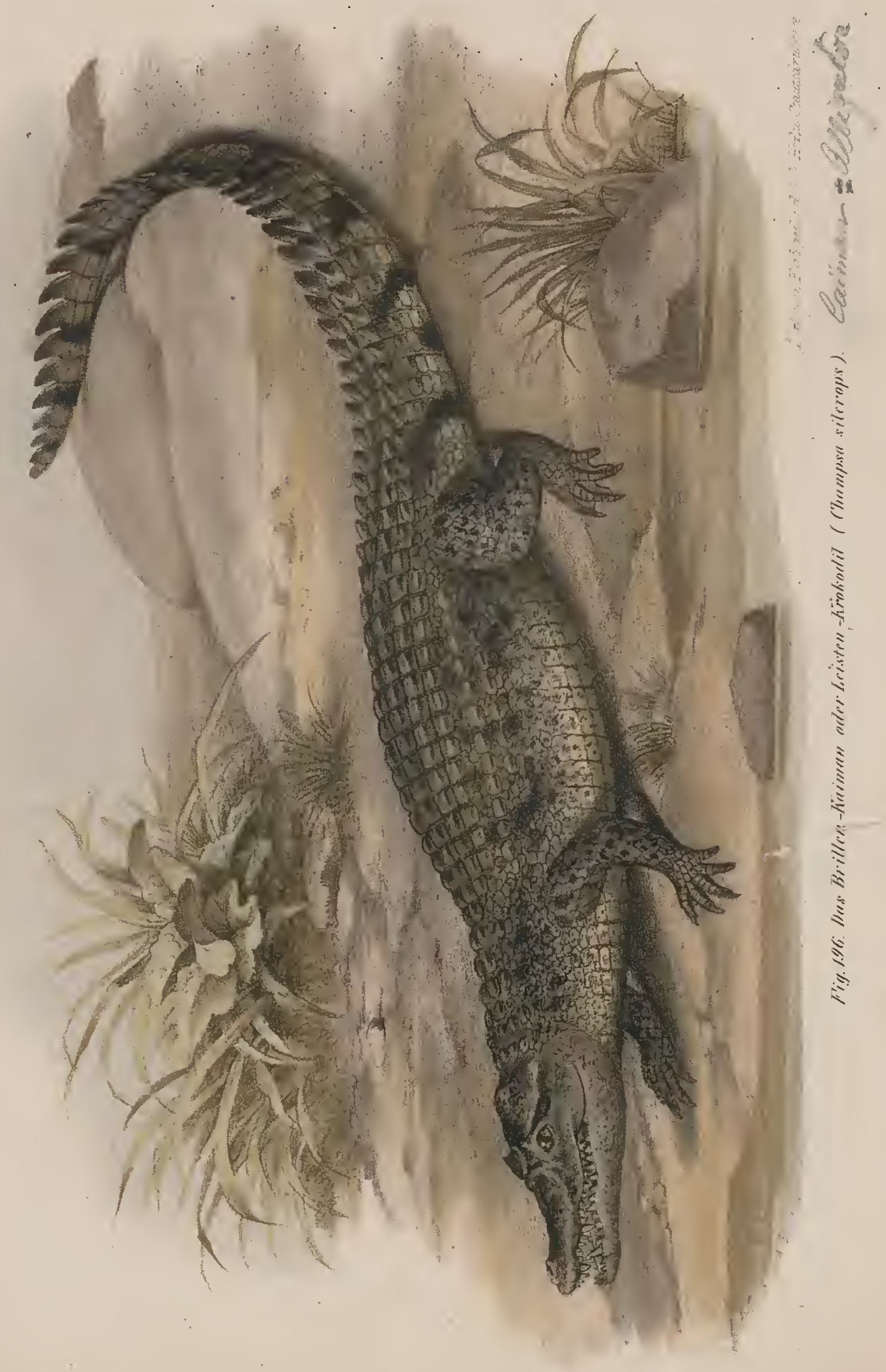




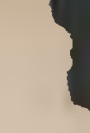

,

$4,1,0,0$

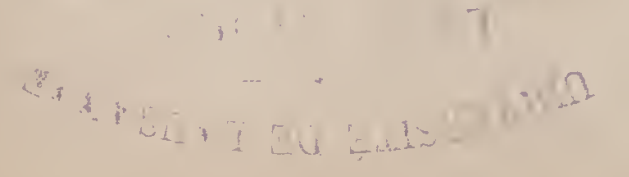



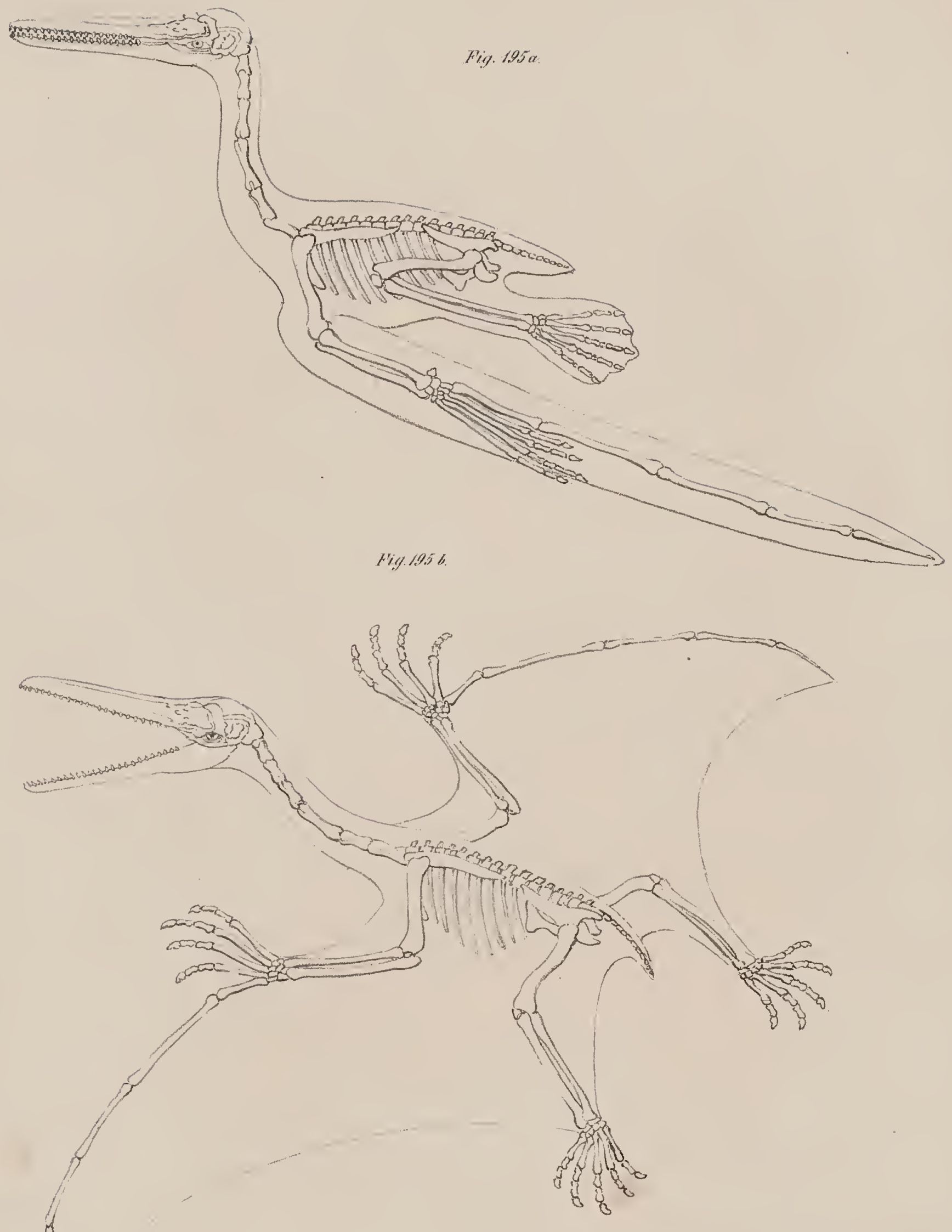

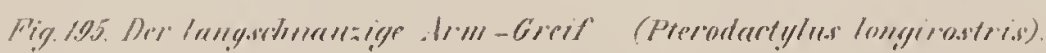


$i$

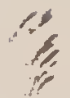

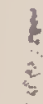

$y$

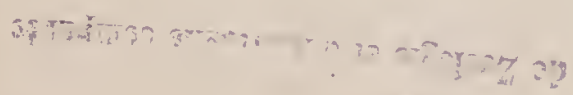

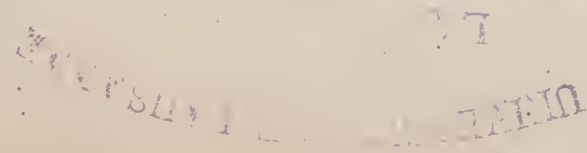




$$
0
$$




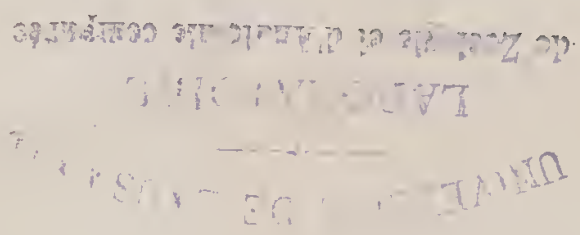




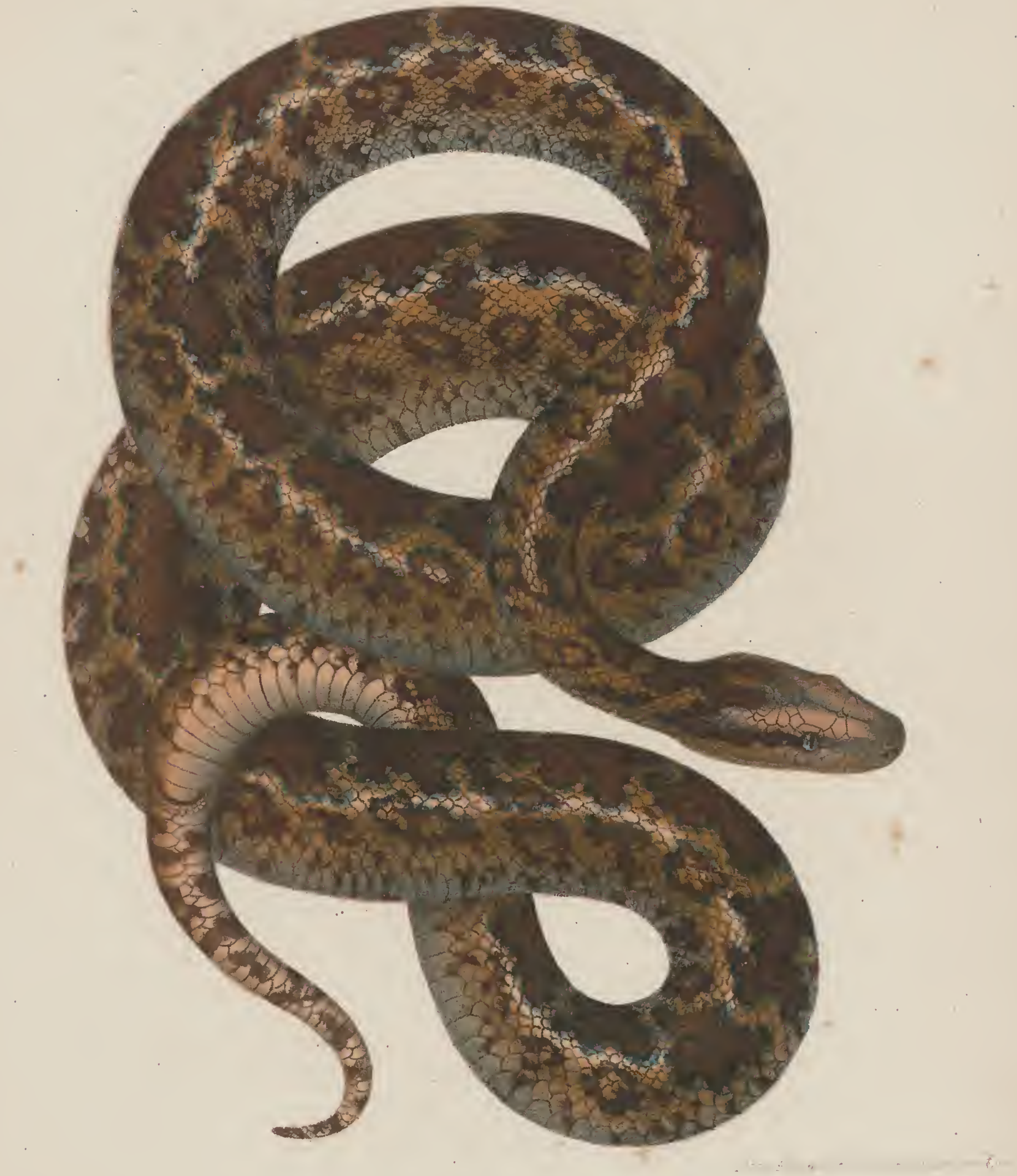

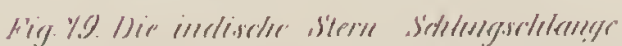

1. Itroplers liggris I. 
a

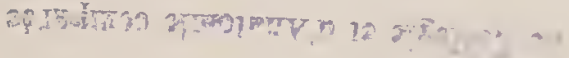

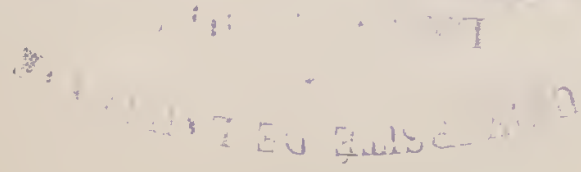




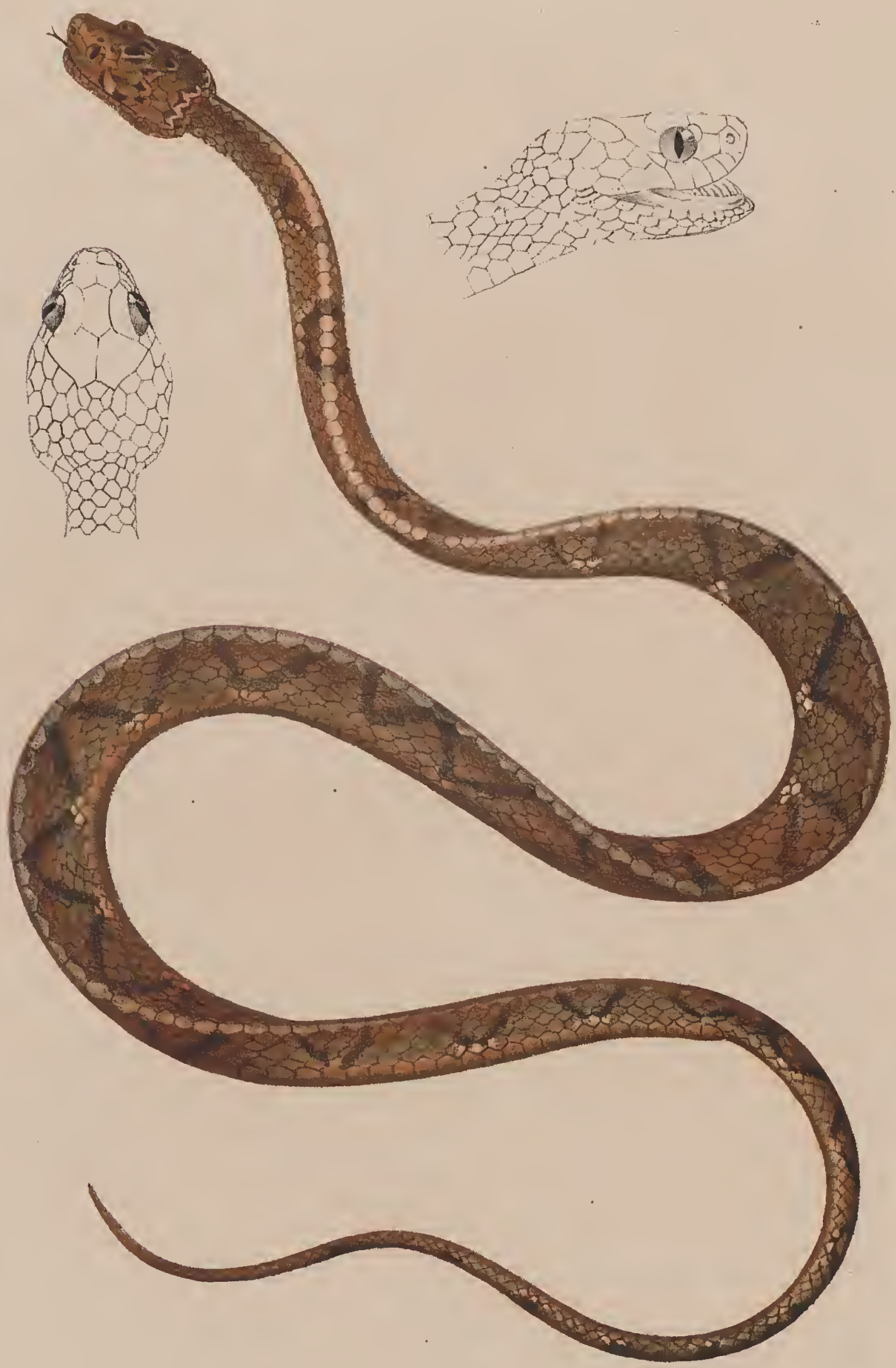

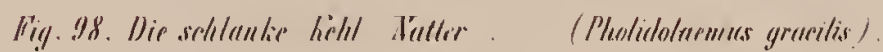




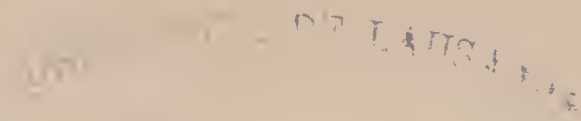

$$
\begin{aligned}
& \text { I }
\end{aligned}
$$

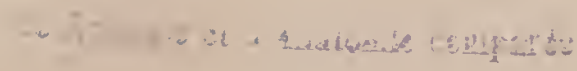

$$
\begin{aligned}
& \text { " }
\end{aligned}
$$




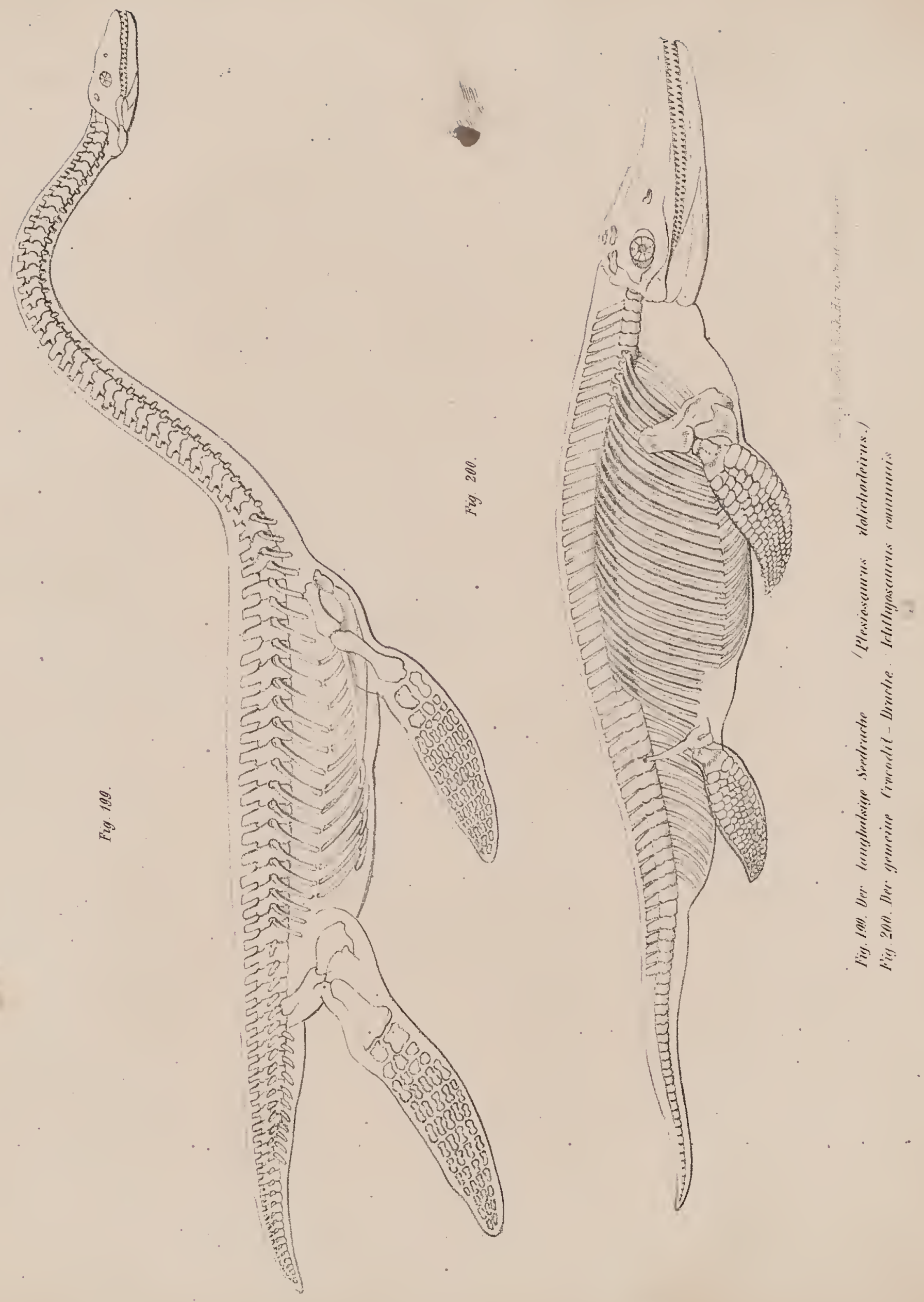


- 
Fiif. Hof. "I

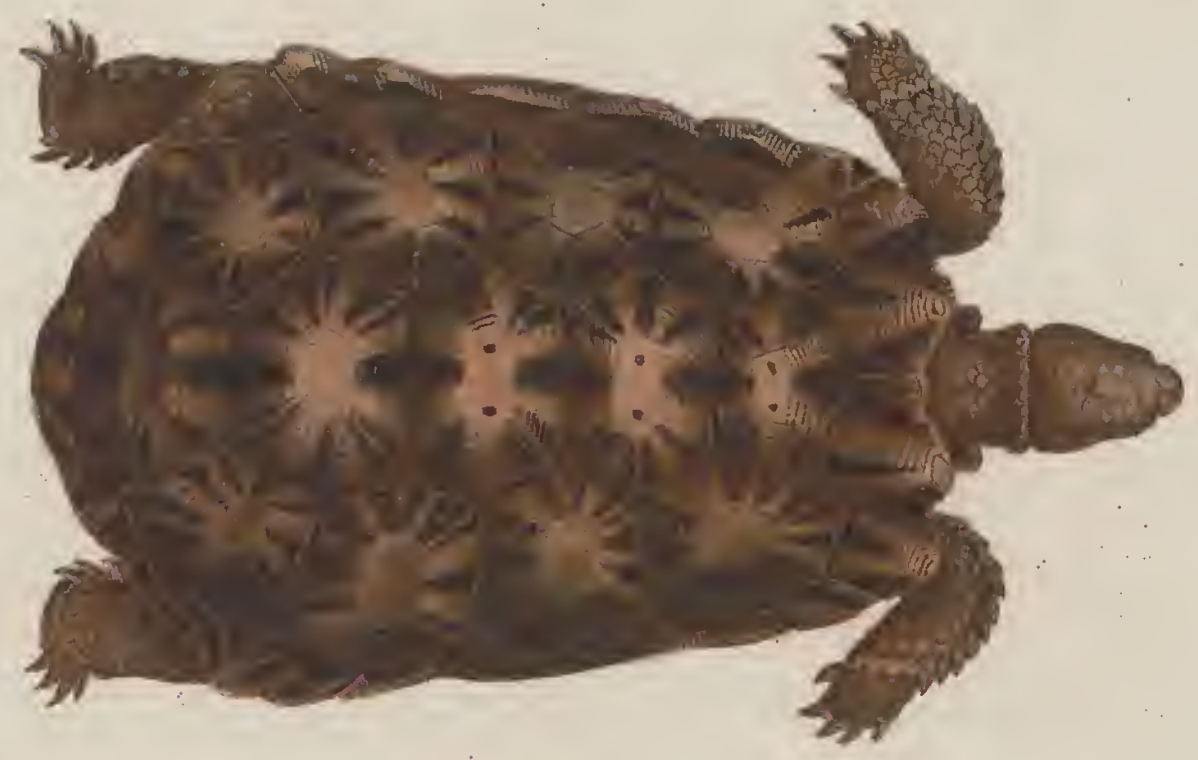

Fig. 116.6

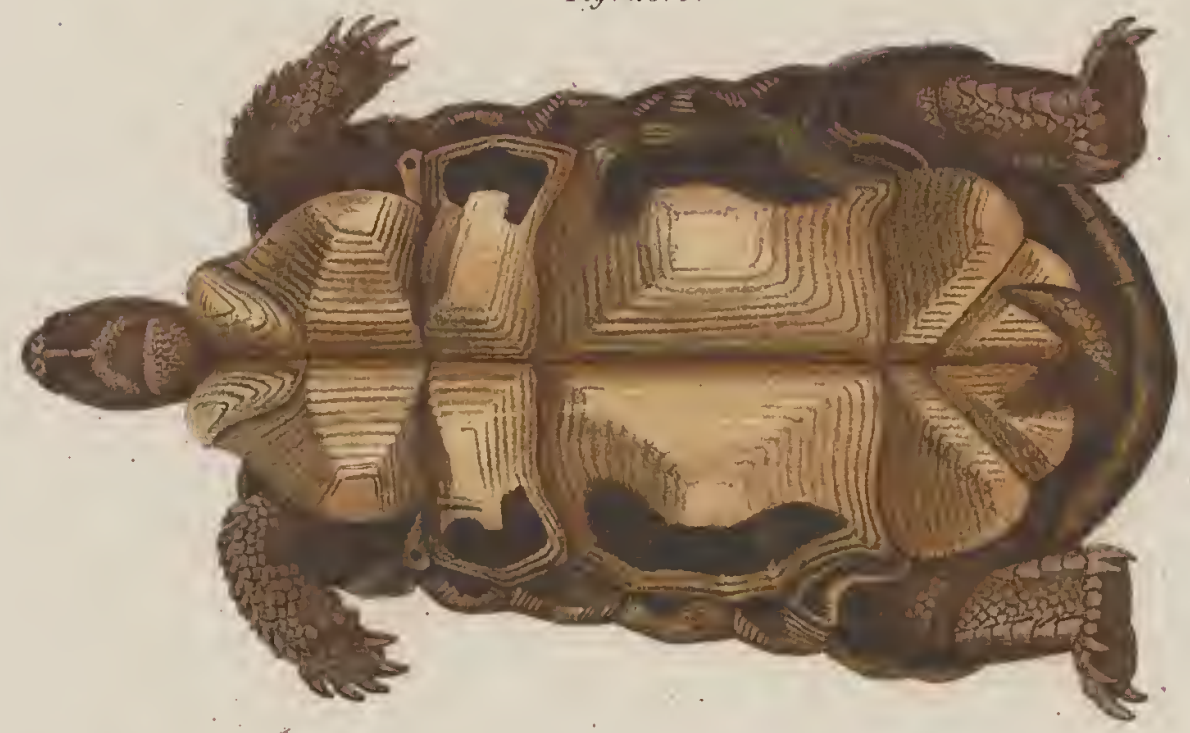

Fig. 117

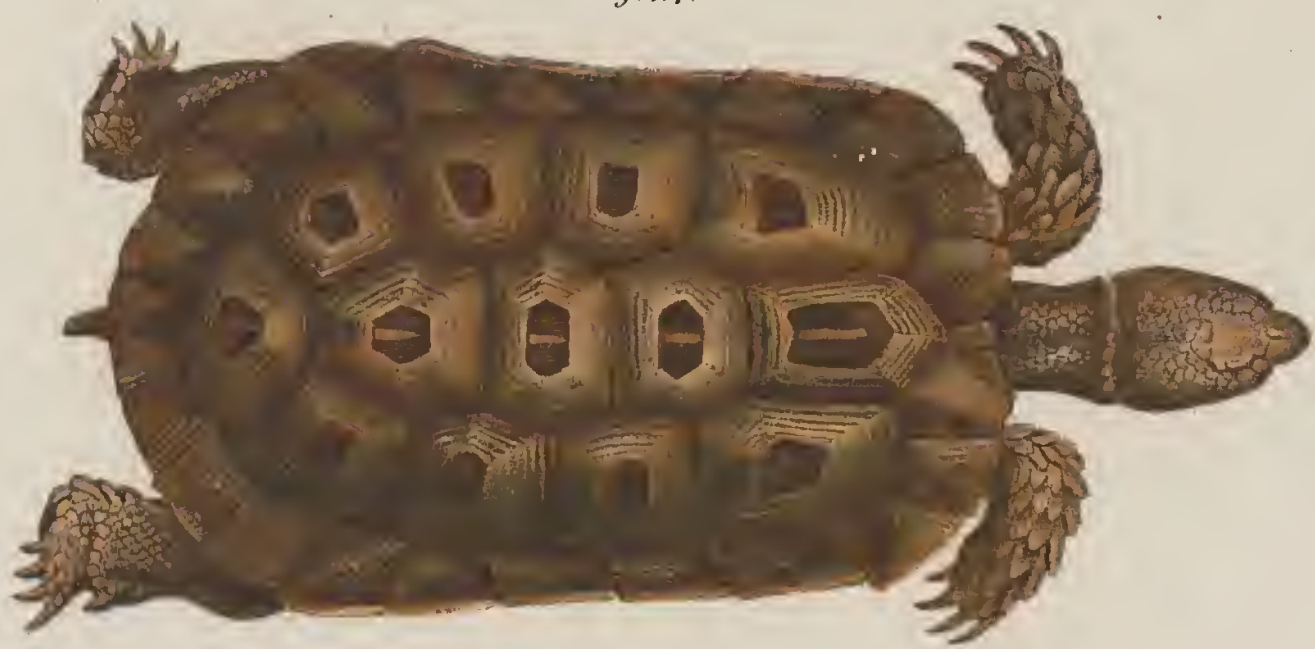

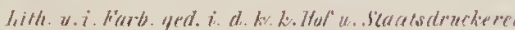

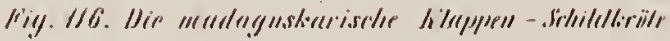

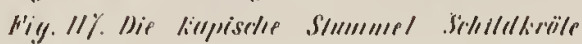

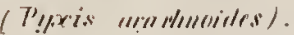

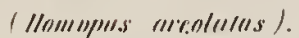




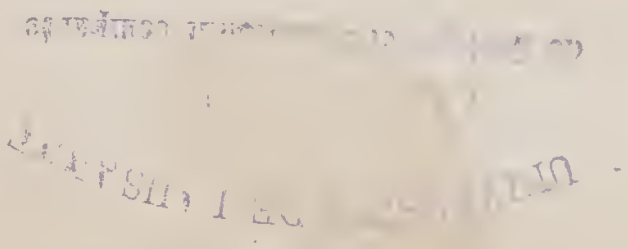


Fi!) I:"
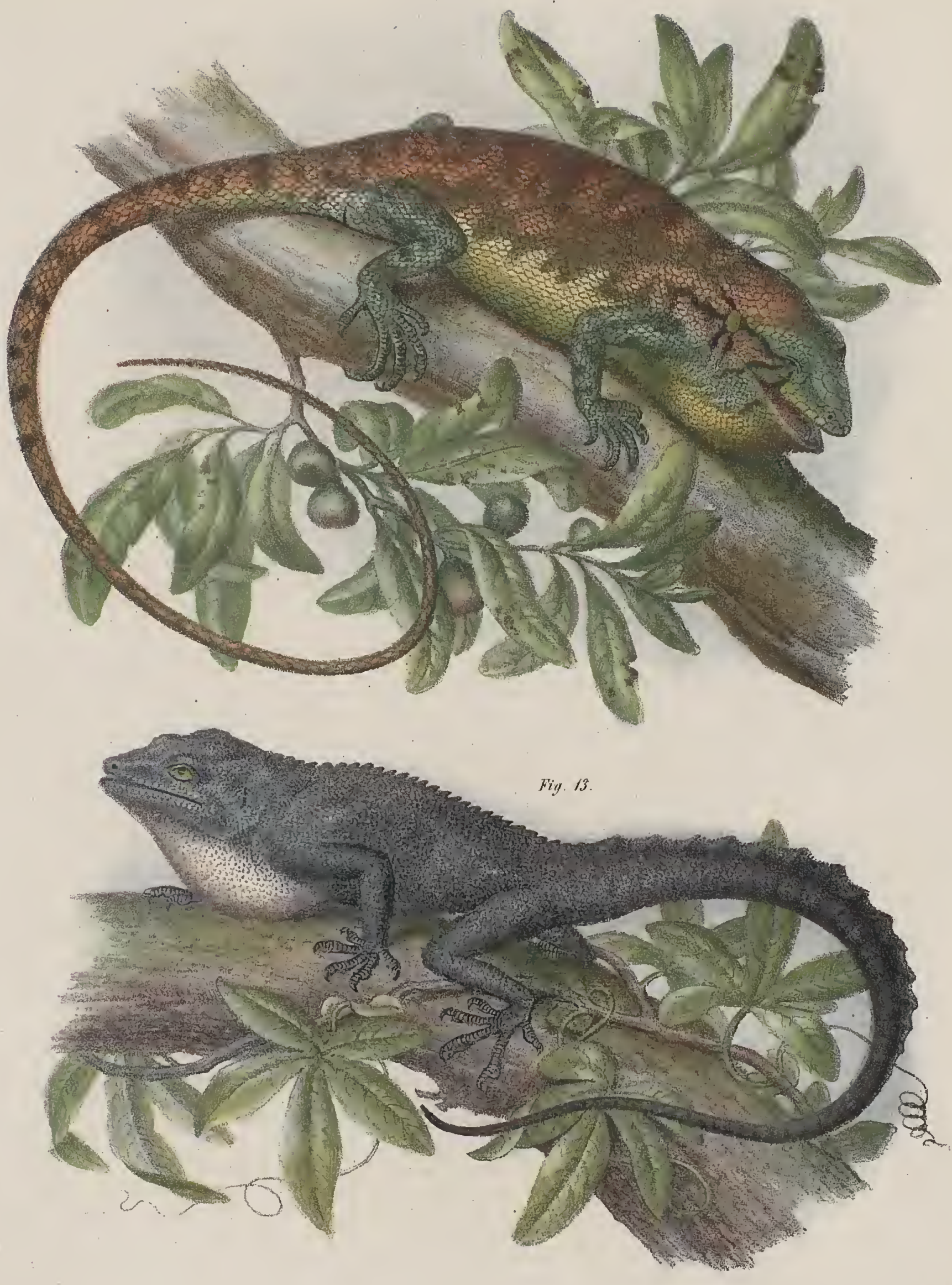

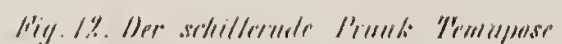

liig. 13. Jir yrofser Hinhuen .luslide

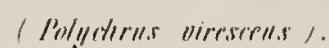

(Seminimeris levierri) 
$y^{4}$

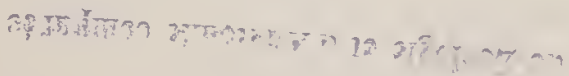

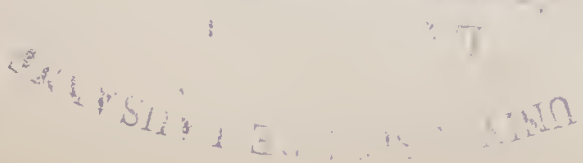


Nig. 14

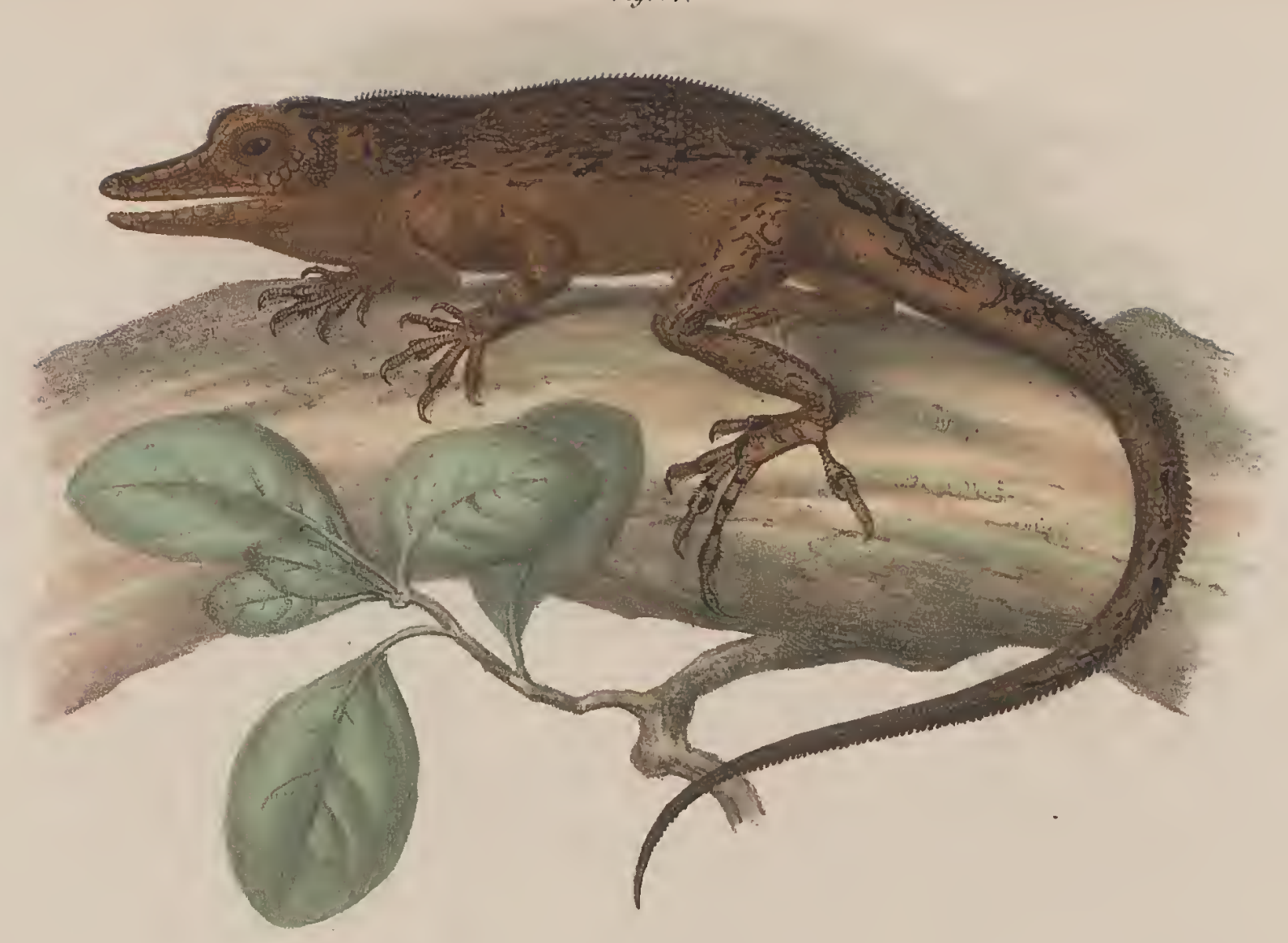

Nig. 15.

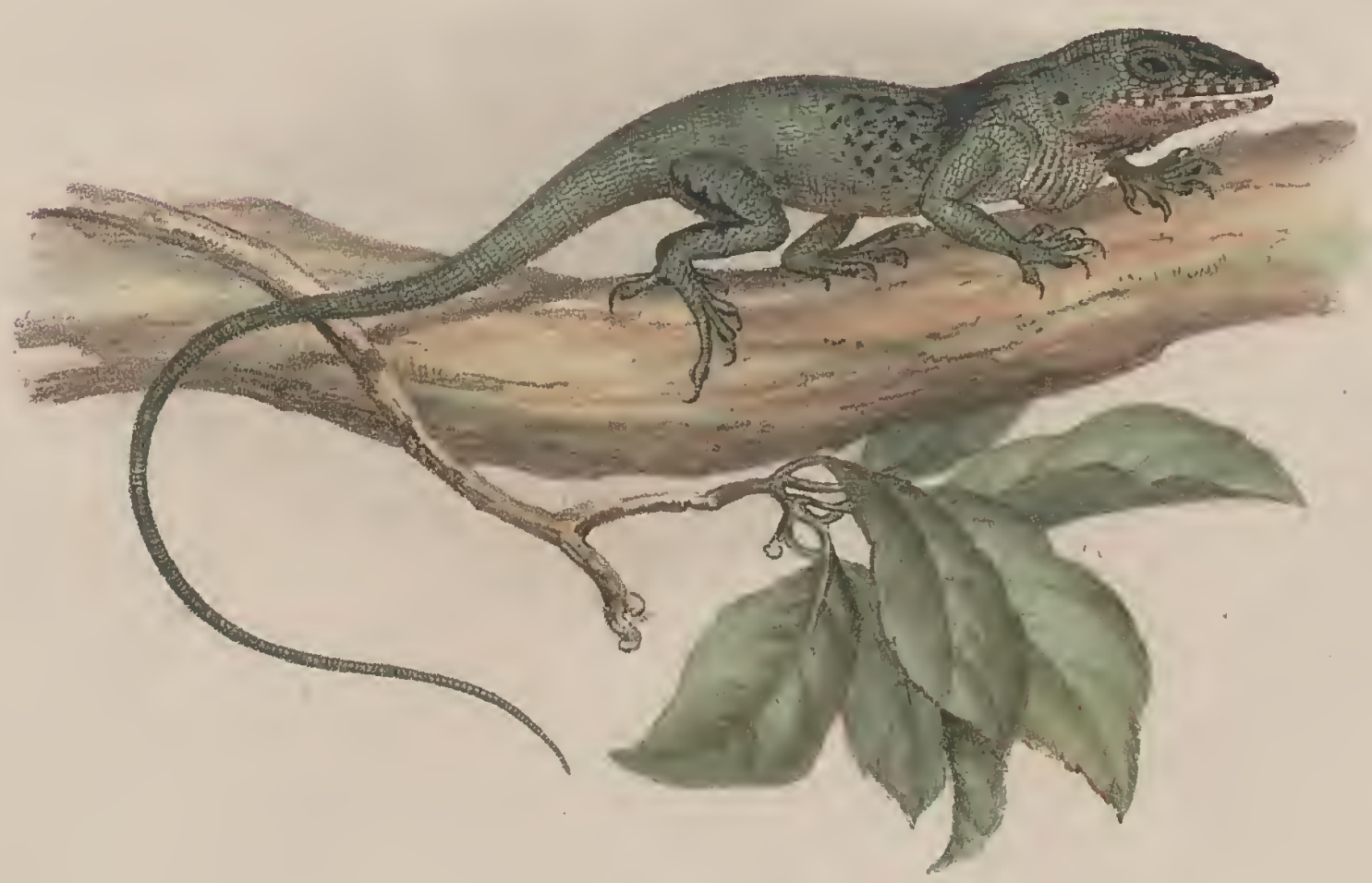

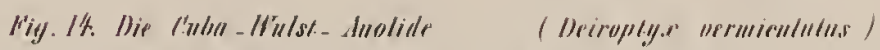

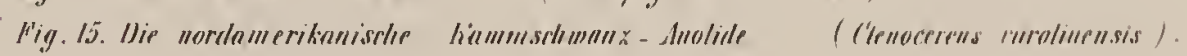




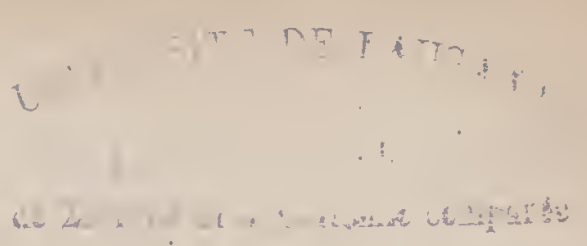




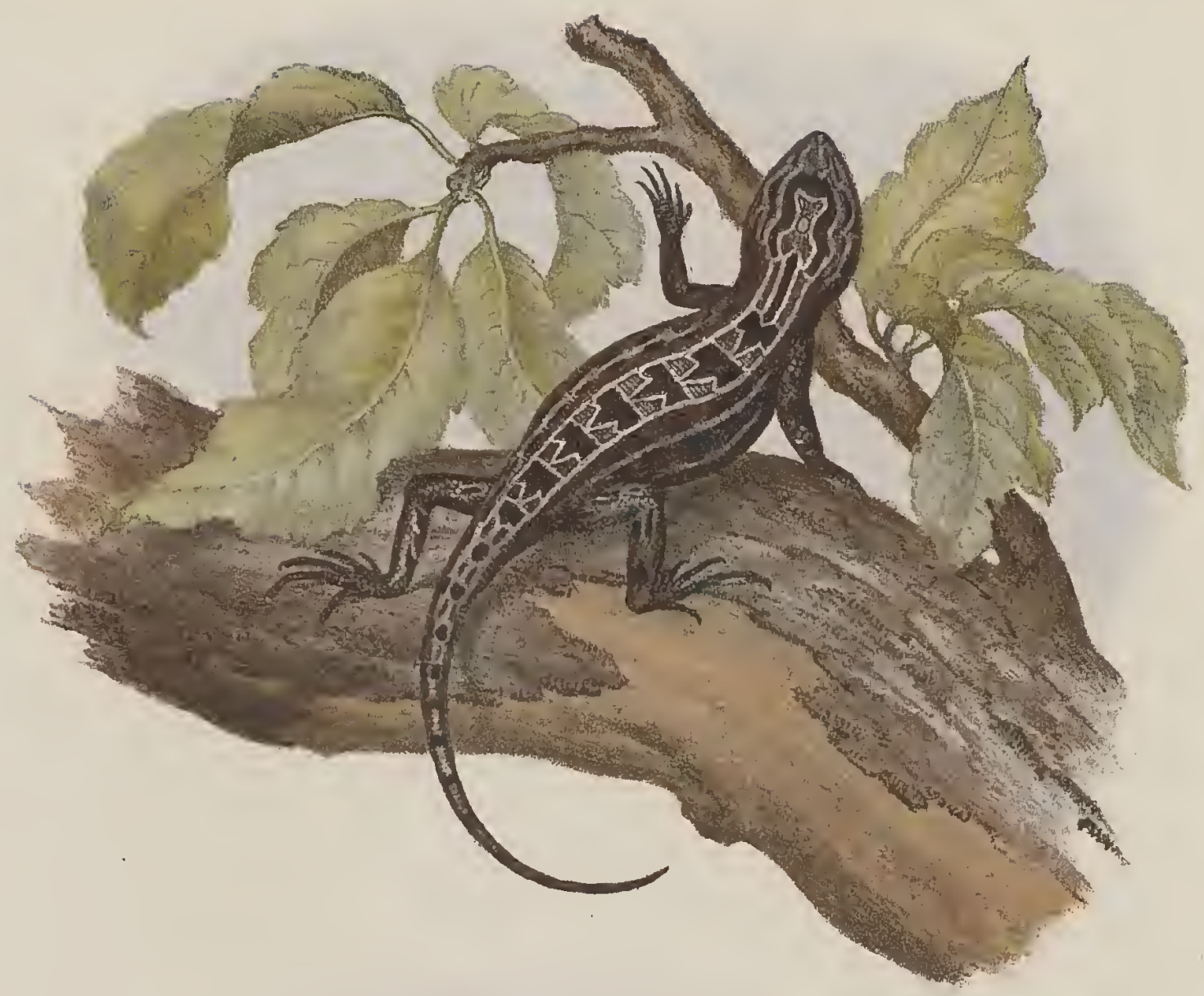

lig./1.

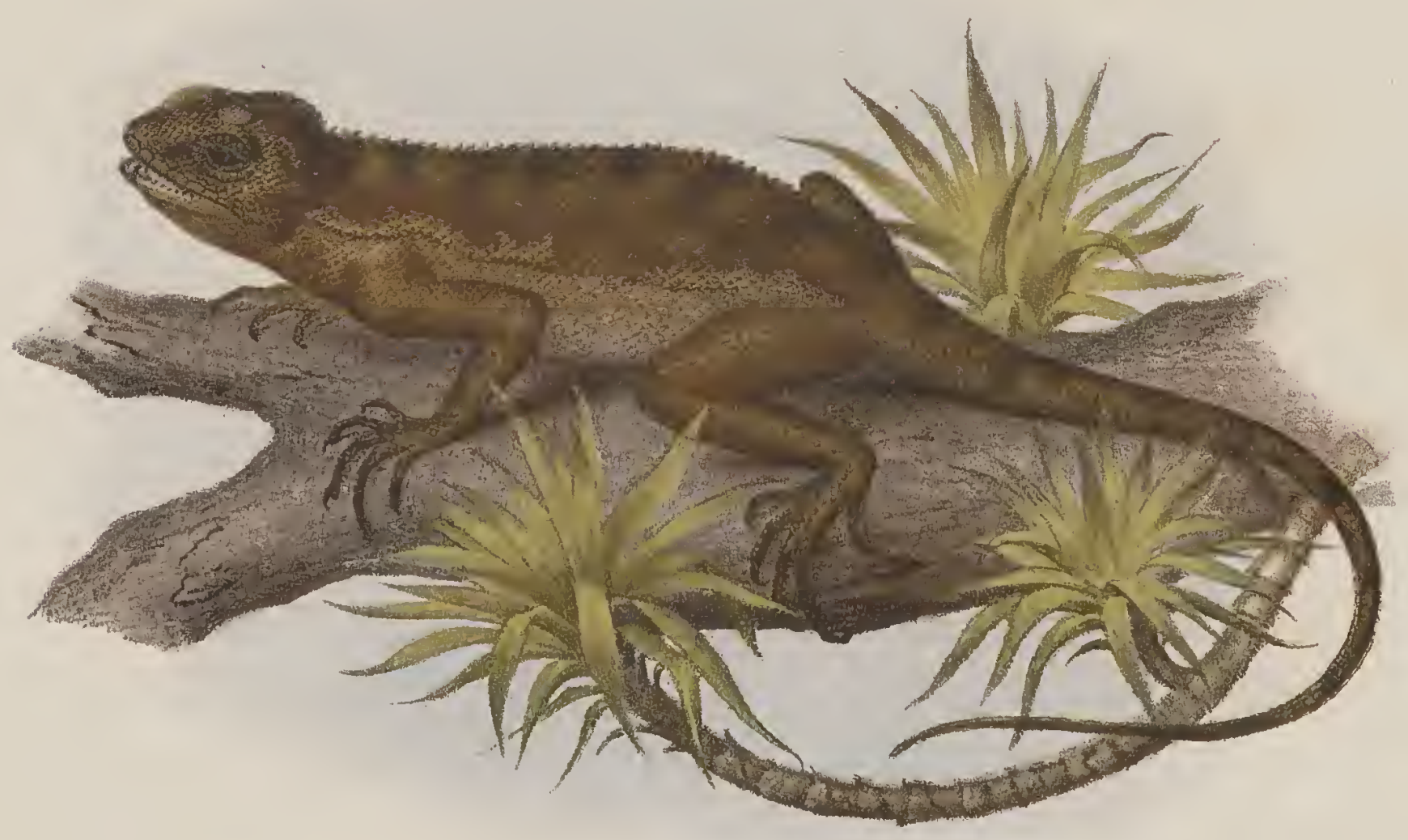

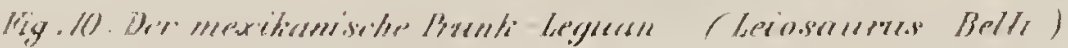

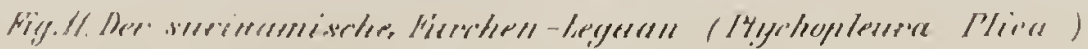


a

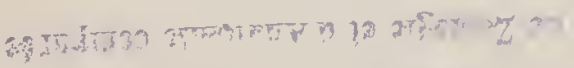

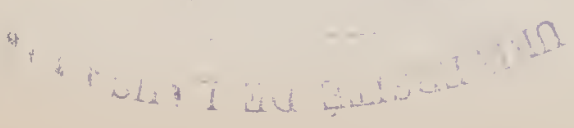



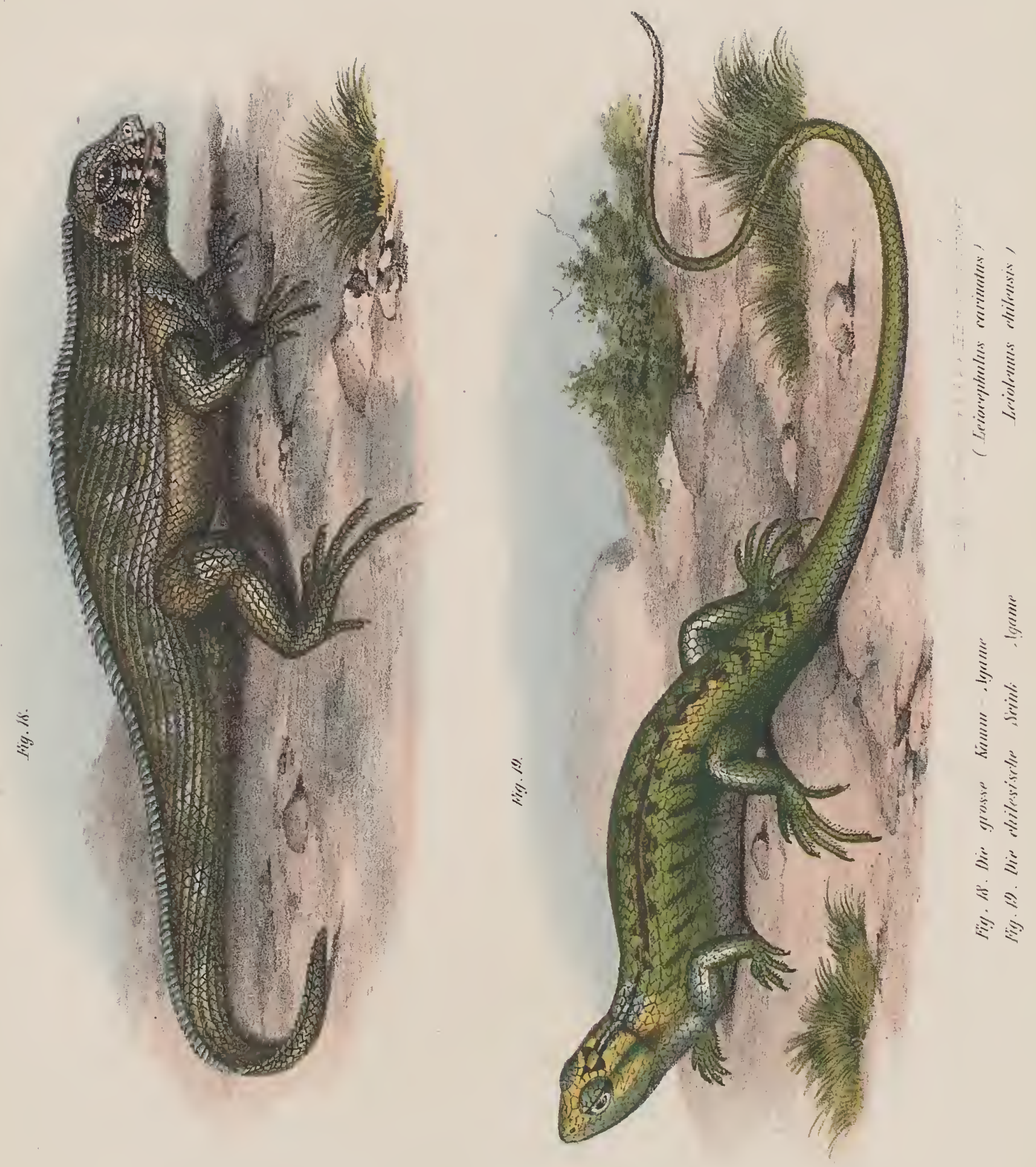

Fig. 38.
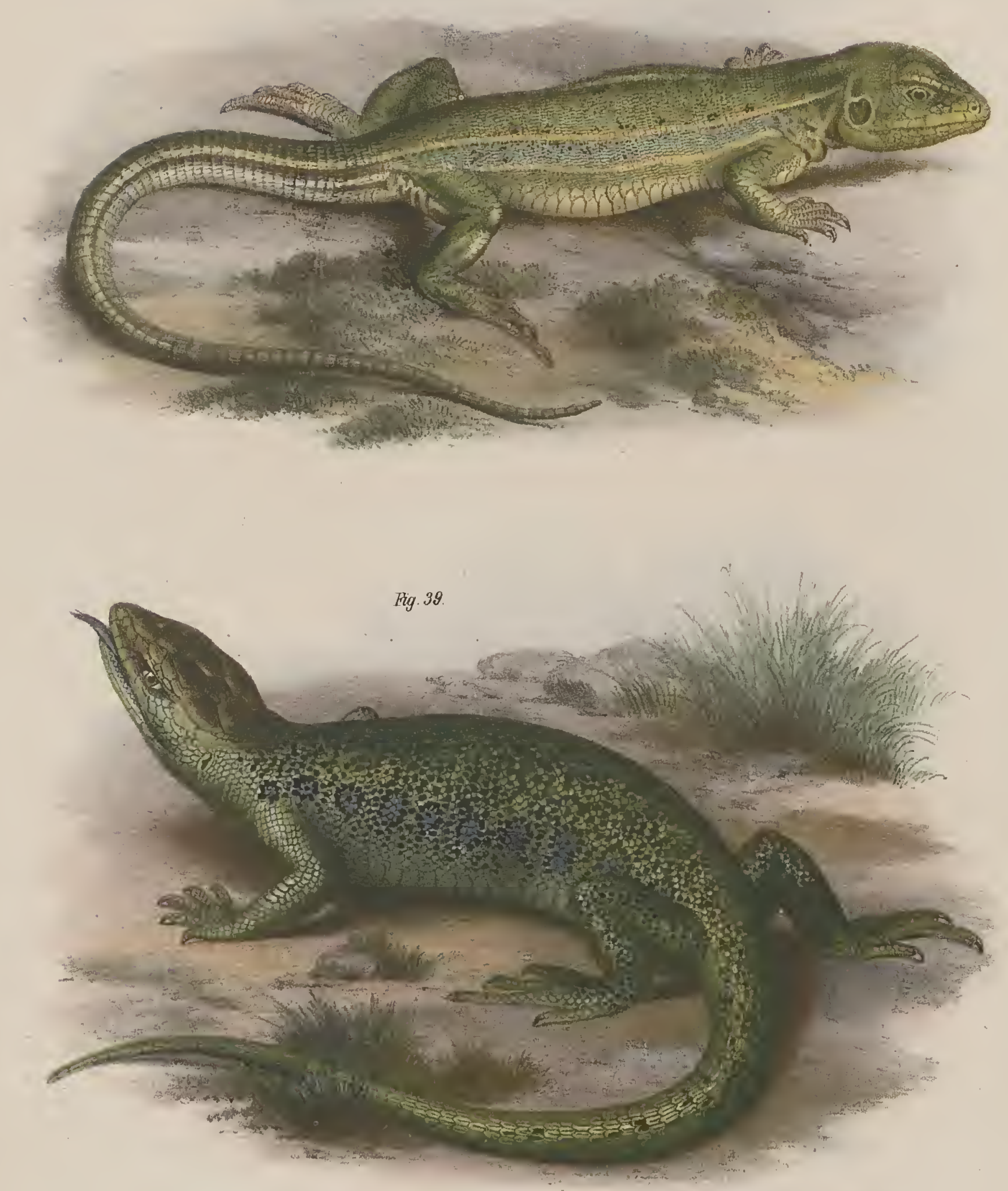

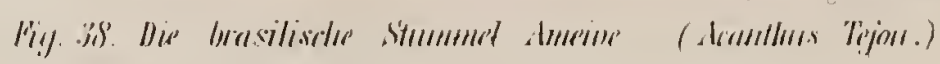

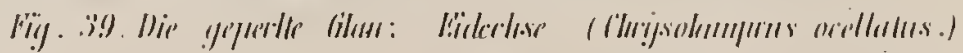




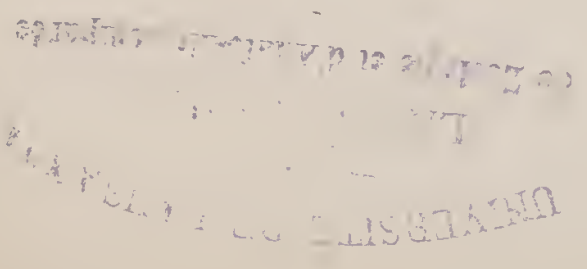


Fig. 16
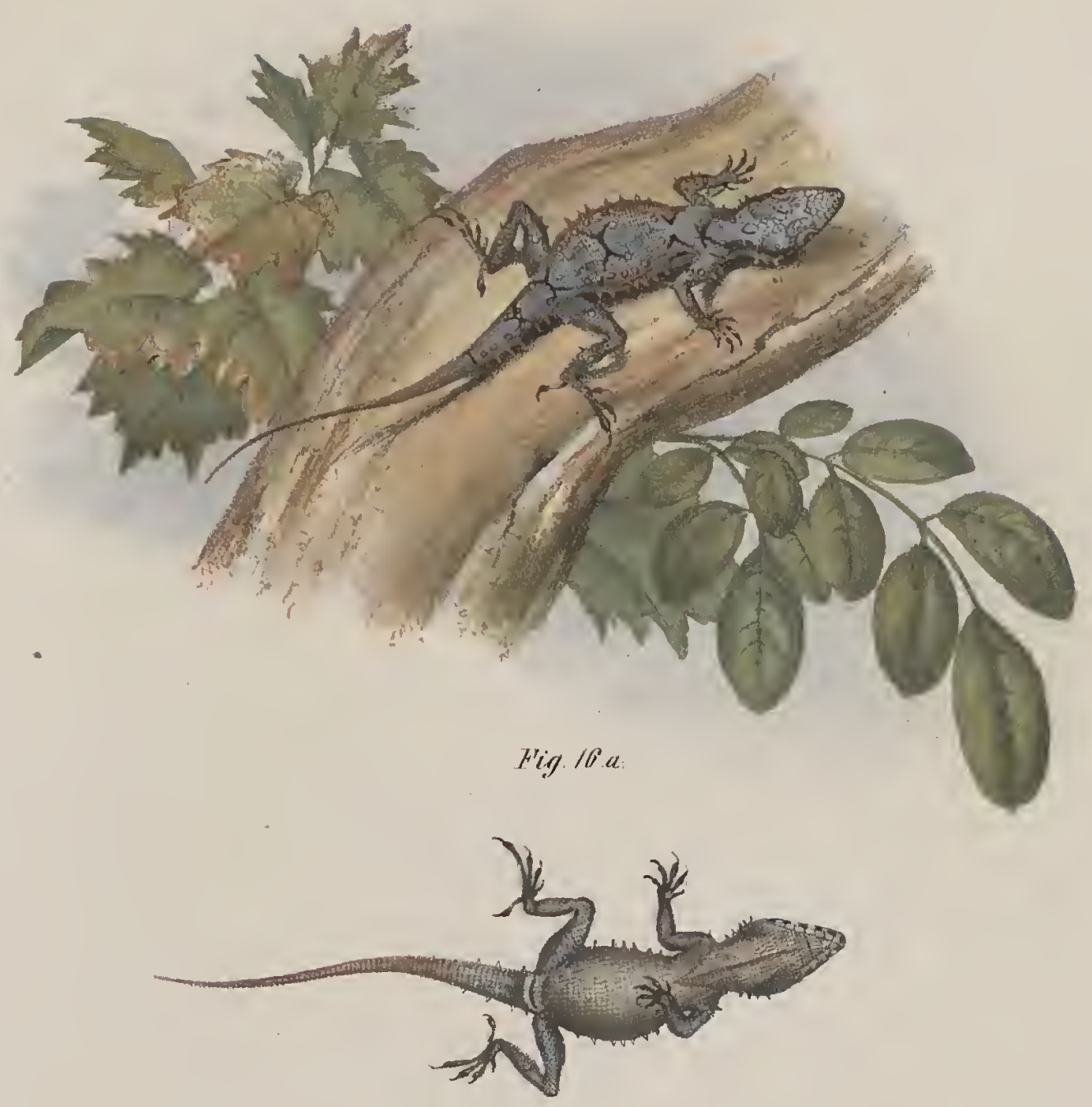

Fig. 17

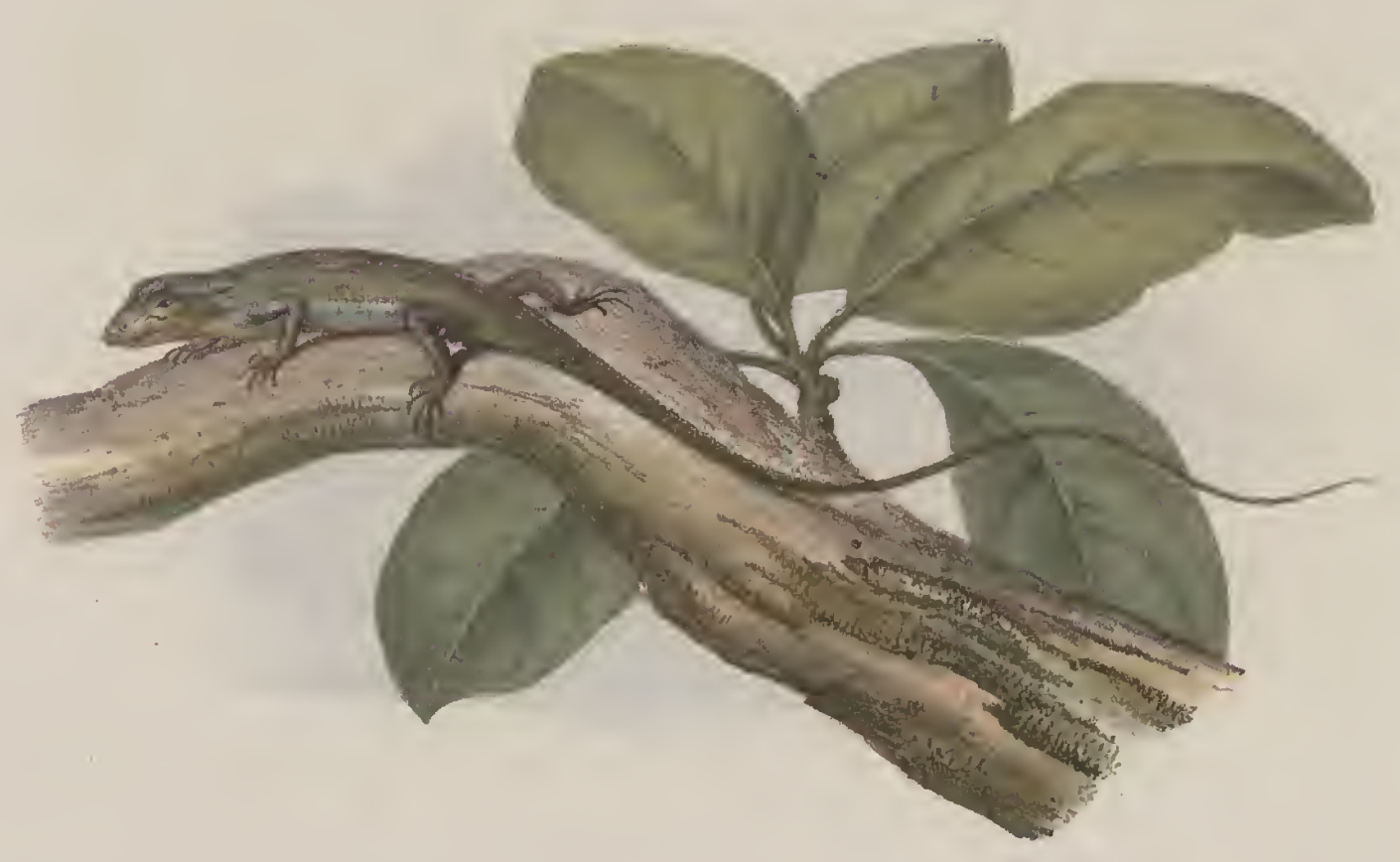

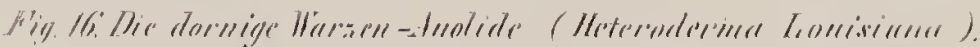

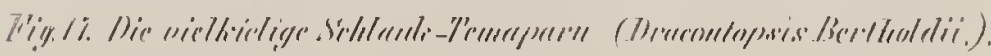




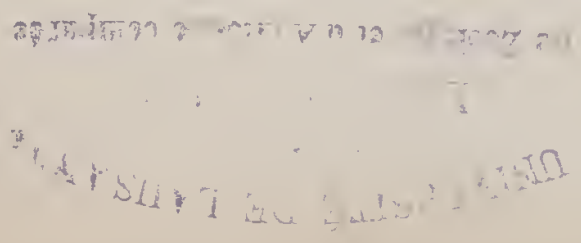



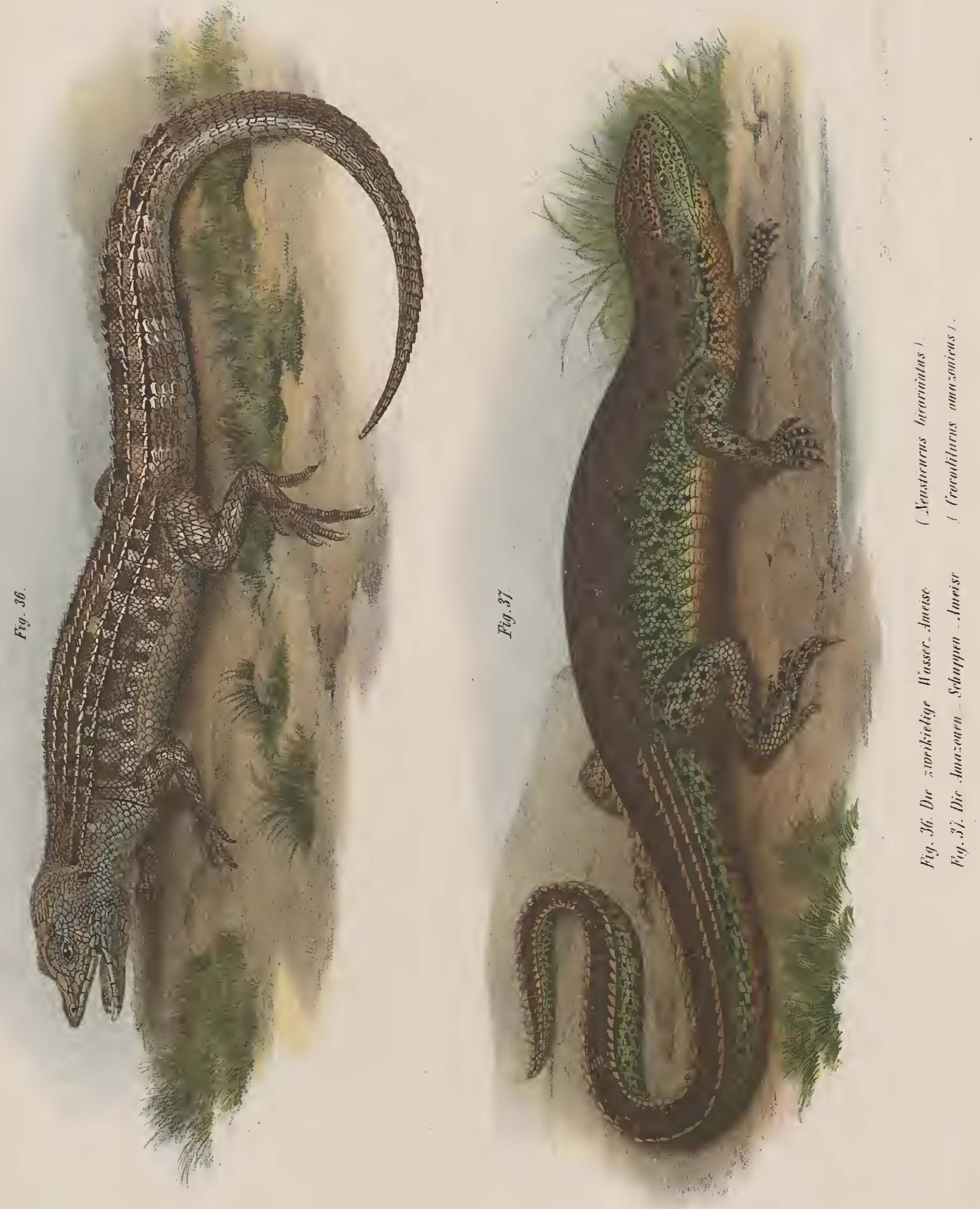
Uस: רर

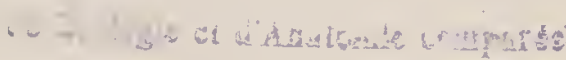


Fig. 26.
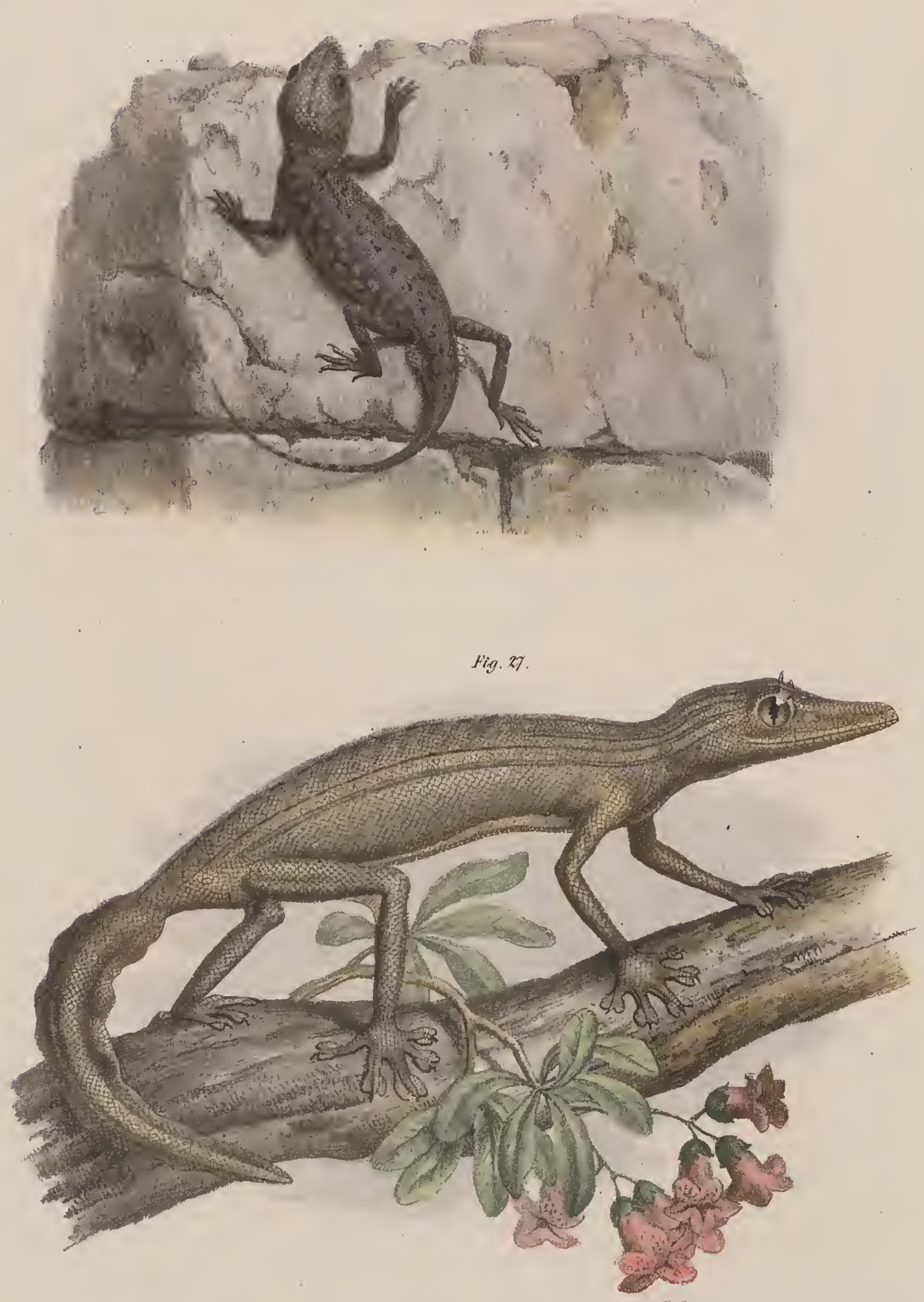

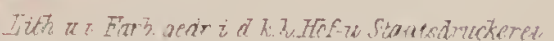

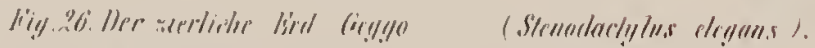

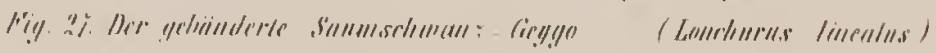




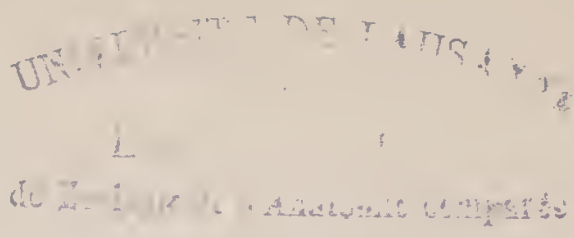


Fig. 51.

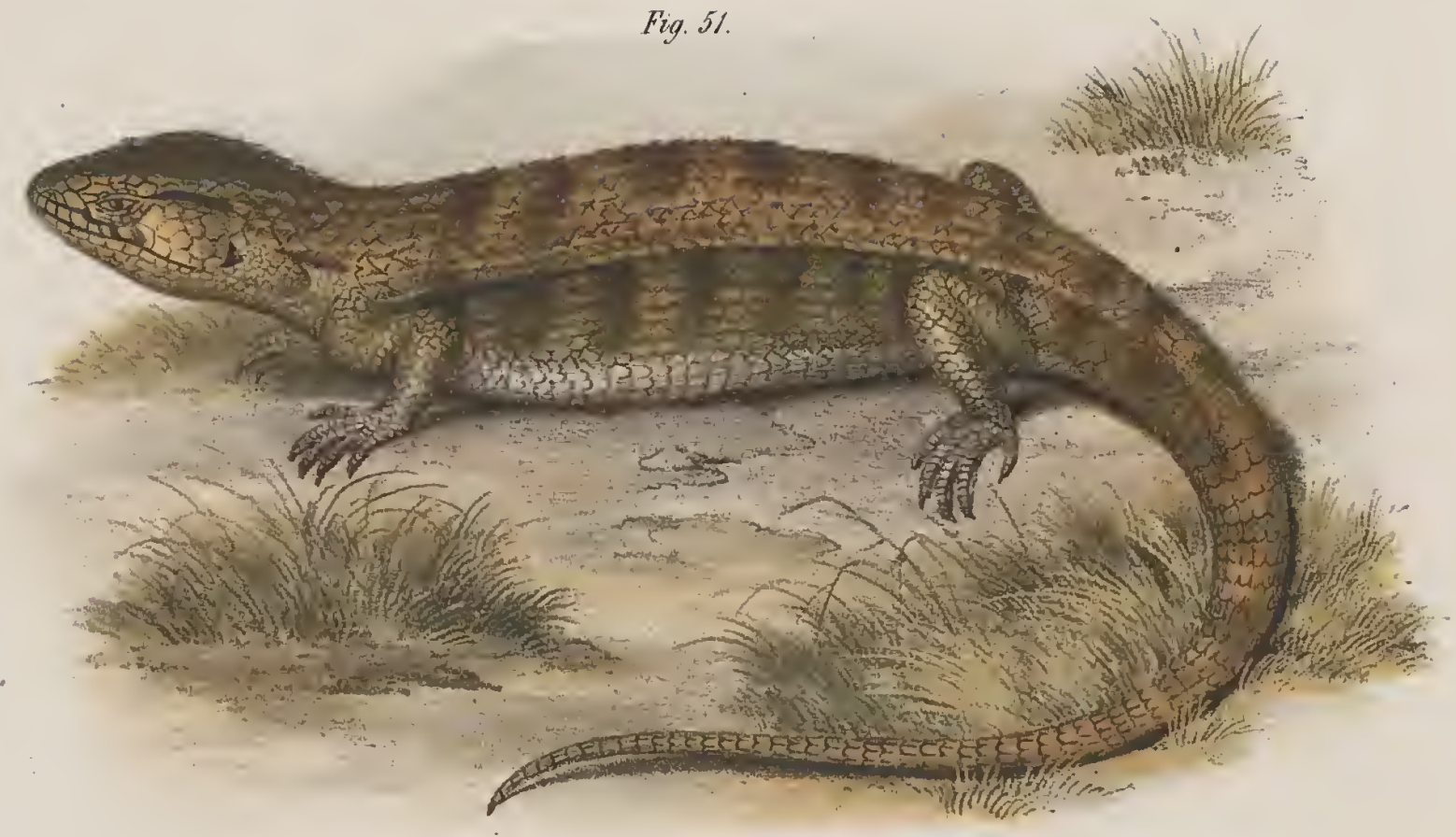

Fig. 52 .

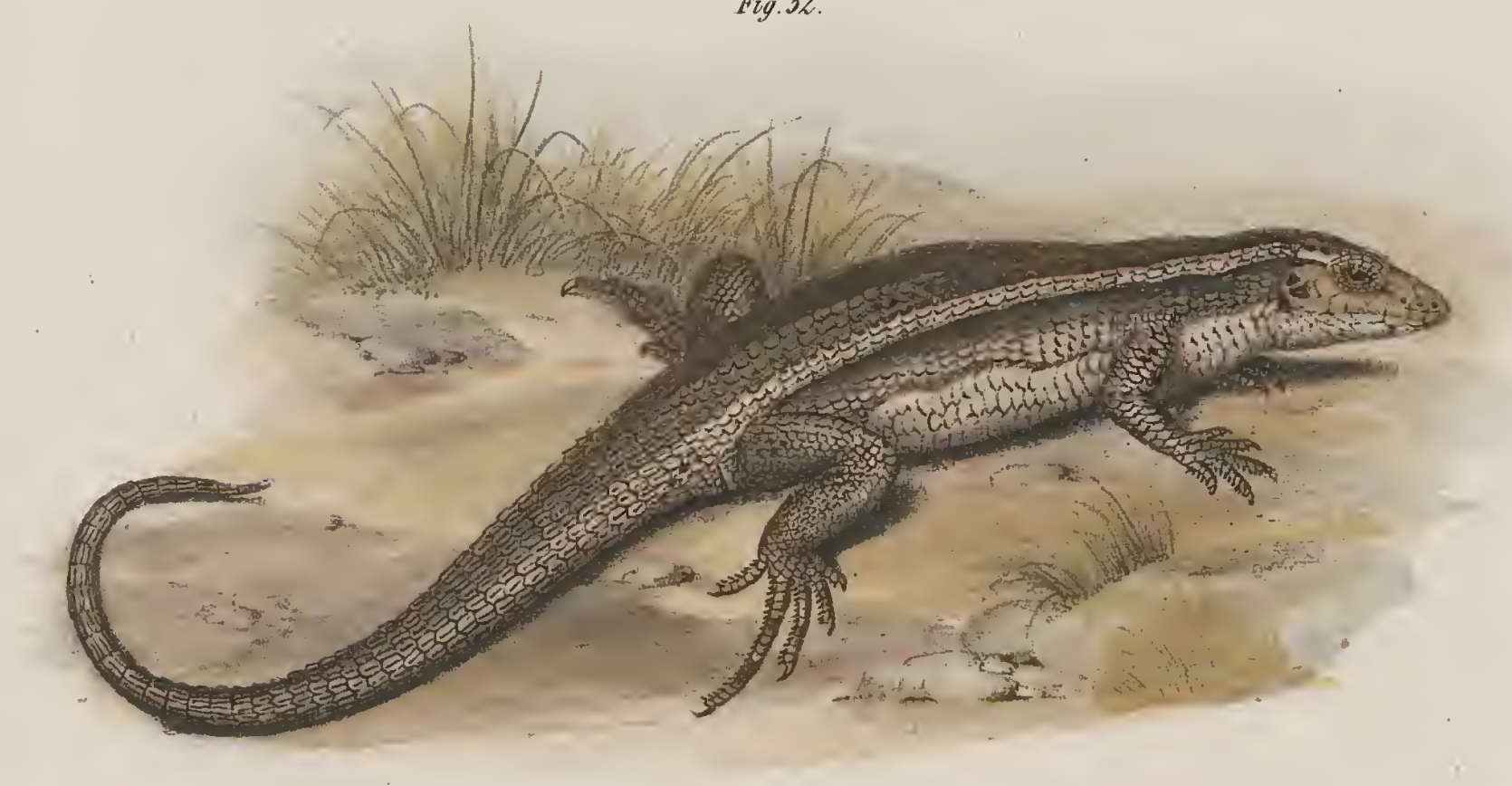

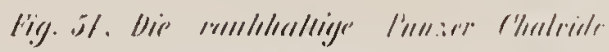

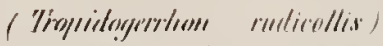

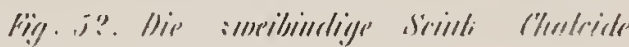

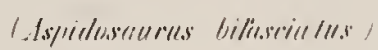




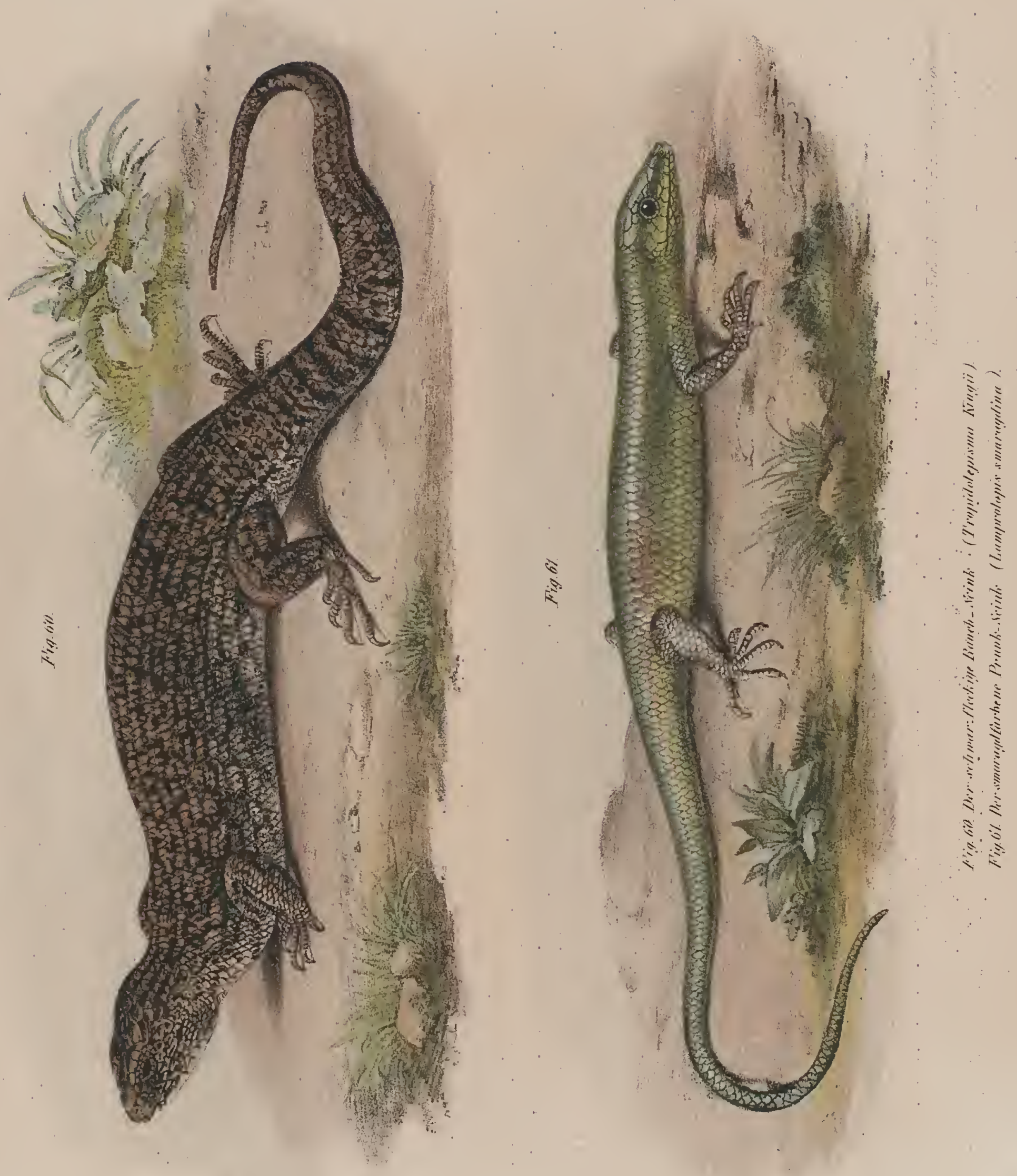


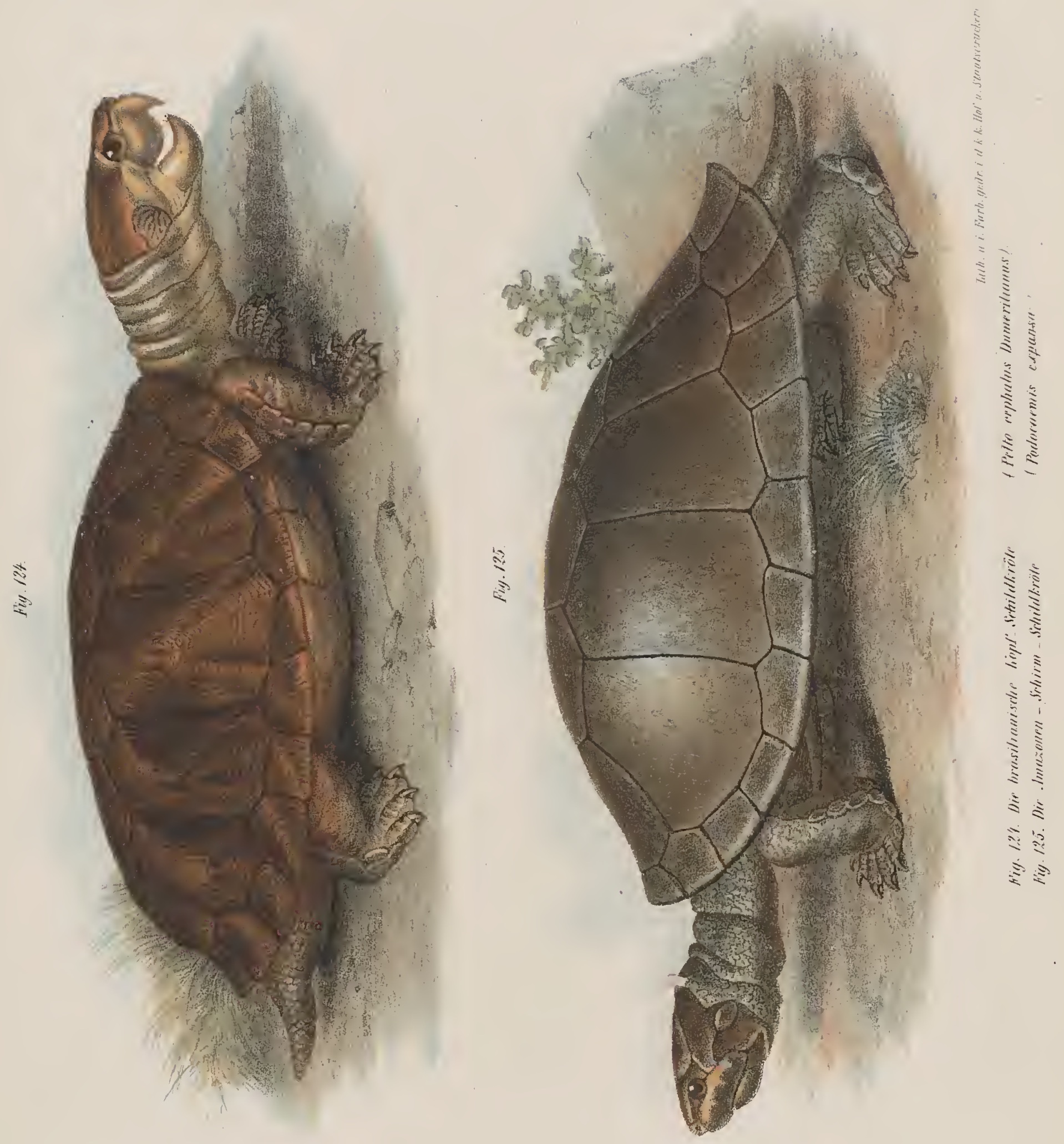


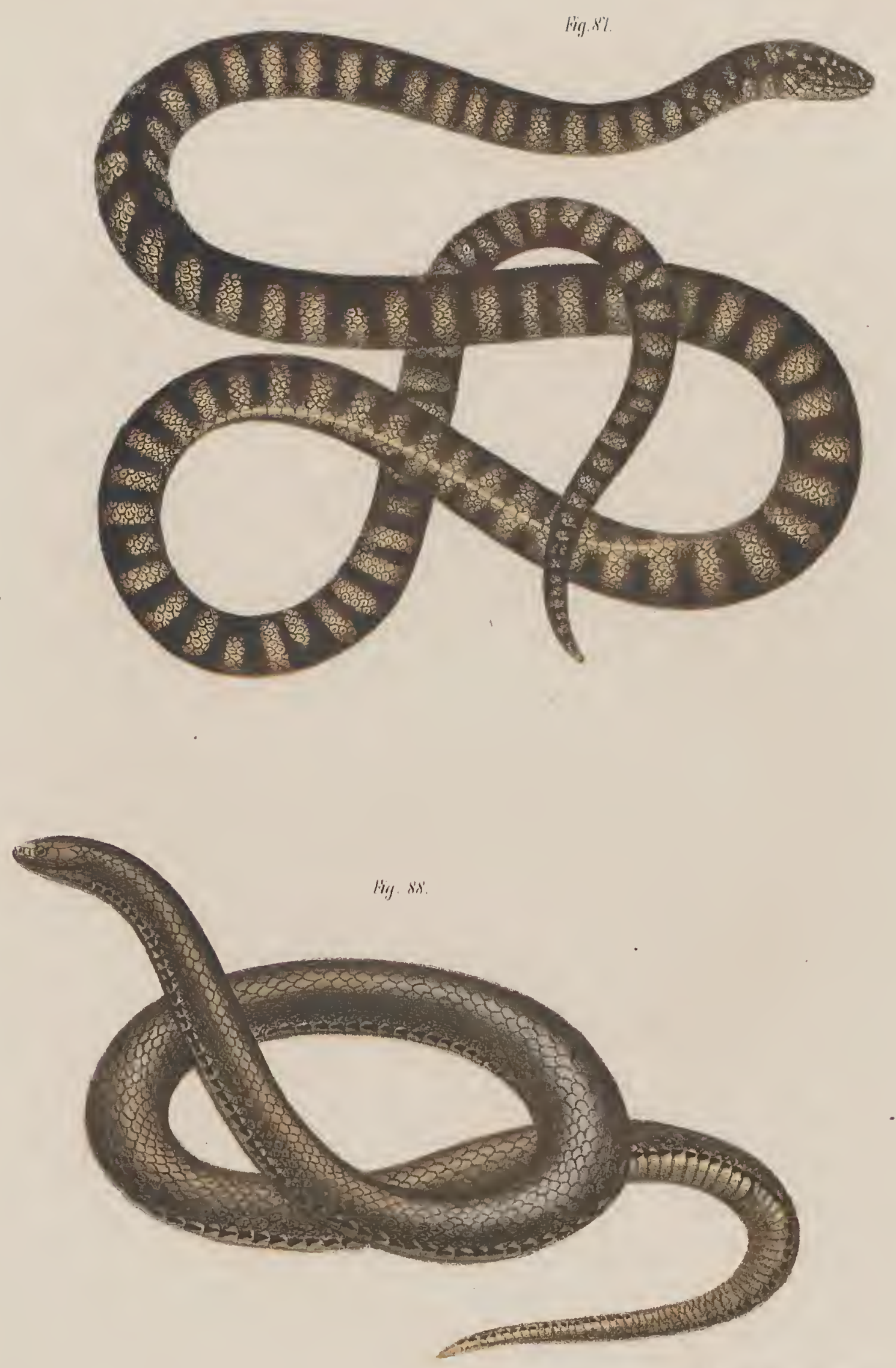

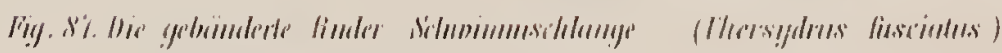

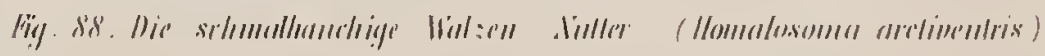




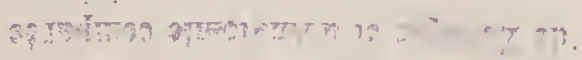




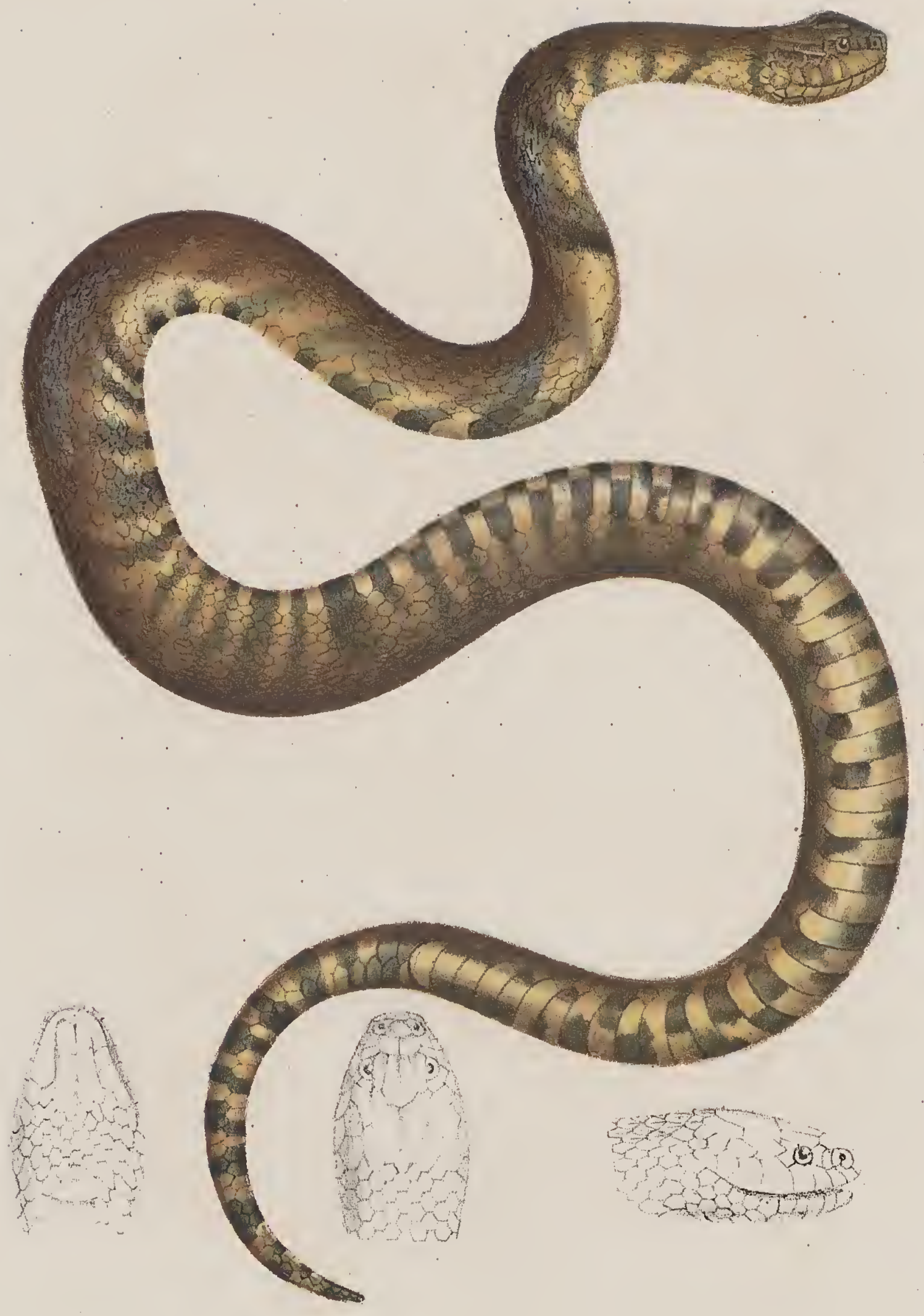

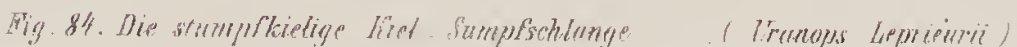


are

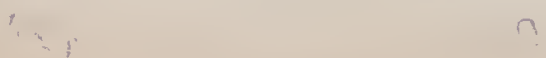




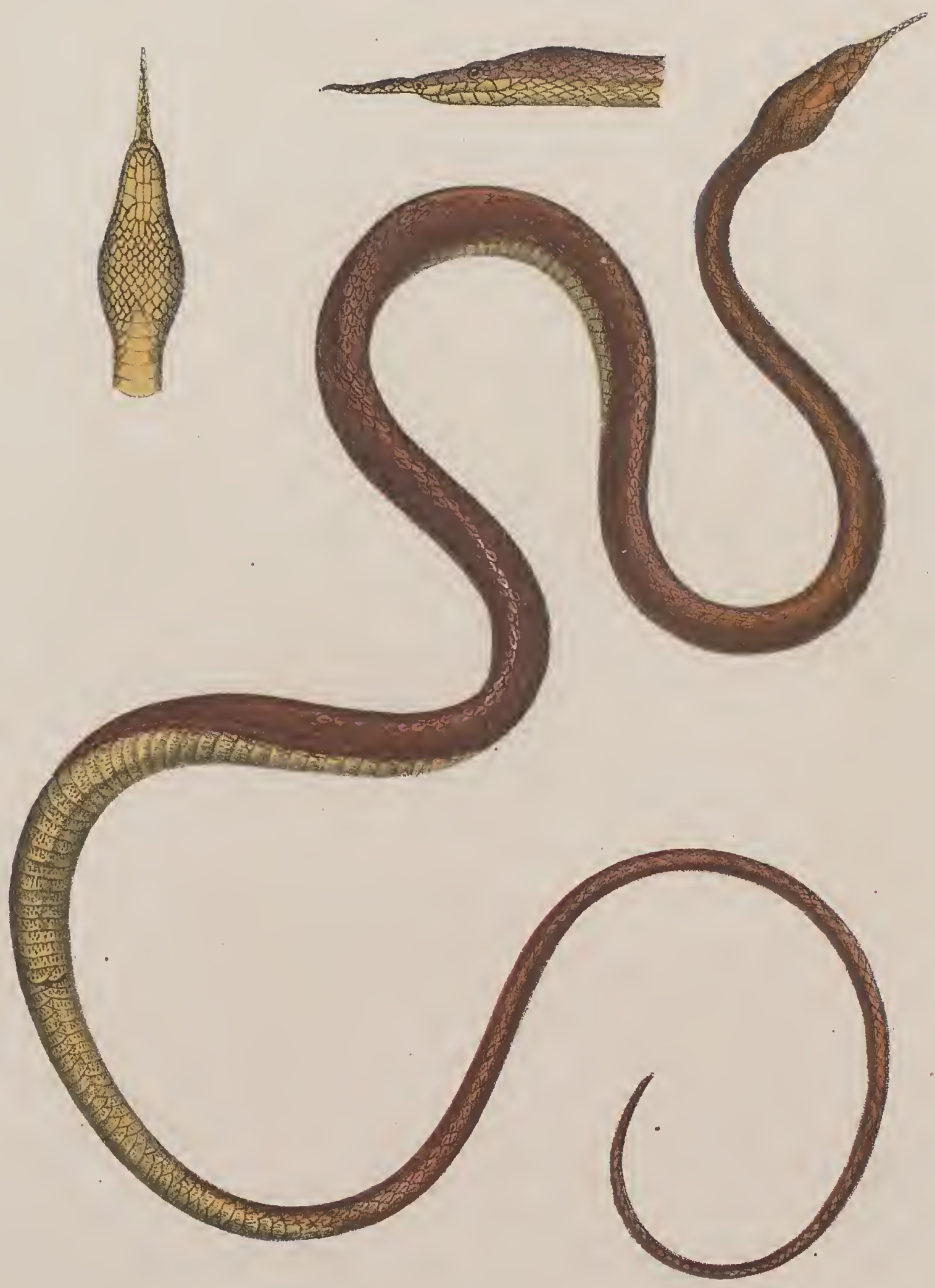

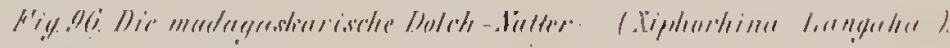




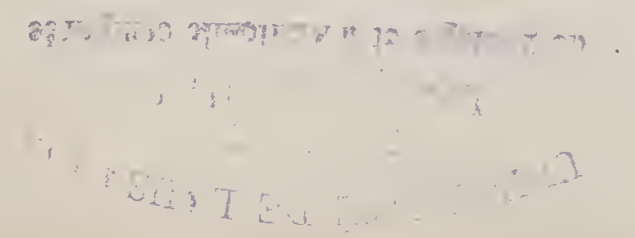



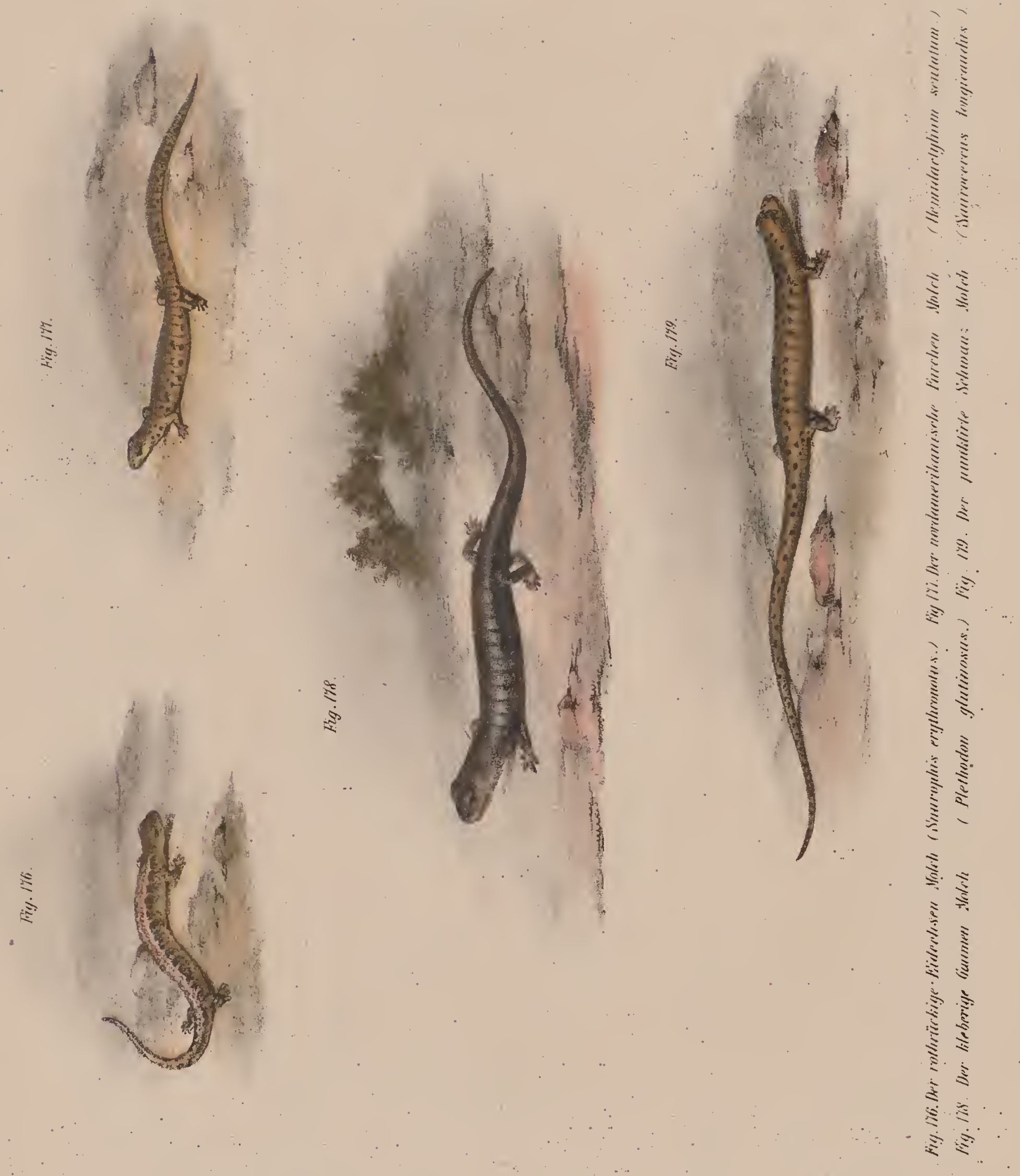



$$
3
$$


15:

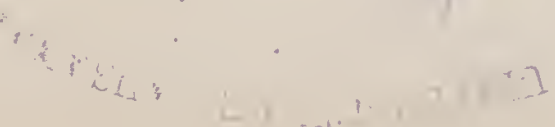




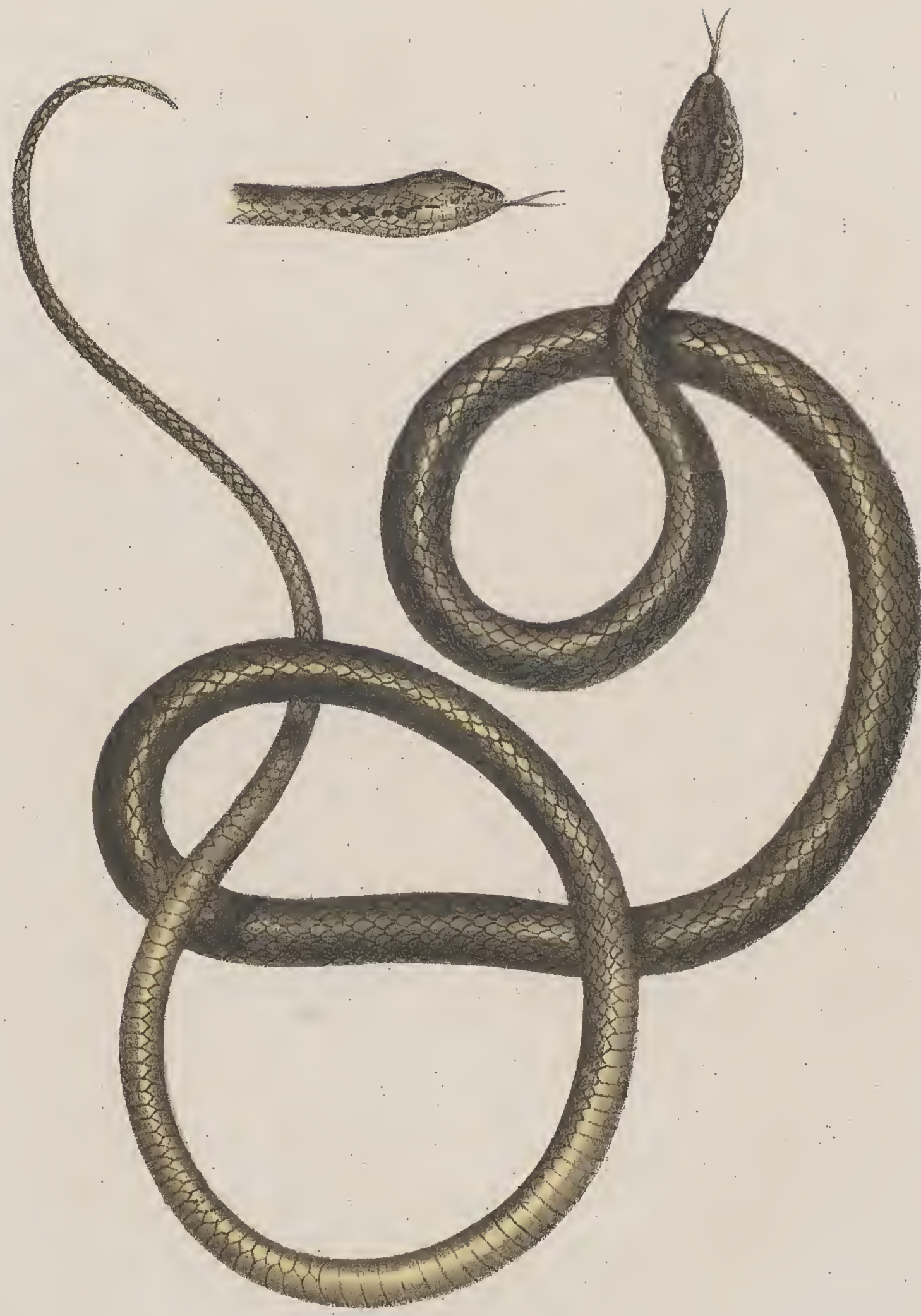

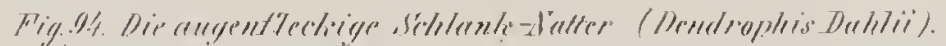




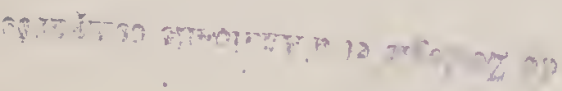

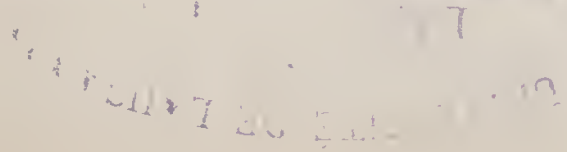



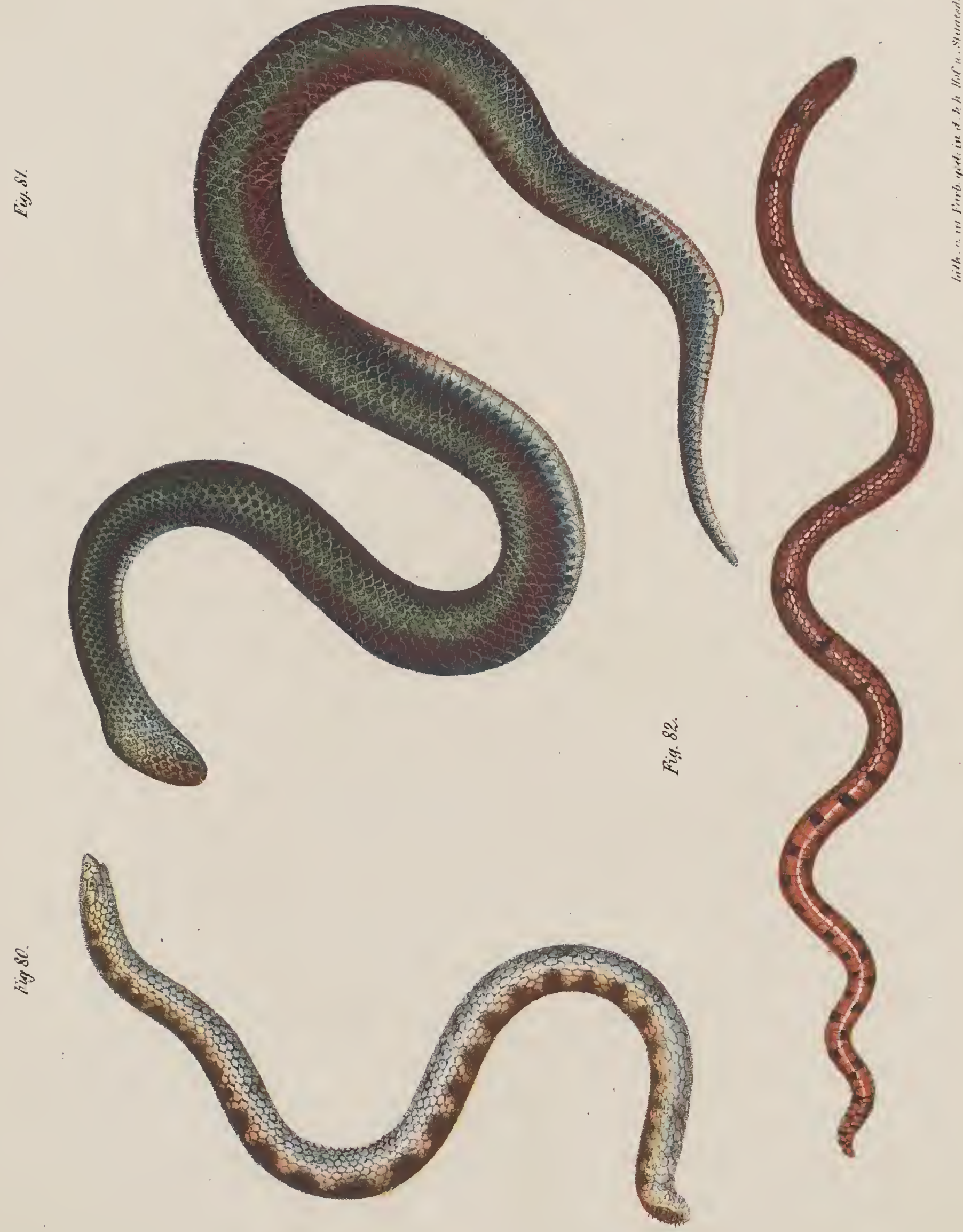

告 


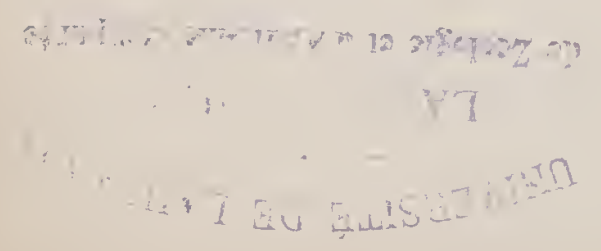



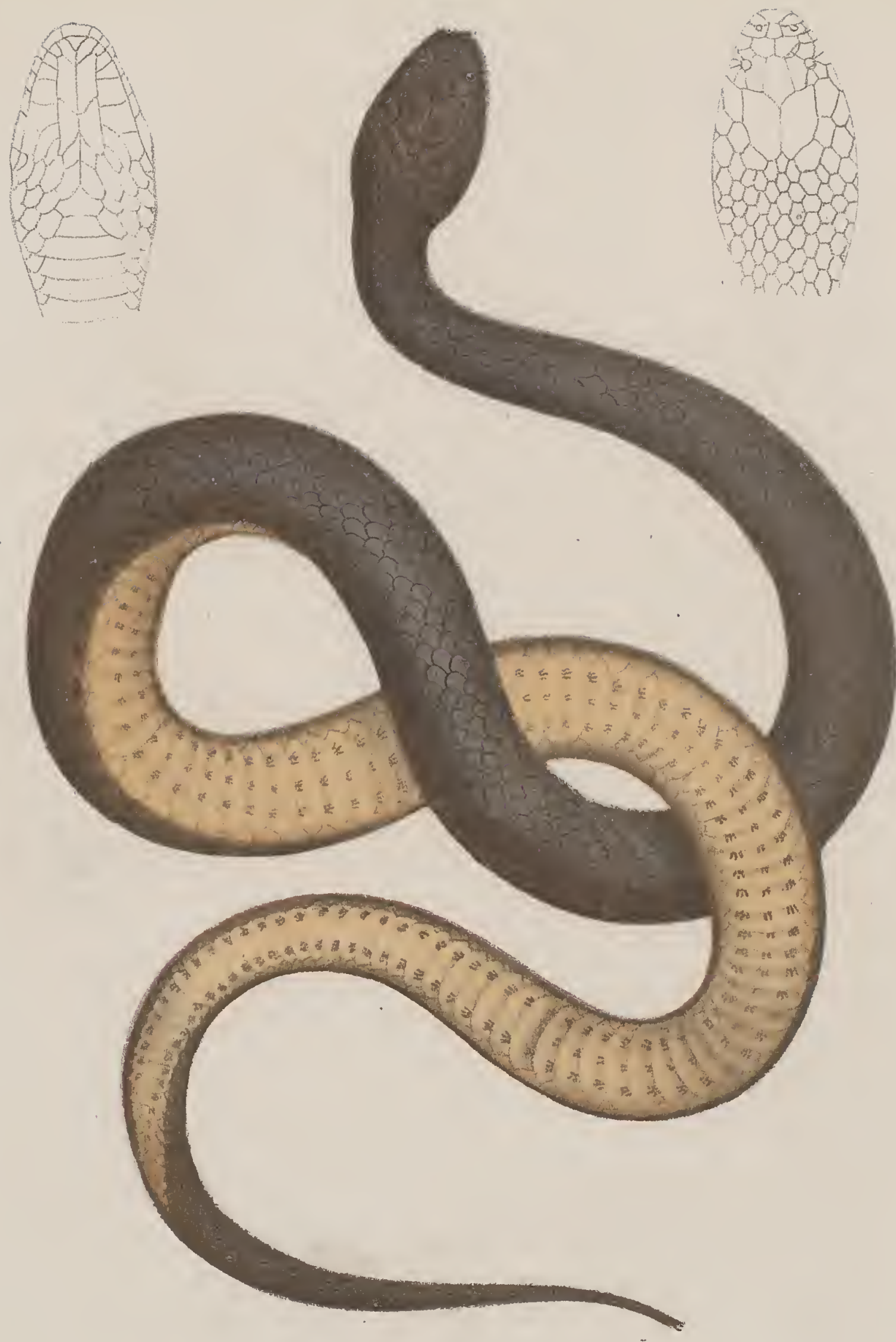

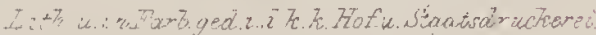

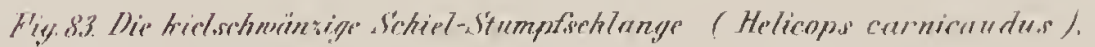





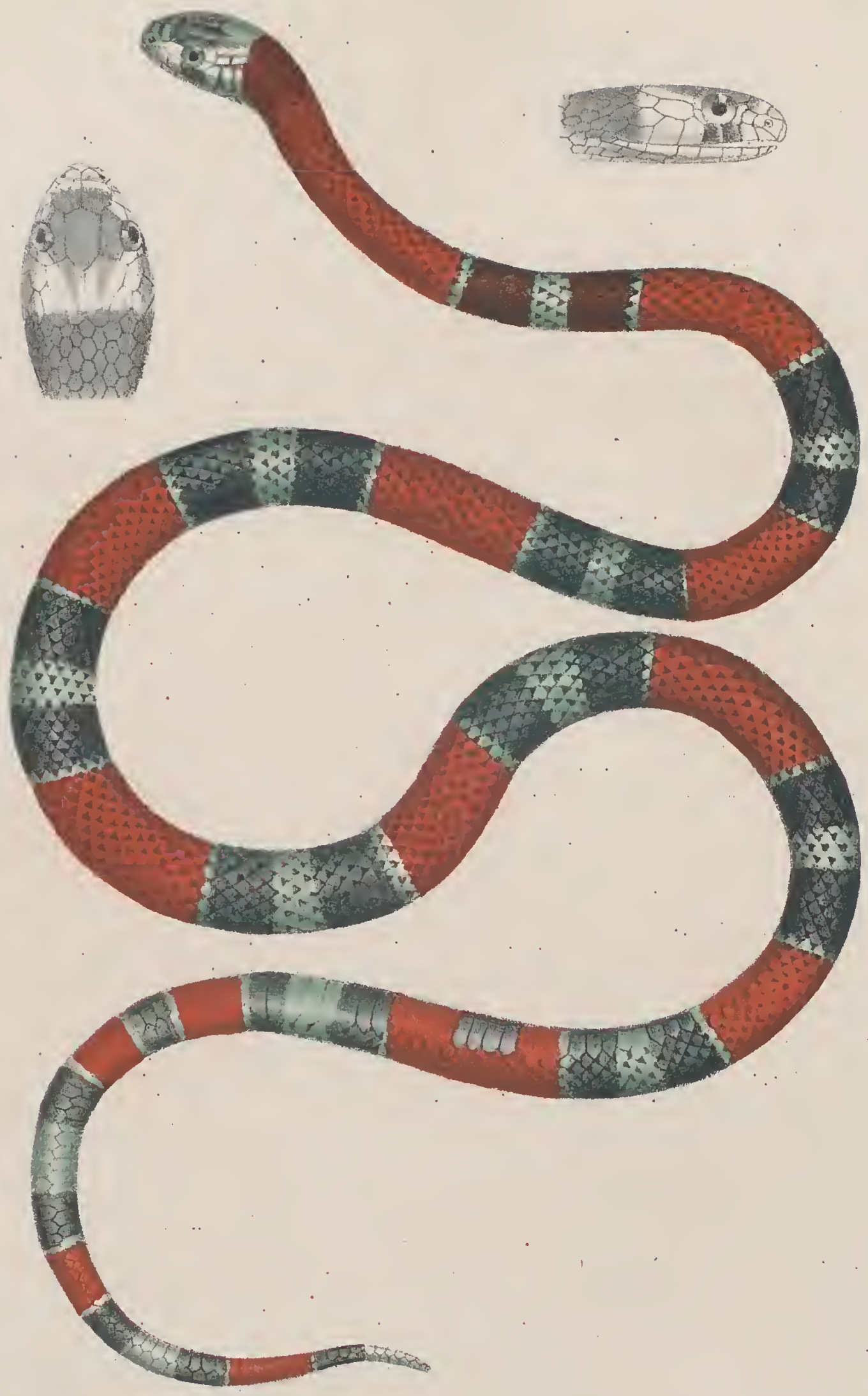

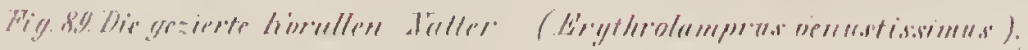




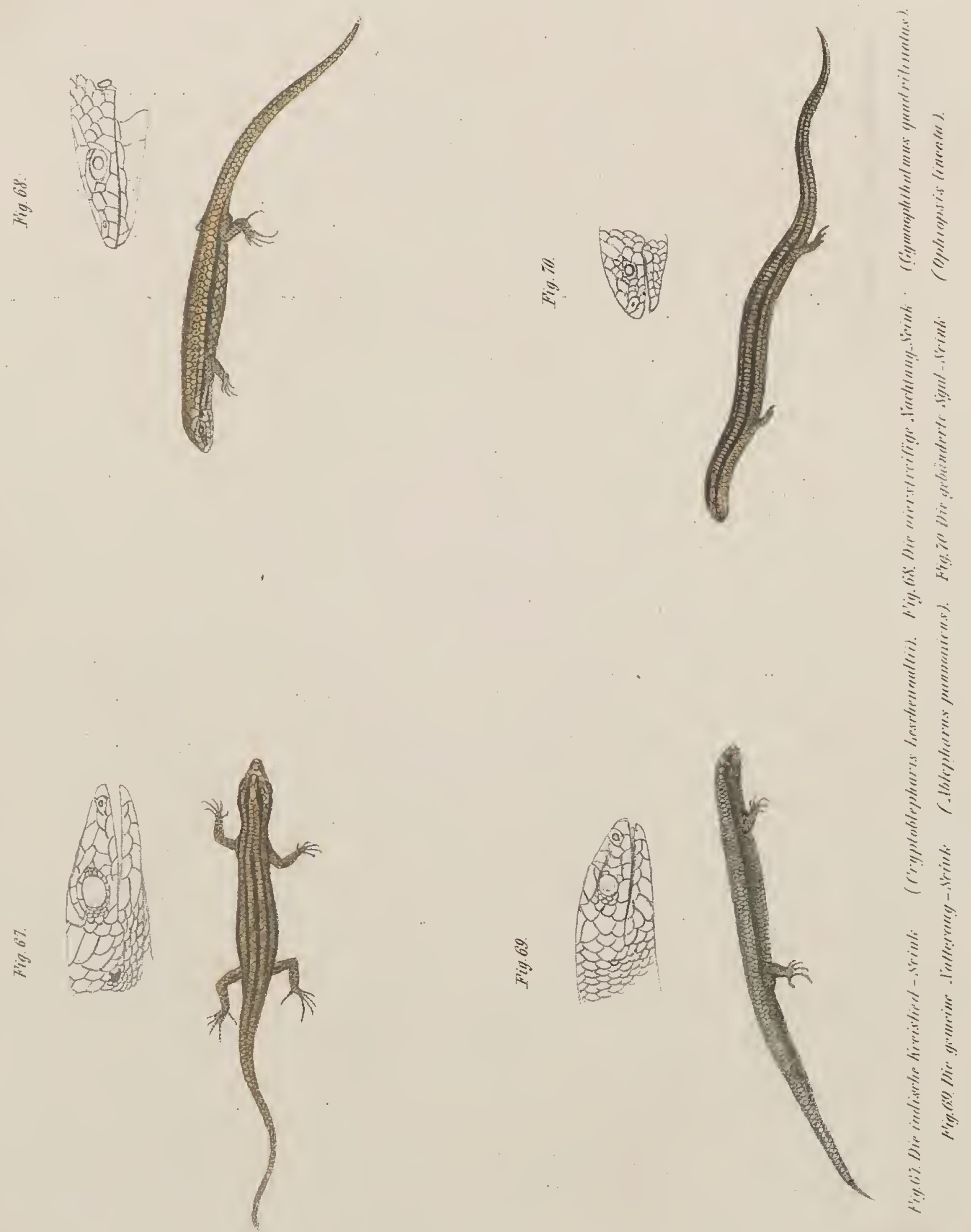


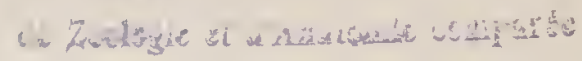


Fig. 49

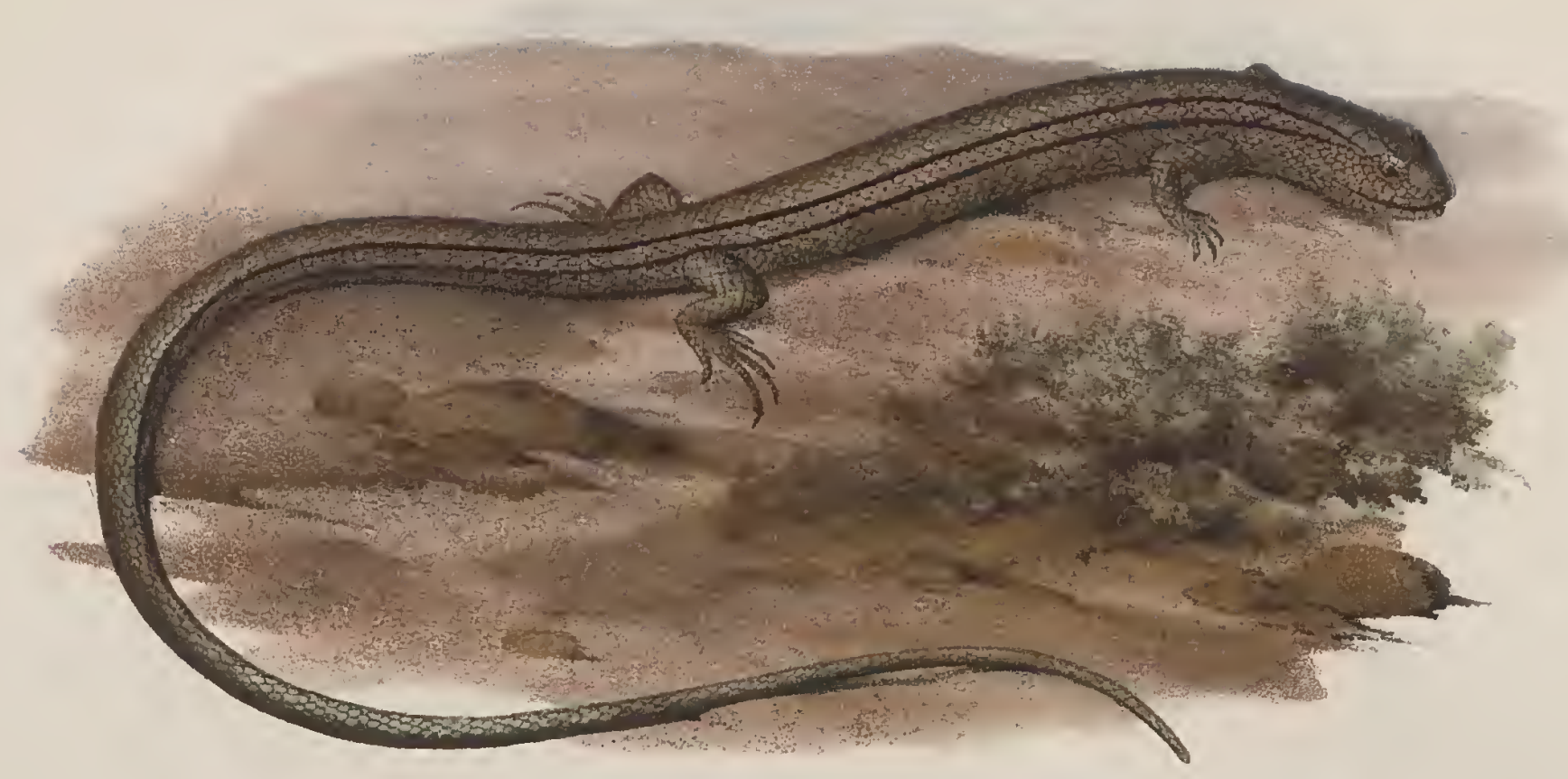

Fig. 50

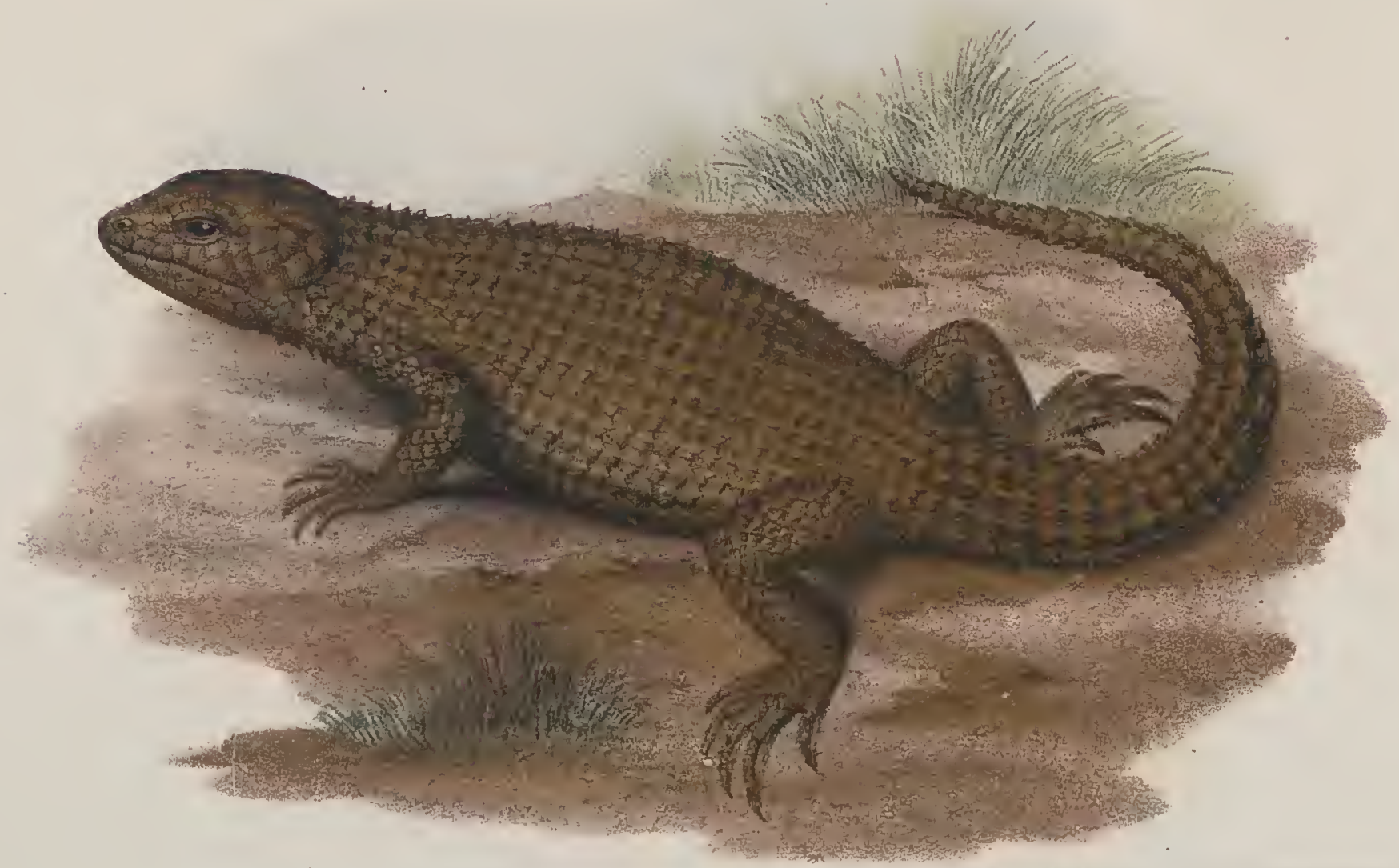

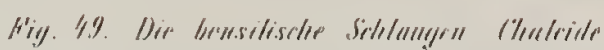

(Chiraralnes imthrirutus 1.

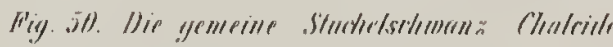

( Hontreres ariseres) 

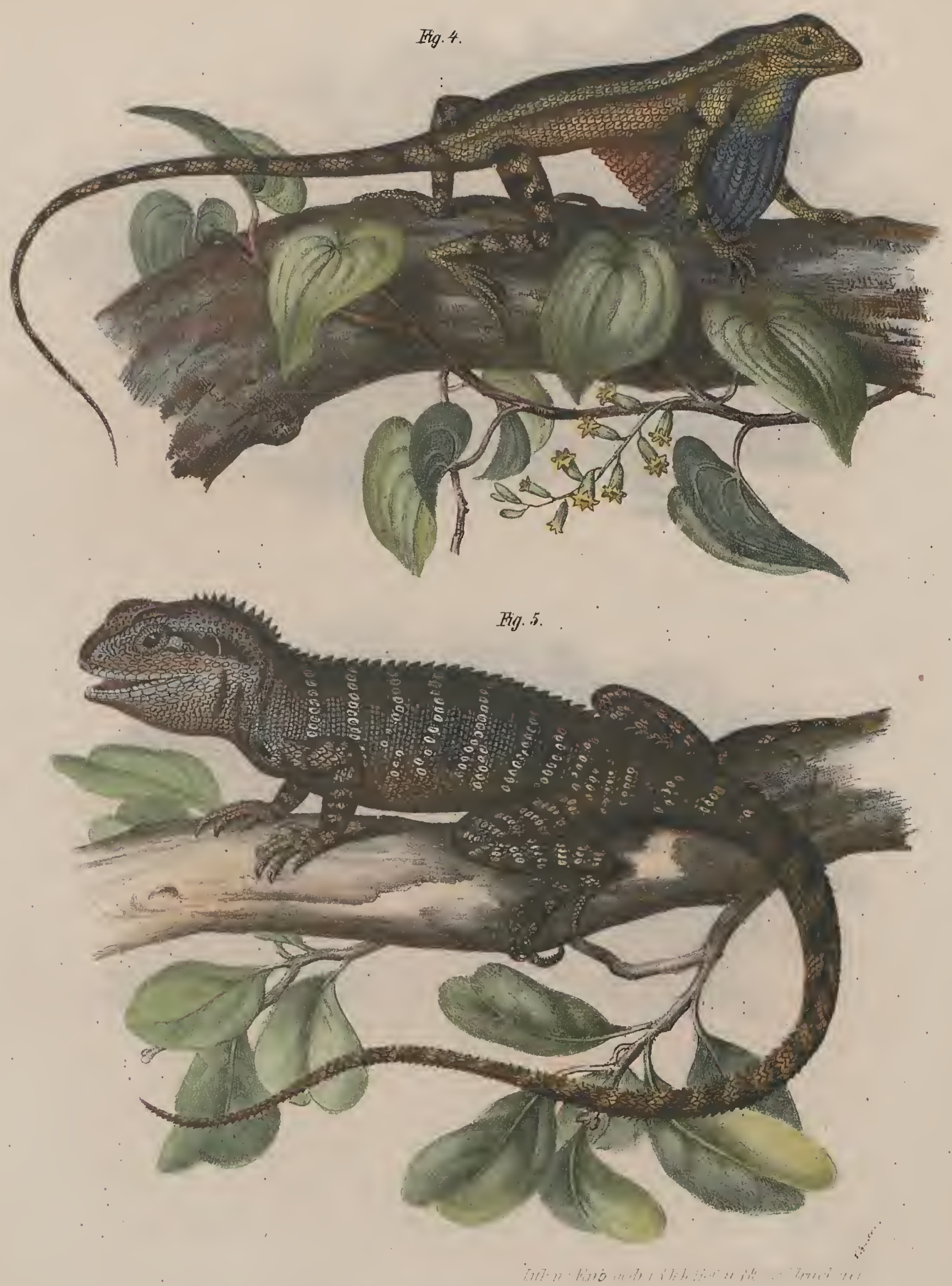

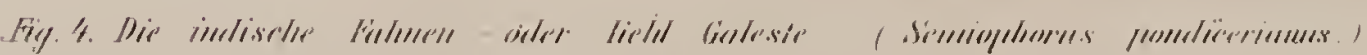

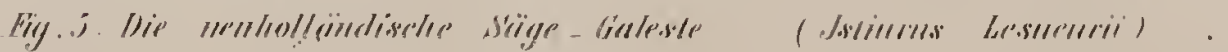




\section{$+$}

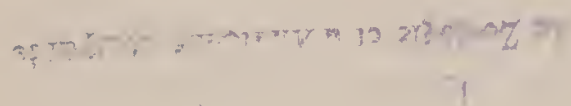

$\therefore+1, \quad 4$ 
Fil. 189
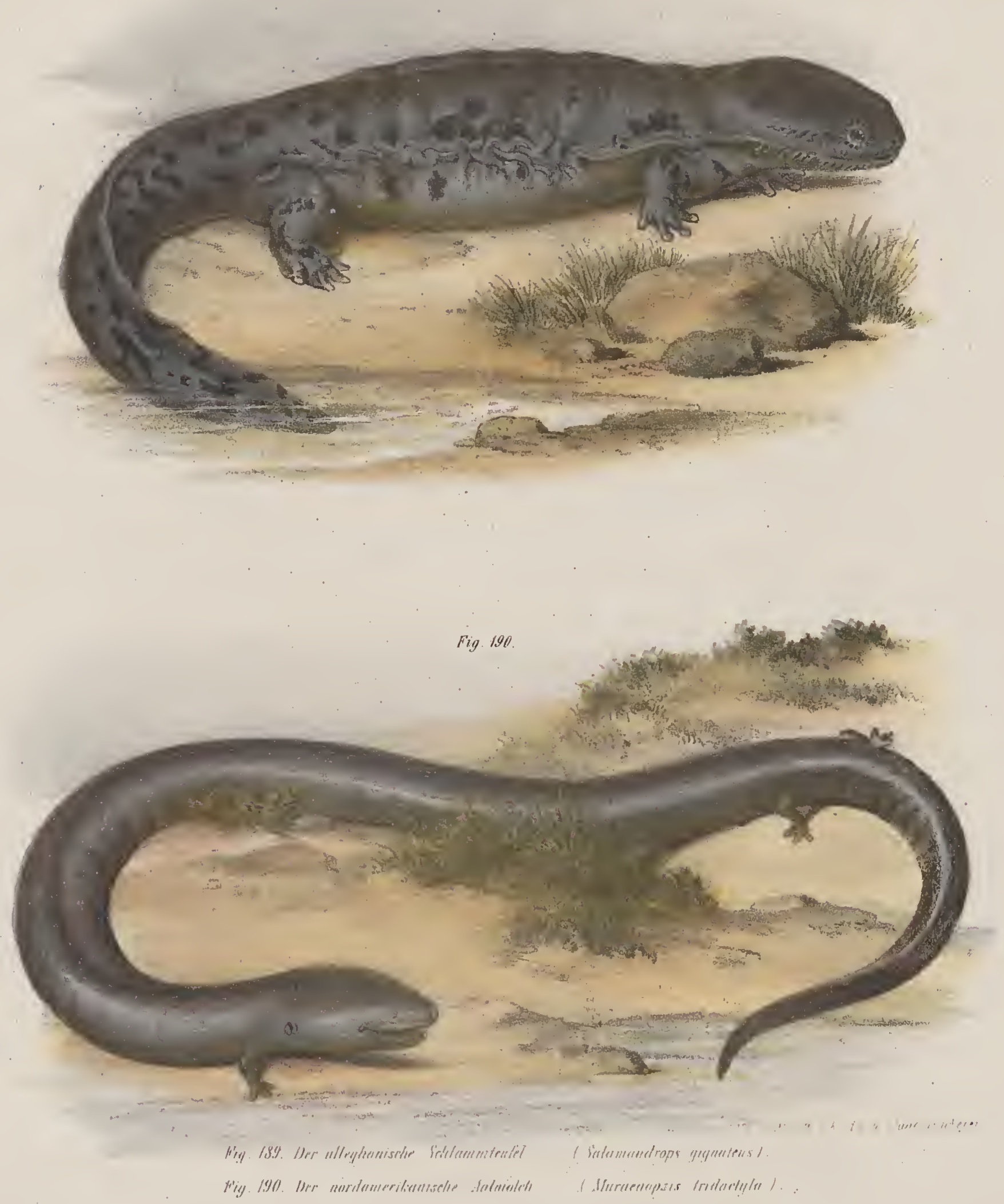


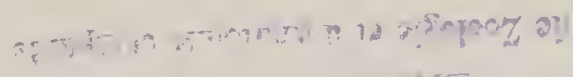

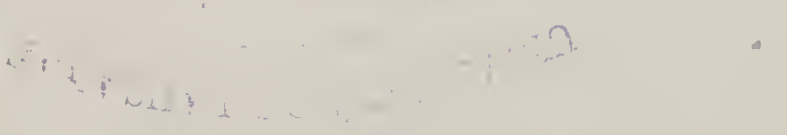



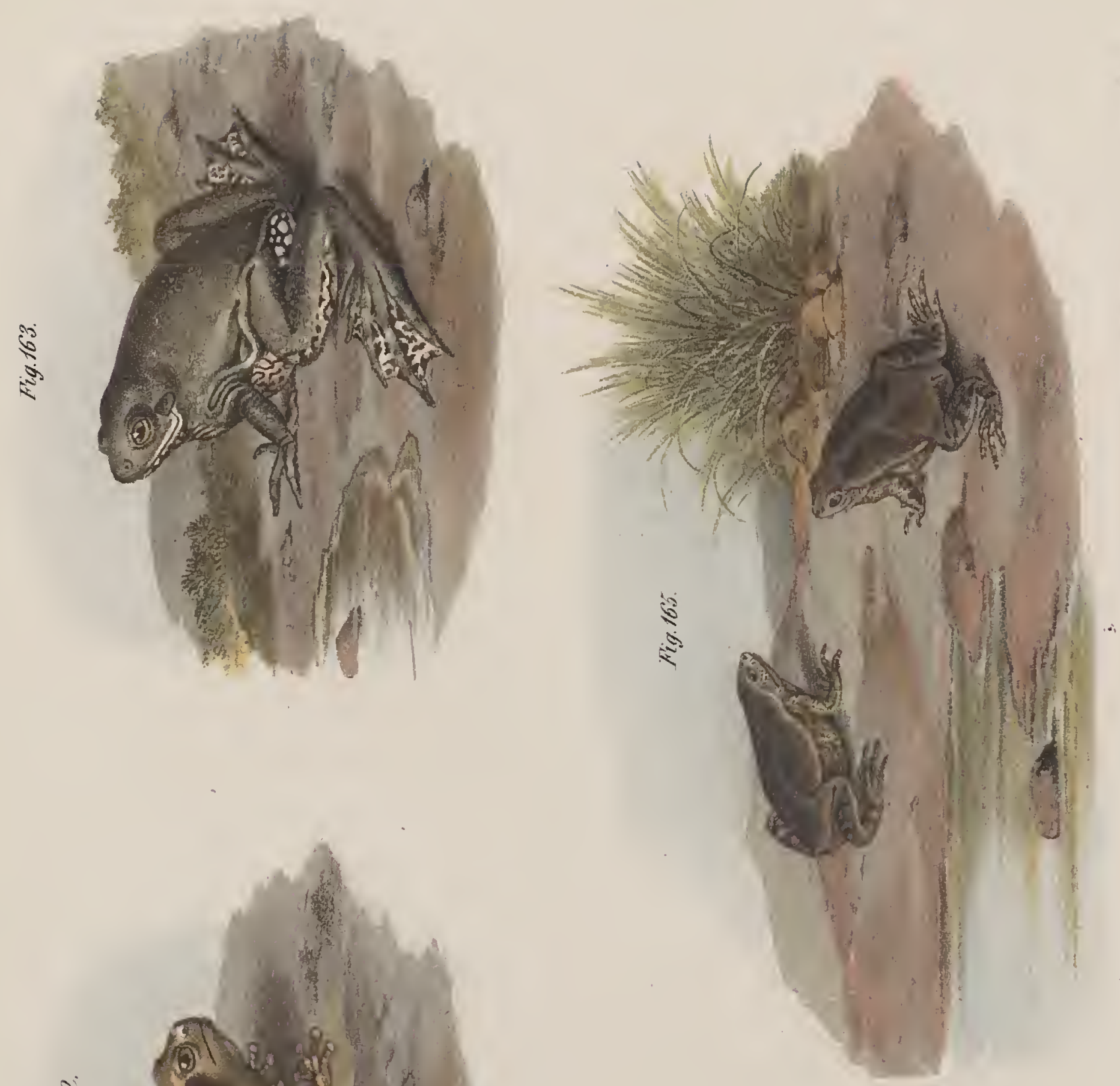

c)

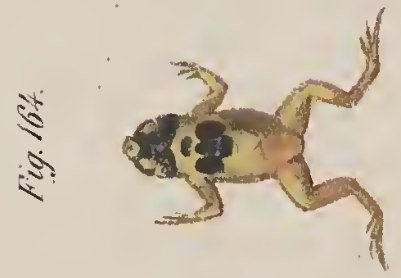




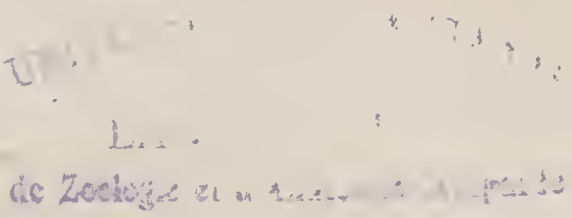




$$
\text { కి }
$$





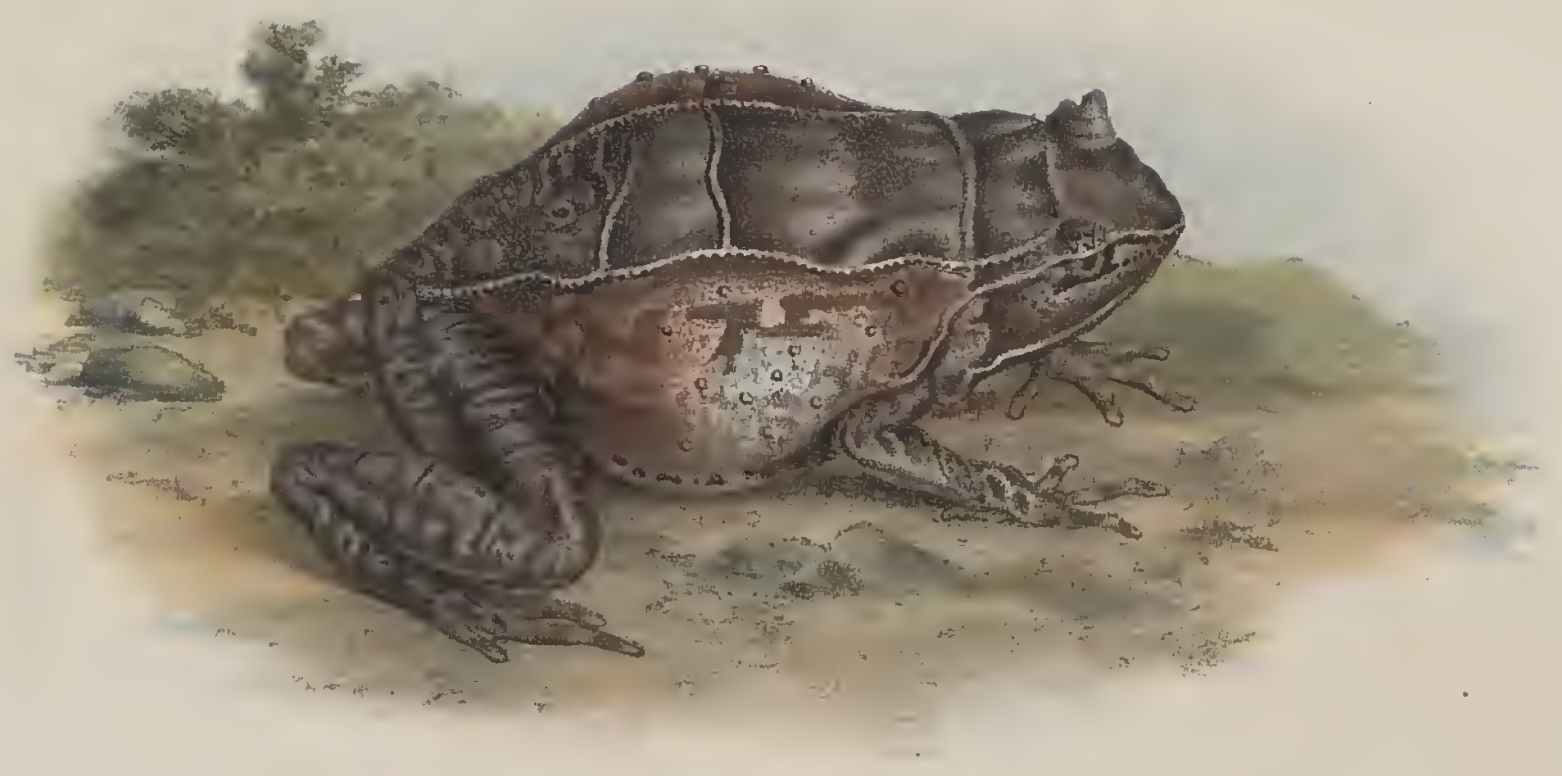

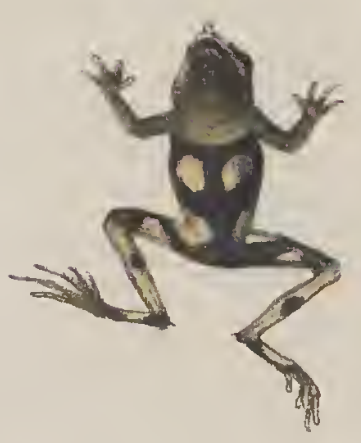

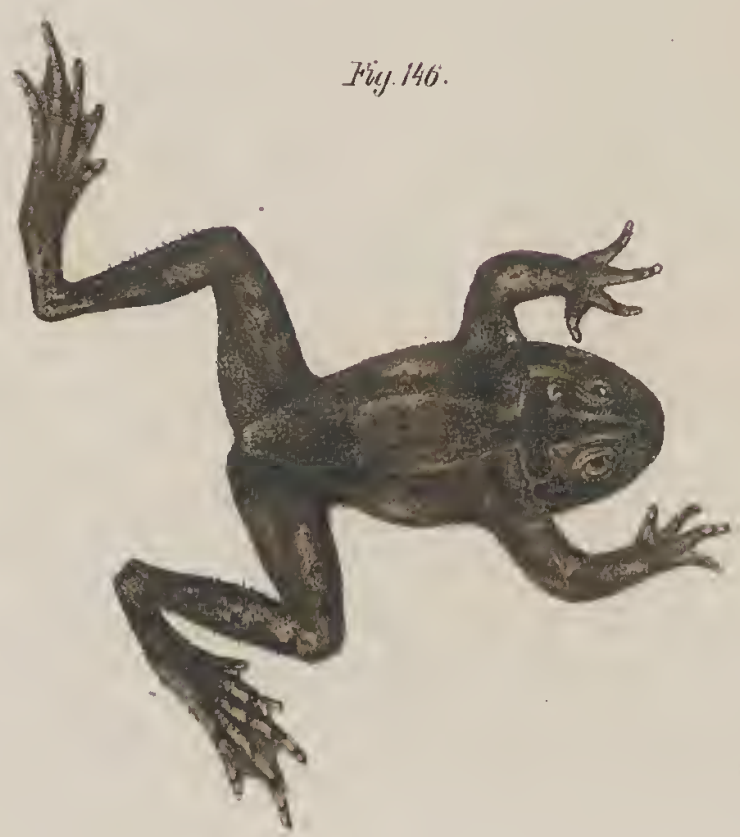

Fig. 145

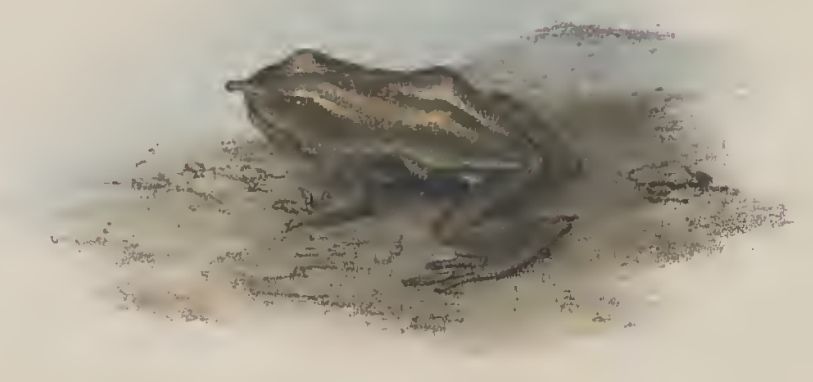

Fig. 14\%.

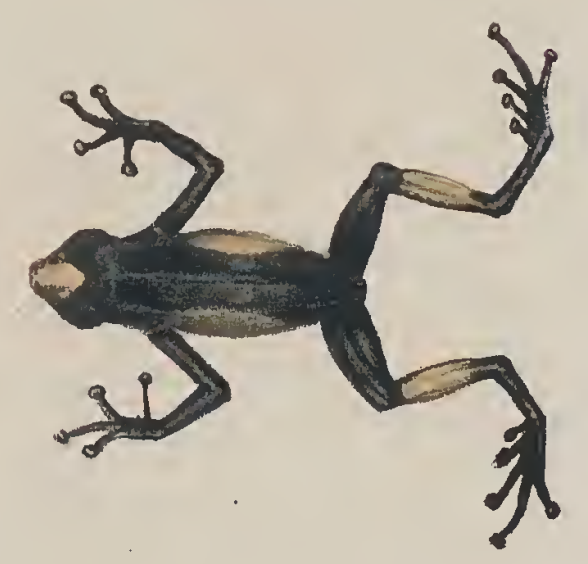

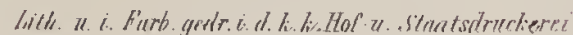

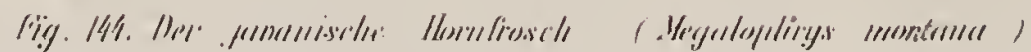

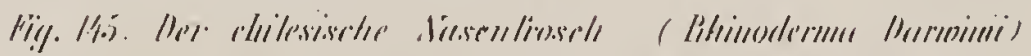

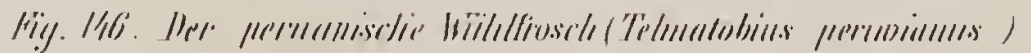

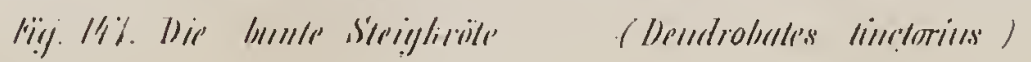




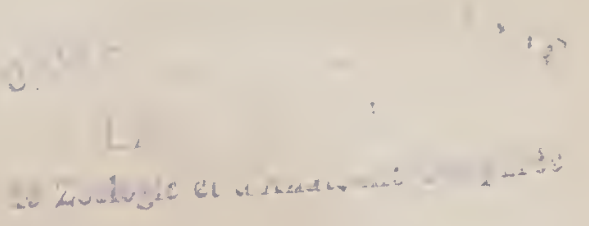




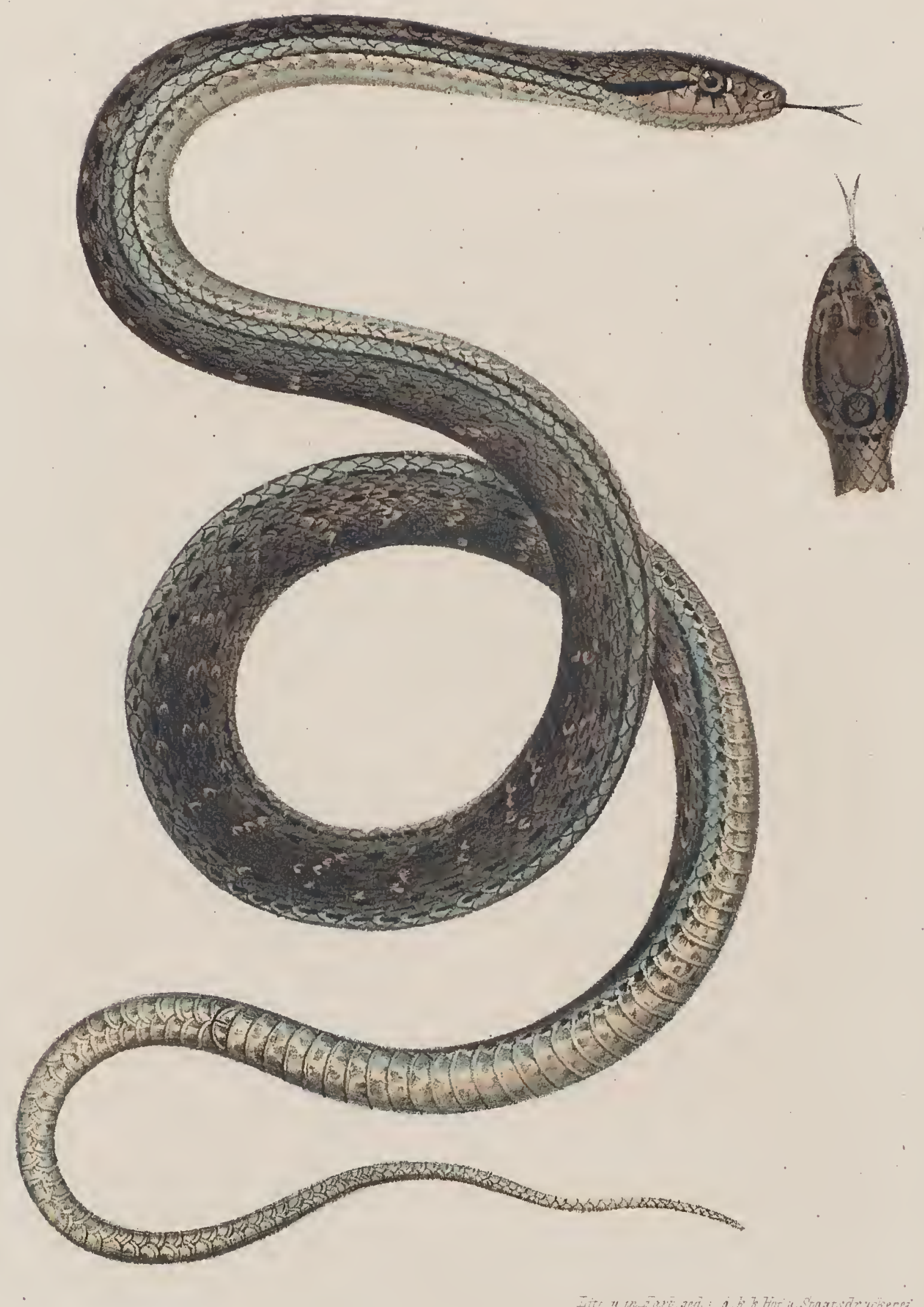

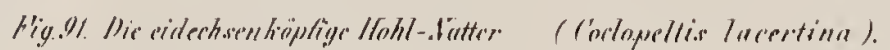




$$
\mathfrak{S}
$$




$$
\text { ¿ }
$$




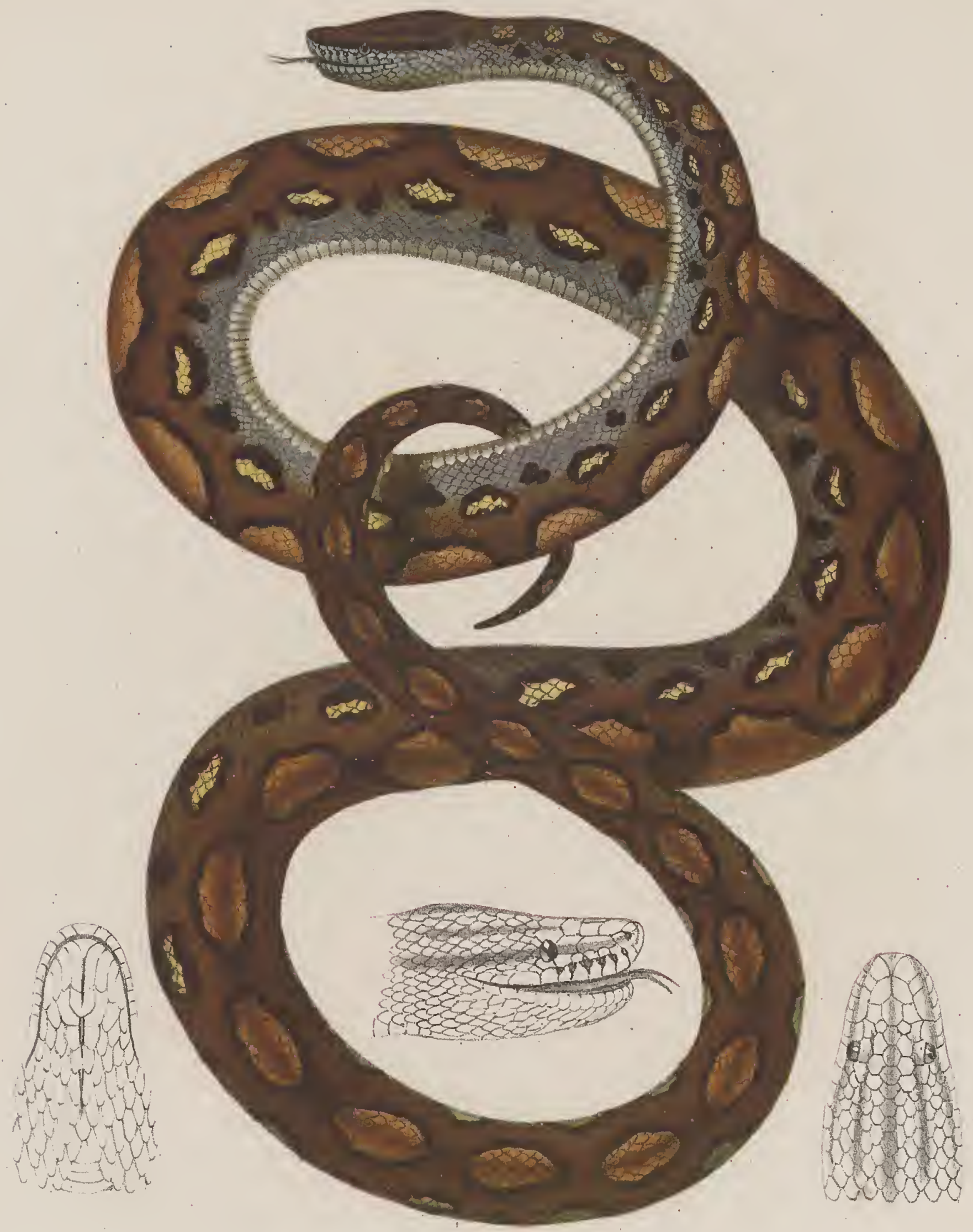

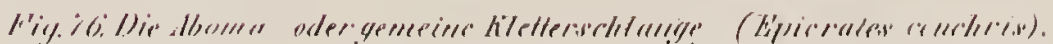


$=1, \cdots+2$

3

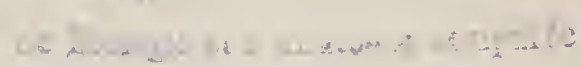

4 


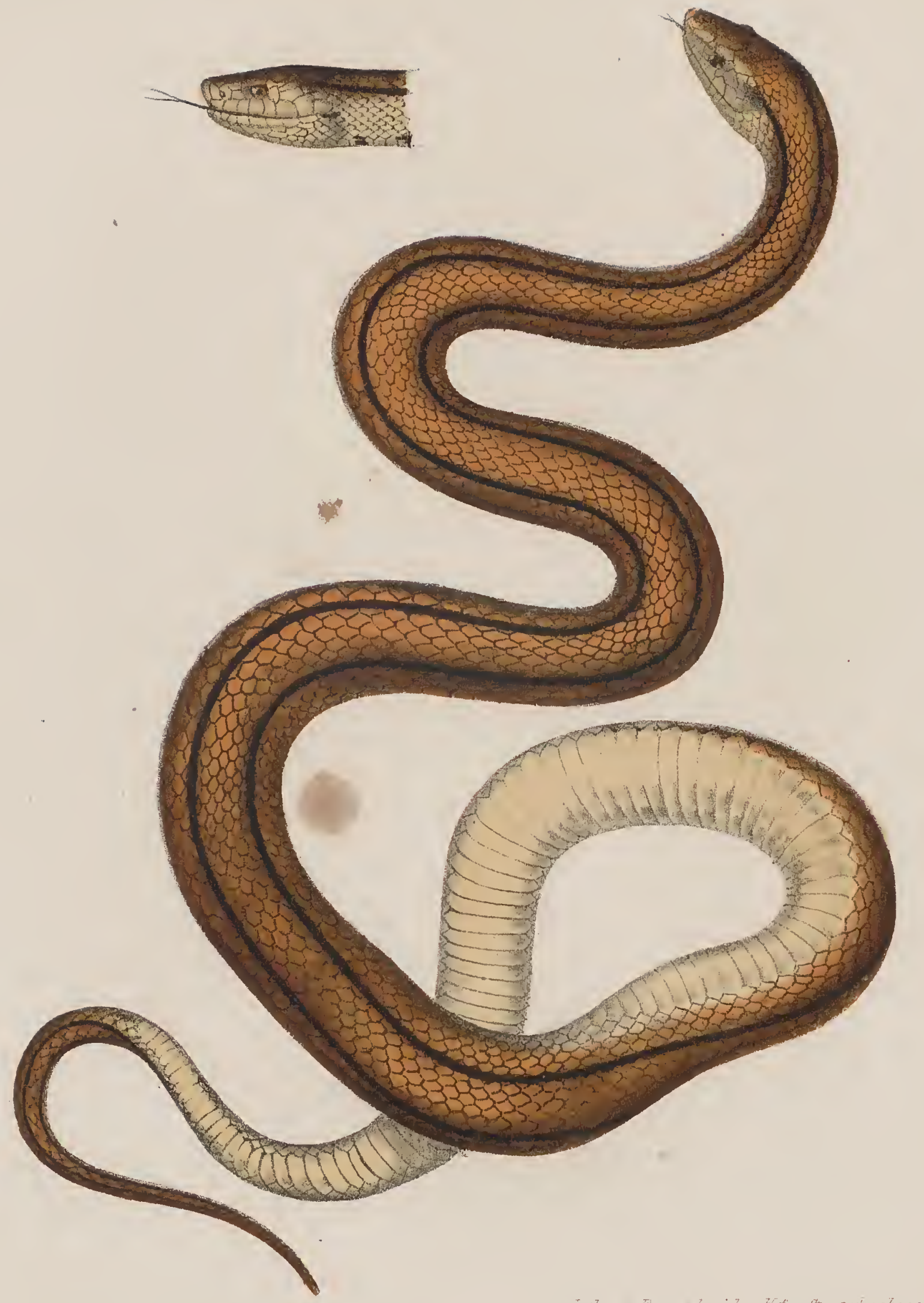

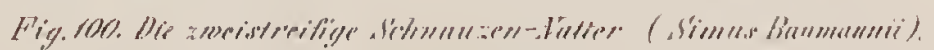





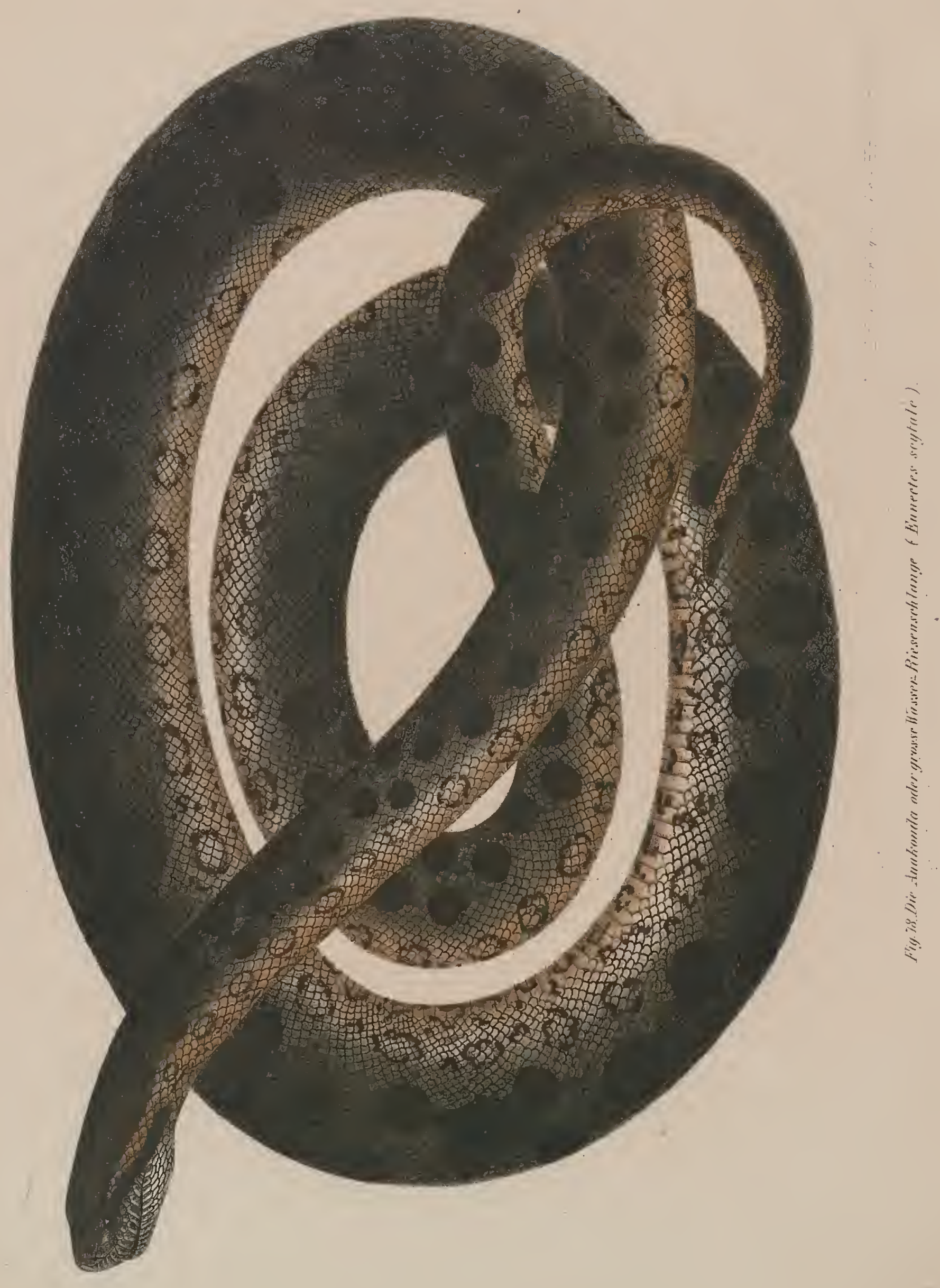





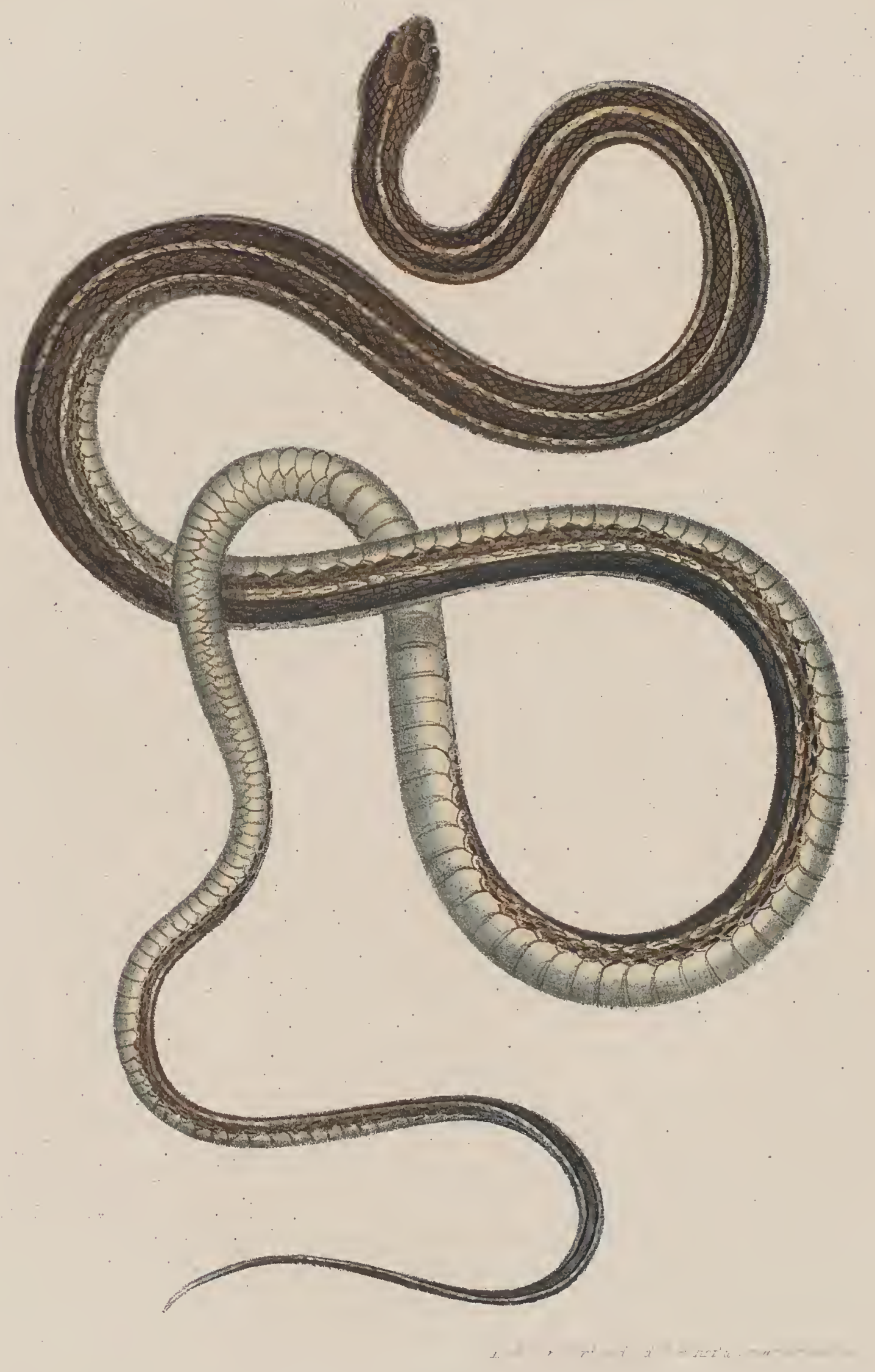

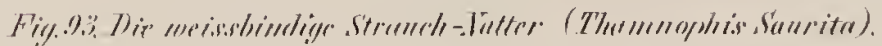



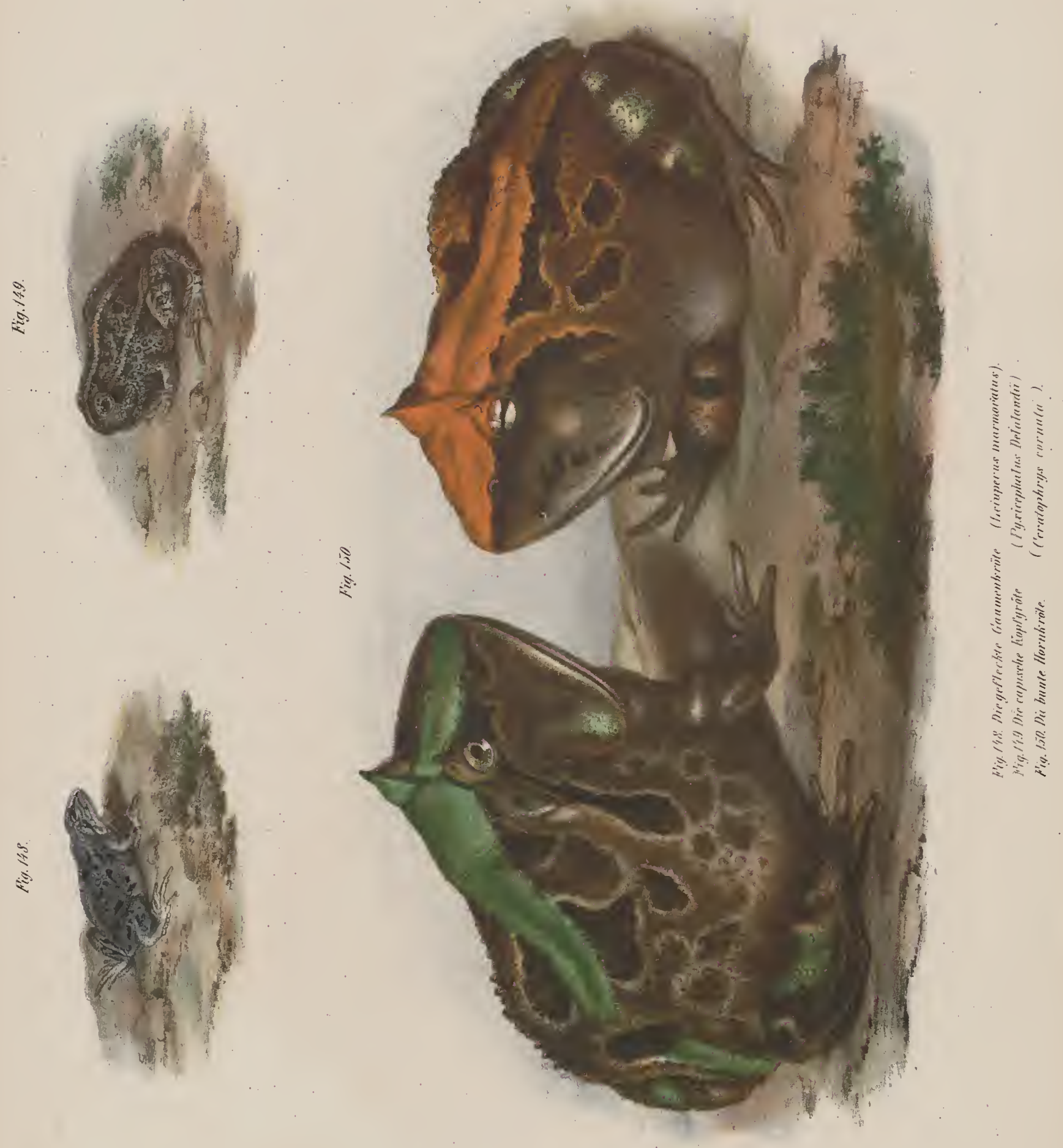

-

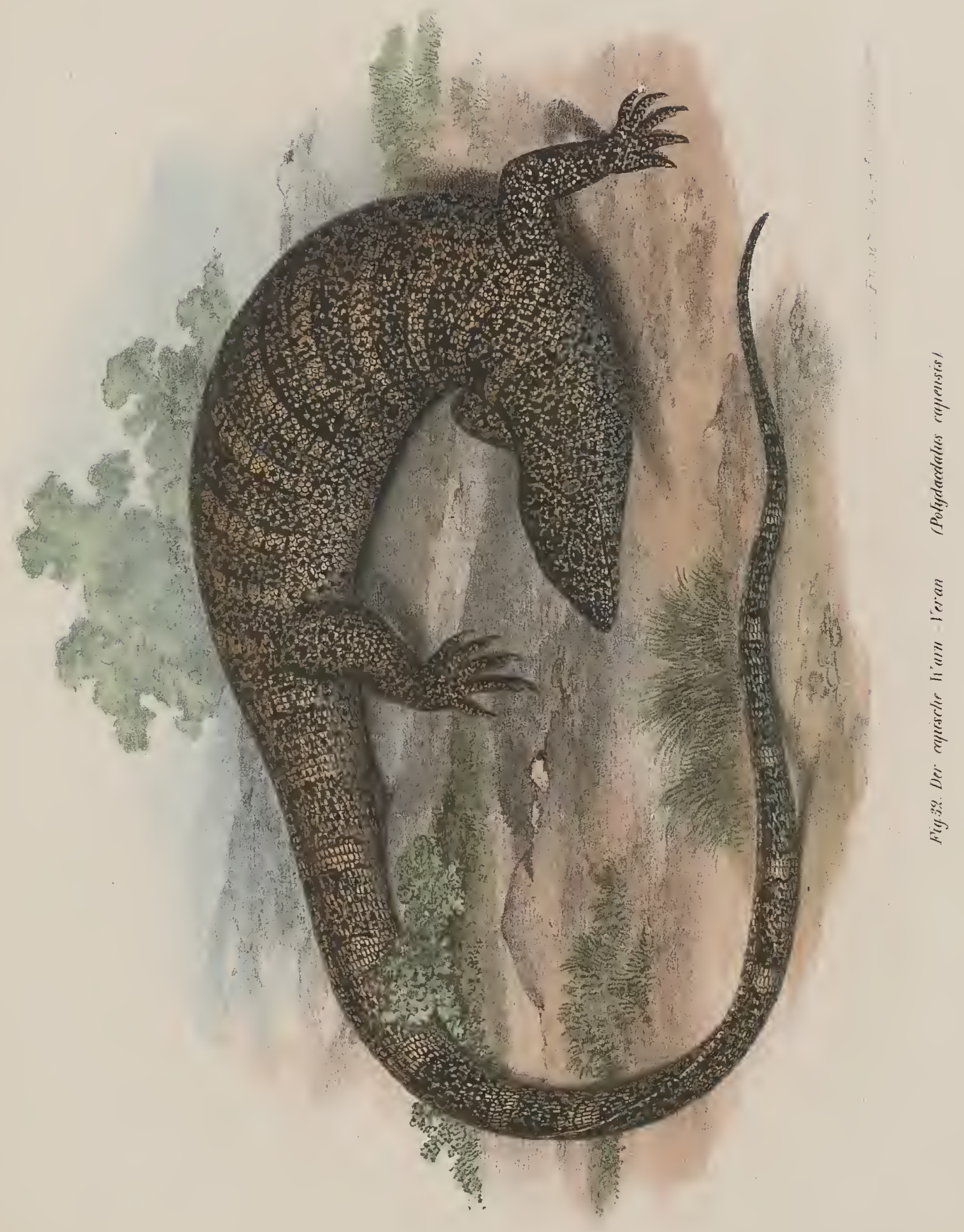




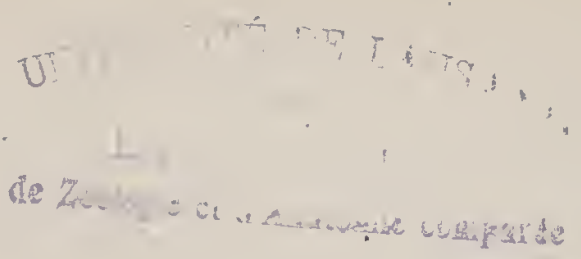



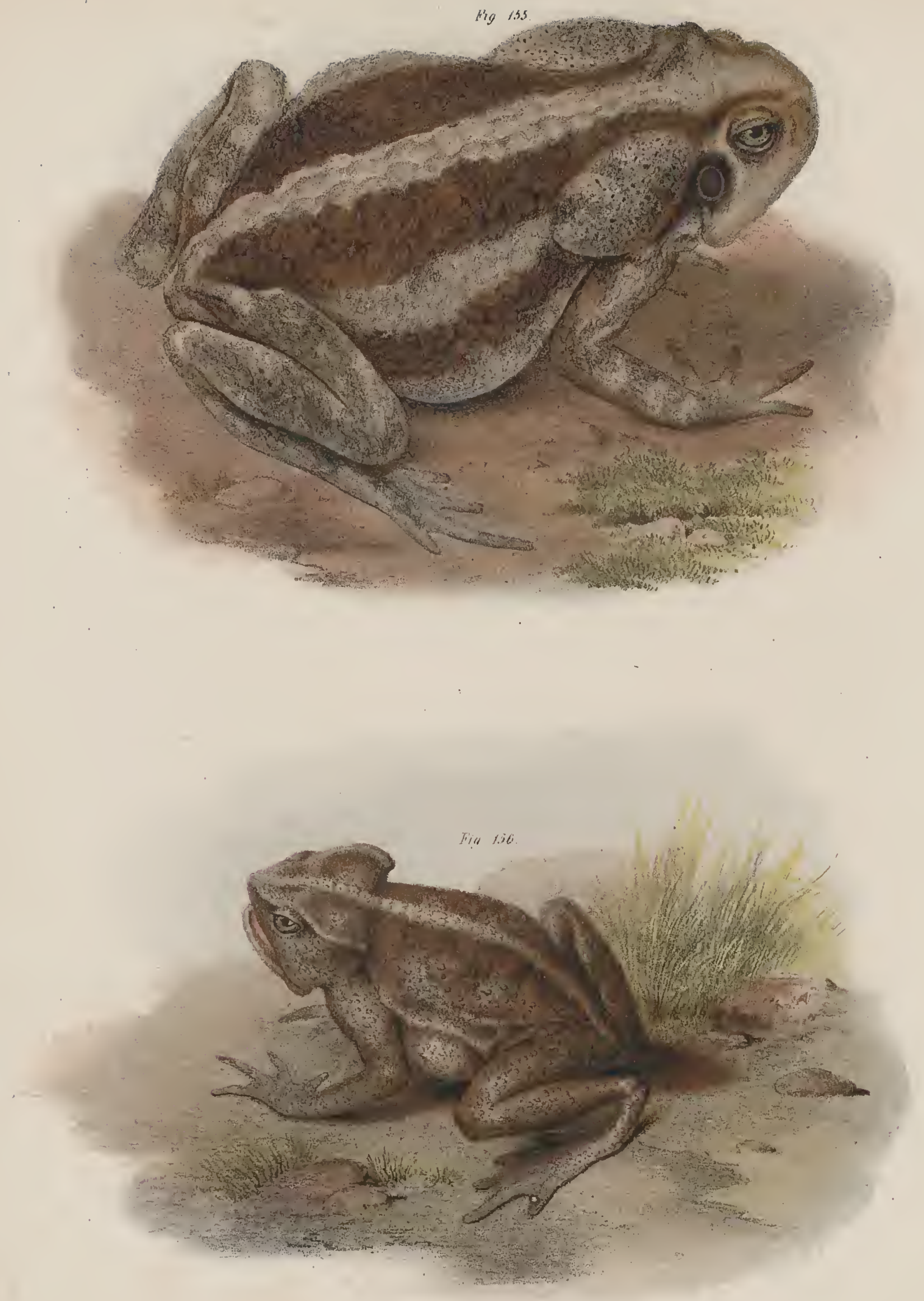

liig. 15.5. Die -lgun odler gemene Leistenkräte

(Docidophryue aguna).

Iig. 156. Die geperlte Olirenkrote

(Otilophus margaritifer) 
spry -

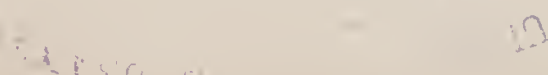

Sll $1: 2$ 

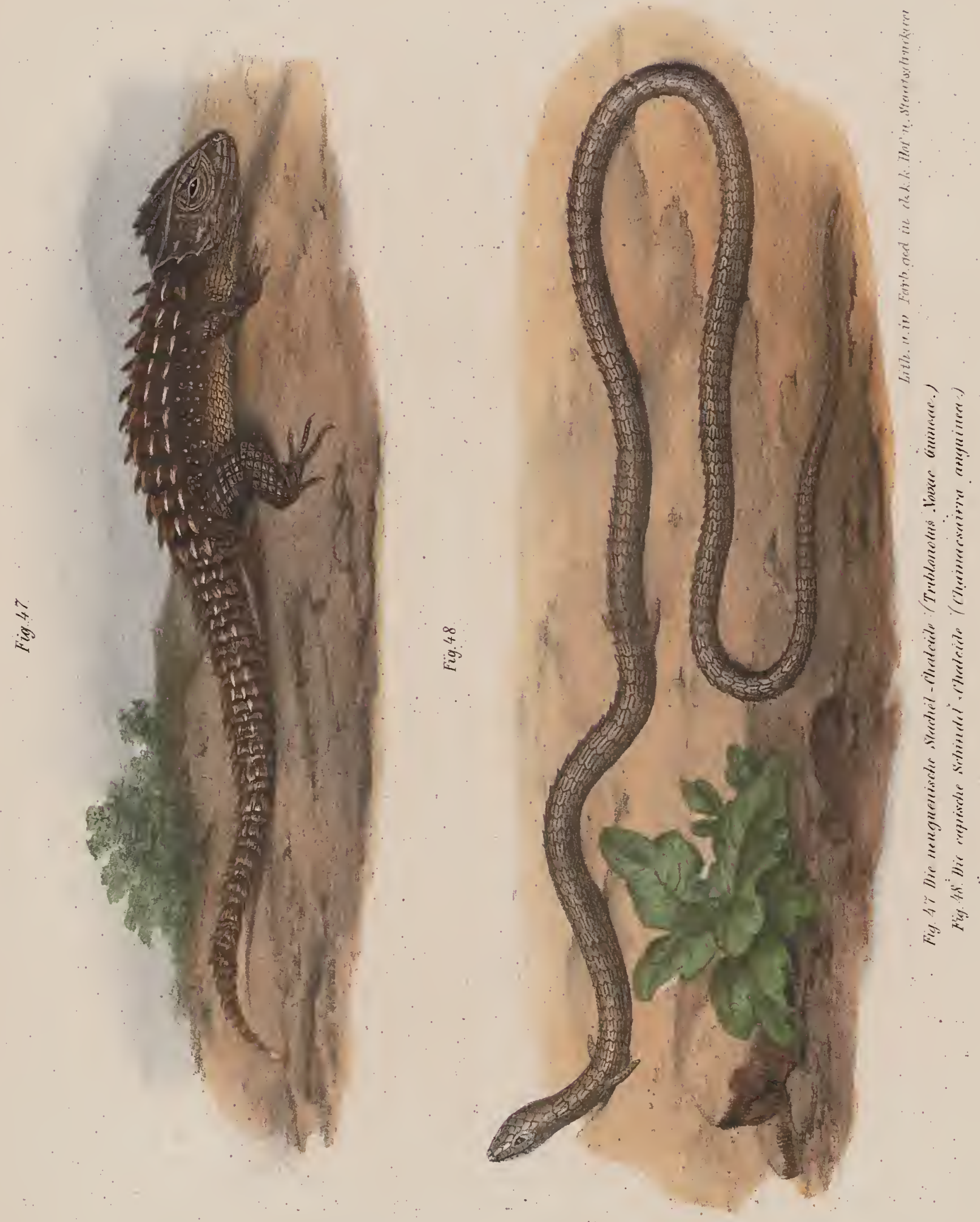



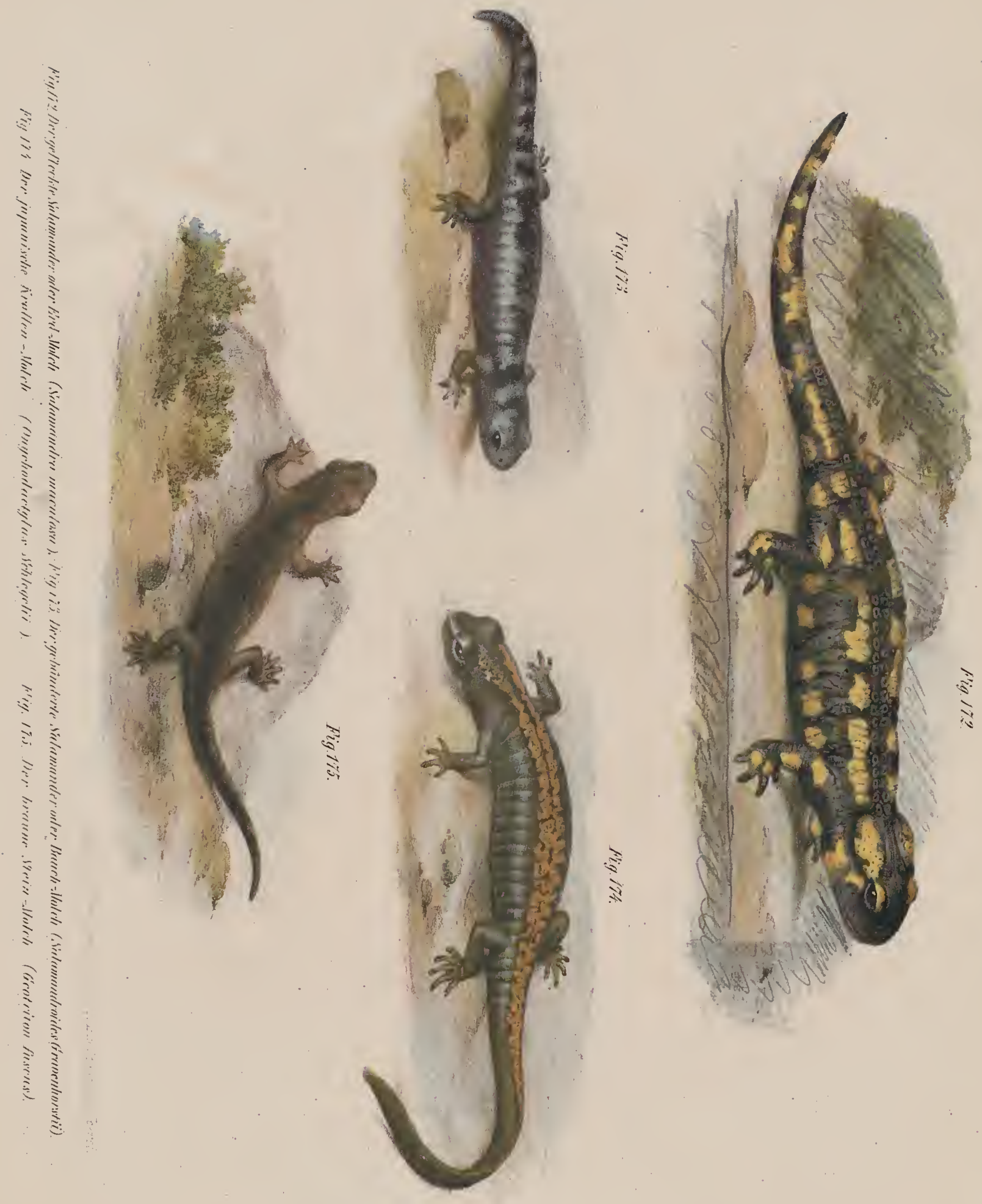





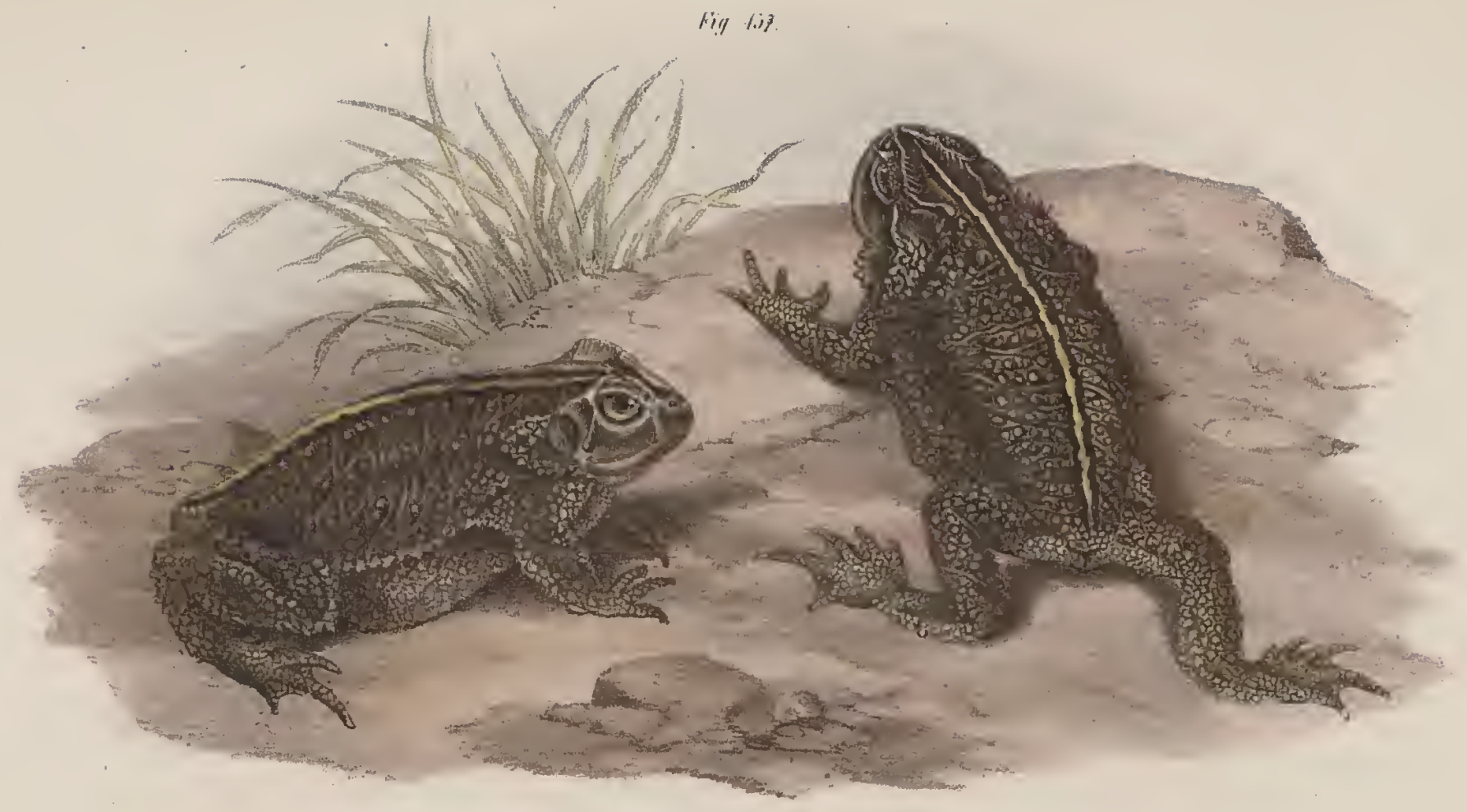

Fig. 15,8

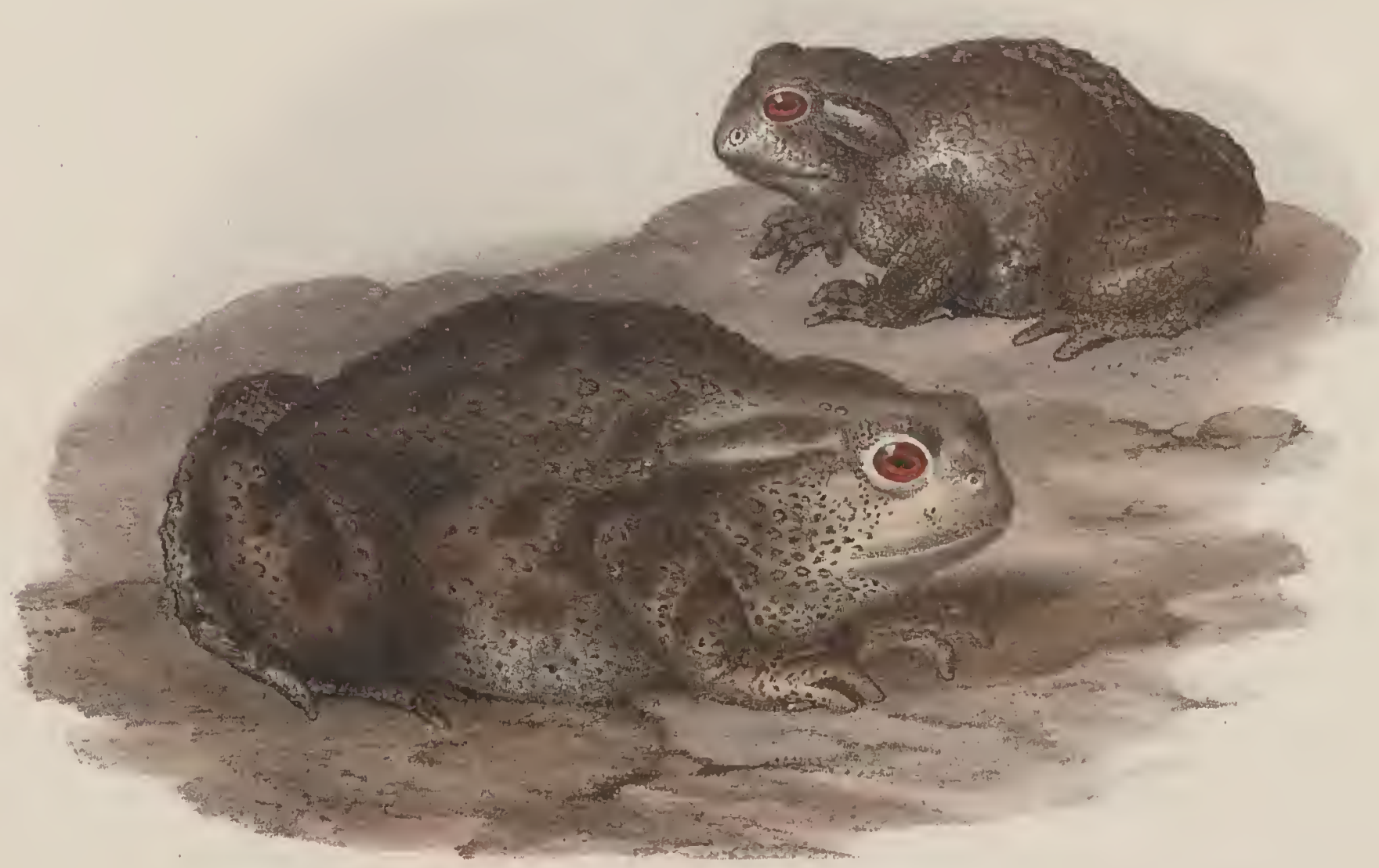

Iithe.

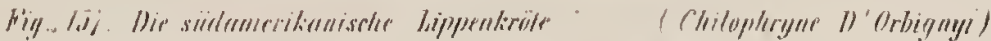

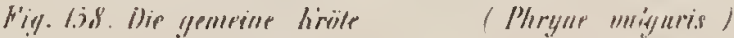




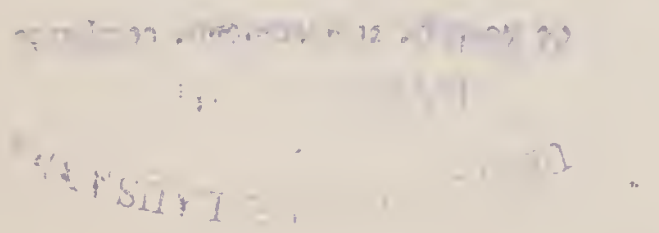




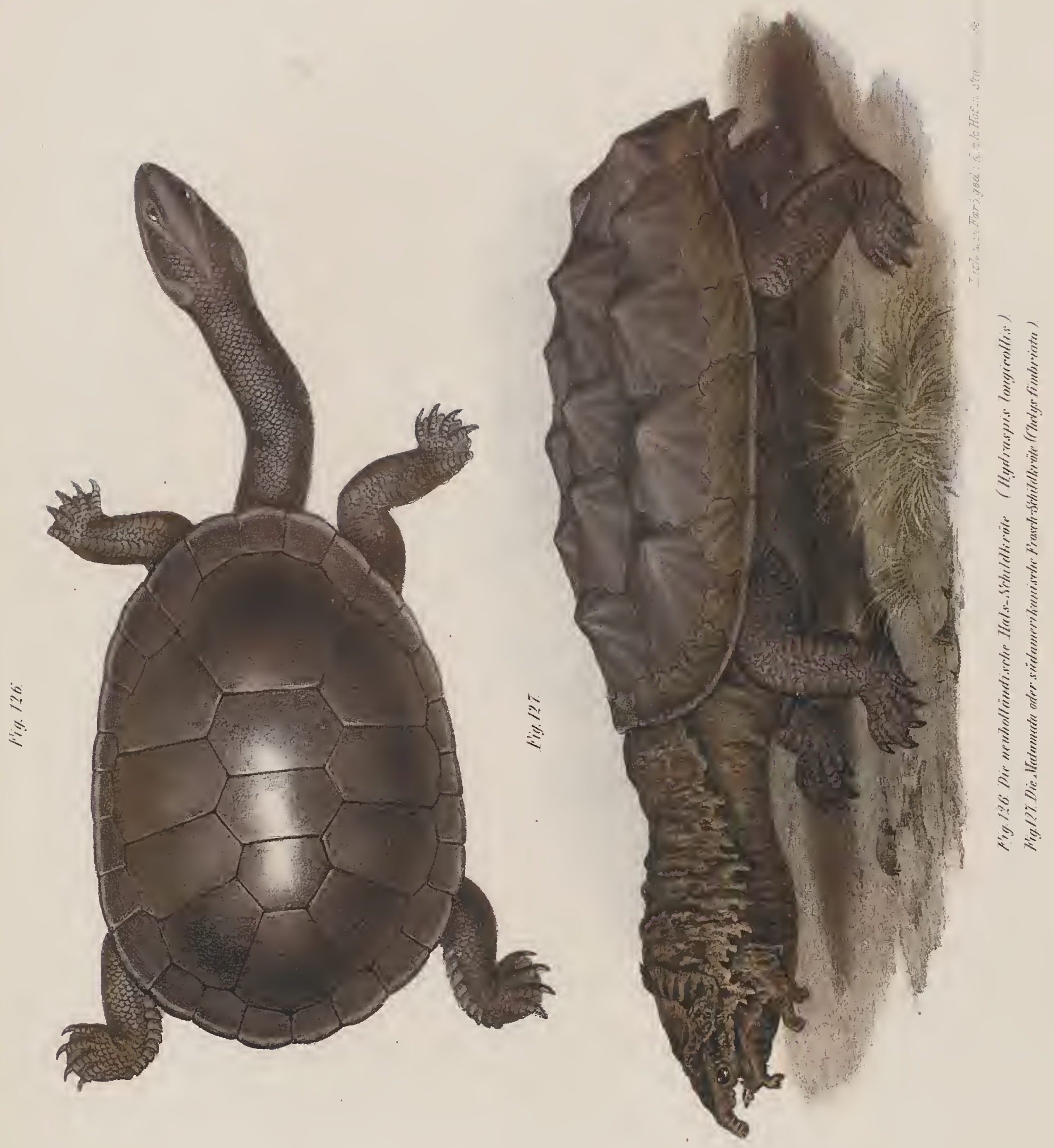




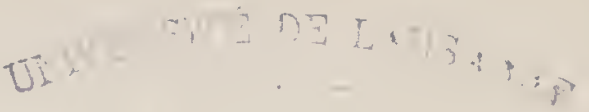

L

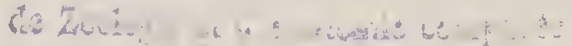



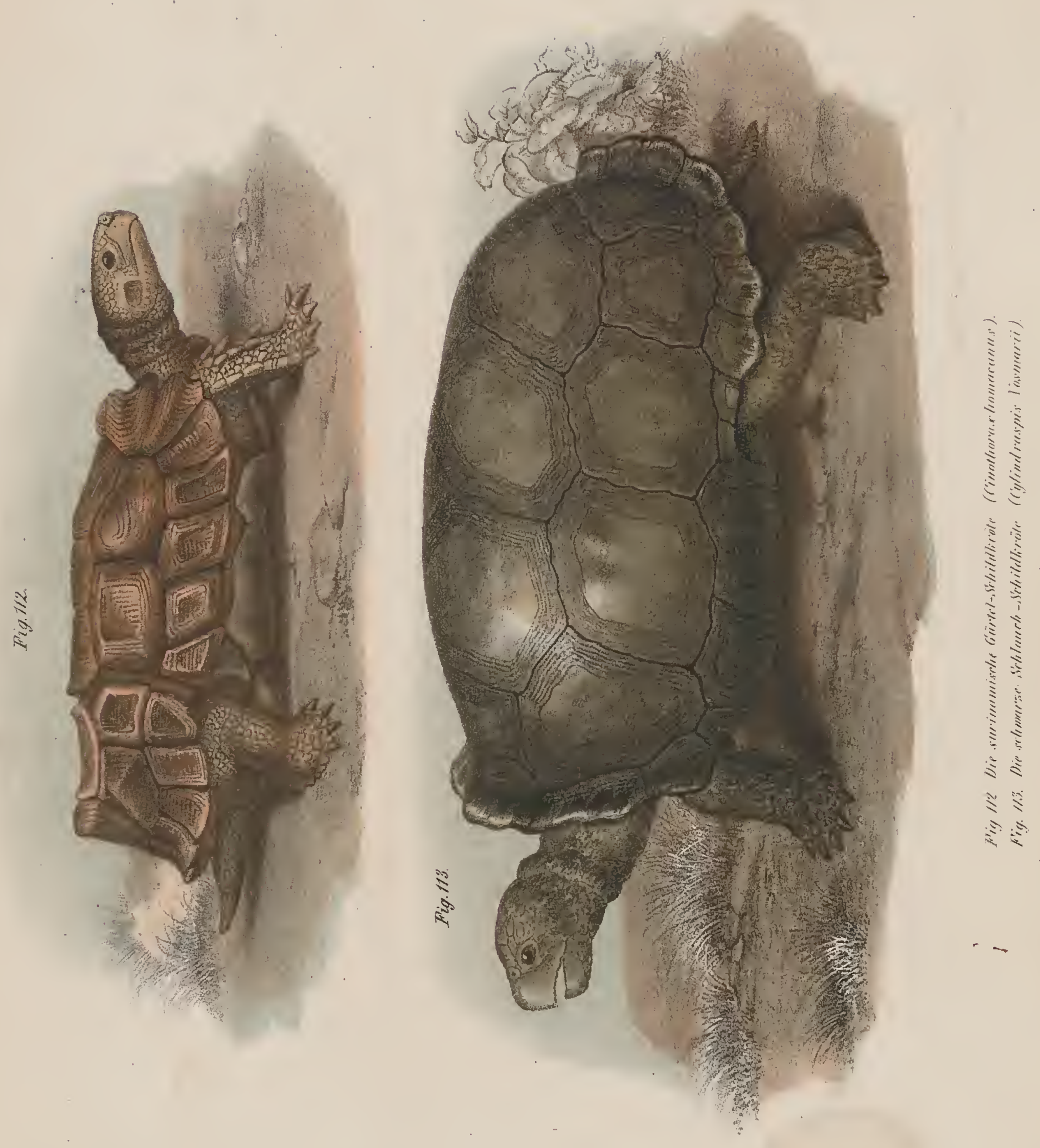


$$
1+11112+4
$$




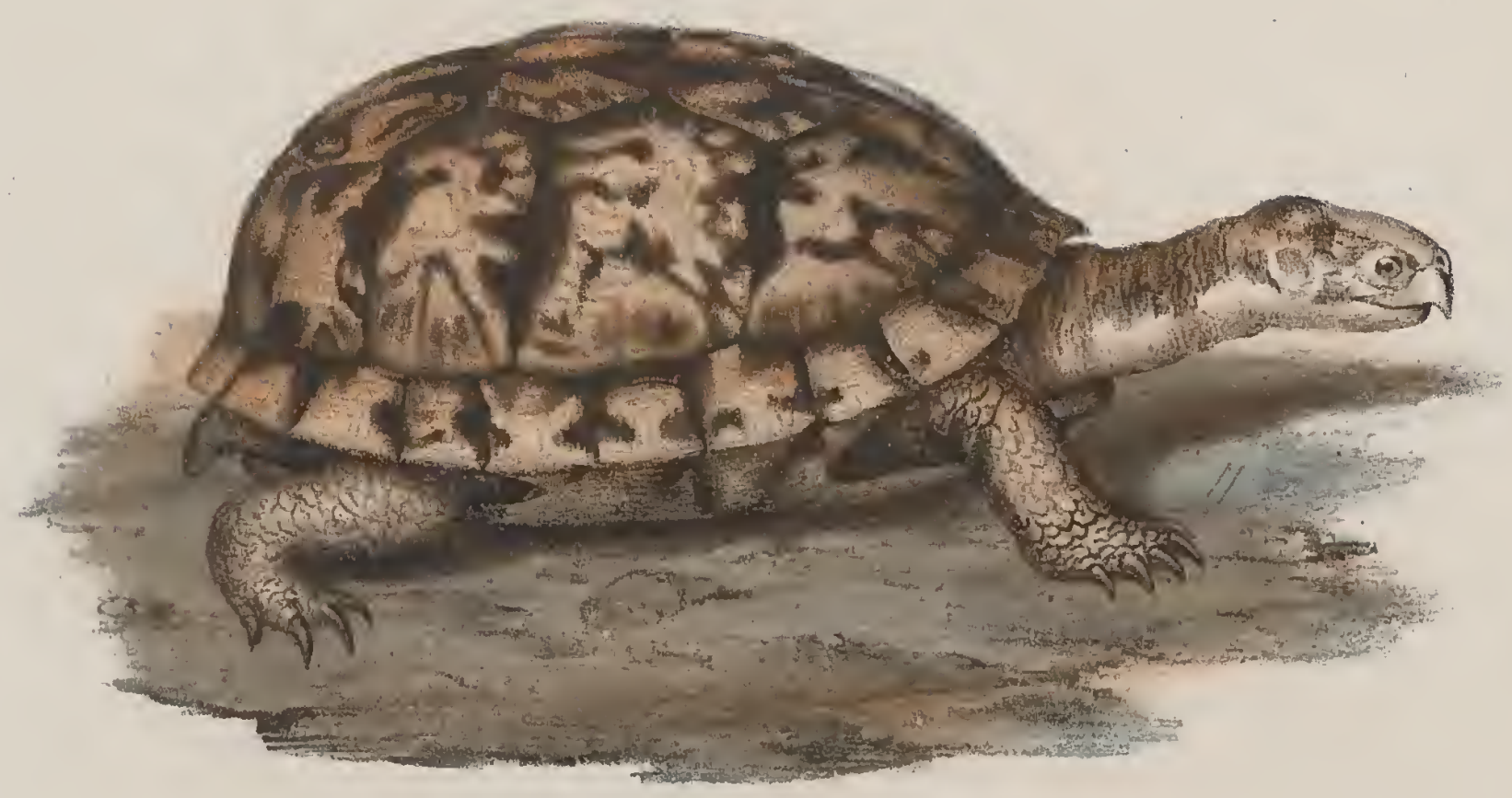

Fig. $1 / 8 . a$
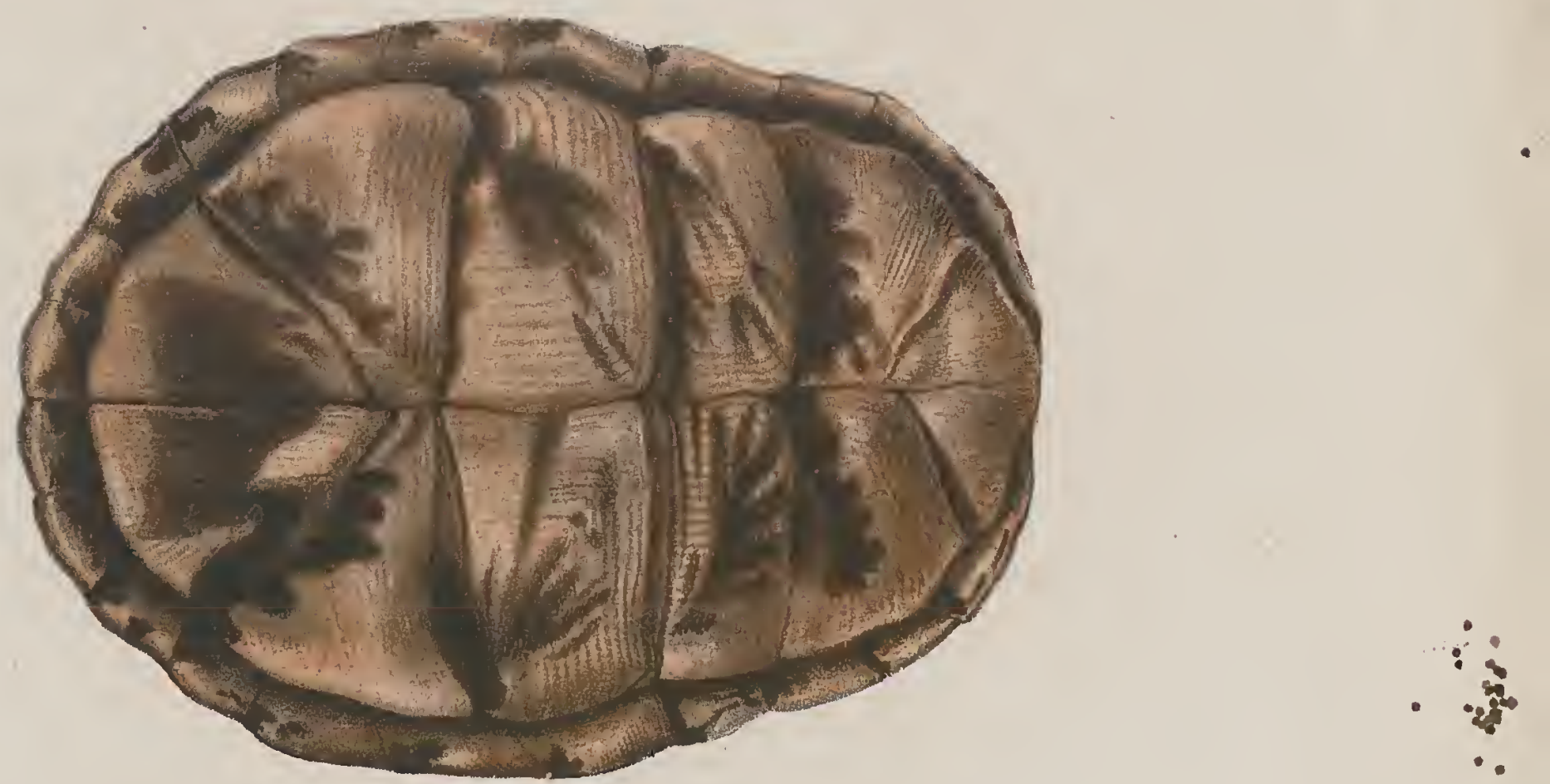

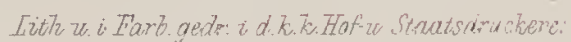




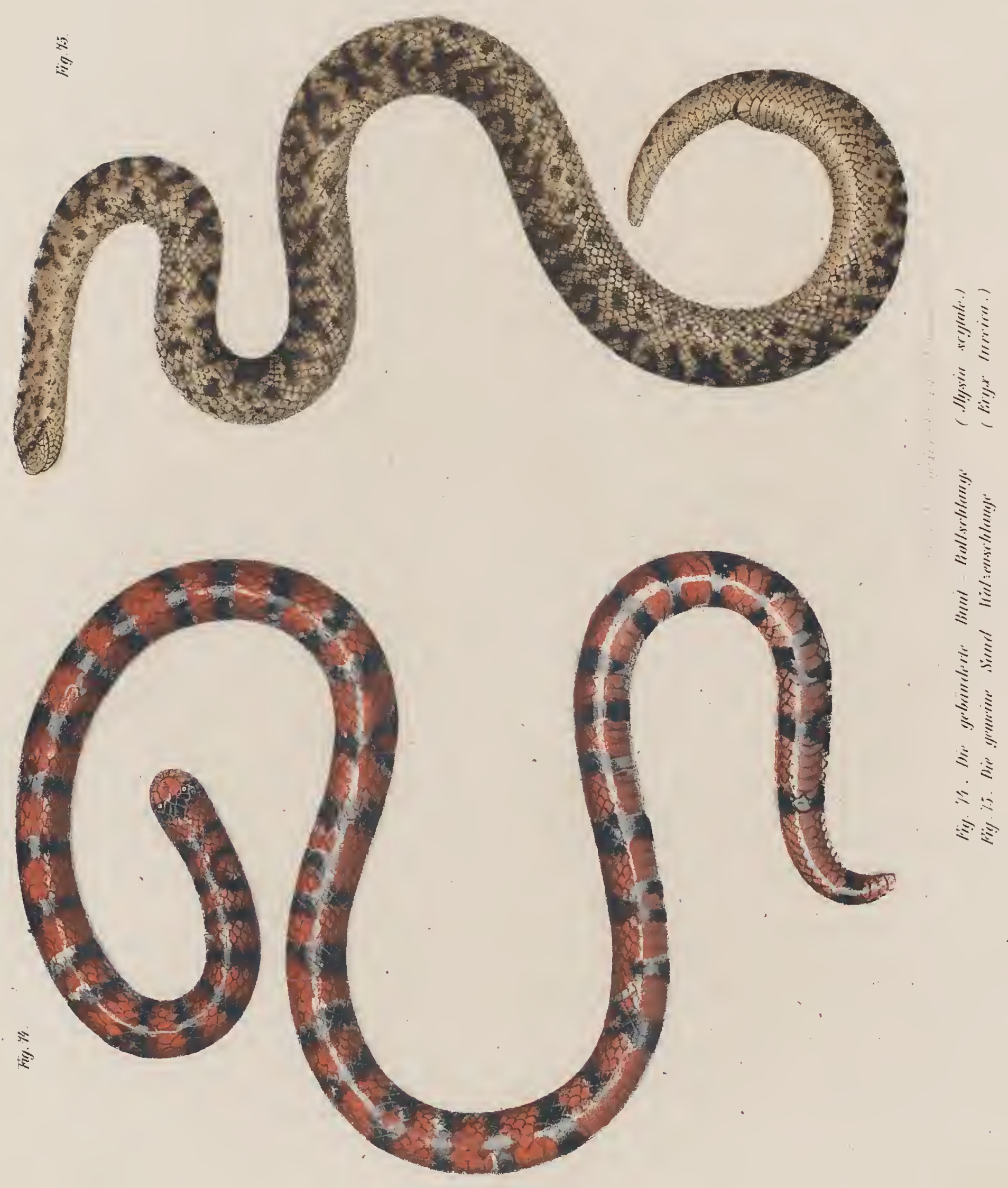




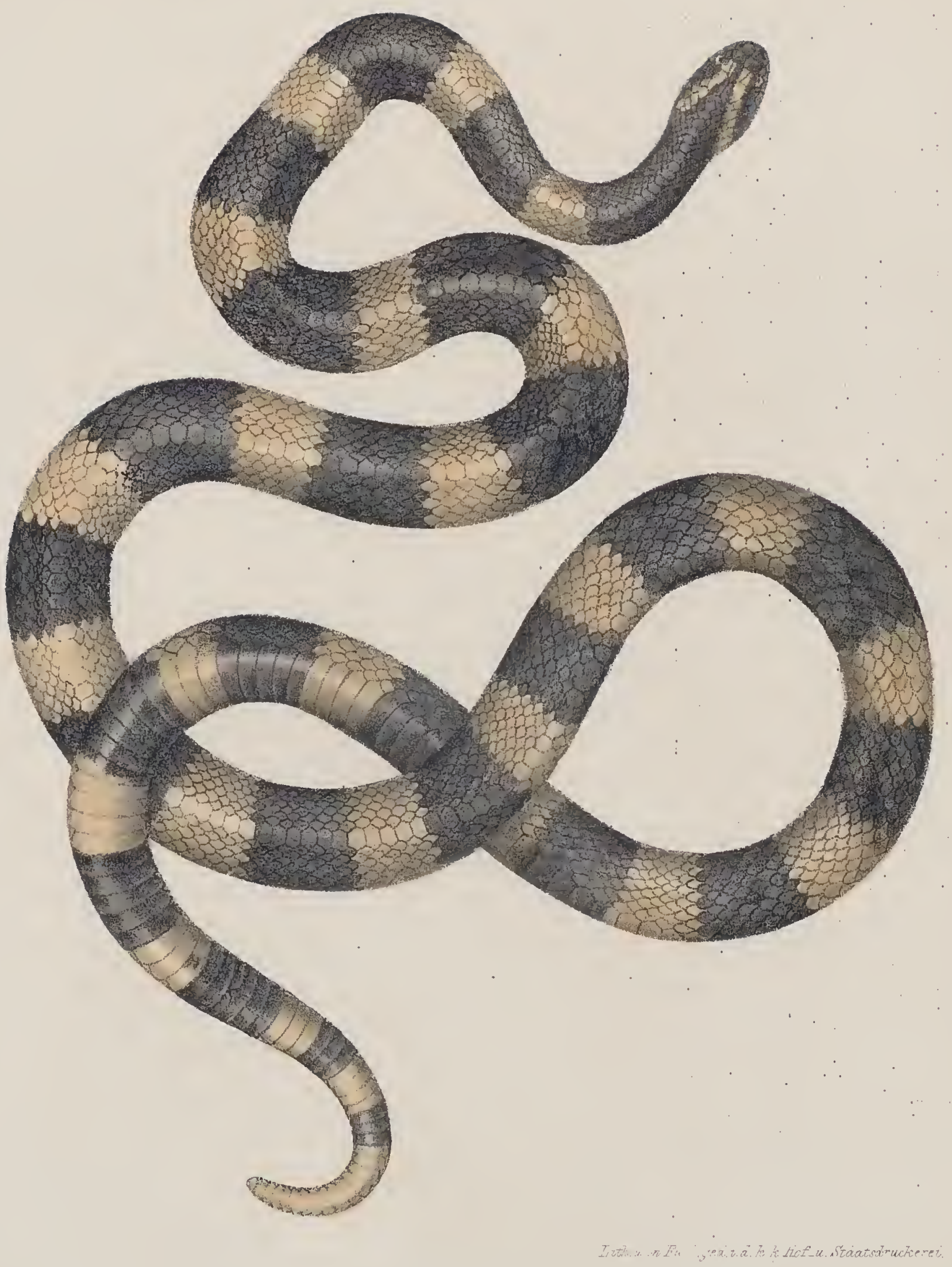

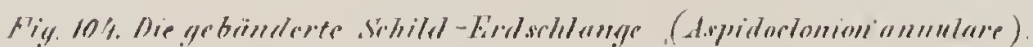





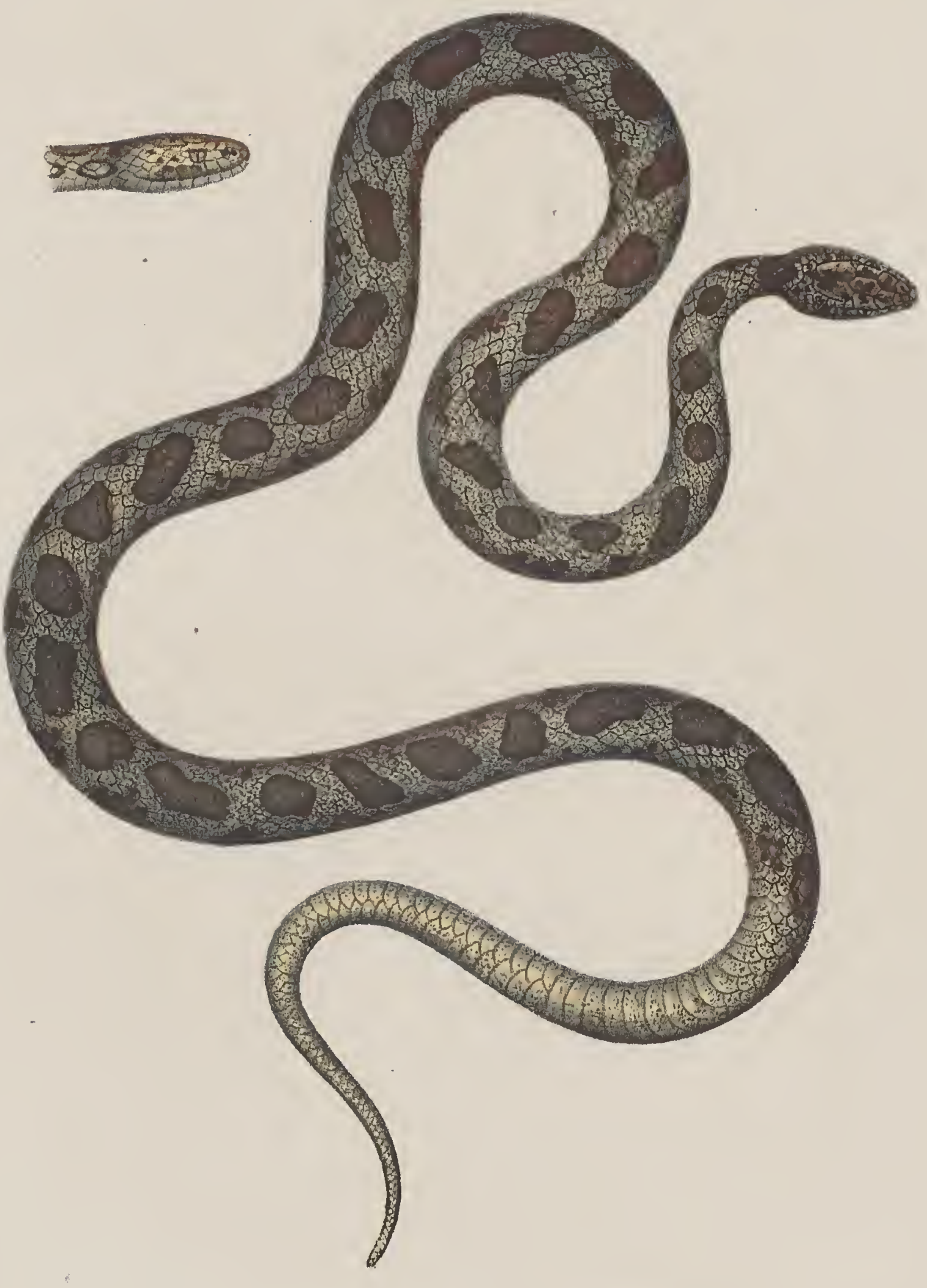

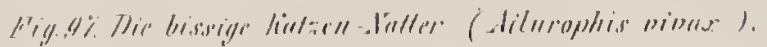




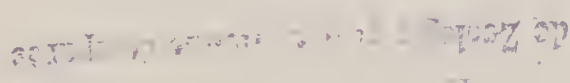

整:-1 

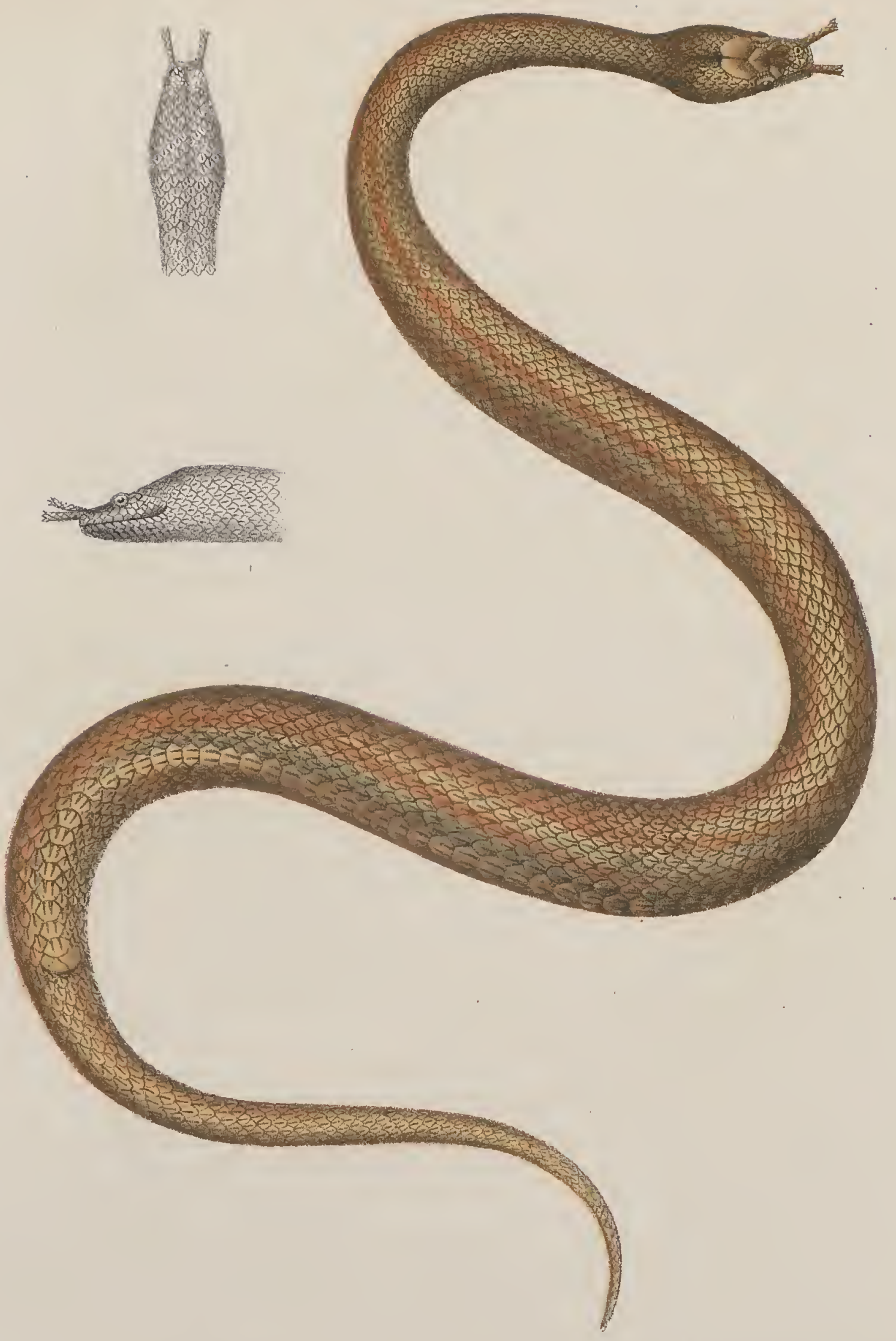

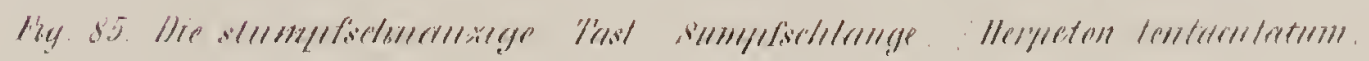




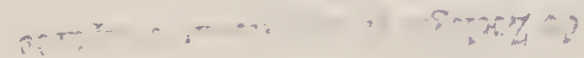

4ton 


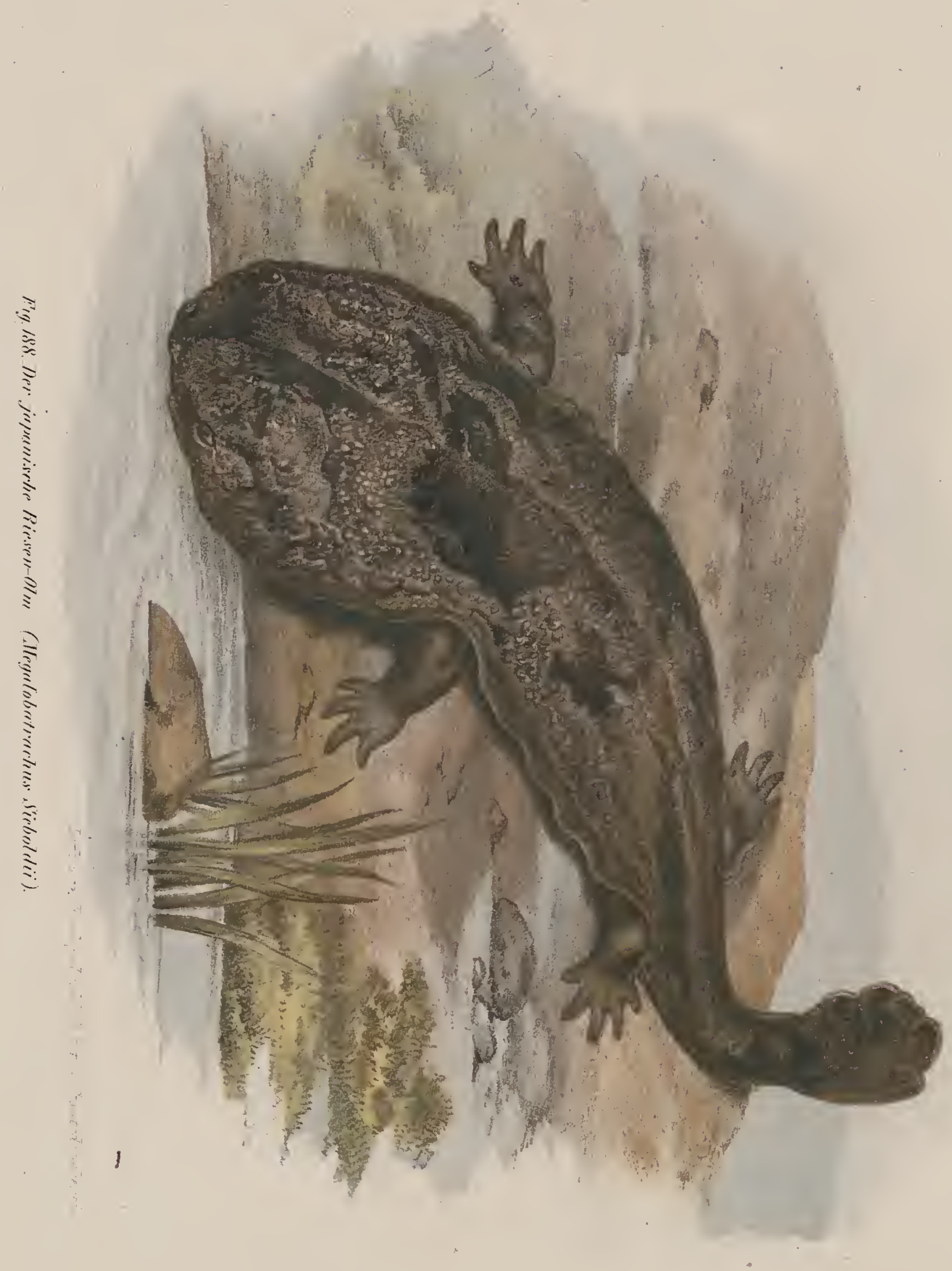


and

ind I I

ind 
Fing. 141.

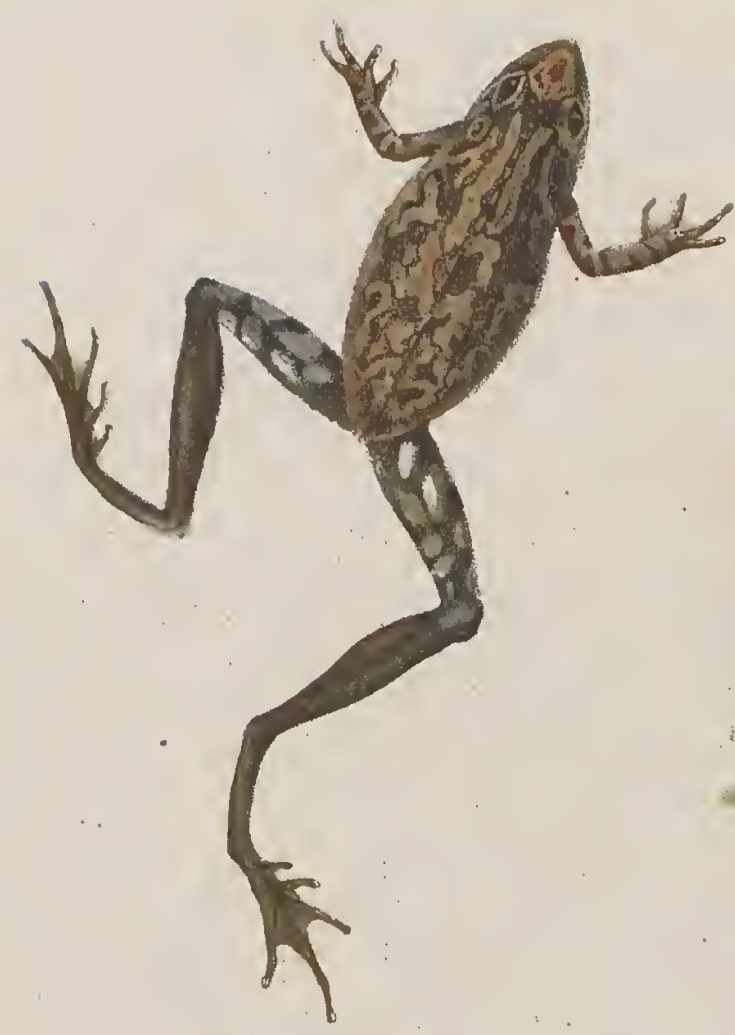

Fing. 14,3

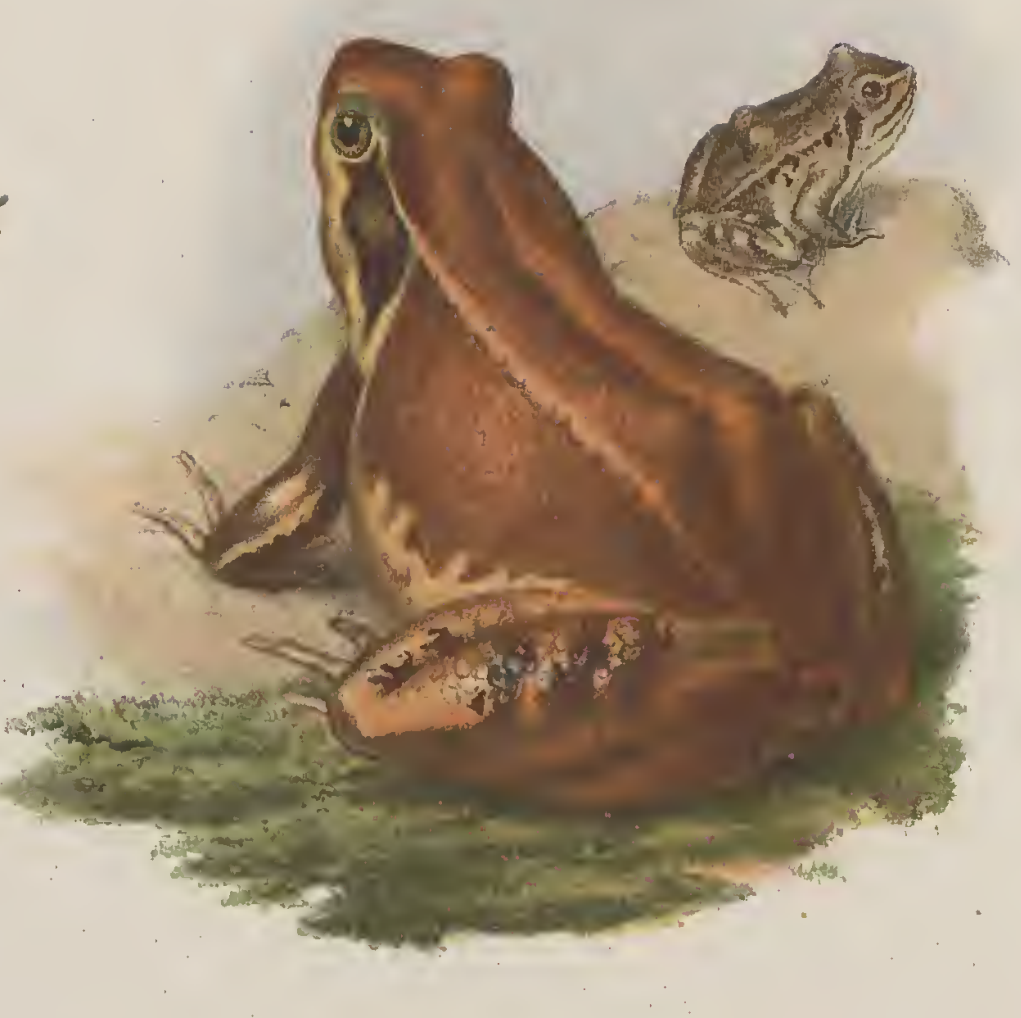

Pig. 14?

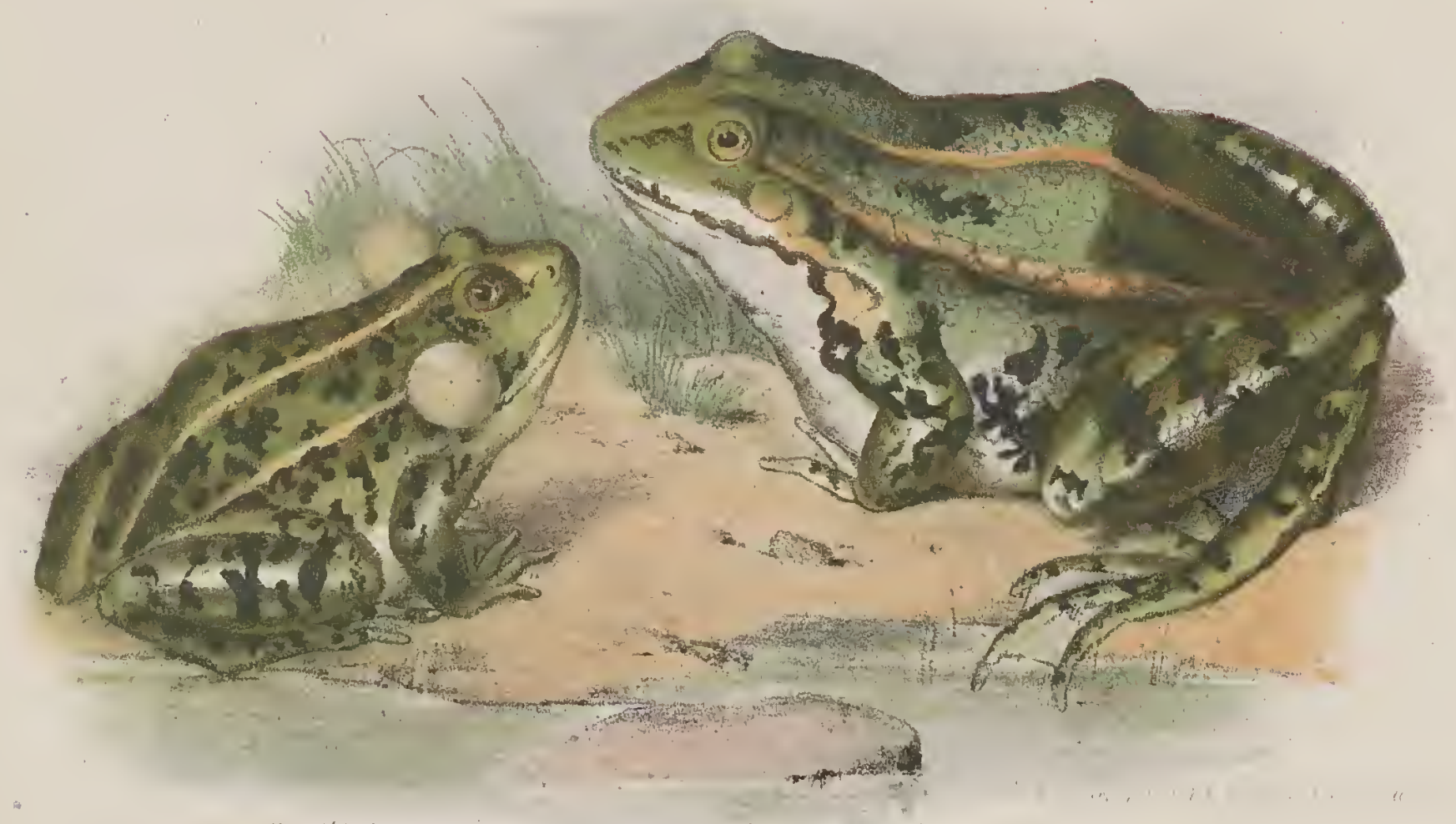

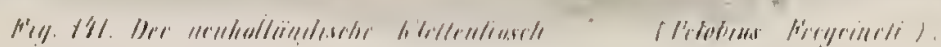

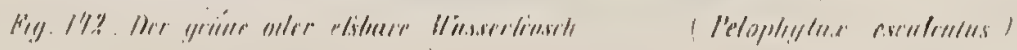

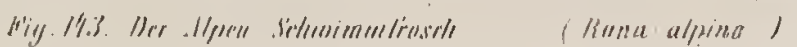


$\therefore$ 
ling lin.

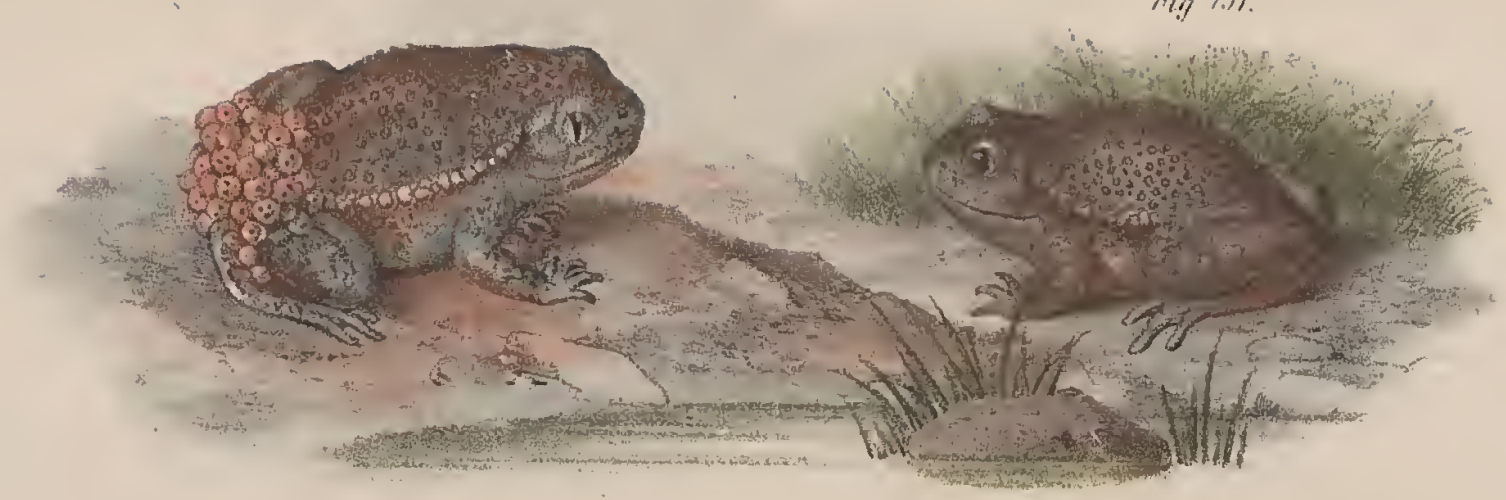

ling lis,

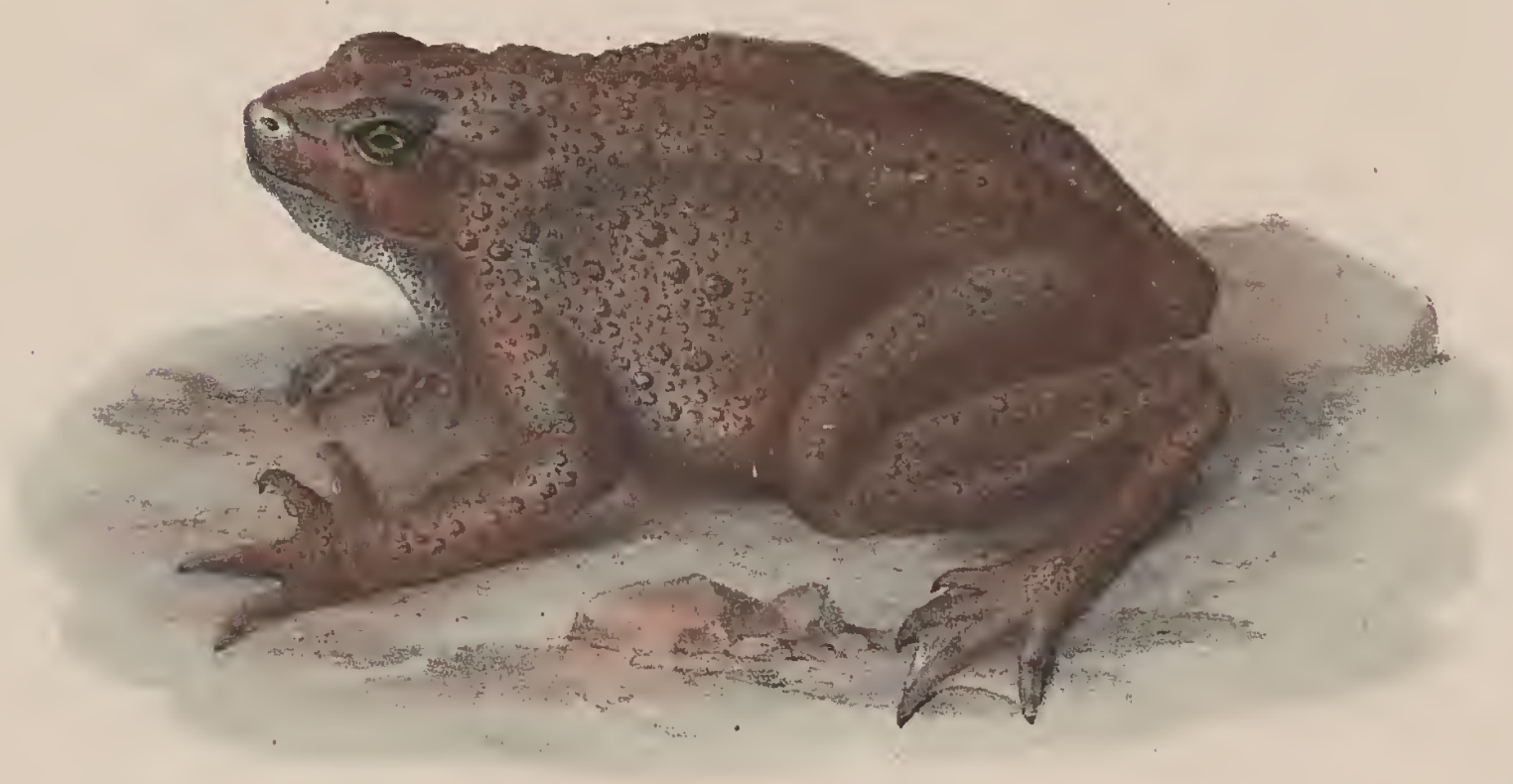

Fig. lis"

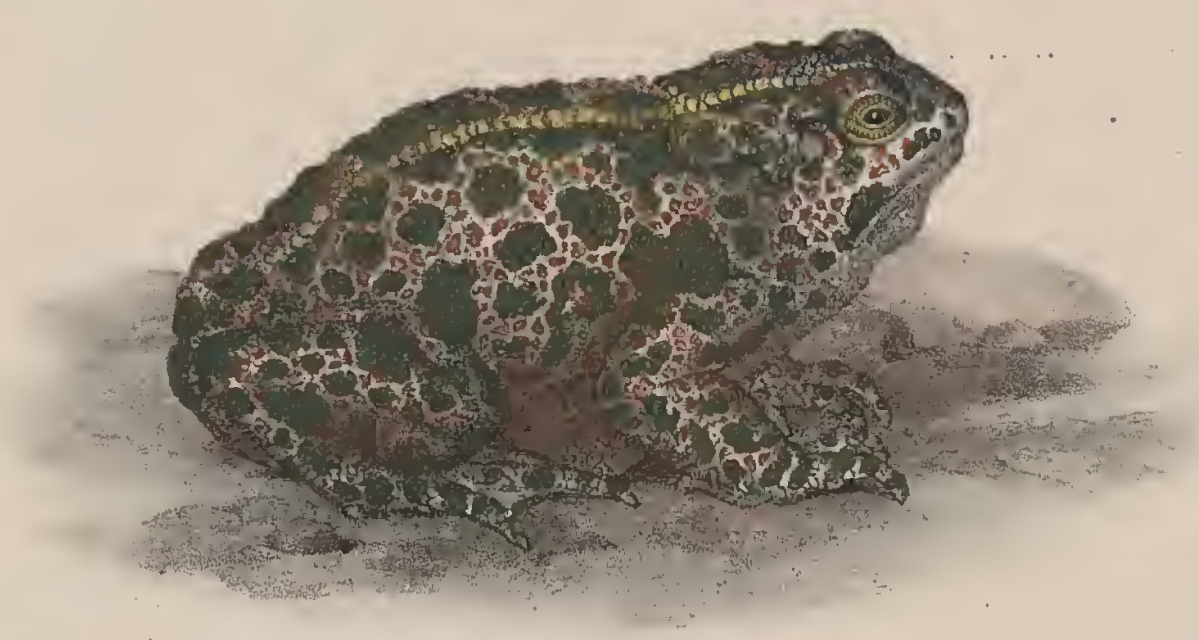

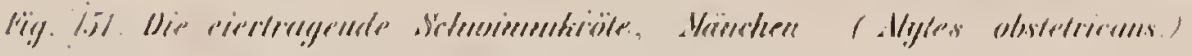

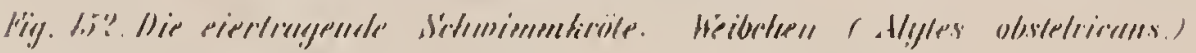

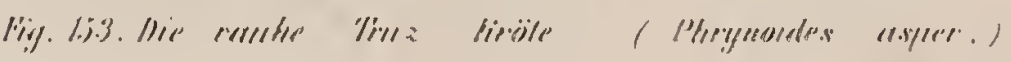

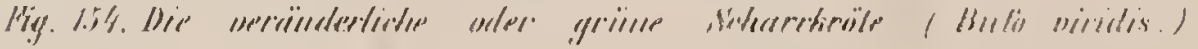


Fir. 1i, is.
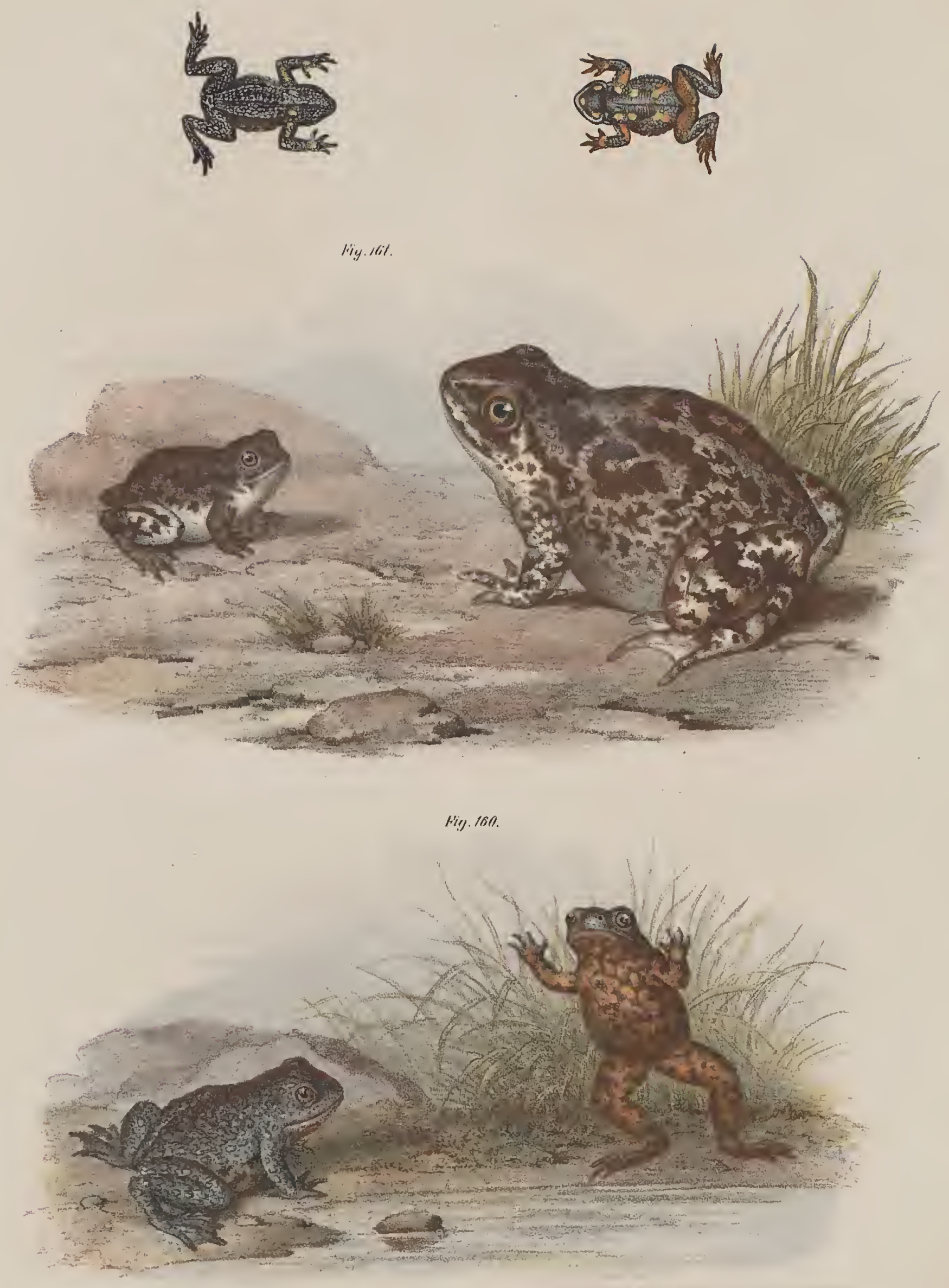

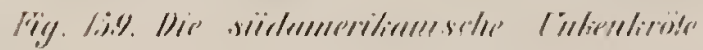

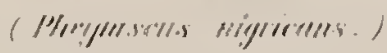

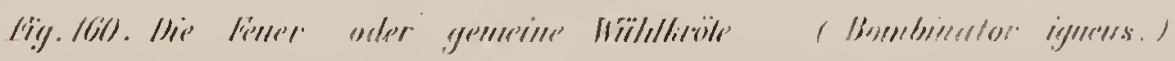

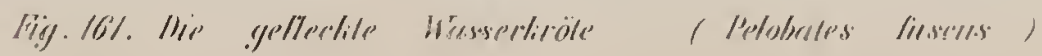



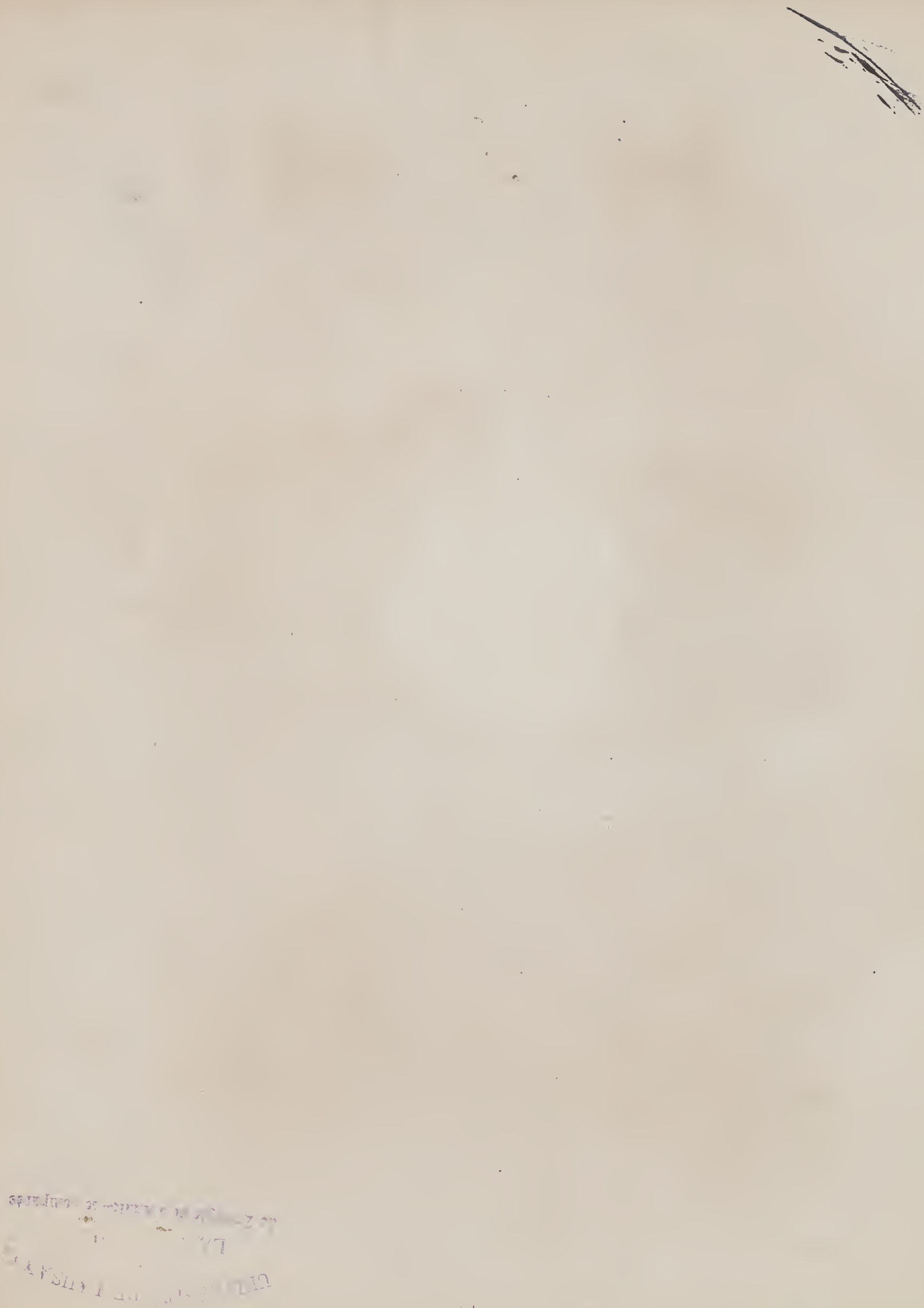

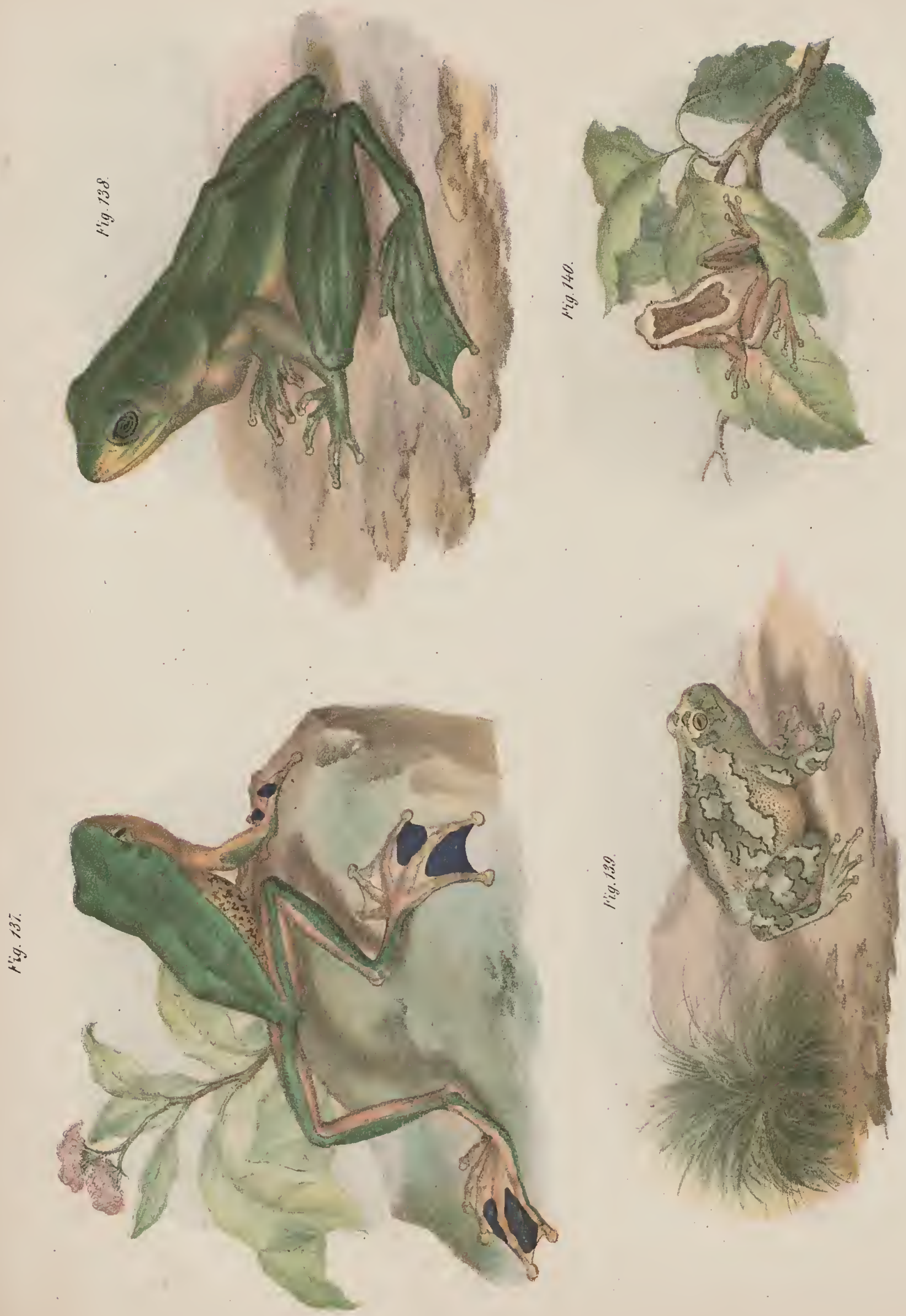

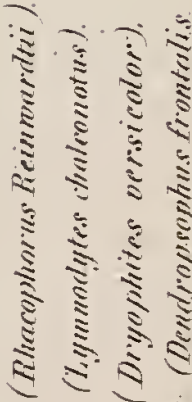

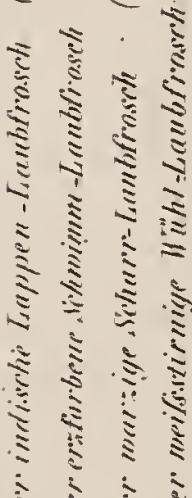

ละ

웣

송 


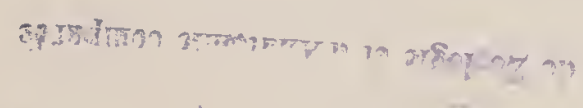

3. 


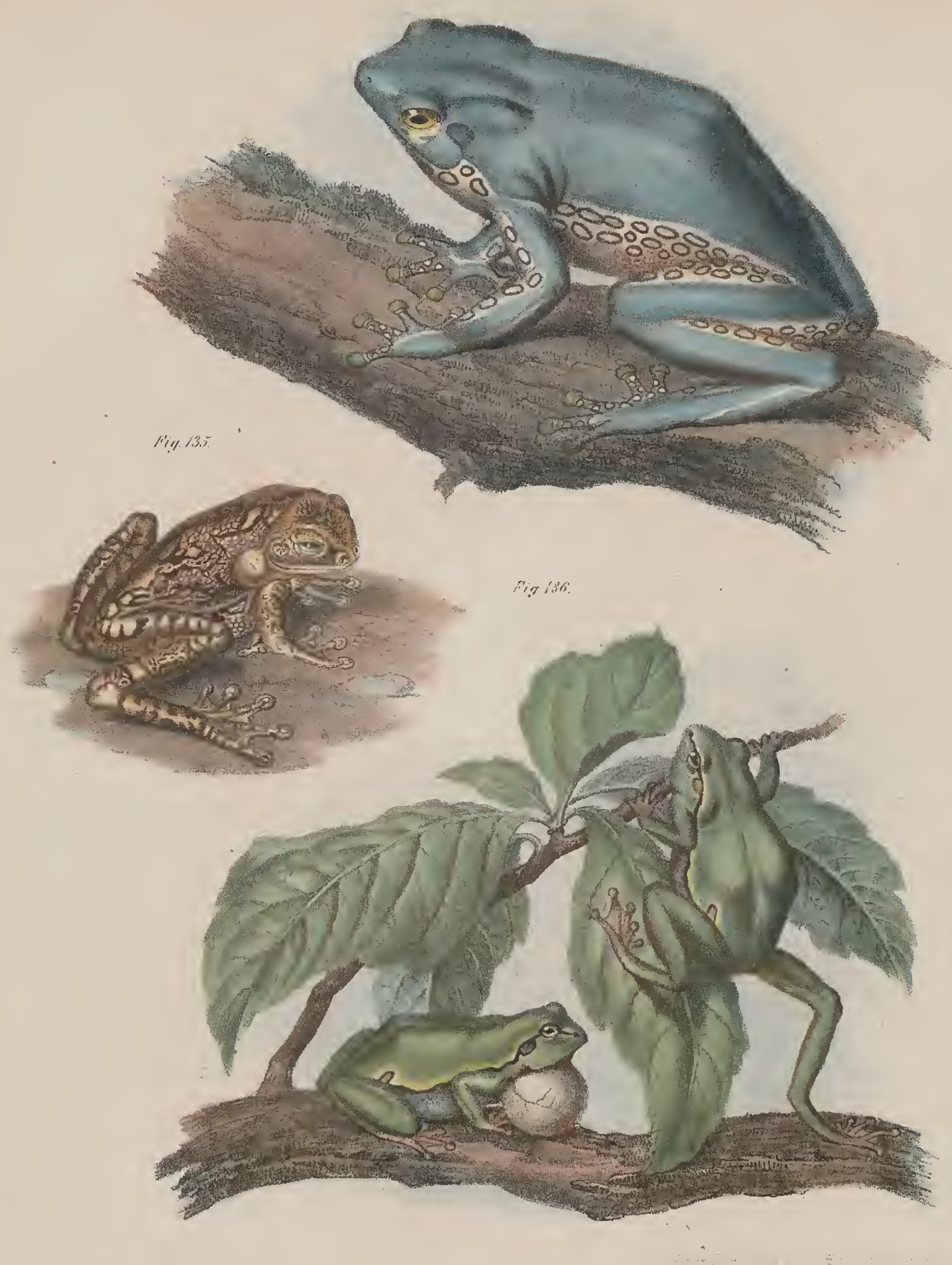

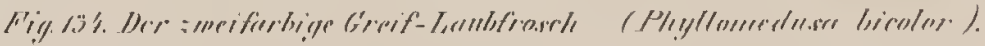

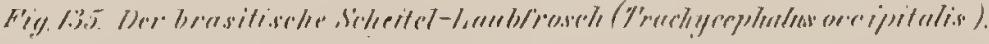

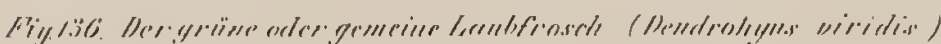


Fig. 166 .

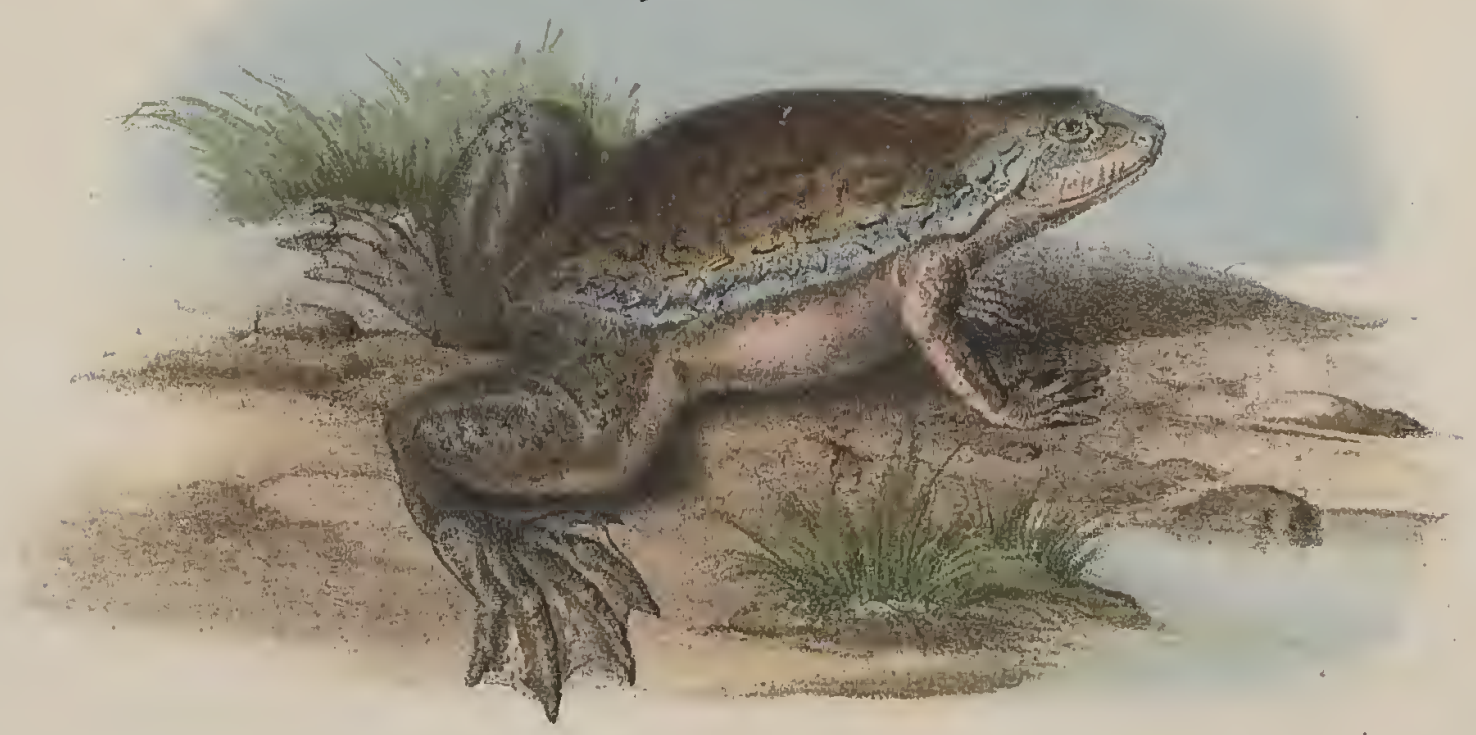

Fig. 167.

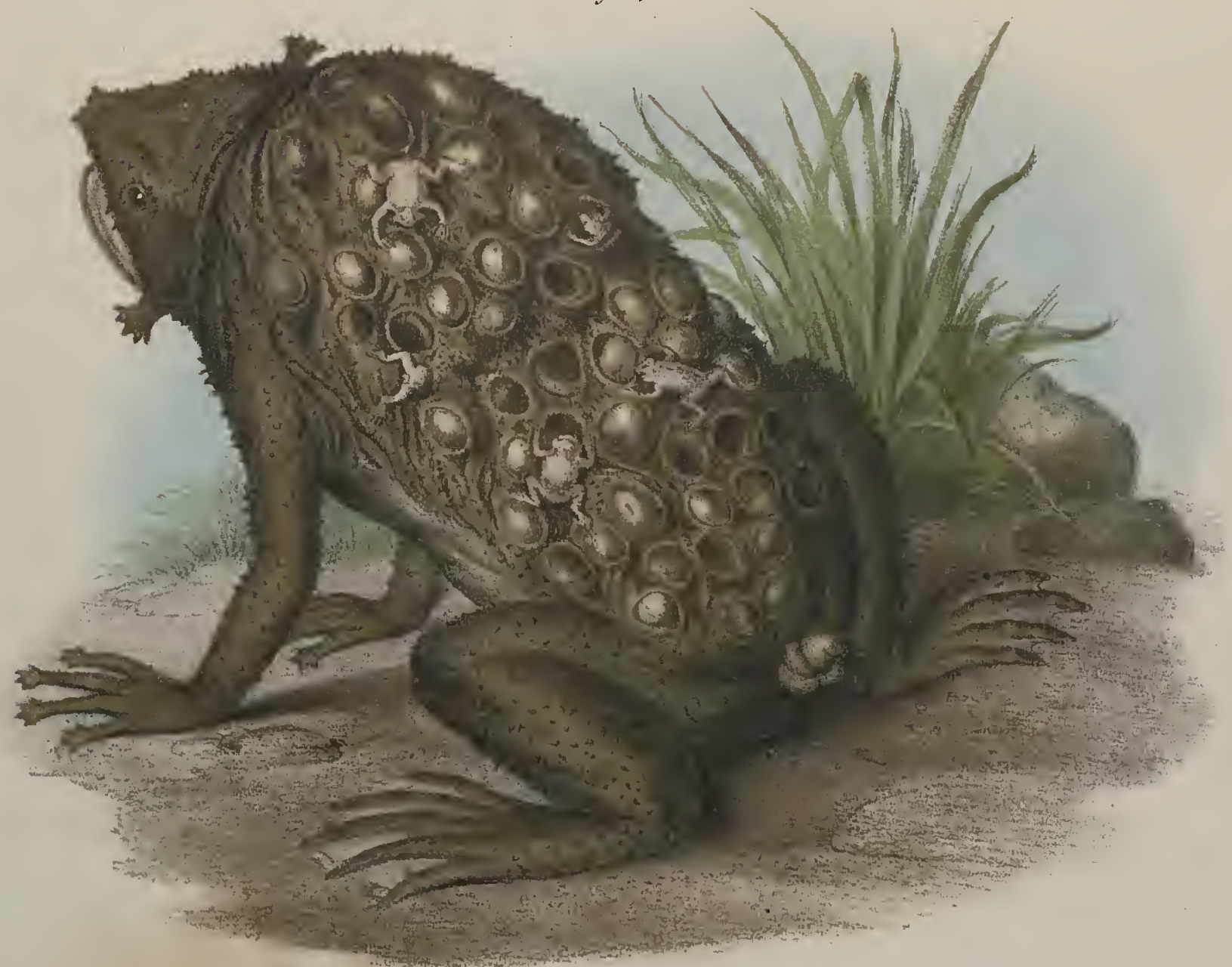

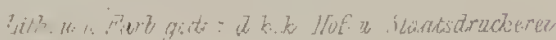

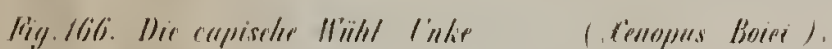

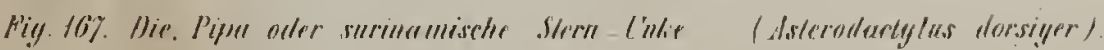




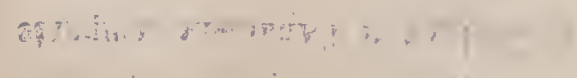

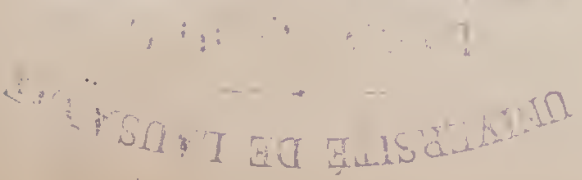


riction

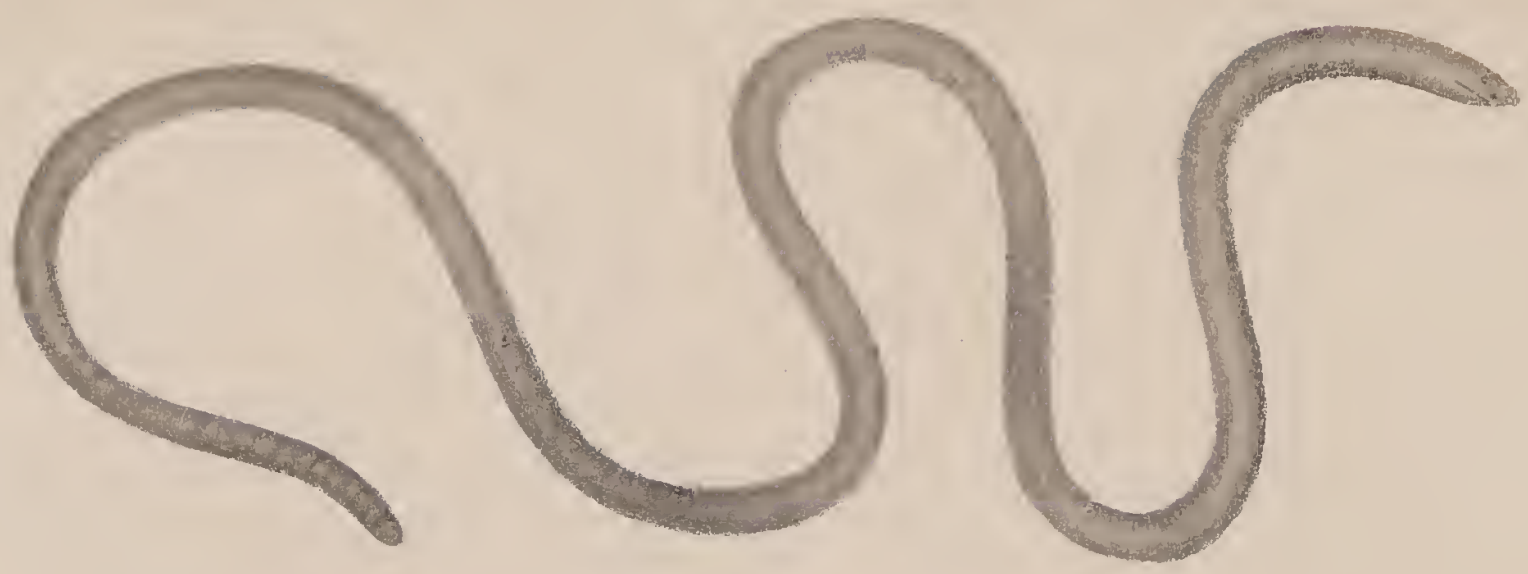

Fig. 186:
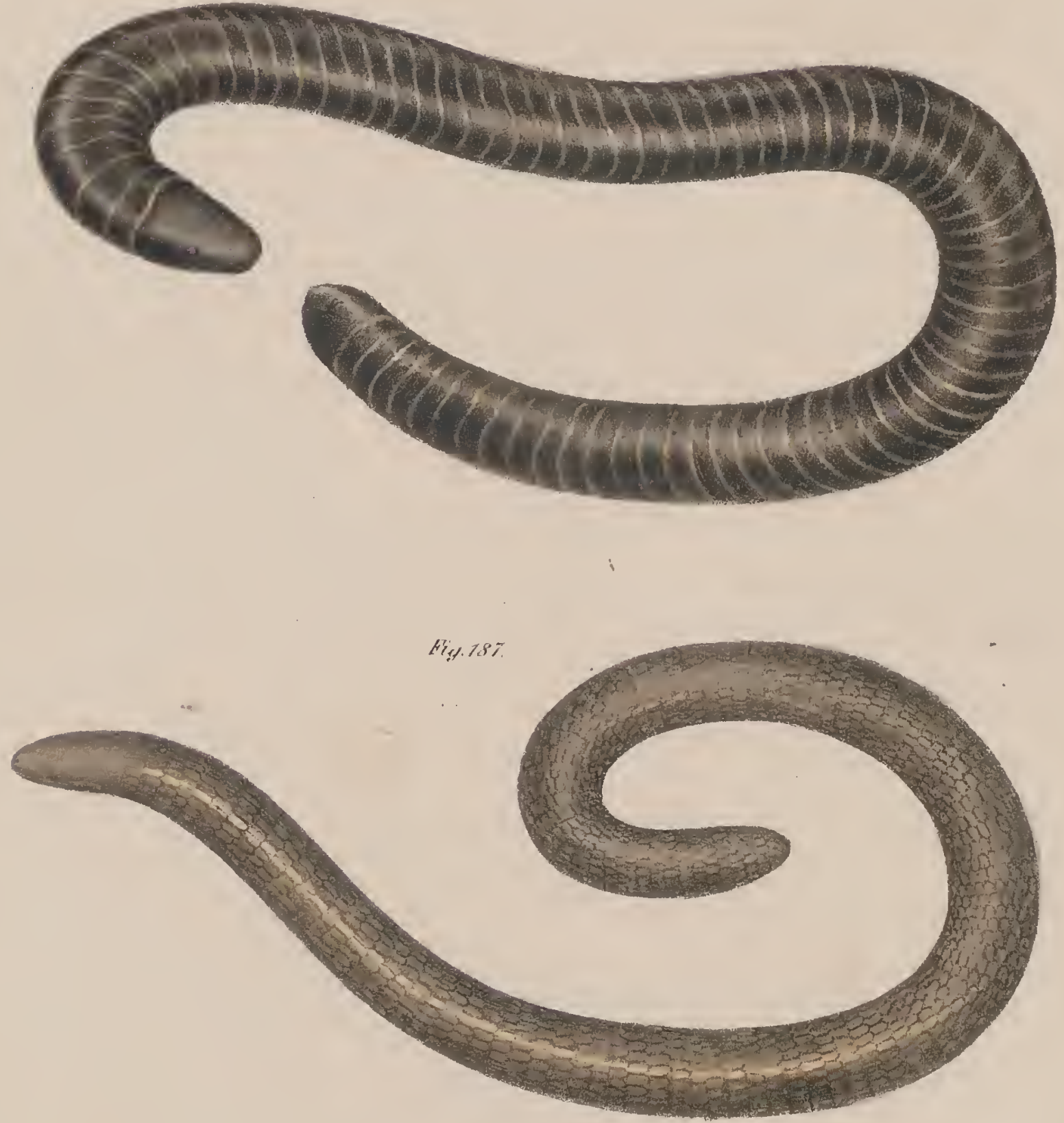

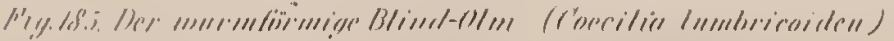

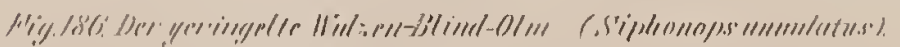

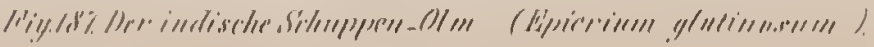




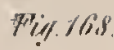
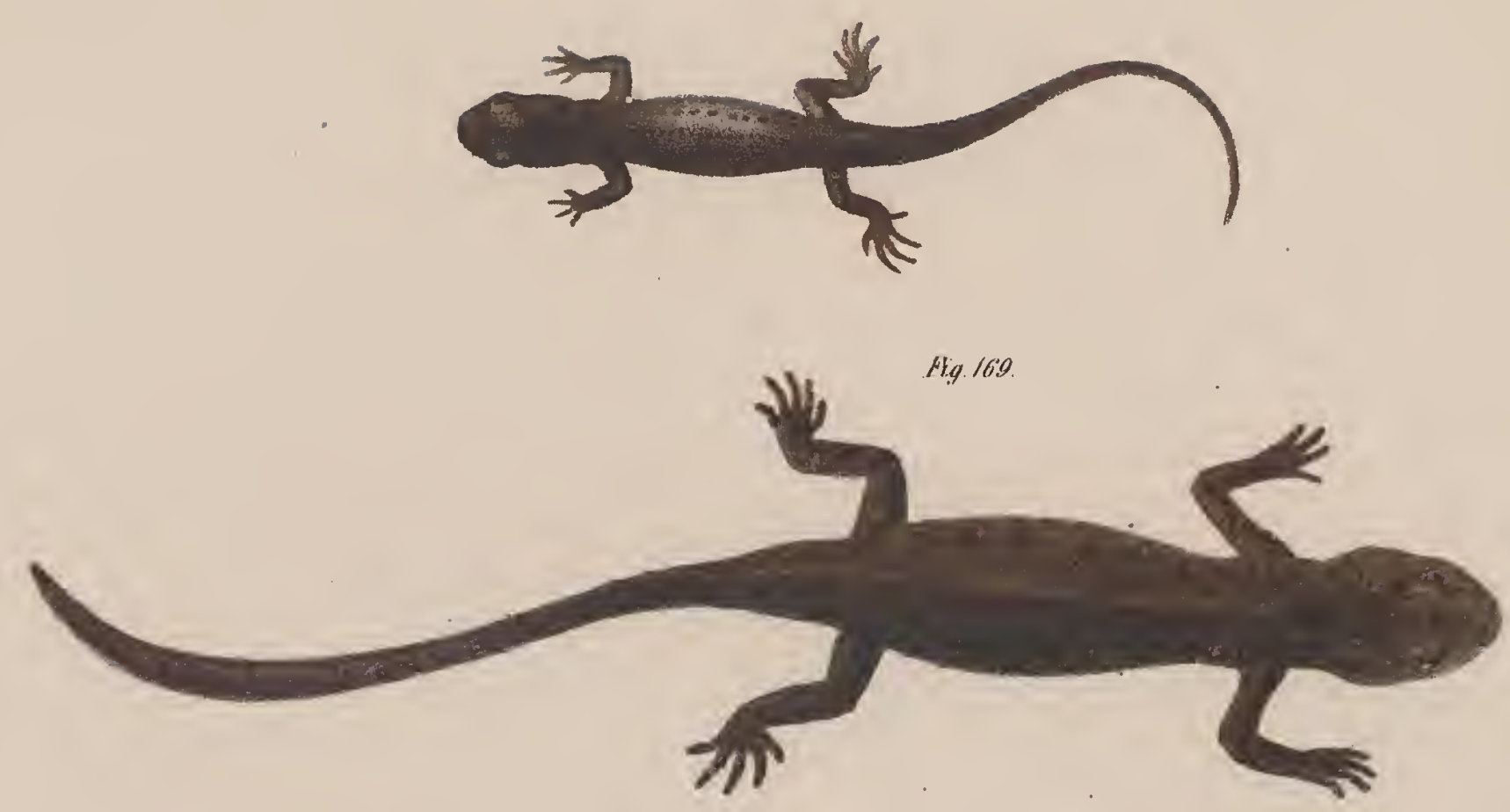

Fig. 1699 a.

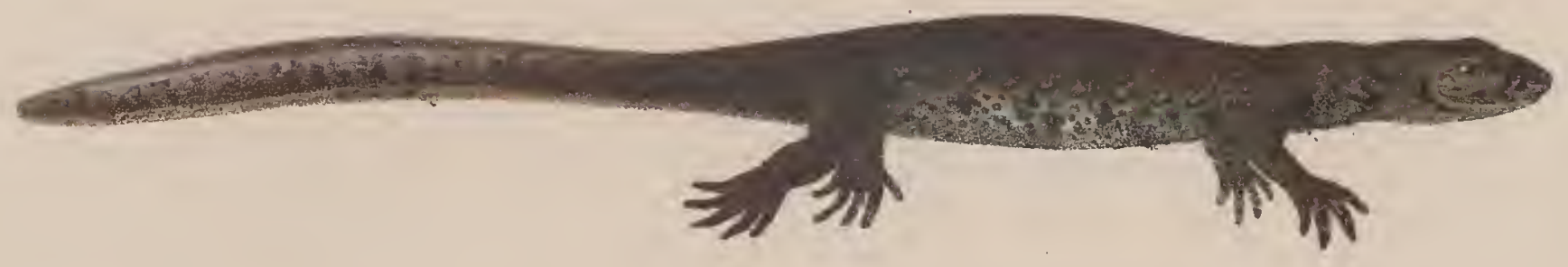

Fig. 170
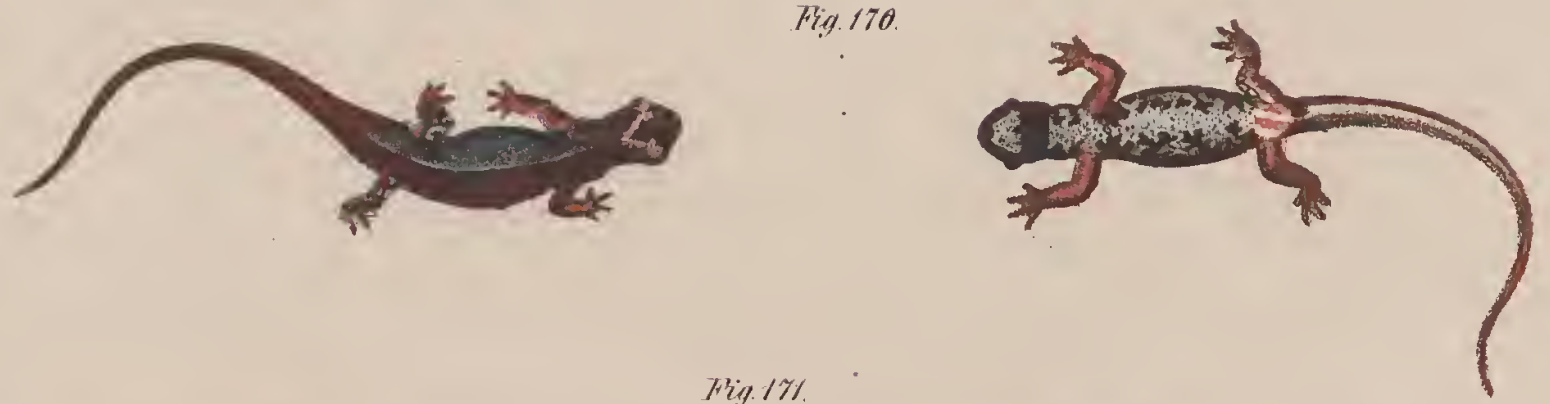

This. 1\%

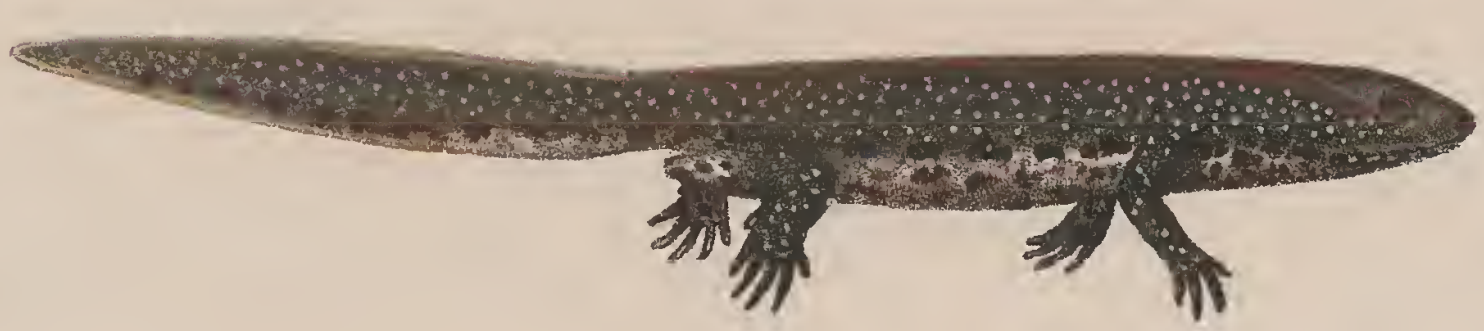

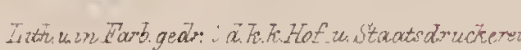

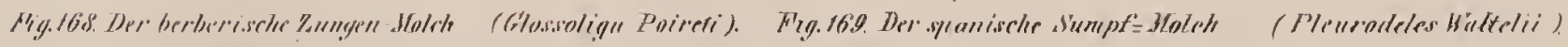

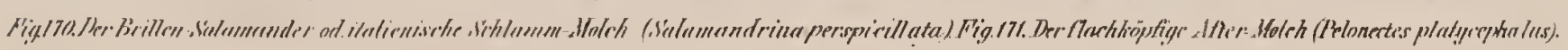




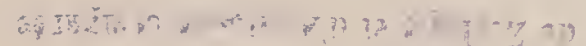
$\because: ! ?+\frac{1}{1}$

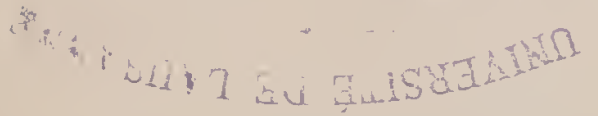


Fig. 180.
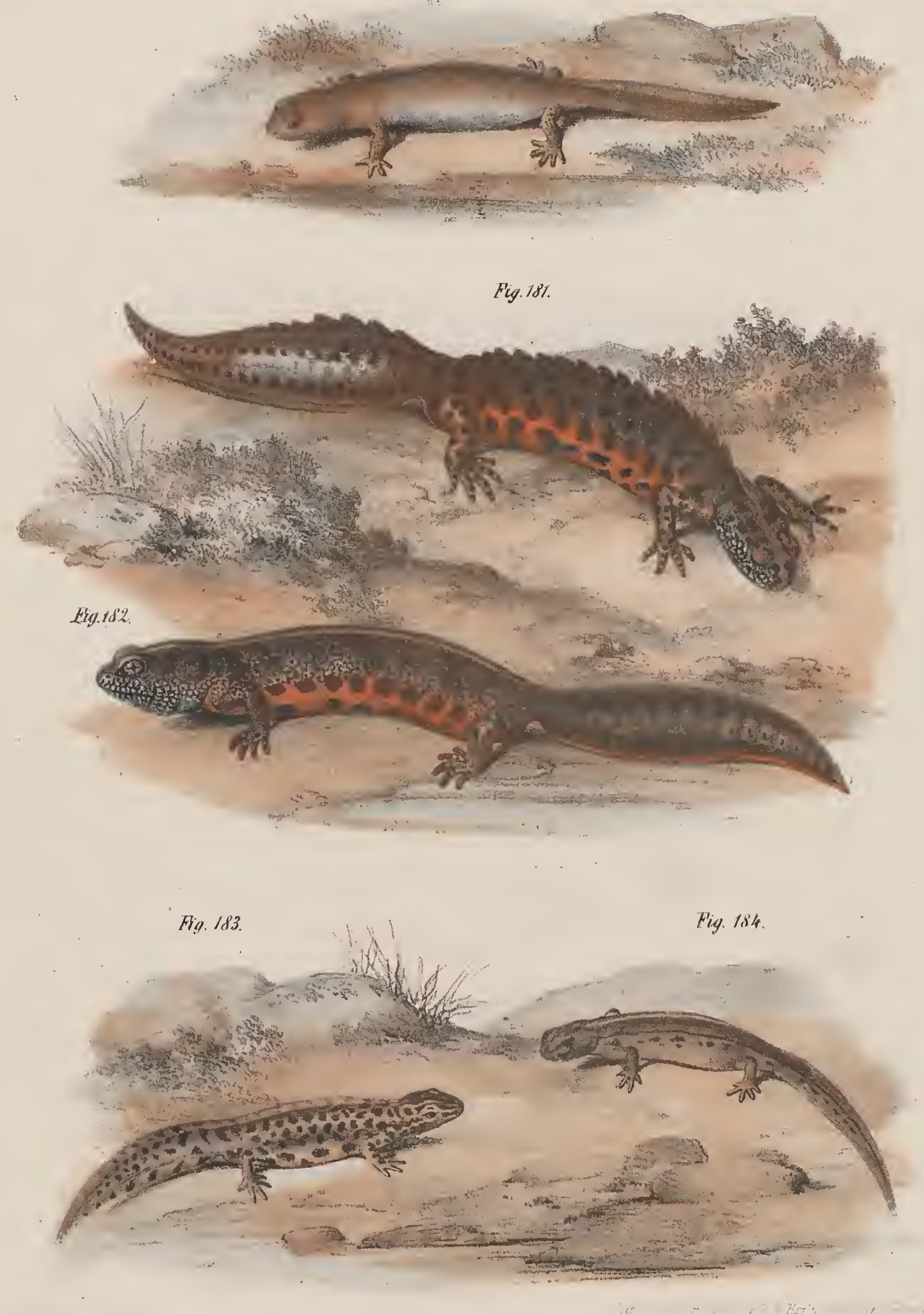

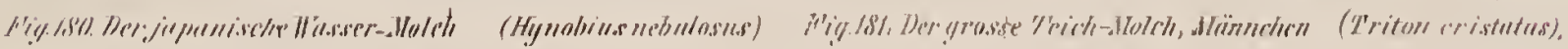

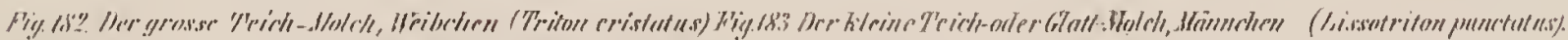

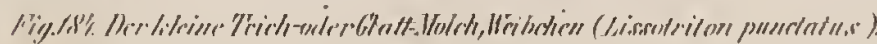


$=$

. .

n 


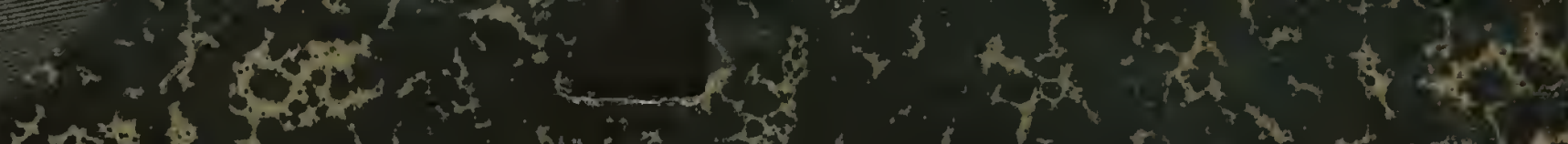

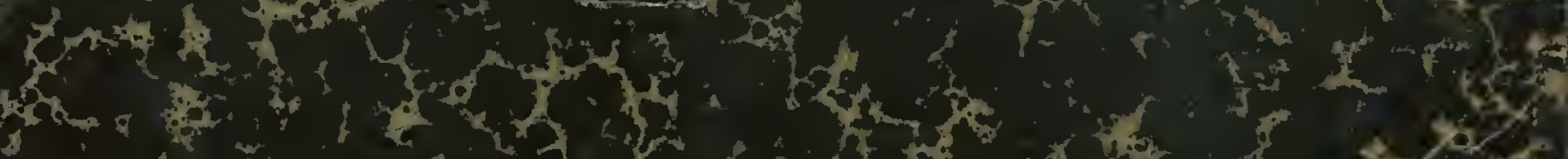

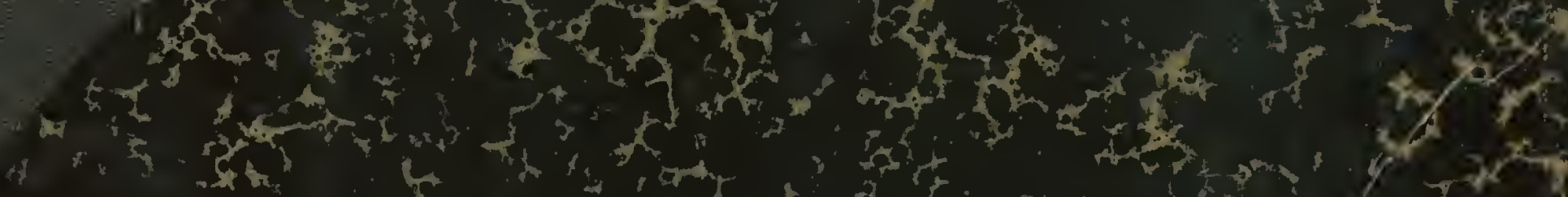

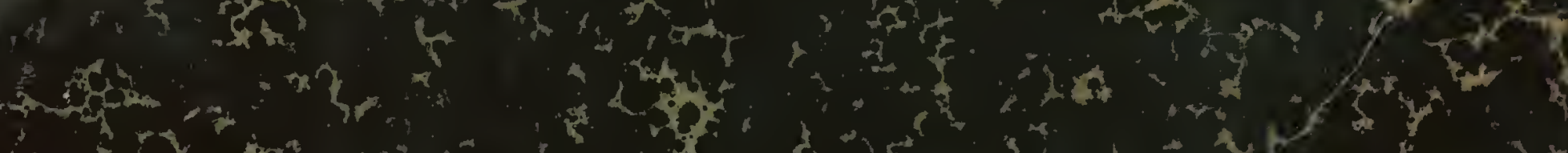
and

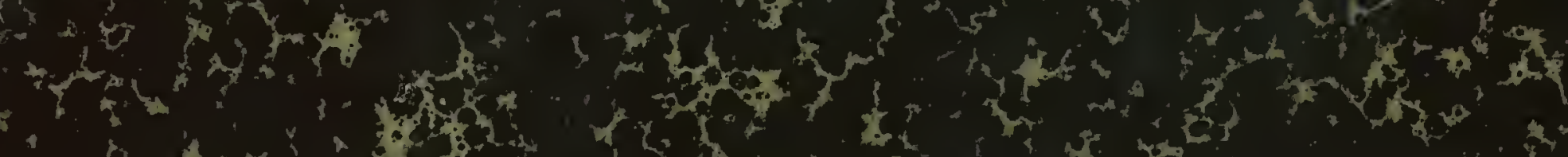

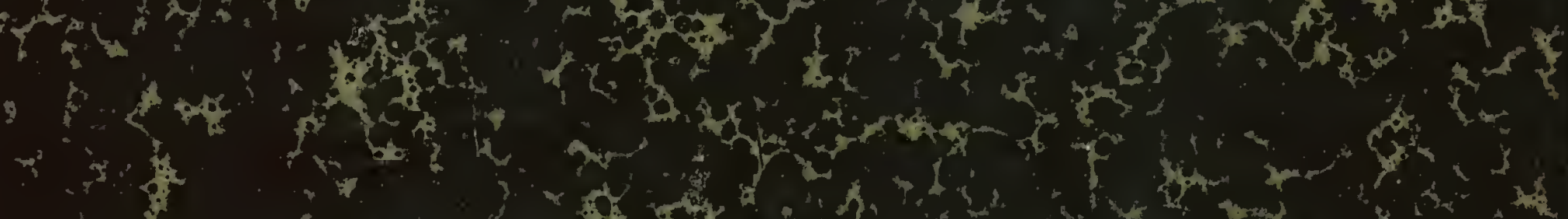

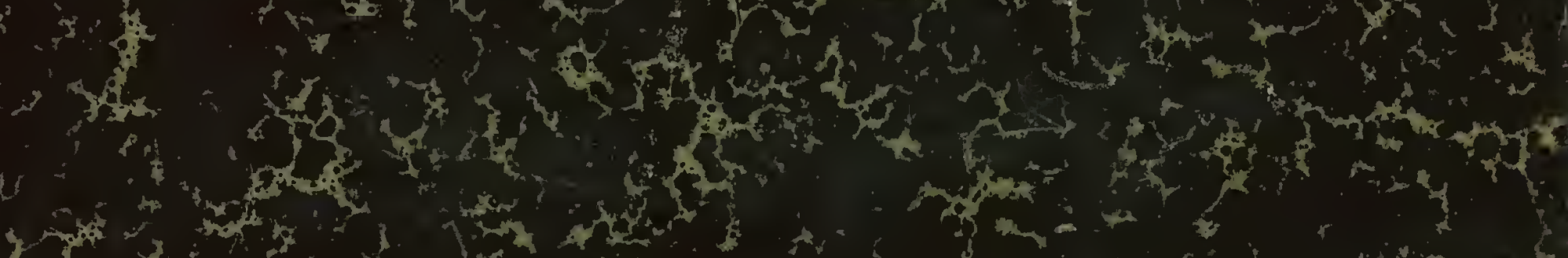

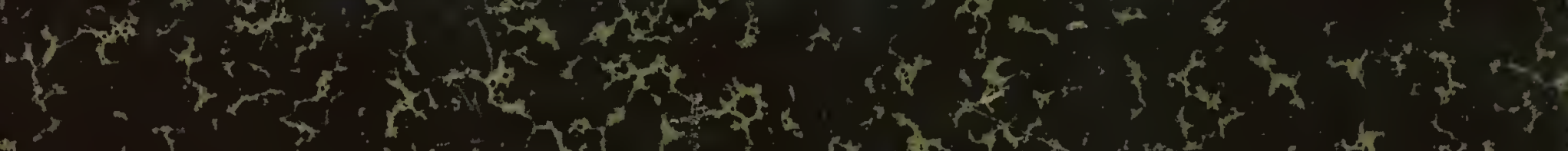

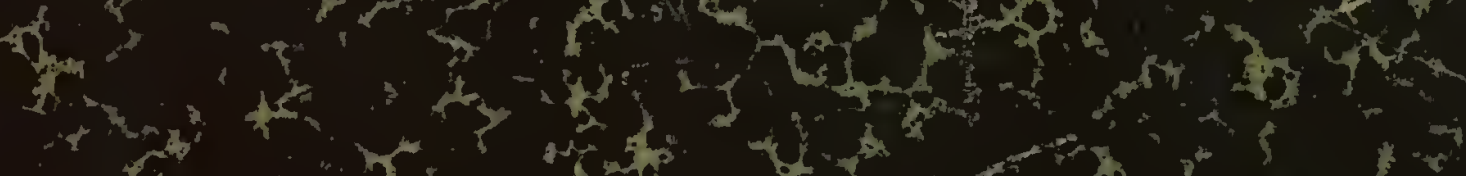

a 15s 1

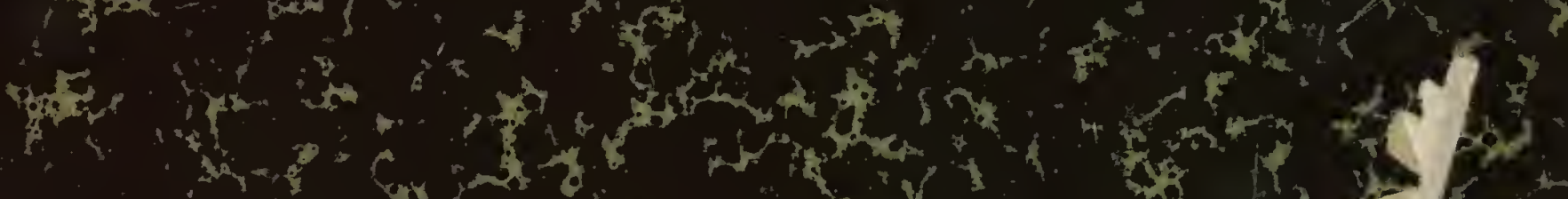
me

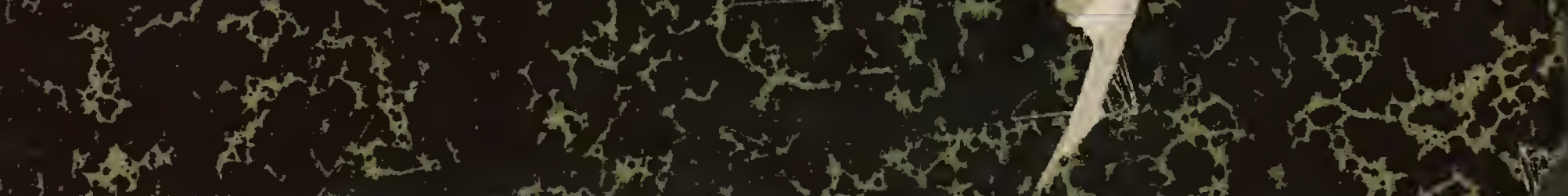

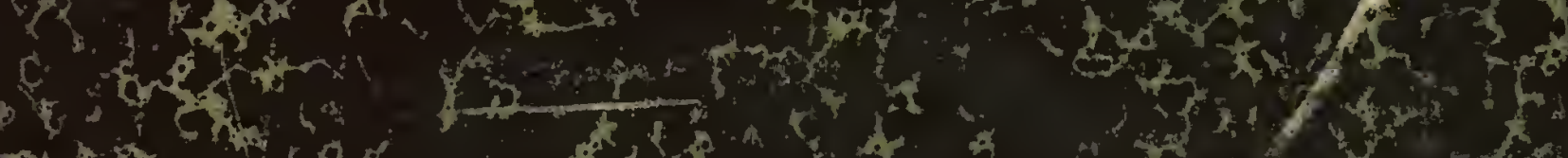
(a) os row (5) 